SANDIA REPORT

SAND95-3024 * UC-814

Unlimited Release

Printed December 1995
RECEIVEO

JAN 25 WMG

OSTI

\title{
1994 Fernald Field Characterization Demonstration Program Data Report
}

\author{
C. A. Rautman, M. V. Cromer, G. C. Newman, D. A. Beiso
}

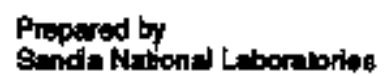

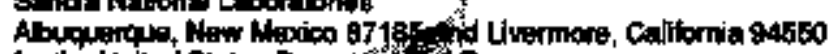

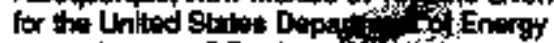
under Comtrat DE-ACO4-\$1;

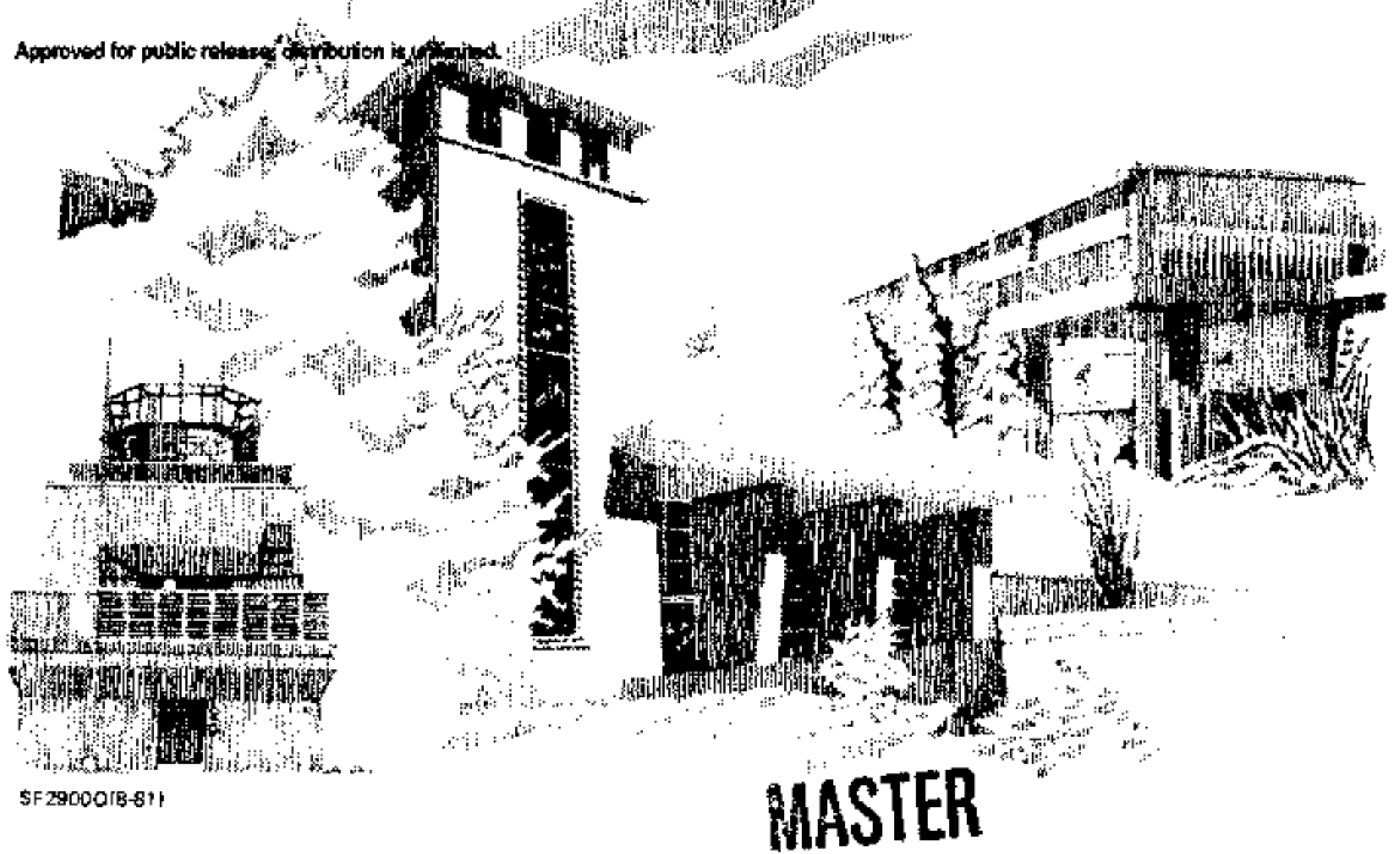


Inoued by Sandin National Lahoratories, oporated for the United States Departanent of Energy by Sandia Corporation.

NOMCE: This report was prepared as an ncoount of work aponsored by an ergency of the United States Covernment. Neither the United Statea Goverm. ment nor any agency thereof, nor any of their employees, nor any of their contractors, eubcontractors, or thefr employees, makes any warranty, exprests or impliod, or aneumes eny legal liability or responedility for the aceuracy, completenean, or usefulnese of sny information, apparatno, produet, or process disclosed, orepresento that ite use wowld not infringe privately owned rights. Reference herein to any apecific commereinl product,

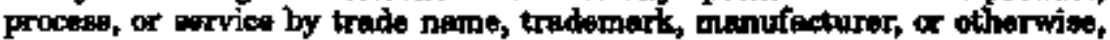
does not necesearily constitute or Imply jte endorioment, recommendiation, o favoring by the United Btates Government, any agency thereof or iny of thoir contractors or abeontractors. The viows and opimions expresesed herein do not neceaserily state or reflect thow of the United States Covernment, any agency thereof or any of thefr eintractors.

Printed in the Unised Btatea of Amorice. This roport has been reproduced directly from the bedt available copy.

Asrailable to DOE and DOE contractors from Office of Scientific and Thechnical Information

PO Bax 62

Oal Ridge, TN 37831

Prices available from (615) 576-8401, FTs 626-8401

Available to the public from

National Tehmical Information Service

US Departiment of Commercs

5285 Pont Royal Rd

Springfield, VA 22161

NTIS price codeg

Printed copy: A09

Mierofiche copy: 101 


\title{
1994 FERNALD FIELD CHARACTERIZATION DEMONSTRATION PROGRAM DATA REPORT
}

\author{
C. A. Rautman, M. V. Cromer, G. C. Newman, ${ }^{2}$ and D. A. Beiso ${ }^{3}$ \\ Geohydrology Department \\ Sandia National Laboratories \\ Albuquerque, New Mexico 87185
}

\begin{abstract}
The 1994 Fernald field characterization demonstration program, hosted by Fernald Environmental Management Project, was established to investigate technologies that are applicable to the characterization and remediation of soils contaminated with uranium. An important part of this effort was evaluating field-screening tools potentially capable of acquiring high-resolution information on uranium contamination distribution in surface soils. Furthermore, the information needed to be obtained in a cost- and time-efficient manner. Seven advanced field-screening technologies were demonstrated at a uranium-contaminated site at Fernald, located 29 kilometers northwest of Cincinnati, Ohio. The seven technologies tested were: (1) alpha-track detectors. (2) a high-energy beta scintillometer, (3) electret ionization chambers, (4) and (5) two variants of gamma-ray spectrometry, (6) laser ablation-inductively coupled plasma-atomic emission spectroscopy, and (7) long-range alpha detection. The goals of this field demonstration were to evaluate the capabilities of the detectors and to demonstrate their utility within the U.S. Department of Energy's Environmental Restoration Program. Identical field studies were conducted using four industry-standard characterization tools: (1) a sodium-iodide scintillometer, (2) a low-energy FIDLER scintillometer, (3) a fjeld-portable $x$-ray fluorescence detector, and (4) standard soil sampling coupled with laboratory analysis. Another important aspect of this program was the application of a cost/risk decision model to guide characterization of the site. This document is a compilation of raw data submitted by the technologies and converted total uranium data from the 1994 Fernald field characterization demonstration.
\end{abstract}

\section{Acknowledgments}

The authors thank the members of the Sandia Cost/Risk Performance Assessment team and the Fernald Environmental Management Project team: Kim Nuhfer (USID Coordinator). Rochelle Chernikoff (Field Data and Field Testing Coordinator), Jim Schwing (Project Engineer and Field Testing Coordinator), and Kevin Pylka (Project Engineer). The authors also thank all the Technology Principal Investigators for their professional expertise and contributions.

\footnotetext{
1. SPECTRA Reșearch Inștitute

${ }^{2}$ GRAM, Inc.

${ }^{3}$ Los Alamos Technited Associales
} 
This work was supported by the U.S. Department of Energy, Office of Technology Development-Landfill Focus Area (formerly the Uranium-in-Soils Integrated Demonstration Program), under contract DE-ACO4-94ALS5000. 


\section{Table of Contents}

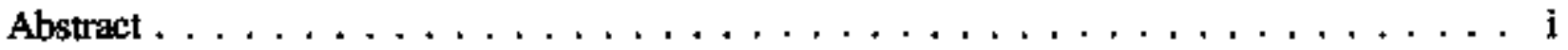

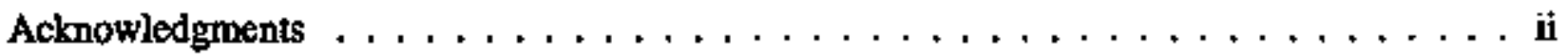

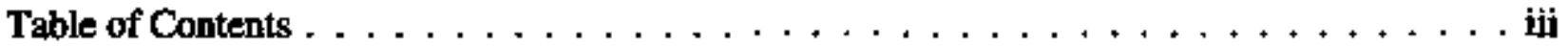

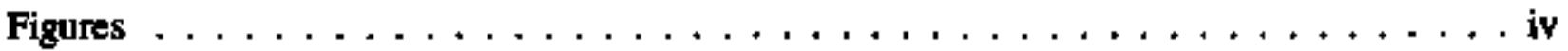

Tables . . . . . . . . . . . . . . . . . . . . . v

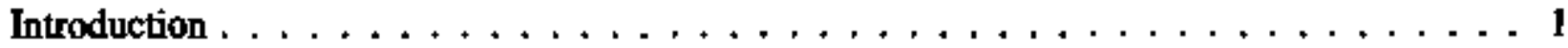

Methods. . . . . . . . . . . . . . . . . . . . . 2

Site Selection and Preparation . . . . . . . . . . . . . . . 2

Field Screening Technologies. . . . . . . . . . . . . . . . . . . . 5

Alpha Track Detector . . . . . . . . . . . . . . . . . . . .5

High-Energy Beta Scintillation Sensor . . . . . . . . . . . . . . . . .5

Electret Ionization Chamber . . . . . . . . . . . . . . . . . . . .6

In-Situ Gamma-Ray Spectrometry . . . . . . . . . . . . . . . . . . .6

Laser Ablation-Inductively Coupled Plasma-Atomic Enission Spectrometer . .6

Long-Range Alpha Detector . . . . . . . . . . . . . . . 7

Industry-Standard Technologies . . . . . . . . . . . . . . . . . 7

FIDLER Detector . . . . . . . . . . . . . . . . . . . .

Soil Sampling and Laboratory Analysis $\ldots \ldots \ldots \ldots \ldots \ldots$

Sodium-Iodide Scintillometer . . . . . . . . . . . . . . . . . . .7

Field X-Ray Fluorescence Detector . . . . . . . . . . . . . . . . . . .8

Field Data Collection and Data Managenent. . . . . . . . . . . . . 8

Results. . . . . . . . . . . . . . . . . . . . . . . . . 9

Location Data . . . . . . . . . . . . . . . . . . . .

Meteorologic Data . . . . . . . . . . . . . . . . . . 9

Technology Calibration . . . . . . . . . . . . . . . . . . 9

Standard-Sites Measurements. . . . . . . . . . . . . . . . . . . . 14

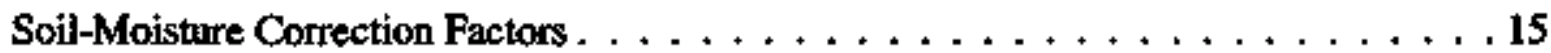

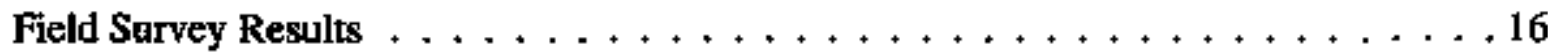

Depth Distribution of Urasium . . . . . . . . . . . . . . . . . . . 25

Duplicate Field Sampling and Laboratory Analyses . . . . . . . . . . . 26

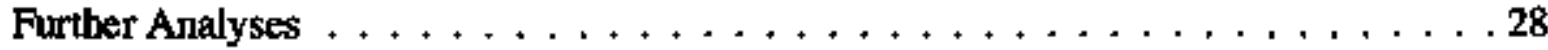

Conclusions . . . . . . . . . . . . . . . . . . . . . . . . .29

References. . . . . . . . . . . . . . . . . . . . . . . . . . 29 29

Appendix A: Field Demonstration Project Plan . . . . . . . . . . . . . . . . 31

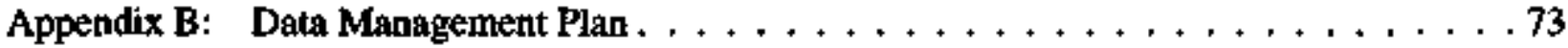

Appendix C: Ohio State Plane X-Y Coordinates for Geolocation Grid . . . . . . . . . . 93

Appendix D: Meteorologic Data. . . . . . . . . . . . . . . . . . . . 95

Appendix E: Calibration Data. . . . . . . . . . . . . . . . . . . 109

Appendix F: Standard Sites Data . . . . . . . . . . . . . . . . . . 117

Appendix G: Technology Data . . . . . . . . . . . . . . . 125 


\section{Figures}

Figure 1. Index map showing location of the Fernald site in southwestem Ohio. . . . . . . 1

Figure 2. Map of the Fernald Environmental Management Project site showing the location of the incinerator area and the site selected for the 1994 Fernald field characterization demonstration program...............

Figure 3. (a) Generalized plan showing the proposed baseline measurement grid and associated geolocation indexing scheme; (b) map showing the final sample-collection grid used in the 1994 Fernald field characterization demonstration program. $\ldots \ldots \ldots \ldots \ldots \ldots \ldots \ldots \ldots \ldots \ldots \ldots \ldots$

Figure 4. Variation in temperature, relative humidity, and total daily rainfall amounts with respect to the times field measurements were taken by the different characterization technologies. $\ldots \ldots \ldots \ldots \ldots \ldots \ldots \ldots$

Figure 5. Diagram showing mean uranium concentration and variability of laboratory measurements of the five Femald calibration beds. . . . . . . . . 11

Figure 6. Cross plots of calibration data for (a) alpha-track detector, (b) beta scintillometer, (c) electret ionization chamber, (d) FIDLER scintillometer, (e) high-mount gamma-ray spectrometer, and (f) low-mount gamma-ray spectrometer.

Figure 7. Cross plots of calibration data for (a) laser ablation-inductively coupled plasma-atomic emission spectrometer, (b) long-range alpha detector, (c) sodium-iodide scintillometer, and (d) field x-ray fluorescence tunit. $\ldots \ldots \ldots \ldots \ldots \ldots \ldots \ldots \ldots \ldots \ldots \ldots \ldots \ldots \ldots$

Figure 8. Schematic illustration of quantities involved in calculation of a linear soil-moisture correction factor for a field-survey measurement. . . . . . . 16

Figure 9. Grey-scale location maps showing uranium activities for the 1994 Fernald field characterization demonstration grid as measured by (a) alpha-track detectors, (b) beta scintillometer, (c) electret jonization chambers, (d) FIDLER detector, and (e) high-mount and (f) low-

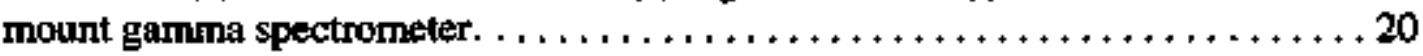

Figure 10. Grey-scale location maps showing uranium activities for the 1994 Fenald field characterization demonstration grid as measured by (a) laser ablation-inductively coupled plasma-atomic emission spectrometer, (b) long-range ałpha detector, (c) soil sampling and laboratory analysis, (d) sodium-iodide scintillometer, and (d) X-ray fluorescence unit.

Figure 11. Field measurements of total uranium activity arranged sequentially by geolocation index code, as measured by (a) alpha-track detectors,

(b) beta scintillometer, and (c) electret ionization chambers, and

(d) FIDLER scintillometer. 22

Figure 12. Field measurements of total uranium activity arranged sequentially by geolocation index code, as measured by (a) high-mount gamma 
spectrometer, (b) low-mount gamma spectrometer, and (c) laser ablation-inductively coupled plasma-atomic emission spectroscope $\ldots \ldots \ldots \ldots, 23$

Figure 13. Field measurements of total uranium activity arranged sequentially by geolocation index code, as measured by (a) long-range alphs detector, (b) sodium-iodide scintillometer, and (c) field $x$-ray fluorescence unit. . . . . . 24

Figure 14. Depth profiles of total uranium activity for five 8 -inch (20-cm) soil cores.

Figure 15. Cross plot showing total uranium activities of 8-inch composite soil core samples compared to the activity of standard "surficial" field (FLD) samples taken at the same spatial location.

Figure 16. Cross plot comparing total uranium activities for replicate soil samples.

\section{Tables}

Table 1: Classification and brief description of alternative characterization technologies demonstrated at the Fernald site $\ldots \ldots \ldots \ldots \ldots \ldots$

Table 2: Laboratory measurements and statistical summary of uranium contamination for the five calibration beds

Table 3: Statistical summary of raw measurement values at the calibration beds for 10 characterization technologies from the 1994 Fernald field characterization demonstration program $\ldots \ldots \ldots \ldots \ldots \ldots$

Table 4: Regression coefficients for equation relating raw measurement data to total uranium activity $\ldots \ldots \ldots \ldots \ldots \ldots \ldots \ldots \ldots$

Table 5: Statistical summary of measured uranium activities of the standard

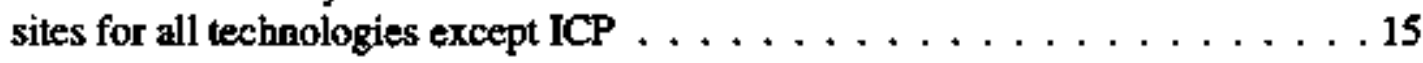

Table 6: Statistical summary of measured uranium activities of the standard sites by ICP technology $\ldots \ldots \ldots \ldots \ldots \ldots$

Table 7: Composite tabulation of field survey results for geolocation grid . . . . . . 17

Table 8: Uranium contamination measurements for selected depth intervals

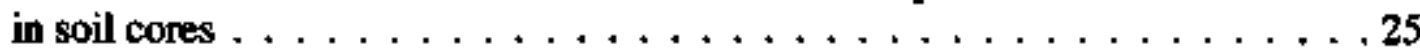

Table 9: Comparison of Total Uranium Activities for 8-inch Core Samples and Standard Field Grab Samples . . . . . . . . . . . . . 26

Table 10: Replicate Soil Samples and Laboratory Analyses at Selected Grid Locations From Appendix Table G-8 . . . . . . . . . . . . . . . 29

Table C-1: Ohio State Plane X-Y Coordinates for Geolocation Grid . . . . . . . . . . . . 94 
Table D-1: Meterologic Data for 1994 Fernald Field Characterization

Demonstration Program . . . . . . . . . . . . . . . .96

Table E-1: Calibration Measurements for Alternative Characterization

Technologies . . . . . . . . . . . . . . . 110

Table F-1: Standard-Sites Measturements by all Technologies Except ICP . . . . . . . . 118

Table F-2: Standard Sites Measurements by Laser Ablation-Inductively

Coupled Plasma-Atomic Emission Spectroscopy Technology . . . . . . . . . 122

Table G-1: Composite Data Listing for Alpha-Track Detector Technology , . . . . . . . 126

Table G-2: Compasite Data Listing for Beta Scintillometer Technology . . . . . . . 130

Table G-3: Composite Data Listing for Electret Ionization Chamber Technology . . . . 134

Table G-4: Composite Data Listing for FIDLER Scintillometer Technology . . . . . . . . 138

Table G-5: Composite Data Listing for High-Mount Gamma Spectrometer

Technology . . . . . . . . . . . . . . . . . . . 143

Table G-6: Composite Data Listing for Low-Mount Gamma Spectrometer

Technology . . . . . . . . . . . . . . . . . . 146

Table G-7: Composite Data Listing for Laser Ablation-Inductively Coupled

Plasma-Atomic Emission Spectrometer Technology

Table G-8: Composite Data Listing for Soil Sampling and Laboratory

Geochermical Analysis Technology $\ldots \ldots \ldots \ldots \ldots \ldots$

Table G-9: Composite Data Listing for Long-Range Alpha Detector

Technology . . . . . . . . . . . . . . . . . . 158

Table G-10: Composite Data Listing for Sodium-Iodide Scintillometer

Technology . . . . . . . . . . . . . . . . . . . . . 161

Table G-11: Composite Data Listing for X-Ray Fluorescence Detector

Technology . . . . . . . . . . . . . . . . . 165 


\section{FERNALD FIELD CHARACTERIZATION DEMONSTRATION PROGRAM DATA REPORT}

\section{Introduction}

One of the major problems facing the U.S. Department of Energy's Environmental Restoration Program is the characterization and remediation of uranium-contaminated soils. In response to this problem, the Office of Technology Development within U.S. Department of Energy sponsored the 1994 Fernald field characterization demonstration program. The program was designed to evaluate and compare the versatility, efficiency, and economics of various technologies for the characterization and remediation of uraniumcontaminated soils. The Fernald Environmental Management Program site, located 29 kilometers northwest of Cincinnati, Ohio (figtre 1), was selected as the location for the demonstration. Site selection was based on known environmental problems stemming from past production of uranium metal for defenserelated applications. In support of the demonstration, a task group was appointed to design and administer a program that would address site characterization issues relative to uraniuncontaminated soils, specifically the demonstration of altemative Imethods and instruments for obtaining rapid and cost-effective measurements of uranium activity. Cunnane and others (1993) and Tidwell and others (1993) presented a description of earlier activities leading to the 1994 Fernald field characterization demonstration program.

The demonstration was conducted from May through July 1994 at the Fermald Environment Management Program site. Seven proposed alternative field-screening technologies were demonstrated. These pro* posed technologies are (1) passive alpha-track detectors, (2) a high-energy beta scintillometer, (3) electret ionization chambers, (4) a high-

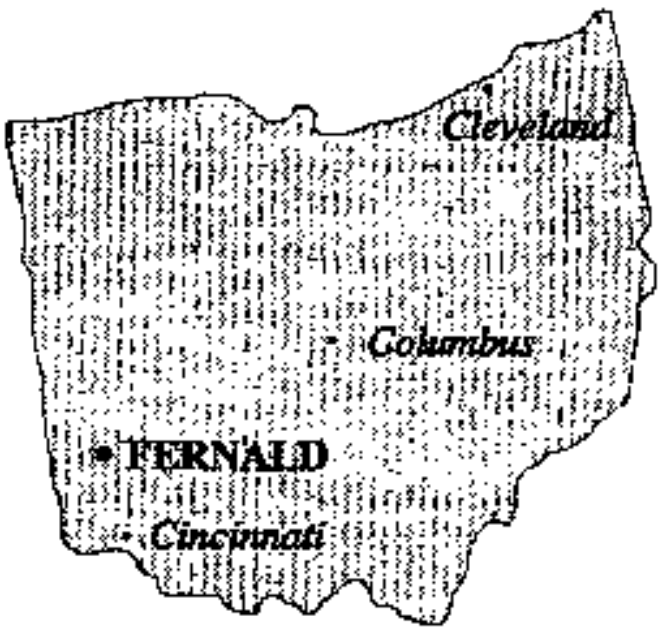

Figure 1. Index map showing location of the Femald site in southwestern Ohio. Not to exact scale.

mounted and (5) low-mounted gamma-ray spectrometer, (6) a field laser ablation-inductively coupled plasma-atomic emission spectrometer, and (7) a long-range alpha detector. Four other techniques that are considered to be current industry-standards were also demonstrated for comparison purposes. These standard technologies are (1) a sodium-iodide scintillometer, (2) a FDLER low-energy scintillometer, (3) a field-portable $x$-ray fluorescence unit, and (4) conventional soil sampling coupled with laboratory chernical analysis.

This report contains the basic measurement data and supporting information that were obtained during the 1994 Fernald field characterization demonstration prograrn. It also provides a simple description of the operation and capabilities of the various characterization techniques and references to more comprehensive descriptions of the different methodologies. The data from the field demonstration program were to be evaluated eco- 
nomically through use of a cost-risk decision analysis. Additional evaluation of the field demonstration program and the results of the economic-decision analysis will be described in greater detail in future reports.

\section{Methods}

Demonstration of the various fieldscreening and industry-standard measurement techniques involved site preparation and measurement of the total uranium activity at a number of field survey locations. Uranium activity measurements were also obtained at a suite of plots containing known levels of uranium contamination similar in nature to in-situ Fernald soils for purposes of calibrating the technologies using a common, on-site reference. Additional replicate measurements were obtained at two standard sites, also located in the field adjacent to the base grid. The replicate measurements were to provide data for evaluating the accuracy and precision of the various alternative measurement technologies. Meteorologic observations (temperature, relative humidity, wind speed and direction, total daily rainfall) were obtained at episodic times throughout the course of the field demonstration to identify any effects of changes in local environmental conditions on the measurements reported by the alternative technologies. A more detailed description of planned activities constituting the 1994 Fernald field characterization demonstration program are presented in the original "project plan," which is reproduced as it existed at the beginning of the demonstration in Appendix A.

\section{Ste Selectlon and Preparation}

The site selected for the 1994 Fernald field characterization demonstration program is adjacent to a region known as the incinerator area, located east of the main Fernald production area (figure 2). Uranium contamination in this region resulted principally from airtorne emissions produced by the incineration of ura- nium-contaminated combustibles. The genera] magnitude of uranium activity in the incinerator area was thought to be suitable for demonstration of the various technologies, and the mode of contaminant deposition was believed to be relatively amenable to geostatistical evaluation as part of the cost-risk exonomic decision model.

A site comprising approximately 126,000 square feet or 2.9 acres $(10,000$ square meters) was identified for the actua] field demonstration. The initially proposed survey grid, shown in figure $3(a)$, is a systematic sampling network designed specifically to focus on the spatial densities and scales needed to characterize the spatial-correlation structure among samples. Quantitative description of spatial continuity is fundamental to the geostatistical procedures used in the evaluation. Of the 89 sample locations that were originally proposed, 42 locations are located on a regular, 60-foot (18-m) grid; these gridded locations provide areal coverage of the entire site. Within this regularly gridded network, an additional 29 locations were defined on 30-foot (9m) spacings to capture shorter-scale spatial relationsbips. Another 18 locations were selected to examine contaninant heterogeneity at a fine scale using 5 -foot $(1.5 \mathrm{~m})$ sample spacing. Conflicts with existing cultural features, principally roads through the incinerator area, reduced the total number of actual sample locations to 85 and slightly modified the regularly gridded nature of the proposed design. The actual field survey grid is shown in figure $3(\mathrm{~b})$.

Site preparation, including marking the site and restricting access once the field demonstration effort had begun, was the responsibility of Fernald Environmental Management Project personnel. Prior to taking field measurements, the base grid was staked and surveyed using the Ohio state plane coordinate system. For ease of reference, each grid location was assigned a unique letter-number 


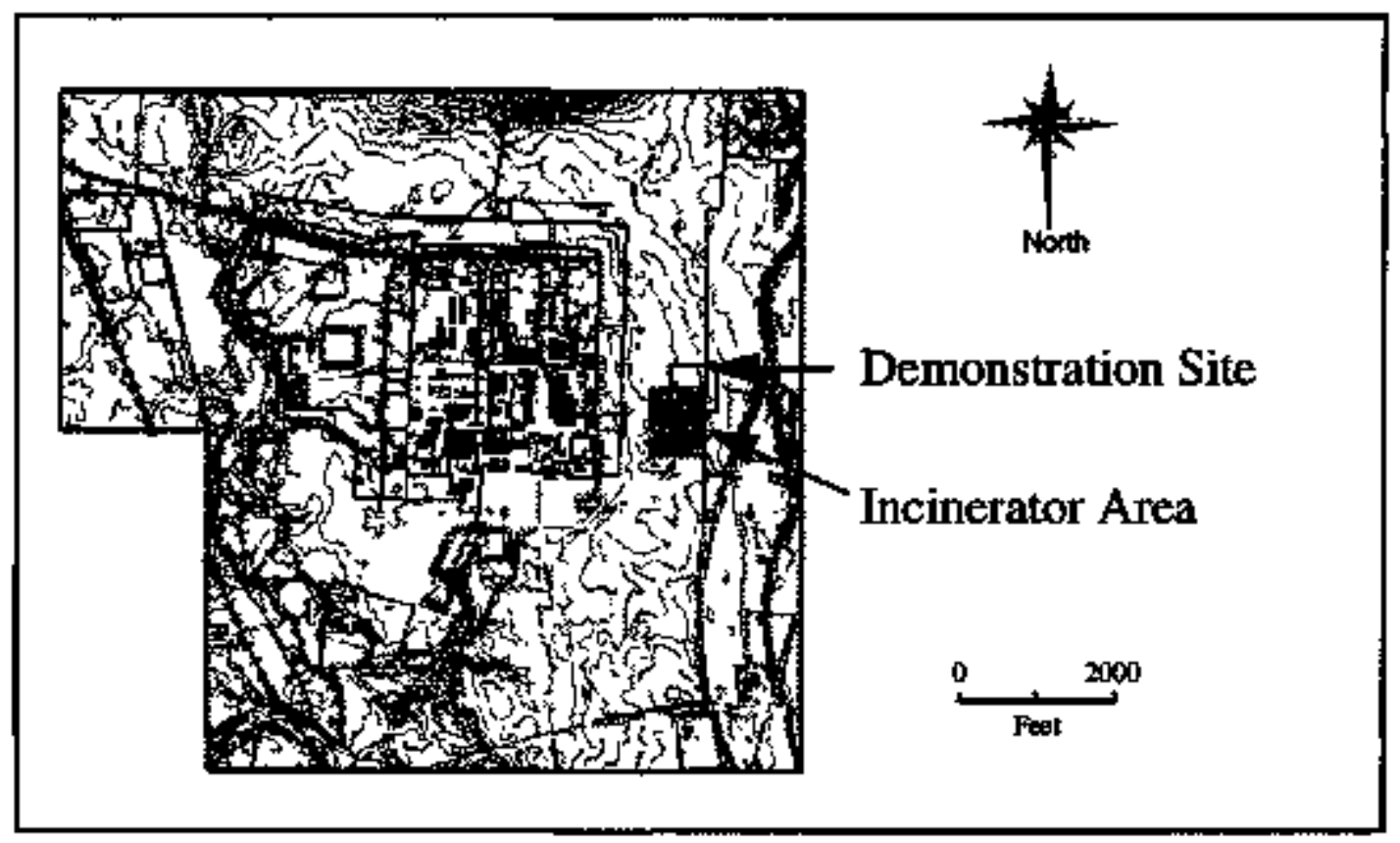

Fgure 2. Map of the Femald Environmental Management Project site showing the location of the indinerator area and the site selected for the 1994 Femald fleld characterization demonstration program.

"geolocation" code based on a row-column numbering scheme, as indicated in figure 3(a). Grass at each measurement location was cropped and resicual thatch was removed to reduce the influence of naturally occurring ground cover; only bare ground and short grass stubble were visible to the detectors. All technologies recorded their measurements at a location approximately 6 inches $(15.2 \mathrm{~cm})$ north of each staked geolocation. Each characterization technology strveyed the complete field grid, resulting in matched data sets to facilitate comparison.

Two standard sites, used to obtain replicate measurements by each technology of the same (standardized) uranium-contamination levels and identified as $\mathbf{S} 1$ and $\mathbf{S} 2$, were also staked and located in the field within the boundaries of the field grid [figure 3(b)]. Each of these sites were maintained and measured in the same manner as the sites constituting the general field survey grid.

Four calibration beds were prepared in the field to allow calibration of the alternative measurement techniques to a common reference. The calibration beds consisted of boxes 5.25 feet $(1.6 \mathrm{~m})$ square by 9 inches $(22.5 \mathrm{~cm})$ deep containing Fernald soils spiked with variable but known levels of uranium contanination. Soils composing the calibration beds were homogenized by mixing clean native soils with contaminated Fernald soils in a rotary mixer similar to that used to mix concrete. Ohio state plane coordinates are not applicable to these artificially constructed measurement locations. However, the calibration beds were located immediately adjacent to the survey grid; thus calibration data were taken under effectively the same environmental conditions as the routine field measurements. 
(a)

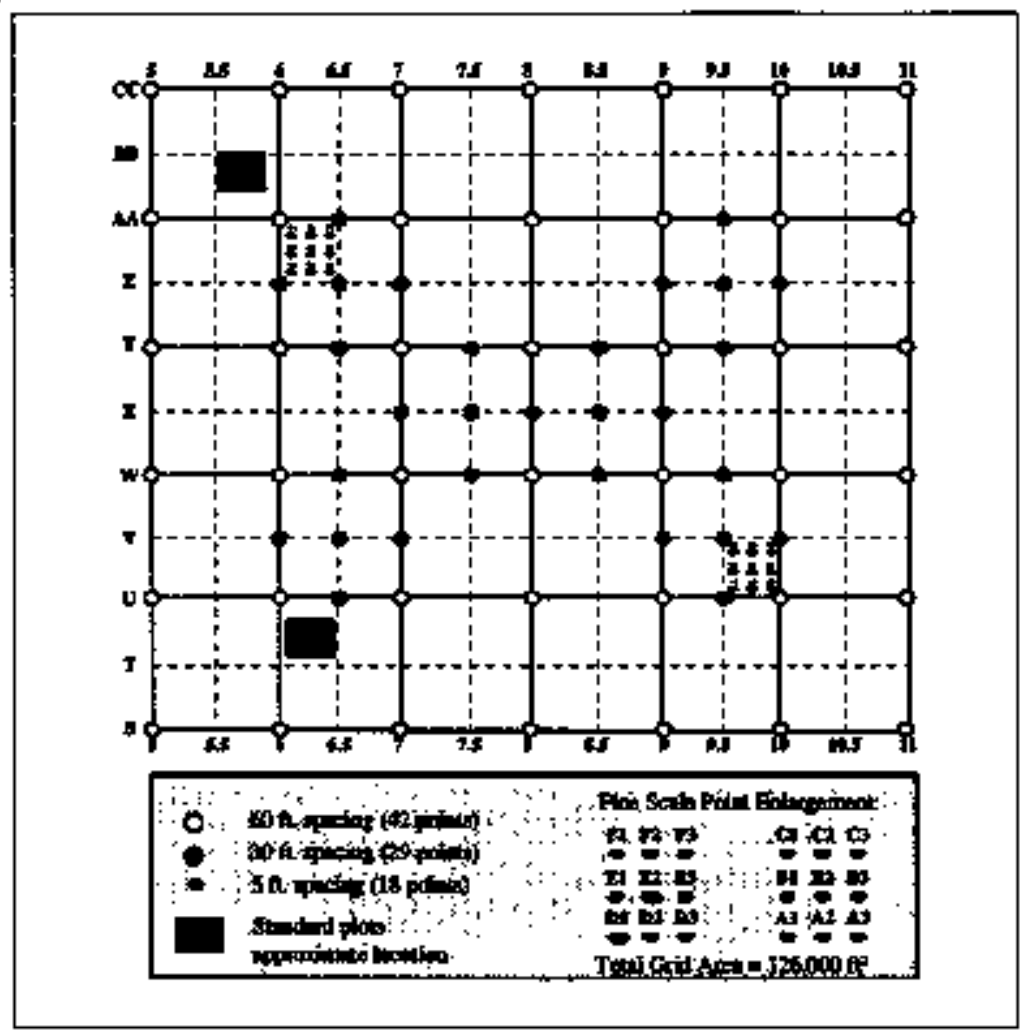

(b)

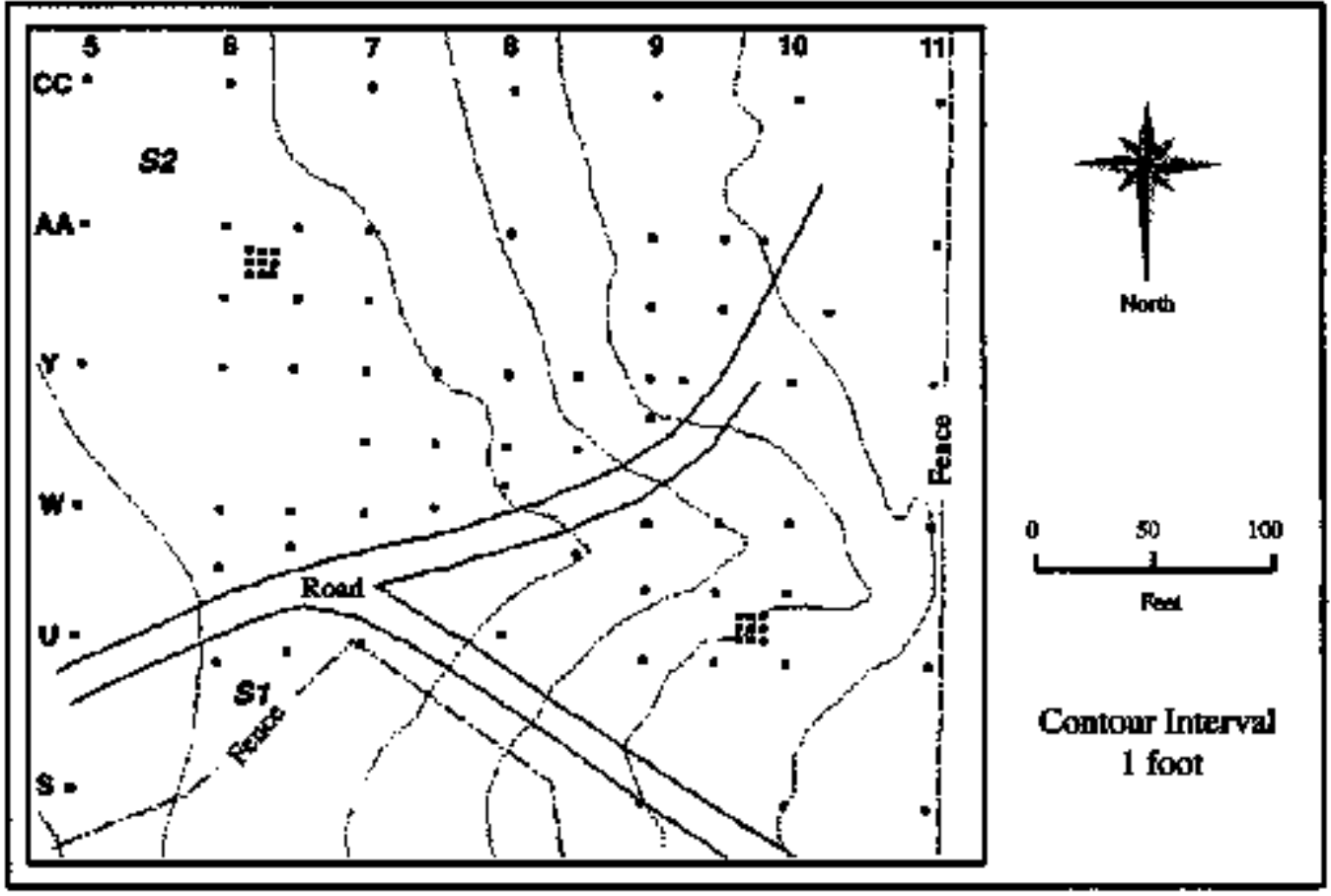

Flgure 3. (a) Generalized plan showing the proposed basetine measurement grid and associated goolocation indexing scheme; (b) map showing the final sampde-collection grid used in the $1994 \mathrm{Fem}$ ald field characterization demonstration program. S1 and S2 are actual bocations of standard gites. 


\section{Fiold Screening Technologies}

Seven proposed alternative fieldscreening technologies were tested during the 1994 Fernald field characterization demonstration program. These technologies are capable of measuring alpha, beta, or gamma radiation or, in some cases, a combination of radiation types. A listing of the seven technologies, the three-character identifier or abbreviation used in this data report and associated tables, and a brief tabulation of the detection principle(s) used, are given in table 1 . The technologies themselves are described in some greater detail in the remainder of this section; the listing is in alphabetical order for conventence; see also Appendix A.

\section{Alpha Track Detector}

An alpha track detector (abbreviated ATD) is a passive, single-use device originally developed to measure indoor airborne alpha activity (Alter and Fleisher, 1981), principally from radon gas. Detection of alpha particles is through observation of damage tracks left in a proprietary polymer material (Lantrack ${ }^{*}$ ). Damage tracks within the plastic detector material are etched chemically for greater visjbility and then counted. The density of tracks is proportional to the monitored alpha activity. The alpha track detector demonstrated in the field was a few square centimeters in size and is sensitive to total alpha radiation emitted from within 10 to 20 micrometers of the soil surface.

\section{Hiah-Energy Beta Scintillation Sensor}

The high-energy beta scintillation sensor (BET) was developed to measure uranium concentrations in surface soils on a real-time basis (Schilk et al., 1993a). The system consists of multiple tayers of plastic scintillating material designed to measure surficial uranium-238 $\left({ }^{238} \mathrm{U}\right)$ contamination by detecting the $2.29 \mathrm{MeV}$ (million electron volts) maximum-energy beta particles from a ${ }^{238} \mathrm{U}$ daughter product, metastable protactinium-234 ( ${ }^{234 \mathrm{~m}} \mathrm{~Pa}$ ). The system discriminates between high-energy beta particles and other interfering background radiation using coincidencecounting techniques. This technique identifies high-energy beta particles by the depth to which they penetrate into the scintiljating-

Tabie 1: Classification and brief description of altemalve characterlzation technologles demonstrated at the Femald site

\begin{tabular}{|c|c|c|c|}
\hline Abbrtaviation & Technelogy Nams & \multicolumn{2}{|c|}{ Dotaction Principle } \\
\hline \multicolumn{4}{|c|}{ Proposed Altemalfve Field-8croenling Tothnologles } \\
\hline ATD & Alpla-track detector & passive & afpha particles \\
\hline BET & Beta scintillometer & passive & betre particles \\
\hline EIC & Electret ionization chamber & passive & atpha particles \\
\hline GMH, GML & $\begin{array}{l}\text { High-mount / low-mount } \\
\text { gamma spectromater }\end{array}$ & passive & gamma rays \\
\hline ICP & $\begin{array}{l}\text { Laser-ablation inductively cosupled } \\
\text { plasme-atonic emission spectrometry }\end{array}$ & active & $\begin{array}{l}\text { visible and ultraviolet } \\
\text { light }\end{array}$ \\
\hline LRA & Long-range alpha detection & passive & ajpha particles \\
\hline \multicolumn{4}{|c|}{ 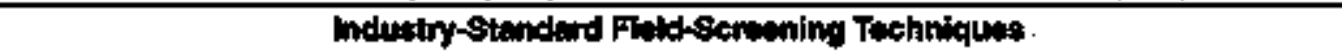 } \\
\hline FID & FIDHER scintillometer & pessive & gamma rays \\
\hline NAD & Sodiun-iodide scintillometer & passive & gantuna rays \\
\hline LAB & Mass spectroscopy & active & ionized elements \\
\hline XRF & X-ray fluorescence unit & active & photons \\
\hline
\end{tabular}


layer stack. The device used in the field tests monitored a surface area of approximately 0.2 square meters. Beta particles are detected from a depth of less than 1 centimeter in the surficial soil.

\section{Electret lonization Chamber}

The electret ionization chamber (EIC) is similar to the alpha track detector in that both are small, passive devices originally developed to measure indoor alpha activity (Kotrappa and others, 1991, 1988). The EIC device consists of a positively charged piece of Teflon", known as an "electret." The electret ionization chamber is activated by screwing the electret into a special conductive polymer holder that establishes a static electric field inside the chamber. Ionizing radiation, including alpha particles, passing through the sensitive volume of the detector creates electron showers that are attracted to the positively charged electret, thus neutralizing that chatge in proportion to the radiation load. The charge remaining in the electret ionization chamber detector after a timed exposure can be measured and the known voltage drop converted to activity.

Because the electret ionization chambers are sensitive to all ionizing radiation, a pair of detectors is utilized in mixed radiation fields, such as exist at the Fernald site. An unshielded detector measures the effect of all ambient radiation, while another is shielded by Tyvek ${ }^{\text {to }}$ plastic, which absorbs low-energy alpha particles before they reach the detector. Alpha activity is determined as the difference between the two readings. Electret ionization chambers measure uranium in the surficial soil to depths of 10 to 20 micrometers.

\section{In-Situ Gamma-Ray Spectrometry}

Field demonstration of the in-situ gamma-ray spectrometry system was conducted using two instrument configurations to monitor surface contamination; these are referred to as the high- (GMH) and lowmounted (GML) positions. Both configurations use the same special thallium-activated sodium-iodide crystal and measure the full gamma spectrum, using the $1.0 \mathrm{MeV}$ maximum-energy ganma rays from ${ }^{230} \mathrm{~Pa}$ as the primary indicator of uranium activity (Schilk and others, 1993b).

The high-mount configuration of the in-situ gamma-ray spectrometer positions the detector crystal on a tripod about 3 feet (1 meter) above the ground surface. The unshielded device detects incoming radiation from all directions. The effective surface measurement area of the high-mount gamma detector is approximately 14,000 square feet $\left(300 \mathrm{~m}^{2}\right)$, or a circle with a radius of approximately 30 feet $(10 \mathrm{~m})$. Because gamma radiation is penetrating, contaminants can be detected up to 6 to 9 inches $(15$ or $20 \mathrm{~cm})$ in depth immediately beneath the spectrometer. The depth of detection in surficial soil decreases radially outward with increasing distance from the center of the detector.

The low-mornt configuration of the insitu gamma-ray spectrometer positions the detector crystal on a tripod somewhat less than a foot (a few cm) above ground level. In contrast with the high-mount gamma configuration, the field-of-view of the detector in the low-mounted position is collimated by the addition of a tungsten shield. This collimation effectively reduces the size of the region examined to approximately 30 square feet (10 $\left.\mathrm{m}^{2}\right)$, or a circle with a radius of 10 feet $(3 \mathrm{~m})$. Depths of penetration of gamma rays within the soil are similar to those of the high-mount configuration.

\section{Laser Ablation-Inductively Coupled Plasma-Atomic-Emission Spectrometer}

The laser ablation-inductively coupled plasma-atomic emission spectrometer technique (abbreviated more simply as ICP) is a 
standard laboratory analytical method modified for field application (Baldwin et al., 1993; D'Silva et al., 1992). A neodymium-yttriumaluminum gamet laser is focused directly on the soil surface, and this laser beam ablates insitu soil. As the laser ablates the soil, an argon gas stream entrains ablated sample particles and transports them directly into an inductively coupled plasma burner. The emittedlight spectrum is then transferred by fiber optics to a spectrometer for quantitative analysis of total elemental uranium. During the course of an individual measurement, the laser beam is rastered over an area of about 6.5 square centimeters, removing particles from only the upper 100 micrometers of soil.

\section{Lono-Bance Alphe Detectox}

The long-range alpha detector (LRA) system detects alpha particles and other ionizing radiation by collecting and measuring the ions produced when alpha particles are stopped in air (Caress et al., 1993; MacArthur et al., 1992). Because the ambient air is the detector gas, the field long-range alpha detector system was configured to be placed directly on the ground. In this configuration, it detects the uranium in the surface soil by monitoring the air ionization near the soil surface produced by contaminants to a depth of approximately 10 to 20 micrometers. The long-range alpha detector system tested at the Fernald site was designed to monitor contamination present on a 1 square meter surface area.

\section{Industry-Standard Tochnologies}

Several standard measurement technologies in widespread industrial use were tested at the demonstration for comparison with the proposed alternative field-screening technologies.

\section{FIDLEB Detector}

FIDLER is an acronym standing for "Field Instrument for Detecting Low-Energy
Radiation." The FIDLER scintillometer (FID) uses a thallium-activated sodium-iodide crystal that converts passing gamma-ray photons to visible light, which is then detected by a photomultiplier tobe and associated electronics. The detector crystal is only 1.5 millimeters thick. This relatively small detector volume reduces the probability that high-energy photons, such as cosmic radiation, will interact with the scintillating material and be detected. The device is sensitive principally to gamma rays in the energy range 10 to $200 \mathrm{KeV}$ (thousand electron volts), which includes the primary gamma spectrum of the uranium decay chain. The FIDLER detector measures soil contamination present within a few centimeters of the soil surface $(<15-20 \mathrm{~cm})$.

\section{Soil Sampling and Laboraton Analysis}

Soil samples were collected and submitted for laboratory analysis (LAB) to provide a means of comparison. Soil samples were analyzed in the laboratory using EPA-certified mass-spectrometry procedures (US EPA. 1992). Uranium measurements produced by this method are routinely accepted by regulatory agencies and thus serve as a basis for comparison among other detectors and measurement technologies. Both surface (maximum depth of $1 \mathrm{~cm}$ ) and core samples [to a depth of 8 inches $(20 \mathrm{~cm})$ ] were collected for anaiysis.

\section{Sodium-lodide Scintillometer}

Sodium-iodide scintillometers (NAD) detect the total $\mathrm{x}$-ray and gamma-radiation emitted from the soil. The scintillometer uses a thallium-activated sodium-iodide crystal that converts adsorbed gamma-ray photons to visible light, which is detected by a photomultiplier tube and associated electronics. A typical detector crystal is 5 centimeters in diameter and 5 centimeters in height. The sodiumiodide detector is sensitive to gamma radiation more energetic than about $60 \mathrm{KeV}$, which 
includes photons from sources other than the uranium decay chain. A thin lead shield may be placed around the detector to decrease sensitivity to very high-energy cosmic radiation. The sodium-iodide scintillometer is sensitive to contanination in the upper few centimeters of soil $(<15-20 \mathrm{~cm})$.

\section{Field X-Bay Fluorescence Detector}

$X$-ray fluorescence detector (XRF) is an active nuclear technique in which one or more ralioactive sources contained in an aluminum probe are used to excite the specific target elements. A mercuric iodide crystal is then used to detect and quantify the $x$-ray photons emitted by the excited atoms. The field-portable $x$ ray fluorescence unit used at the Fernald site was configured to detect oraniuma and thorium through a window of observation measuring approximately one inch $(2.5 \mathrm{~cm})$ square. The measurement technique is sensitive to uranium atoms that can be activated by $x$-radiation from the activation sources (depths of $<15-20 \mathrm{~cm}$ ).

\section{Fleld Data Collection and Data Management}

A number of different data were collected during the course of the 1994 Fernald field characterization demonstration program. During field operations, developers and operators of each characterization technology recorded: (1) a sequential measurement number: (2) the date and time of each measurement; (3) the measurement type [field survey data (FLD), standard-site data (STD), calibration data (CAL)]; (4) the geolocation grid index or other location-specific identifier (calibration plot ID, standard site ID); and (5) the raw measurement value (instrument reading) in units appropriate for the specific technology. A small number of additional soil samples were collected for laboratory analysis as (6) location-specific duplicate (DUP) samples, and (7) as soil cores (COR) to assist in evaluating the depth distribution of uranium contamination.
Field environmental conditions were also recorded during the 1994 Fernald field characterization demonstration program. Meteorologic data consists of (1) date and time of reading; (2) temperature; (3) bumidity; (4) wind speed and direction; and (5) total daily precipitation. (6) cloud cover and heights are available for some times. Most of the meteorologic data was recorded at the Fernald meteorology tower, which is located approximately one-third of a mile (one-half kilometer) northwest of the survey field site. Supplemental data were also recorded at the field site itself. In addition to daily readings, meteorologic measurements (excluding rainfall and cloud cover) were also recorded during the calibration-plot and standard-site measurements by the various technologies.

The diverse types and large quantity of data involved in the 1994 Femald field characterization demonstration program, as well as the need to merge different data sets by date and time, required standardized procedures and a comprehensive computerized database. Data received during the field demonstration program were entered into a Microsoft Access ${ }^{*}$ relational database management system. Copies of the resulting data tables were verified by the technology principal investigators. Ohio state plane coordinates were linked to geolocation codes, and the raw measurement values were converted to total uranium activities in picocuries per gram ( $(\mathrm{CCi} / \mathrm{g})$ using calibration information. All data used for visualization and analysis were retrieved from this database, which serves as a single source for both raw and reduced data from the 1994 Fernald field characterization demonstration program. A copy of the data management plan used to design and implement the field demonstration is included as Appendix B for reference and historical purposes. 


\section{Results}

A variety of data were collected daring the 1994 Fernald field characterization demonstration program. These data include meteorologic information and geographic-location data for the gridded and supplemental surveyed locations, calibration data, replicate standardsite measurements, and instrument readings (both raw and calibrated) that result from the actual field measurements. Complete data tables containing all data obtained during the 1994 Fernald field characterization demonstration program are included as appendices to this report.

\section{Location Data}

The majority of the field measurements were taken at pre-marked locations coded to a geolocation grid system [figure 3(a)]. Grid and supplemental locations were surveyed by Fernald Environmental Management Project personnel and referenced to the Ohio state plane coordinate system in general use for environmental restoration purposes at the Fernald site. Coordinate values corresponding to each geolocation index are presented in Appendix C. Supplemental field survey points were measured by some of the demonstrated technologies after preliminary analysis of the completed survey grid to provide follow-up characterization in regions of significant uncertainty. These supplemental locations may be identified as lacking an alphanumeric geolocation code; they are referenced only by state plane coordinates in the composite data tables of the appendix.

\section{Meteorologic Data}

Field environmental conditions were measured and recorded by project engineers on a daily basis. Meteorologic data consists of daily and episodic measurements of temperature, precipitation, humidity, wind speed and direction, and cloud cover/height, plus daily rainfall totals. A complete listing of meteoro- logic data relevant to the 1994 Fernald field characterization demonstration program, including records from both the local field site and the meteorology tower, is provided in Appendix D. A simplified diagram showing changes in the major environmental variables measured during the field demonstration program is presented in figure 4 .

\section{Technology Callbration}

The alternative characterization technologies tested at the 1994 field characterization demonstration program were calibrated to total uranium activity in picocuries per gram using a series of calibration beds with known activity. Uranium activities by isotope were measured using EPA-certified laboratory mass spectroscopy. Five calibration beds consisting of variably contaminated Fernald soils were available during the course of the field demonstration program. Replicate laboratory determinations of total uranium activity for these calibration beds are presented in table 2 .

Four calibration beds were availabte at the beginning of the field program. These plots were numbered $\mathrm{C} 0, \mathrm{C} 35, \mathrm{C} 100$, and $\mathrm{C} 200$ in recognition of their intended approximate uranium activity. When it became apparent that the measured uranium activity levels were generally higher than originally anticipated (table 2), bed $\mathrm{C} 2 \mathrm{O}^{\circ}$ was dismantled and diluted with clean Fernald soil to produce calibration bed CP. Plot CP occupied the same physical location as the defunct $\mathrm{C} 200$ plot. As a result of this reconstruction, not all of the technologies obtained calibration measurements at all five plots. The relative magnitudes and internal variability of uranium samples taken from the calibration beds are presented in figure 5 . The internal homogeneity of calibration plot $C P$ is markedly less [a coefficient of variation (C.V.) $>36$ percent] than for the other calibration beds (C.V. $<10$ percent). 


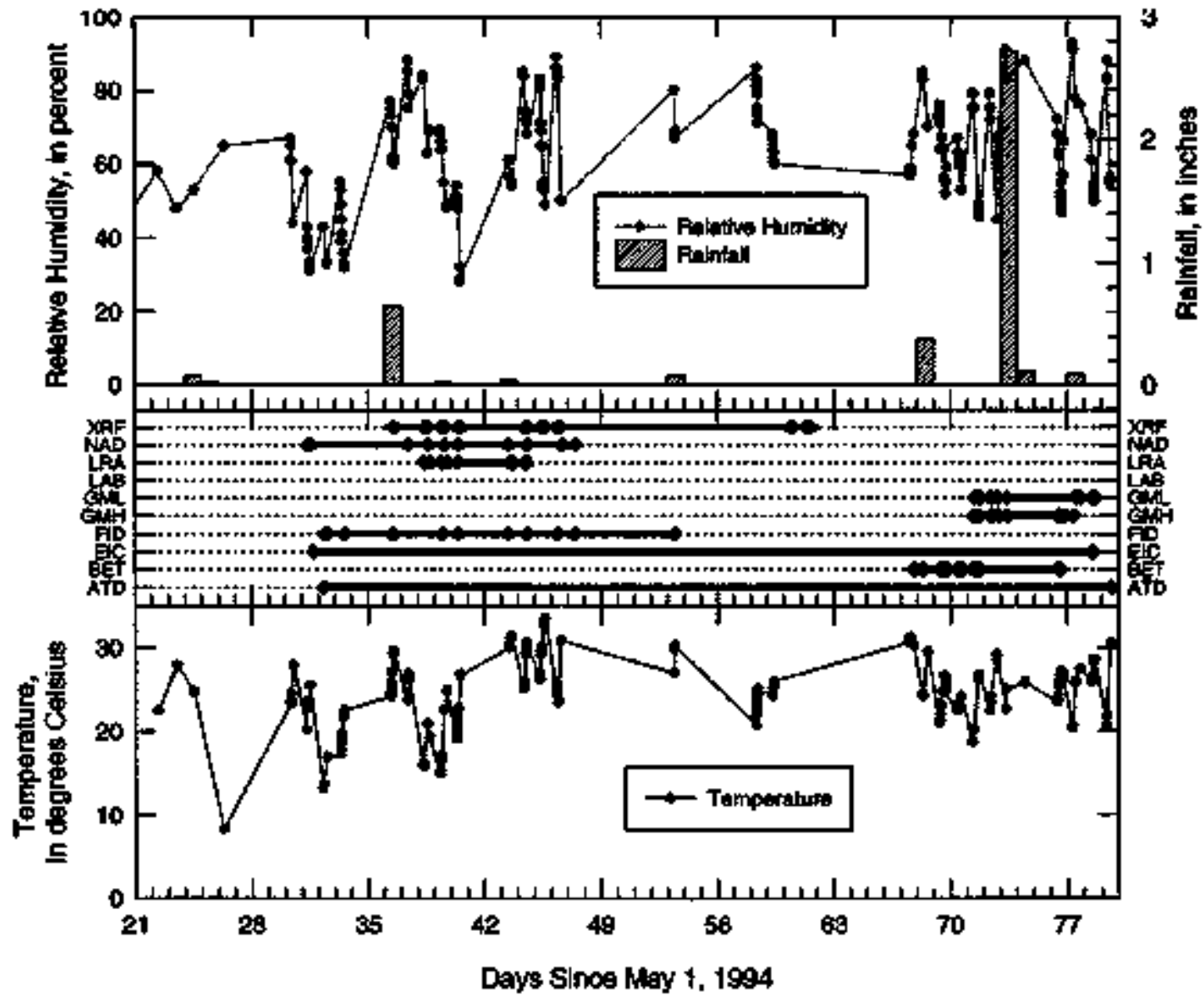

Figure 4. Variation in temperature, nelative humidity, and total daily rainfall amounts with respect to the times field messurements were taken by the offferent characterization technologies (indicated by $\rightarrow$ symbols alorg individual technology bars; many symbols overlap). Meteorological information from Appendix $\mathbf{D}$.

The raw measurement values obtained for each calibration bed by each technology are tabulated in Appendix E. The individual characterization technologies were calibrated as follows: For each demonstrated technology, the individual measurement values were averaged (table 3 ) and plotted against the mean laboratory uranium activity taken from table 2 . These cross plots are shown (alphabetically by technology abbreviation) in figures 6 and 7 . Note that the number of raw measurement values varies markedly among the different technologies.

Visual inspection indicates that the measurement response of the technologies is essentially linear with increasing total uranium activity. A keast-squares regression of the form

$$
U_{s}=b_{0}+b_{1} X
$$

was fitted to the averaged data, where $U_{\mathrm{r}}$ is mean total uranium activity in picocuries per gram, $b_{0}$ and $b_{i}$ are the regression coefficients (intencept and slope, respectively), and $X$ is the mean observed raw-measurement value (units vary). No attempt was made to force the regression equation through the origin. Table 4 presents the regression coefficients determined for the calibration data obtained by each technology demonstrated at the 1994 Fernald field characterization demonstration program. Coefficients of determination ( $r^{2}$ values) associated with the regressions all exceed 0.9 (table 4). 
Table 2: Laboratory measunements and statistical summary of uranium contamination for the five calloration beds

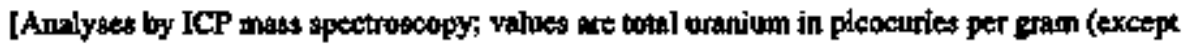
C.V and N). Sta Dev.: standerd deviation; C.V.: coefficient of variation, defined as the standard devizikin divided by the mean; $N$ : sumber of samples. Leaders ( - ); not applicahle]

\begin{tabular}{|c|c|c|c|c|c|}
\hline & Co & CO56 & c10 & 6200 & $\mathrm{CP}$ \\
\hline & 5.962 & 97.33 & 144.66 & 312.28 & 79.655 \\
\hline & 5.962 & 92.84 & 153.71 & $303.0 \mathrm{x}$ & 26.15 \\
\hline & 5.612 & 92.65 & 141.91 & $331.0 x$ & 36.862 \\
\hline & 6.450 & 84.26 & 158.78 & $380.4 x$ & 43.412 \\
\hline & 5.272 & 95.11 & 150.40 & $364.4 x$ & 69.946 \\
\hline & 5.612 & 97.25 & 128.54 & $315.7 x$ & 52.802 \\
\hline & 5.262 & 90.72 & 145.19 & 322.15 & 48.837 \\
\hline & -- & 106.39 & -- & - & + \\
\hline Mean & 5.73 & $94 \overline{57}$ & 146.17 & 332.71 & 51.09 \\
\hline Sud.Dev. & 0.42 & 6.76 & 9.71 & 28.82 & 18.54 \\
\hline $\mathrm{C.V}+\mathrm{S}_{0}$ & 7.33 & 7.15 & 6.64 & 8.66 & 36.29 \\
\hline Mínìnum & 5.26 & 84.26 & 128.54 & 303.01 & 26.15 \\
\hline Maximum & 6.45 & 106.3 & 158.78 & 380.42 & 79.66 \\
\hline $\mathbf{N}$ & 7 & 8 & 7 & 7 & 7 \\
\hline
\end{tabular}

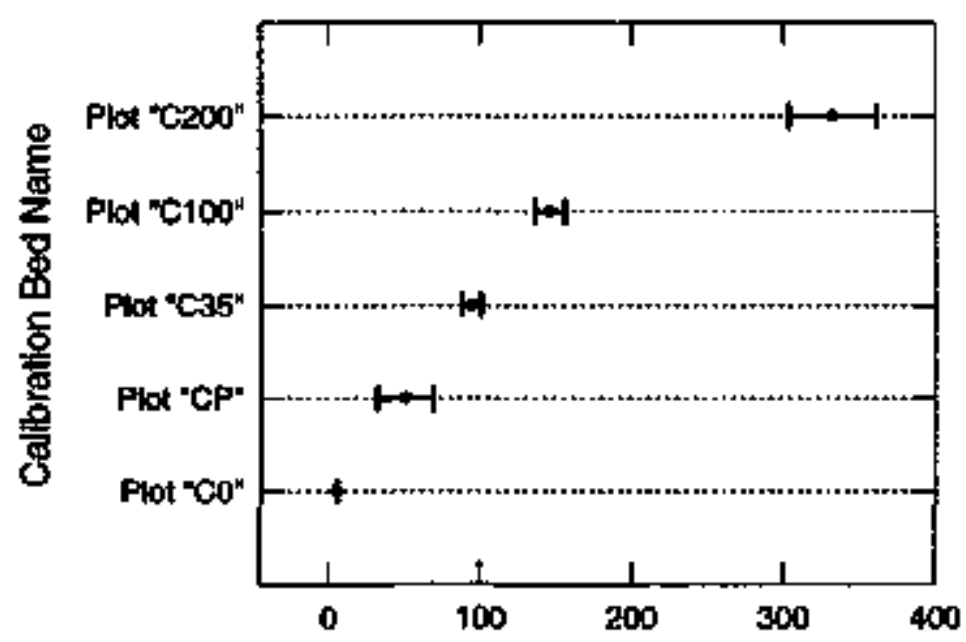

Figure 5. Diagram showing maan uranium concentratton and vartability of laboratory measurements of the five Femald calibration beds. Emor bars represent plus and minus one standard deviation. 
Table 3: Statistical summary of raw measurement values at the caltoration beda for 10 characterization technologtes from the 1994 Femald field characterization demonstration program

[Std.Dev.; fanderd deviation; $N$ : aumber of saniples; keaders ( $-Y_{+}$not measured or not appliceble. Values art hotal uraniun activity in picocaries per gram (exexpt for $N$ )]

\begin{tabular}{|c|c|c|c|c|c|c|c|c|c|c|}
\hline & ATD & BET & ENC & FID & CAMH & GNL & ICP & IPA & MAD & $\overline{X F F}$ \\
\hline \multicolumn{11}{|c|}{ Calibration Bed Co } \\
\hline Mean & 0.0648 & 6.67 & 2.16 & 457.85 & 1.94 & 2.24 & 0.00 & 6090 & 3723 & 4.92 \\
\hline Std.Dev. & 0.0516 & 0.43 & 1.52 & 15.24 & - & 1.72 & 0.00 & 494.97 & 74.72 & 3.39 \\
\hline $\mathbf{N}$ & 5 & 6 & 5 & 13 & 1 & 3 & 7 & 2 & 9 & 15 \\
\hline \multicolumn{11}{|c|}{ Calibration Bed C35 } \\
\hline Mean & 0.1498 & 23,13 & 3,87 & 773.36 & 34.60 & 35.80 & 0.09 & 7700 & 5407 & 78.68 \\
\hline Std.Dev. & 0.0567 & 2.94 & 1.74 & 20.68 & $m$ & 1.73 & 0.01 & 141.42 & 107.76 & 9.51 \\
\hline $\mathbf{N}$ & 5 & 6 & 5 & 14 & 1 & 3 & 16 & 2 & 10 & 15 \\
\hline \multicolumn{11}{|c|}{ Calibration Bed C100 } \\
\hline Mean & 0.1851 & 31.17 & 7.80 & 927.38 & 46.00 & 49.33 & 0.06 & 9700 & 6280 & 126.02 \\
\hline Stod Dev. & 0.0191 & 3.63 & 6.11 & 23.77 & -- & 1.66 & 0.01 & 141.42 & 142,48 & 12.09 \\
\hline $\mathbf{N}$ & 5 & 6 & 5 & 13 & 1 & 3 & 4 & 2 & 9 & 15 \\
\hline \multicolumn{11}{|c|}{ Calibration Bed C200 } \\
\hline Mean & 0.3425 & - & $\overline{\text { I3.31 }}$ & 1577.60 & - & $\overline{--}$ & $=$ & 19000 & 9979 & 342.17 \\
\hline Sto.Dev. & 0.0468 & -- & 1.46 & 41.41 & -- & -- & - & - & 103.65 & 72.77 \\
\hline $\mathbf{N}$ & 2 & 0 & 3 & 10 & 0 & 0 & 0 & 1 & 10 & 5 \\
\hline \multicolumn{11}{|c|}{ Calibration Bed CP } \\
\hline Mean & 0.0941 & 15.93 & 4.27 & 532.67 & $\overline{-}$ & $=$ & - & $\overline{-}$ & 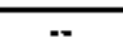 & 57.30 \\
\hline Stch, Dev. & 0.0069 & 0.18 & 2.80 & 19.04 & - & - & .. & $\cdots$ & .. & 12.13 \\
\hline$N$ & 2 & 2 & 2 & 3 & 0 & 0 & 0 & 0 & 0 & 10 \\
\hline
\end{tabular}

The enror bars shown on figures 6 and 7 represent plus and minus one standard deviation for the replicate calibration readings for both the laboratory values and technology measurements. However, the regressions [equation (1); table 4] are based solely upon the irean values indicated by the filled circles at the intersection of the error bars. The regression equations are fitted to these mean values only, and the $r^{2}$ values apply to the mean-versus-mean regression. Neither the regressions nor the coefficients of detemnination consider the variability of the individenal measurements constituting those means. In some instances, this variability is rather large [for example, figure 6(c)] or the calibration may be based only on a single reading for a calibration bed [figure 6(e); see also table 3]. The indicated $r^{2}$ values may overstate the accuracy of the calibration for these technologies.
Table 4: Regression coefficients for equation nelating raw measurement data to total uranium activity

\begin{tabular}{cccc}
\hline $\begin{array}{c}\text { Technology } \\
\text { (Abbreviotod) }\end{array}$ & $\boldsymbol{b}$ & $\boldsymbol{b}$, & $\boldsymbol{r}$ \\
\hline ATD & -68.705 & 1164.4 & 0.996 \\
BET & -36.06 & 5.7448 & 0.996 \\
EIC & -50.42 & 28.09 & 0.965 \\
FD & -115.70 & 0.2832 & 0.994 \\
GMH & -2.696 & 3.084 & 0.986 \\
GML & -2.828 & 2.918 & 0.992 \\
ICP & -6.782 & 3425.7 & 0.997 \\
LRA & -104 & 0.02344 & 0.966 \\
NAD & -186.58 & 0.0522 & 0.999 \\
XRF & 8.66 & 0.964 & 0.991 \\
\hline
\end{tabular}

Each technology developer was directed by the Data Management Plan (Appendix B) to measure the calibration bed soils at least three times: (1) prior to the field demonstration, (2) after completing the baseline survey, and (3) following completion of the project. 

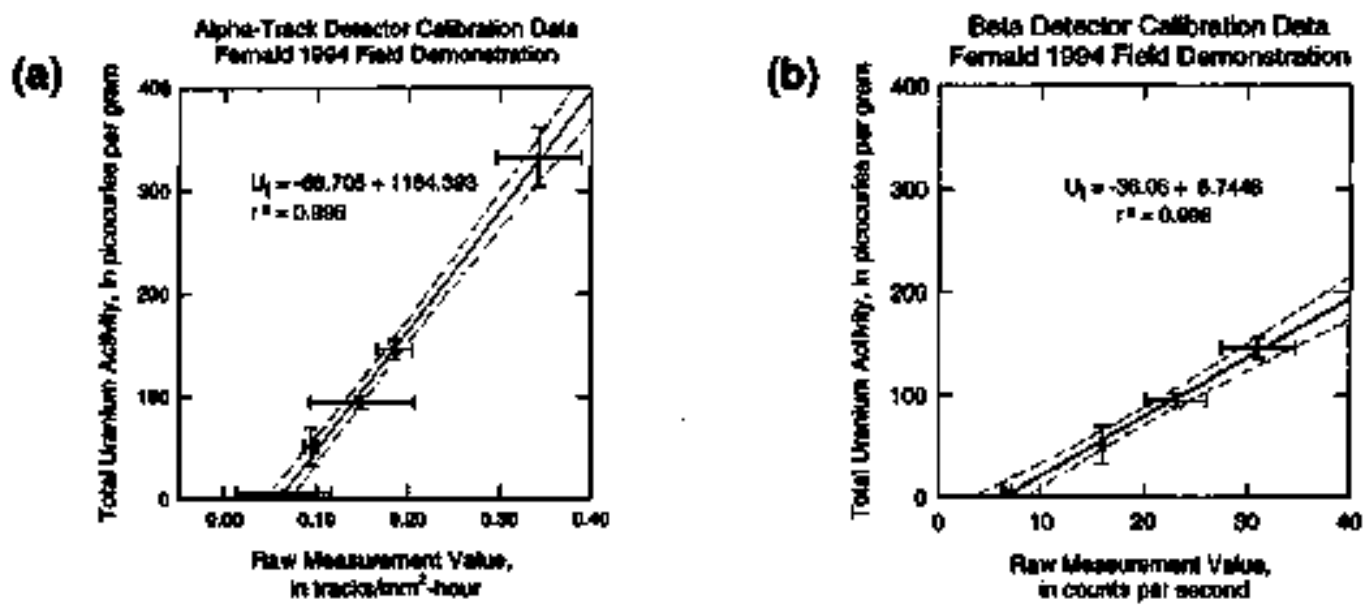

(c)

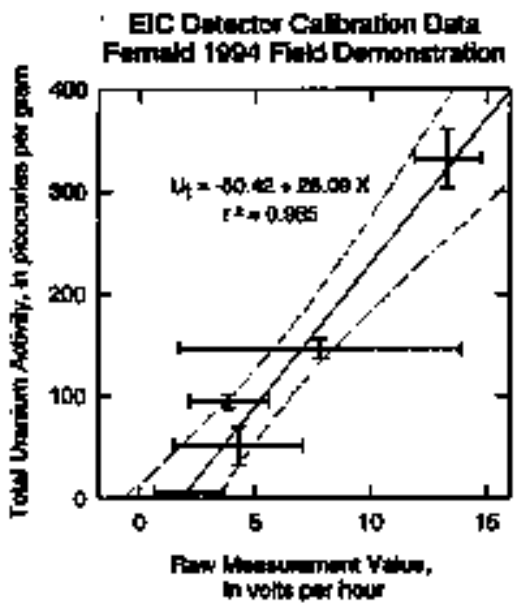

(d)

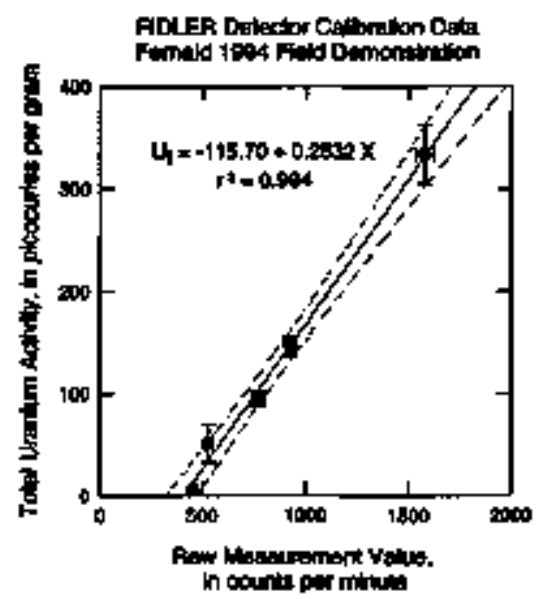

(e)
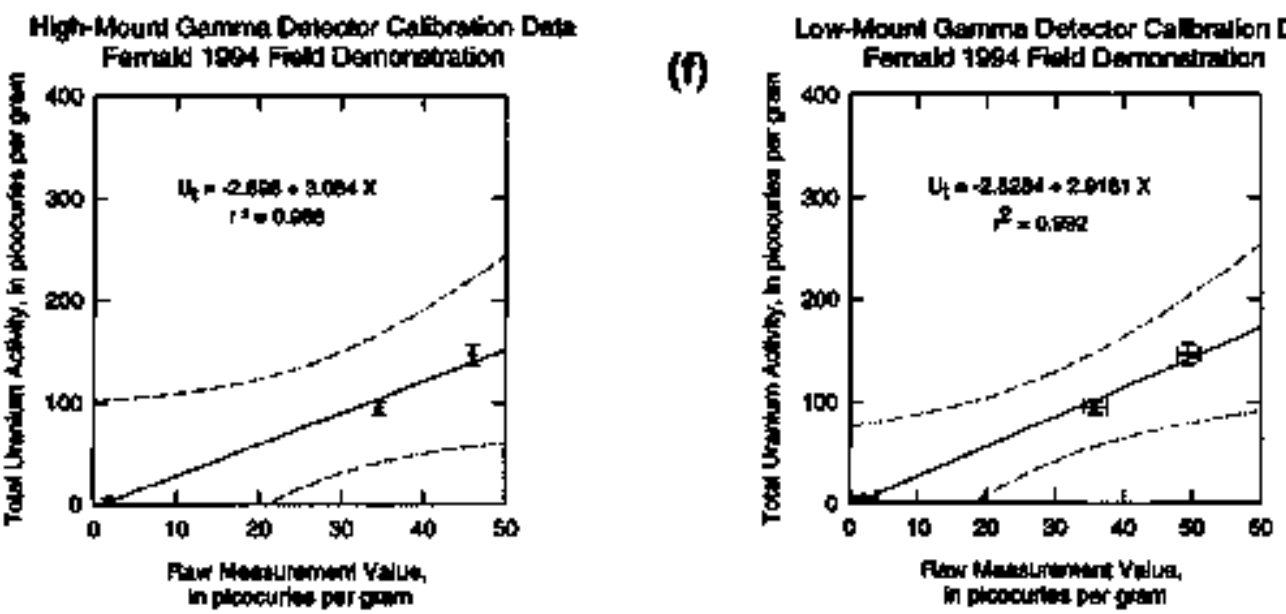

Figure 6. Cross plots of calibration data for (a) alpha-track detector, (b) beta scintillometer, (c) electret tontzation chamber, (d) FIDLER scintillometer, (4) high-mount gamma-ray spectrometer, and (f) low* mount gamma-ray spectrometer. Emor bars on cafbration points represent plus and minus one standard deviation; dashod lines are 95-percent confidence Irrits on solid-line regression equation. 
(a)

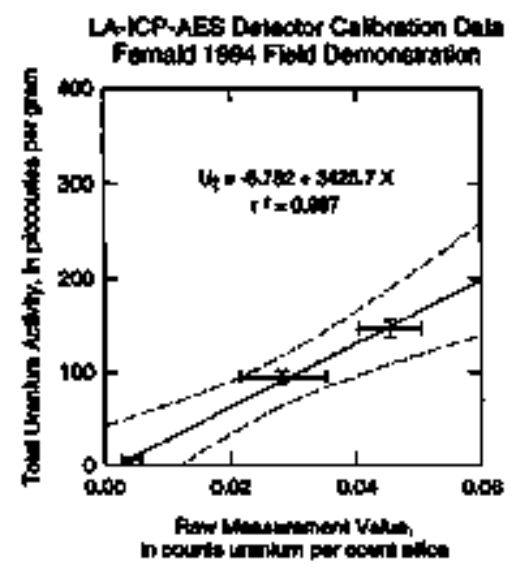

(c)

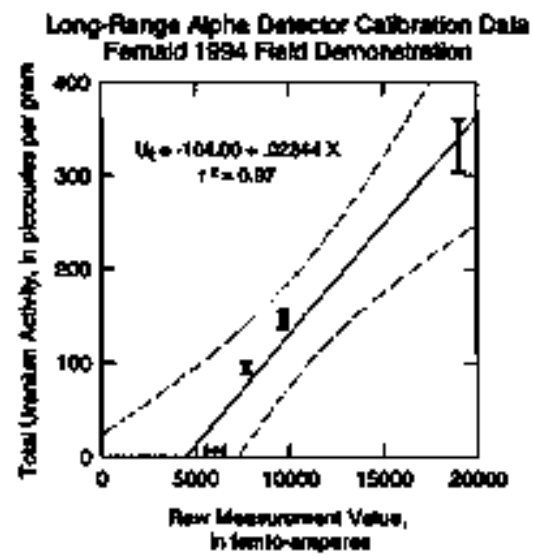

(b)

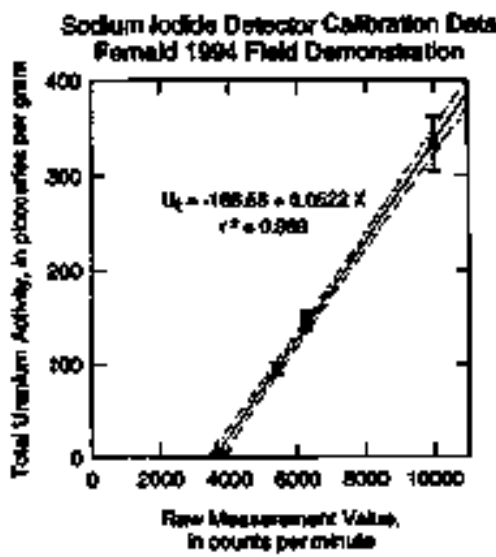

(c)

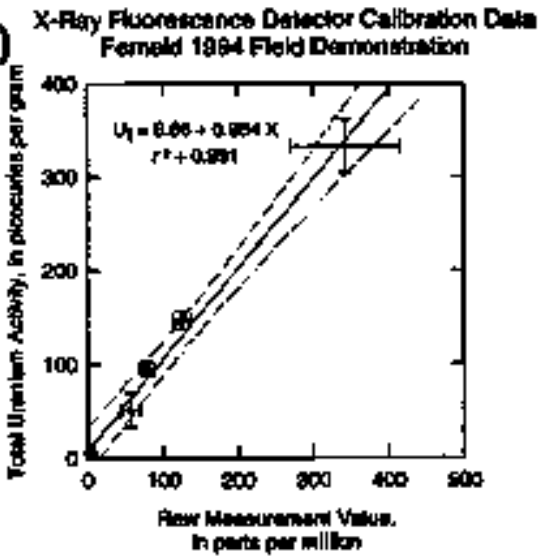

Fipure 7. Cross plots of calitration data for fa\} laser ablation-inductively coupled plasma-atomic emission spectrometer, (b) long-range alpha detector, (c) sodtium-iodide scintilometer, and (d) field $x$-ray fluorescence unit. Emor bars on calibration points represent plus and minus one stantdard" deviation; dashed lines are 95-percent confidence limits on solid-line regression equation.

Field conditions also were to be recorded by project engineers at the time the various technology instruments measured the calibration beds. Not all technology đevelopers followed these instructions exactly, leading to calibration datasets of variable quality and reliability

\section{Standard-Sites Measurements}

Two standard sites, jdentified as $\$ 1$ and $\$ 2$, were established on undisturbed native soils within the survey grid. The standards sites were used to make repeated detector measurements to quantify detector precision. These standard-sites data are tabulated in
Appendix $F$, and a summary of the measurements is presented in table 5 . The technologies were to take standard-site measurements twice daily (see Data Management Plan; Appendix B). All technologies took measurements at the S1 and S2 locations (table F-1) with the exception of the laser ablation-inductively coupled plasma-atonic emission spectrometer, which recorded somewhat equivalent, replicate "standard" measurements on calibration beds $\mathrm{CO}$, C35, and CP (table 6; table F-2). The ICP technology developers took their replicate standardized soil measurements from the calibration beds ostensibly because the technology required removing soil for testing. This 
Table 5: Statistical summary of measured uranium activities of the standard siles for all technologles excopt HCP

[Sed.DeV: standard deviation; CV.: coefricient of Variatien, defined as the standard deviation divided by the mean, in percent, N: nomber of samples. Values are total uraniom aetivity in picosaries per eram (except for C.V. and N)]

\begin{tabular}{|c|c|c|c|c|c|c|c|c|c|c|}
\hline & ATD & BET & EIC & FID & GIMH & antal & LAB & LRA & NAD & XAF \\
\hline \multicolumn{11}{|c|}{ Standard Site } \\
\hline Mean & 73.16 & 66.81 & 34,23 & 90.71 & 75.02 & 81.93 & 69.44 & 45.55 & 130.83 & 86.01 \\
\hline StdDer. & 98.21 & 7.41 & 55.36 & 10.90 & 14.33 & 8.88 & 7.50 & 32.51 & 10,56 & 8.14 \\
\hline C.V. 第 & 134 & 11 & 162 & 12 & 19 & 11 & 11 & 71 & 8 & 9 \\
\hline $\mathbf{N}$ & 3 & 19 & 2 & 21 & 9 & 9 & 5 & 10 & 18 & 18 \\
\hline \multicolumn{11}{|c|}{ Standard Site 2} \\
\hline Mean & 24.87 & 53.77 & 15.41 & 76.30 & 49.82 & 48.13 & 48.79 & 68.94 & $\overline{11821}$ & 63.64 \\
\hline Std.Dev. & 24.09 & 11.82 & 10.47 & 12.06 & 6.01 & 799 & 2.25 & 330.78 & 7.10 & 9.60 \\
\hline C.V. $\%$ & 97 & 22 & 69 & 16 & 12 & 17 & 5 & 45 & 6 & 15 \\
\hline $\mathbf{N}$ & 3 & 17 & 2 & 20 & 7 & 8 & 5 & 9 & 57 & 17 \\
\hline
\end{tabular}

procedure ensured the standard plots surface soils remained undisturbed. Consequently, however, the ICP standard data cannot be compared directly to those reported for other techniques.

Table 6: Syatistical summary of measured uranium activities of the standard sites by ICP technology [Stc.Der.; standard deviation; C. Y.; coefficient of variation, in percent; N: muber of samples. Vahes are total uranium wetivty in plcocucies per grant (except for C.V, and N)]

\begin{tabular}{rccc}
\hline & C0 & CS5 & CP \\
\hline Mean & 11.95 & 115.00 & 133.79 \\
Std.Dev, & 12.66 & 145.24 & 19.85 \\
C.V. \% & 106 & 126 & 15 \\
$\mathrm{~N}$ & 16 & 32 & 3 \\
\hline
\end{tabular}

\section{Soll-Moisture Correction Factors}

Raw field measurement values obtained by the majority of the technologies demonstrated were converted directly to total uranium activities through straight-forward application of the appropriate calibration coefficients (table 4). However, three of the fieldscreening technologies adopted a modified approach to converting the raw measured readings in an effort to compensate for varying environmental conditions, specifically changes in soil-moisture levels. The data affected are those obtained by the beta scintillometer and the high-mount and low-mount gamma-ray spectrometer.

The modification involves the development of an empirical "soil-moisture correction factor." Measured values recorded for the affected technologies at the standard sites were observed (by the developers) to decrease markedly following heavy rain during the course of the 1994 Fernald field characterization demonstration program. These values were then observed to increase over somewhat extended periods of time to approximately the levels observed prior to the rainfall events. The developers of the beta scintillometer and gamma-ray spectrometer elected to make use of the concept that replicate measurements obtained from the standard sites should be approximately the same, all other conditions being equal. Soil moisture was inferred to have increased abruptly coincident with rainfall events and then to have decreased progressively to pre-rainfall levels over the course of several hourstis a day or so. An empirical soilmoisture corty tion factor was obtained by distributing the observed drop and subsequent rebound in standard-site measurements over the interspersed field-survey measurements in proportion to the elapsed time associated with 
each individual measurement. Calculation of this time (measurement)-specific correction factor is illustrated schematically in figure 8 , based on a sequence of control readings obtained from one of the two standard sites.

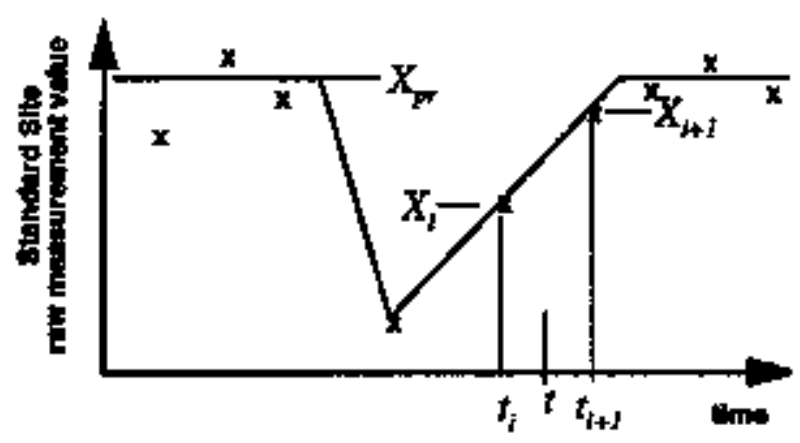

Figure 8. Schematc illustration of quantilies involved in calculiation of a toner soil-moisture correction factor for a field-survey measurement taken at time $t$ from changes in repeated moasurements at a standard site $(x)$.

The soil-moisture correction factor, $F^{*}(t)$, at any arbitrary time, $t$, with $t_{i} \leq t \leq t_{i+1}$, is defined in a general sense as:

$$
F^{*}(t)=\frac{X_{p r}}{X_{i}+\left(t-t_{i}\right) \cdot \frac{X_{i+1}-X_{i}}{t_{i+1}-t_{i}}},
$$

where $X_{p r}$ is the average pre- (and post-) rainfall standard-site measurement value, $X_{i}$ is the standard-site measurement obtained at time $t_{t}$, and $X_{i+i}$ is the standard-site measusement obtained at a later time, $t_{t+1}$. In practice, a best-fit curve through the affected $X_{t}$ values would be used if there were sufficient standard-site measurements that the response of the instrument readings to changes in soil-moisture content would be better represented by some possibly non-linear, temporally averaged rate of change, rather than by simple linear interpolation between individual standard-site meastistements. Soilmoiswre correction factors " directly by the technology developers.

The calibrated results for the three affected alternative technologies, the beta scin- tillometer and the high- and low-mounted gamma spectrometers, are given in Appendix G. The "baseline" results are indicated in the column labeled "Total $\mathrm{U}(\mathrm{pCi} / \mathrm{g}$ )" for consistency and comparison with the uranium activities reported by the other technologies. Additional columns provide the appropriate moisture-correction factors, $F^{*}$, and the "adjusted total U" obtained by multiplying the otherwise calibrated reading [from equation (1)] by $\mathrm{F}^{*}$. The baseline uranium activities (without the soil-moisture factor correction) are used throughout the remainder of this report to facilitate direct comparison with the readings reported by the majority of the demonstrated technologies.

\section{Fleld Survey Results}

Measurements of uranium activity recorded for the baseline Fernald field grid by each different characterization technology are tabulated in Appendix G. Grid measurements are identified by "F.D" in the sample-type category. Calibration (CAL) and standard-site (STD) measurements are also included in these tables, which are organized by sample sequence number. Duplicate (DUP) soil samples, collected at selected grid locations, and a small number of core samples (COR) were submitted for standard laboratory analysis. The baseline field data from Appendix $G$ are summarized in table 7, which presents a comparison of the final, calibrated, baseline uranium activities obtained by all technologies, organized in order by geolocation index. The timing of the field measurements for each technology with respect to major meteorological variables is shown in figure 4 .

Maps showing the baseline calibrated measurements of uranium activity obtained for the field survey grid are shown in figures 9 and 10. Total uranium activities are represented by a small grey-scale-coded circle at the approximate $x$ and $y$ locations corresponding to the actual sample locations in the field.The grey- 
Table 7: Composite tabulation of field survey results for geolocation grid [All vabues are tocal urantium activity in picocurles per gram. Negralvo values are interpreted as below detection limil. Technolory abbreviations from table 1. Leaders (--); not measured]

\begin{tabular}{|c|c|c|c|c|c|c|c|c|c|c|c|}
\hline $\begin{array}{l}\text { Ceclocetion } \\
\text { Index }\end{array}$ & ATD & B日T & Ec & FID & ent & at. & $\operatorname{CP}$ & LAB & LAA & MAD & XFF \\
\hline$\overline{\mathrm{A} 1}$ & 27.71 & 44.19 & -50.42 & 67.81 & 51.27 & 4736 & 79.55 & 63.36 & 83.52 & 95.30 & 72.29 \\
\hline$A 2$ & 30.50 & 45.46 & -2.67 & 64.42 & 48.81 & 46.49 & 57.62 & 56.58 & 95.24 & 95.30 & 60.25 \\
\hline $\mathrm{A}^{3}$ & 30.85 & 68.44 & -45.08 & 75.46 & 46.65 & 51.45 & 94.96 & 65.60 & 95.24 & 110.96 & 61.87 \\
\hline AAS & 0.81 & 41.72 & 16.74 & 72.06 & 53.12 & 50.86 & 32.27 & 39.41 & 60.08 & 124.01 & 61.10 \\
\hline AAG & -16.19 & 49.54 & 20.54 & 81.60 & 56.52 & 49.11 & 36.72 & 59.80 & 36.64 & 131.84 & 72.39 \\
\hline AA6.5 & 10.94 & 54.65 & -31.71 & 88.49 & 58.37 & 5349 & 52.48 & 52.99 & 76.49 & 105.74 & 47.90 \\
\hline AA 7 & -5.13 & 51.84 & 24.78 & 69.51 & 64.54 & 57.28 & 36.72 & 48,42 & 99.93 & 116.18 & 38.16 \\
\hline AA 8 & -5.48 & 49.65 & -1.40 & 77.16 & 68.85 & 71.29 & 52.14 & 61.79 & 34,30 & 116.18 & 33.38 \\
\hline$A A 9$ & -1.64 & 45.57 & 25.20 & 75.74 & 62.99 & 58.45 & 41.18 & 54.20 & 67.11 & 105.74 & 83.75 \\
\hline AA9.5 & 6.98 & 57.70 & -1.26 & 86.22 & 56.83 & 5553 & 49.74 & 68.27 & 67.11 & $110 . \$ 6$ & 104.06 \\
\hline AA10 & 27.12 & 65.45 & 25.31 & 80.27 & 48.50 & 5349 & 52.14 & 53.89 & 76,49 & 97.91 & 91.21 \\
\hline AA11 & -14.79 & 32.76 & 156.94 & 72.34 & 45.41 & 5583 & 54.54 & 51.54 & 88.21 & 87.99 & 74.23 \\
\hline B! & 20.95 & 54.25 & -40.31 & 69.80 & 46.96 & 45.32 & 86.05 & 46.80 & 106.96 & 97.91 & 50.71 \\
\hline B2 & -30.51 & 56.26 & 15.87 & 58.75 & 44.49 & 4941 & 41.18 & 71.08 & 48.36 & 105.74 & 54.16 \\
\hline B3 & -12.93 & 53.85 & -14.75 & 70.36 & 46.34 & 4795 & 40.49 & 64.39 & 85.86 & 100.52 & 63.43 \\
\hline Ct & 1.04 & 62.69 & -19.80 & 76.88 & 42.64 & 4853 & 59.33 & 72.21 & 95.24 & & 83.10 \\
\hline $\mathrm{C} 2$ & 41.45 & 50.97 & 25.98 & 74.04 & 45.41 & 4503 & 52.14 & 61.84 & 60.08 & 97.91 & 61.97 \\
\hline $\mathrm{C3}$ & 3.02 & 58.10 & 25.98 & 74.89 & 46.34 & 4299 & 65.16 & 61.10 & 62.42 & 98.43 & 64.67 \\
\hline $\cos$ & -8.04 & 33.16 & -9.66 & 87.35 & 50.35 & 4590 & 28.50 & 50.12 & 43.67 & 110.96 & 67.78 \\
\hline $\mathrm{CC} 6$ & 8.38 & 58.15 & -13.34 & 90.19 & 55.90 & 6020 & 39.81 & 59.33 & 53.05 & 121.40 & 77.82 \\
\hline CC7 & 3.95 & 56.72 & 12.39 & 9670 & 56.83 & 5816 & 32.27 & 52.48 & 78.83 & $124.0 \mathrm{~J}$ & 65.85 \\
\hline $\mathrm{CC} 8$ & 15.83 & 57.58 & -35.64 & 89.90 & 61.45 & 6049 & 41.18 & 51.36 & 104.62 & 113.57 & 62.58 \\
\hline $\operatorname{cog}$ & - & 63.27 & -20.87 & 92.45 & 46.65 & 68.67 & 40.84 & 61.59 & 109.30 & 113.57 & 82.48 \\
\hline CClo & 0.81 & 46.89 & 19.64 & 86.22 & 46.03 & 4765 & $4 \hat{3.58}$ & 60.74 & 31.95 & 113.57 & 54.89 \\
\hline CC11 & 22.00 & 32.71 & 51.27 & 74.61 & 20.13 & 2927 & 16.51 & 31.41 & 36.64 & 95.30 & 42.44 \\
\hline Dl & 3.95 & 56.78 & .9 .69 & 82.82 & 48.50 & 4561 & 60.36 & 64.89 & 92.90 & 110.96 & 71.69 \\
\hline $\mathrm{D} 2$ & 0.58 & 54.65 & -45.64 & 89.62 & 47.26 & 5203 & 80.23 & 53.81 & 64.77 & 108.35 & 68.26 \\
\hline D3 & -17.59 & 53.16 & -35.81 & 84.24 & 50.04 & 45.61 & 60.36 & 55.36 & 76.49 & 95.30 & 67.35 \\
\hline E1 & -2.10 & 48.10 & +30.20 & 87.07 & 45.72 & 4153 & 56.94 & 56.83 & 76.49 & 105.74 & 54.14 \\
\hline E2 & -0.24 & 45.11 & -24.86 & 82.54 & 56.21 & 5524 & 48.37 & 52,44 & 57.74 & 100.52 & 68.78 \\
\hline E3 & 20.37 & 58.61 & -9.69 & 84.24 & 47.57 & 4765 & 55.57 & 56.38 & 9758 & 106.26 & 71.04 \\
\hline F1 & 5.58 & 58.56 & -50.42 & 88,49 & 48.19 & 4299 & 44.60 & 50.93 & 78.83 & 105.74 & 76.67 \\
\hline $\mathbf{F} 2$ & 10.59 & $\$ 6.49$ & $-36,09$ & 98.68 & 47.57 & 4474 & 45.63 & 49.90 & 95.24 & 105.74 & 60.84 \\
\hline F3 & -2.68 & 53.04 & -35.25 & 85.94 & 46.34 & 4240 & 51.80 & 52.56 & 92.90 & 105.74 & 63.71 \\
\hline S5 & 2.91 & 30.06 & $17+16$ & 77.16 & 58.98 & 5086 & 39.12 & 50.98 & 64.77 & 118.79 & 82.35 \\
\hline 59 & 81.85 & 72.63 & -25.70 & 93.30 & 77.49 & 7246 & 87.77 & 90.68 & 55.39 & 126.62 & 100.41 \\
\hline $\mathbf{s 1 0}$ & 47.15 & 61.08 & 39.81 & 78.01 & 42.95 & 4649 & 47.69 & 71.75 & 20.23 & 95.30 & $\pi .23$ \\
\hline S11 & -1.05 & 41.49 & 38.88 & 57.05 & 26.29 & 2139 & 78.52 & 39.21 & 60.08 & 78.60 & 25.02 \\
\hline
\end{tabular}


Toble 7: Composite tabulation of fleld survey results for geolocation grid (continued) (All values are totsl uranium activity in picucuries per gram. Negalive vahes are interpreted as

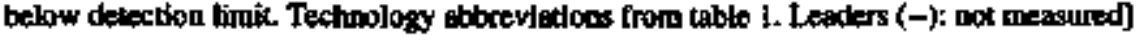

\begin{tabular}{|c|c|c|c|c|c|c|c|c|c|c|c|}
\hline $\begin{array}{l}\text { Cololotetion } \\
\text { medex }\end{array}$ & ATD & ECT & EIC & FD & GMH & GUL & ICP & LAB & LRA & NaD & XRF \\
\hline$\overline{\mathrm{US}}$ & 17.23 & 51.95 & 27.16 & 68.38 & 47.26 & 53.20 & 63.10 & 47.53 & 139.78 & 11357 & 64.98 \\
\hline U6 & 31.78 & 45.46 & -25.70 & 79.42 & 66.08 & 73.92 & 100.78 & 65.60 & 55.39 & 139.67 & 74.38 \\
\hline U6s & 33.99 & 55.63 & 66.27 & 85.66 & 82.73 & 87.92 & 105.24 & 82.55 & 71.80 & 137,06 & 84.24 \\
\hline U7 & 30.62 & 55.57 & 69.66 & 100.38 & 81.19 & 75.67 & 94.28 & 89.03 & 78.83 & 150.11 & 95.11 \\
\hline U8 & 23.86 & 64.13 & 84.6] & 106.33 & 89.82 & 97.85 & 88.11 & 105.50 & 132.74 & 147.50 & 88.94 \\
\hline U9 & 8.14 & 61.54 & 11.35 & 89.05 & 65.77 & 73.63 & 69.27 & 76.02 & 46.02 & 116.18 & 65.83 \\
\hline U9.5 & 32.25 & 46.67 & 49.75 & 70.65 & 49.42 & 53,49 & 47.34 & 52.16 & 95.24 & 100.52 & 78.16 \\
\hline U10 & 3.72 & 64.07 & 36.57 & 76.88 & 47.57 & 53,49 & 67.21 & 59.77 & 27.26 & 103.65 & 62.04 \\
\hline บ!1 & 29.80 & 65.39 & 41.88 & 81.69 & 38.94 & 48.24 & 87.42 & 58.04 & 88.21 & 103.13 & 66.61 \\
\hline V10 & -9.44 & 59.36 & 24.16 & 67.81 & 42.95 & 40.65 & 66.53 & 53.72 & 83.52 & 9791 & 66.58 \\
\hline V6 & $-32,14$ & 59.48 & -20.98 & 94.15 & 62.68 & 71,87 & 55.91 & 58.81 & 146.81 & 129.23 & 68.74 \\
\hline V6.5 & 11.41 & 75.39 & 18.79 & 107.18 & 73.79 & 80.05 & 5454 & 86.46 & 151.50 & 150.11 & 92,91 \\
\hline v9 & 30.85 & 63.61 & $\$ 3.63$ & 8056 & 58.37 & 68.08 & 94.28 & 81.67 & 85.86 & 129.23 & 73.92 \\
\hline V9.5 & -0.01 & 54.77 & 16.46 & 67,25 & 42.33 & 40.07 & 63.79 & 54.12 & 102.27 & 100.52 & 66.66 \\
\hline W5 & 2596 & 36.78 & 45.79 & 87.35 & 50.97 & 56.70 & 26.10 & 61.86 & 118.68 & 13].84 & 69.90 \\
\hline W6 & 5.12 & 53.79 & 112.75 & 102,65 & 67.93 & 64.00 & 38.78 & 70.52 & 106.96 & 137,06 & 74,82 \\
\hline W6.5 & 10.24 & 65.62 & 25.59 & 104,63 & 76.87 & 79.46 & 36.72 & 74.04 & 111.65 & 137,06 & 6.34 \\
\hline w7 & -9.55 & 73.72 & 98.68 & 96.98 & 80.88 & 78.59 & 42.21 & 79.11 & 88.21 & 144.89 & 8723 \\
\hline W7.5 & 23.98 & 67.98 & .1795 & 103.21 & 72.25 & 80.05 & 56.94 & 77.83 & 76.49 & 139.67 & 83.94 \\
\hline W8 & 0.46 & 59.36 & 10.82 & 79.14 & 68.54 & 69.83 & 41.52 & 62.32 & 55.39 & 118.79 & 81.18 \\
\hline W8.5 & $-1,03$ & 58.73 & 2.50 & 92.45 & 79.34 & 87.92 & 75.78 & 81.23 & 109.30 & 124,01 & 88.91 \\
\hline w9 & -22.25 & 55.05 & 23.09 & 87.07 & 48.19 & 48.53 & 45.97 & $\$ 2.94$ & 78.83 & 113.57 & 61.45 \\
\hline w9.5 & 7.33 & 48.33 & 25.06 & 7886 & 45.72 & 41.82 & 65.50 & $\$ 1.20$ & 99.93 & 108.35 & 59.76 \\
\hline W10 & 0.93 & 60.62 & 115.56 & 79.14 & 44.80 & 55.83 & 43.23 & 75.26 & 111.65 & 118.79 & 70.20 \\
\hline W11 & 15.48 & 65.28 & 25.62 & 94,43 & 40.79 & 51.45 & 56.23 & 82.98 & 113.99 & 116.18 & 67.24 \\
\hline$X 7$ & $-[2.81$ & 61.66 & 99.24 & 86.79 & 70.70 & 74.21 & 73.38 & 68.76 & 74.14 & 134.45 & 83.95 \\
\hline$x 7.5$ & 11.75 & 45.69 & -4.41 & 72.91 & 71.32 & 63.41 & 72.69 & 62.73 & 60.06 & 124,01 & 64.19 \\
\hline$x 8$ & 18.51 & 56.60 & -38.06 & 8197 & 74.10 & 73.33 & 52.14 & 62.24 & 46.02 & 126.62 & 8127 \\
\hline X85 & 10.12 & 52.01 & 29.52 & 76.03 & 68.85 & 70.12 & 55.91 & 61.53 & 78.83 & 134.45 & 66.65 \\
\hline$X 9$ & 15.71 & 60.51 & 58.63 & 91.89 & 67.62 & 75.08 & 56.59 & 78.12 & 69.46 & 126.62 & 78.99 \\
\hline Y5 & -13.40 & 50.05 & 68.65 & 80.84 & 52.20 & 55.53 & 45.63 & 49.60 & 76.49 & 109.13 & 54.70 \\
\hline Y6 & 8.61 & 56.83 & 20.45 & 78.29 & 61.45 & 56.70 & 54.88 & 55.32 & 36.64 & 100.52 & 64.92 \\
\hline Y6.5 & -7.92 & 59.94 & 54.05 & 68.95 & 60.53 & 64.58 & 74.06 & 60.17 & 43.67 & 100.52 & 68.34 \\
\hline$Y 7$ & 16.06 & 55.51 & 46.72 & 87.92 & 69.47 & 65.75 & 70.98 & 57.33 & 46.02 & 108.35 & 72.54 \\
\hline Y7.5 & 12.34 & 55.51 & 559 & 103.21 & 72.25 & 80.92 & 98.04 & 76.00 & 43.67 & 118.79 & 65.17 \\
\hline Y8 & -10.95 & 41.78 & 20.45 & 84.24 & 73.17 & 71.87 & 112.77 & 59.93 & 34.30 & 105.74 & 62.38 \\
\hline Y8.5 & 20.02 & 54.88 & -5.62 & 82.26 & 73.48 & 76.54 & 97.02 & 68.69 & 69.46 & 110.96 & 85.20 \\
\hline$Y 9$ & 24.56 & 46.67 & 73.18 & 88.77 & 71.94 & 70.42 & 101.13 & 62.19 & 67.11 & 103.13 & 85.75 \\
\hline
\end{tabular}


Tabte 7: Composite tabuletion of fleld sumey results for geolocalion grid (continued)

(Atl values are tocal uranium extivity in pictcuries per gram. Negative values are interpeed as below dosection limit. Technobsy abbreviations from table 1 . Leaders (-); not measured]

\begin{tabular}{|c|c|c|c|c|c|c|c|c|c|c|c|}
\hline $\begin{array}{l}\text { eeolocellon } \\
\text { molex }\end{array}$ & ATD & BET & تC6 & FID & E.HH & CWIL & ICP & LAB & LBA & MAD & XRF \\
\hline Y9.5 & 14.20 & 55.68 & 33.23 & 69.80 & 49.73 & 46.49 & 86.74 & 60.78 & 67.11 & 113.57 & 60.08 \\
\hline Y10 & -0.01 & 61.26 & 206.49 & B5.94 & 48.50 & 52.32 & 105.92 & 57.80 & 83.52 & 103.65 & 84.49 \\
\hline Y11 & 64,62 & 61.03 & 52.45 & 121.06 & 58.06 & 73.04 & 74.41 & 86.77 & 146.81 & 137.06 & 111.53 \\
\hline Z6 & 1.97 & 50.34 & 42.59 & 83.67 & 54.67 & 54.66 & 69.27 & 45.36 & 78.83 & 108.35 & 62.07 \\
\hline Z6.5 & 10.12 & 62.35 & -24.35 & 93.87 & 59.29 & 64.29 & 97.36 & 56.85 & 74.14 & 108.35 & 65.66 \\
\hline Z7 & 5.58 & 51.43 & 10.31 & 77.16 & 61.76 & 56.99 & 80.23 & 49.57 & 67.11 & 116.18 & 56.75 \\
\hline 29 & -11.77 & 49.54 & 40.45 & 82.26 & 68.85 & 69.54 & 111.75 & 57.49 & 50.70 & 90.60 & 70.41 \\
\hline $\mathbf{Z 9 . 5}$ & -12.35 & 65.97 & 29.07 & 85.66 & 50.35 & 60.20 & 123.05 & 67.36 & 78.83 & 105.74 & 73.88 \\
\hline Z10 & 6,40 & 53.39 & 73.82 & 72.06 & 47.57 & 50.28 & 72.35 & 58.82 & 78.83 & 103.13 & 60.12 \\
\hline
\end{tabular}

scale coding varies from white (low uranium activities) to black (high values) as indicated by the shaded ramp scale on the figures; the scale boundaries are the same for all figures to facilitate comparison of the absolute magnitudes of the measurements chtained by the different technologies. Note that for presentation purpases only, the state plane coordinates indicated on the axes of figures 9 and 10 have been truncated to the right-most three or four digits. The full Ohio state plane coordinates are given in Appendix C.

An alternative presentation of the field survey results is given in figures 11 through 13. In these figures, the baseline, calibrated uranium activities are plotted in an arbitrary, but consistent, sequence of geolocations (effectively row by row). This mode of presentation allows direct visual comparison of nearby spatial measurements among the different technologites demonstrated at Fernald. The equivalent soil-geochemistry values (LAB) are also shown on each figure for comparison; soil geochemical determinations are generally accepted as the "true" uranium contamination level at each sample location. Note that in this set of figures, the total uranium activity scales have been modified so that the full range of variability exhibited by the measurements obtained by each individual technology is reflected.

Examination of the various parts of fig. ures 9 through 13 can provide a first pass assessment of the degree to which the various technologies are measuring the same uranium activities. Figures 9 and 10 clearly indicate that the alpha-track detector and the electretionization chamber methods [figure 9 (a) and $9(c)$, respectively] are producing markedly different results from the other technologies. Although there are definite differences, the remaining characterization techniques produced at least grossly similar spatial patterns of uranium contamination. Figures 11 through 13 emphasize the point-by-point comparisons of the different technologies. For example, compare the similar shapes of the paired curves for the low-mount gamma spectrometer (GML; figure 12(b)) and the sodium-iodide (NAD; figure 13(b)) detectors. The GML measurement curve both tracks and nearly overlies the "ground-truth" laboratory-analysis curve 
(a)

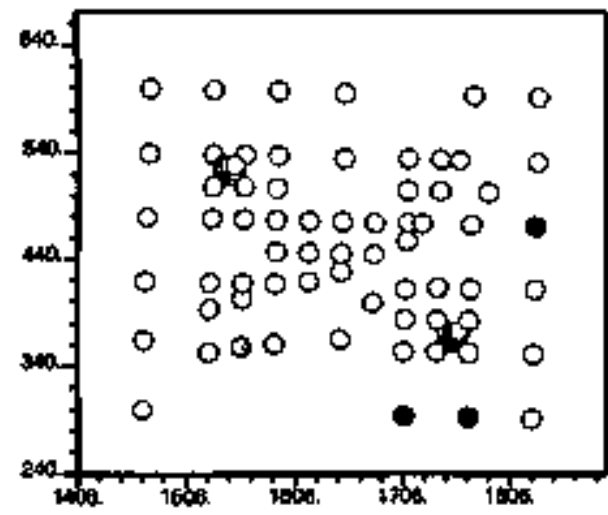

(c)

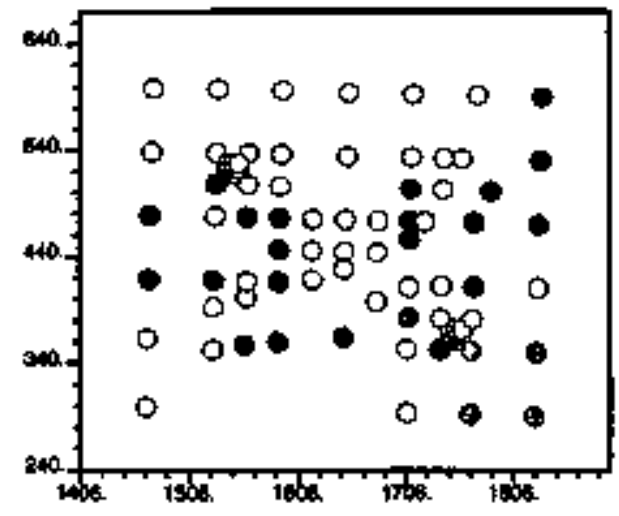

(e)

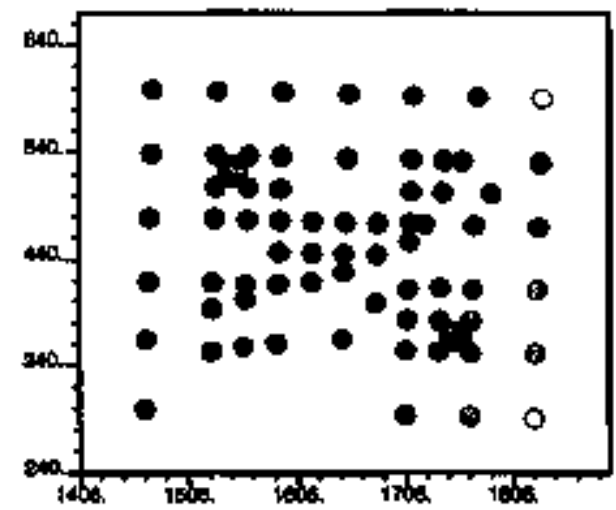

(b)
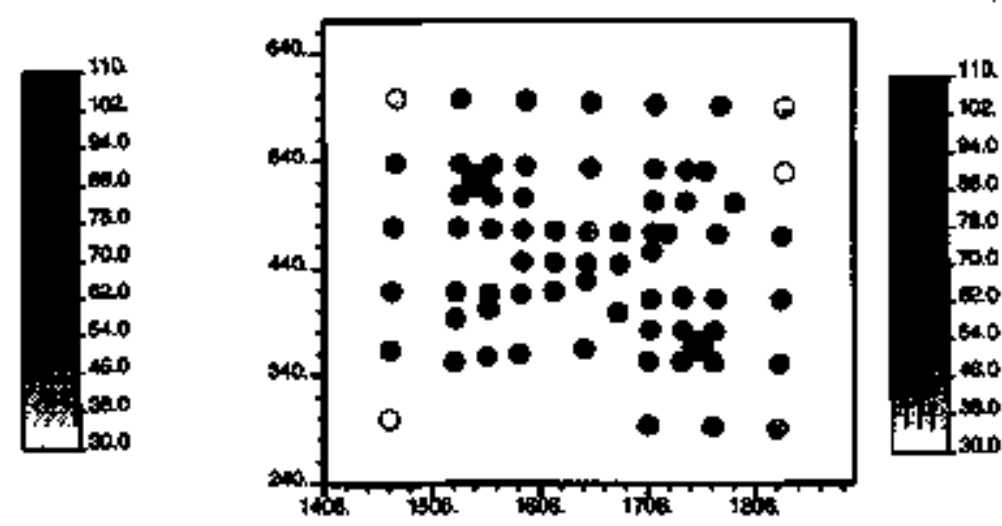

(d)

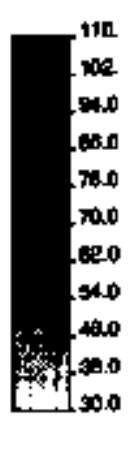

(f)

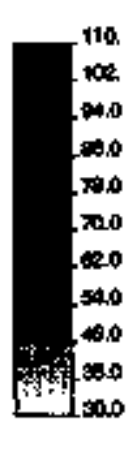

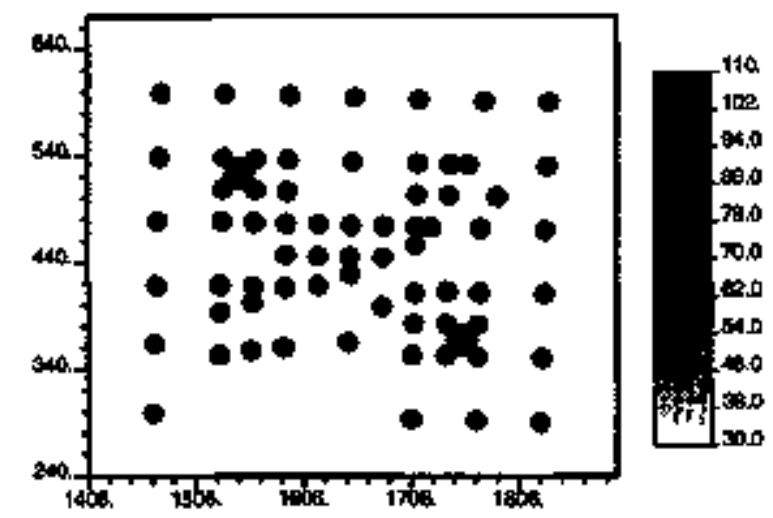

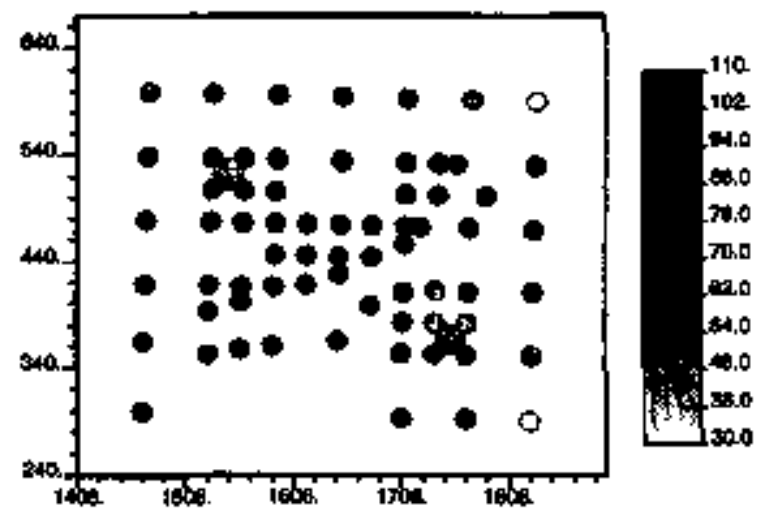

Foure 9. Grey-scale location maps showing uranium activities for the 1994 Femald field characterization demonstration grid as measured by (a) alpha-track detoctors, (b) beta scintilometer, (c) electret ionization chambers, (d) FIDLER detector, and (e) high-mount and (f) lowmount gamma spectrometer. Grey-scale bers indicate tolal uranium activity in pleocuries per gram. $X$ - and $Y$-axis values are trunceled Ohio state plane coordinates in feet. 
(a)

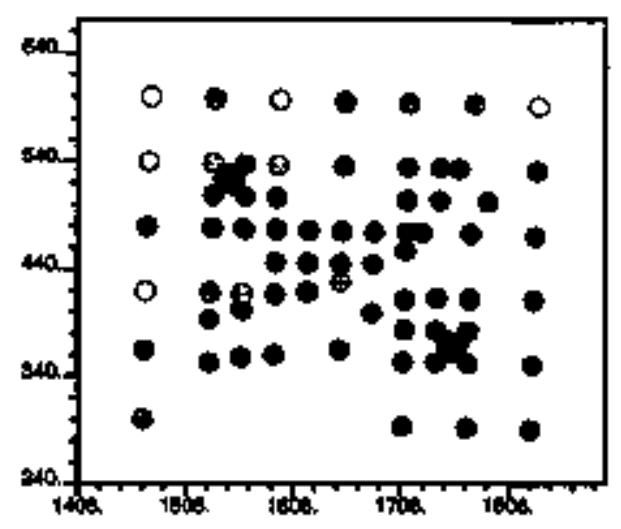

(c)

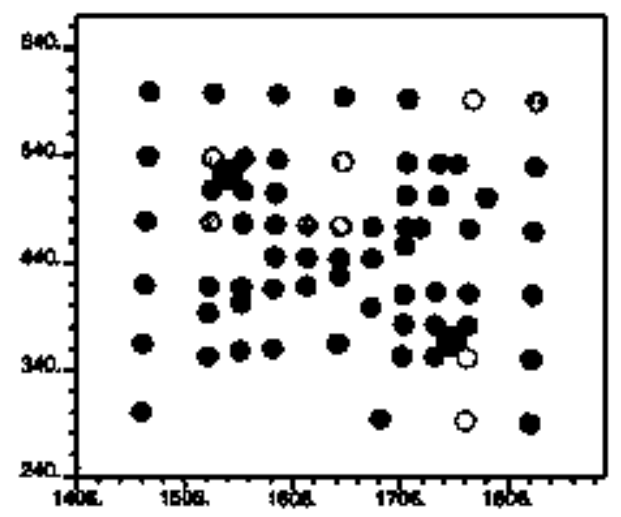

(b)

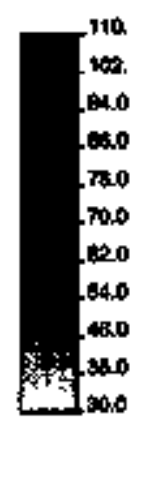

(d)

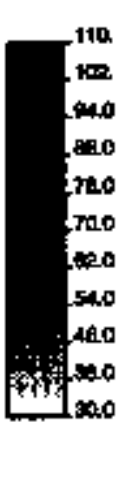

(e)

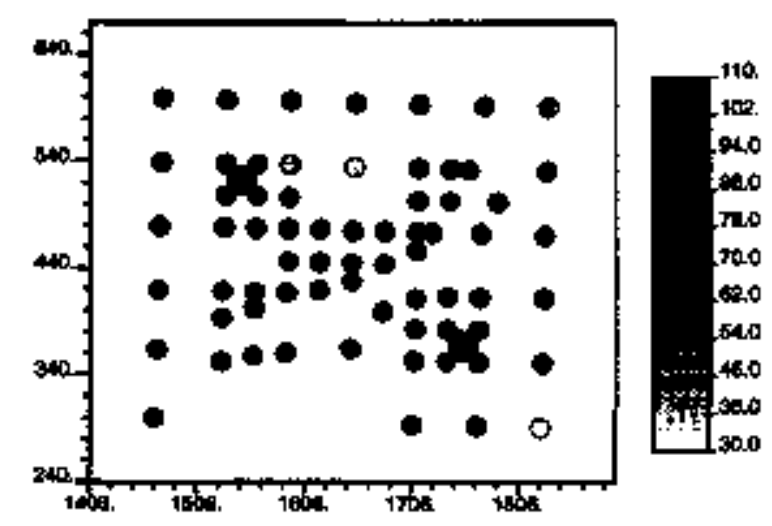

Figure 10. Grey-scale location maps showing uranium activities for the 1994 Femald field characterization demonstration grid as measured by (a) laser abdation-inductively coupled plasma. atomic emission spectrometer, (b) long-range alpha detector. (c) soil sampling and laboratory analysis, (d) eodium-iodide scintillometer, and (d) $x$-ray fluonesconce unit. Grey-6cale bars indicate total uranium activity in plococurites per gram. $X$-and Yaxis vatuas are thuncated Ohio state plane coordinates in foet. 
(a)

ATD
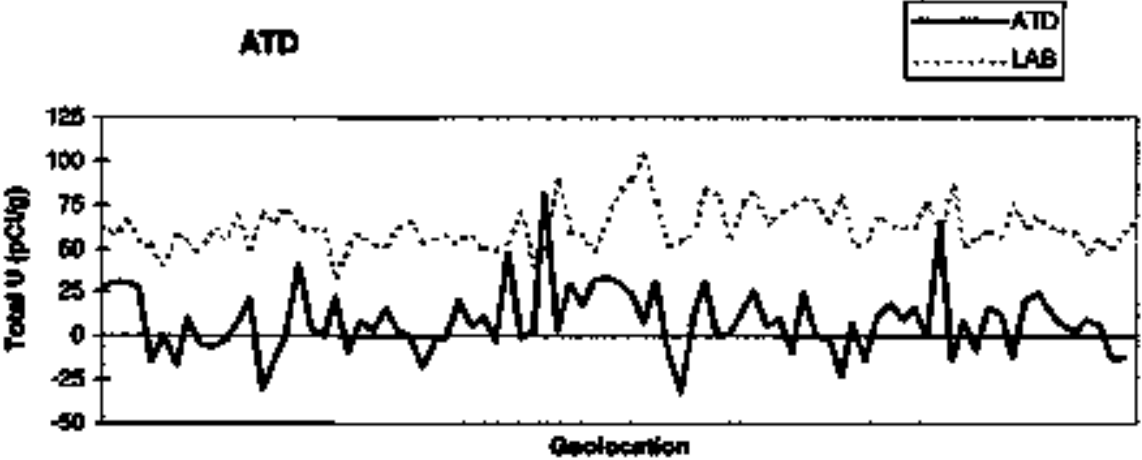

(b)

(c)
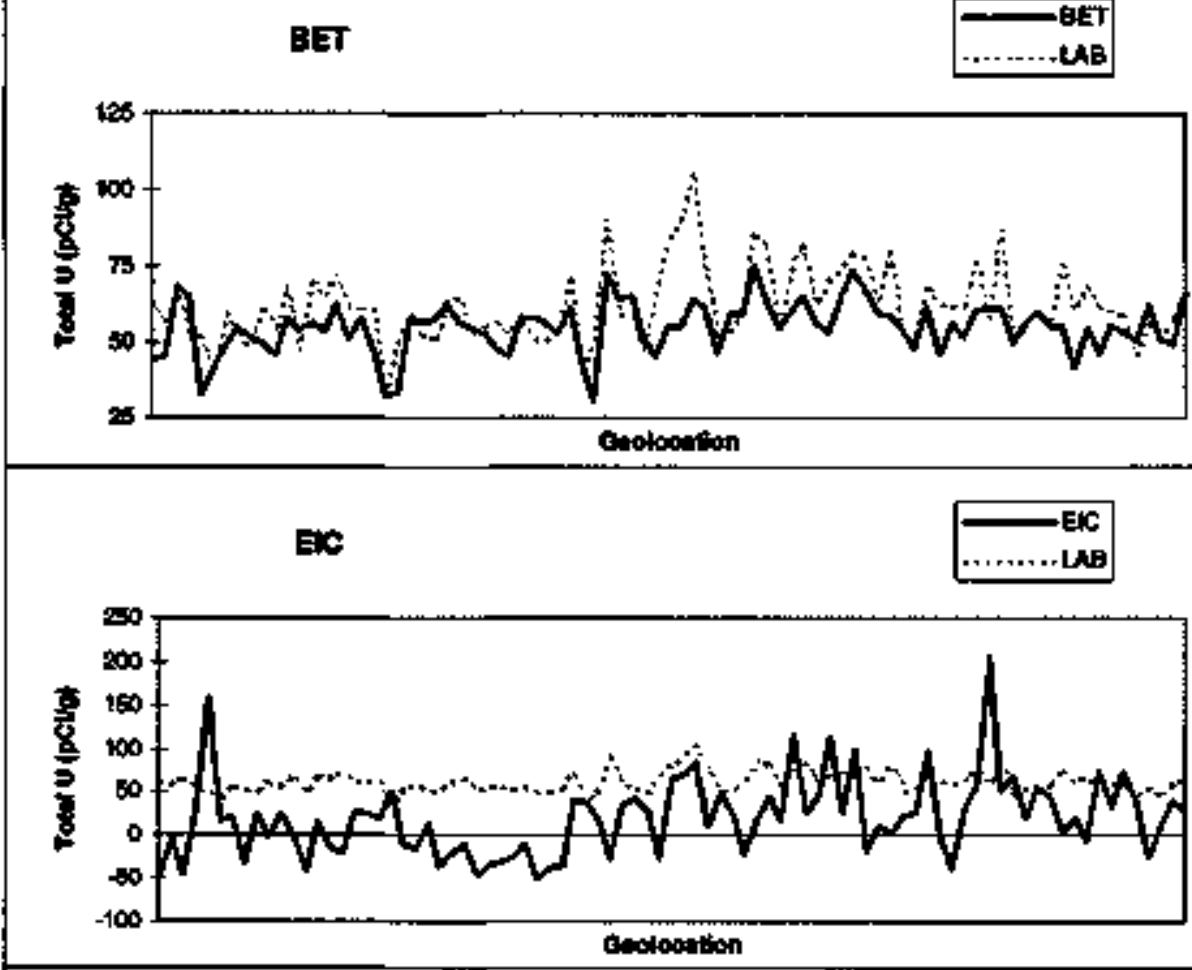

(d)

d)

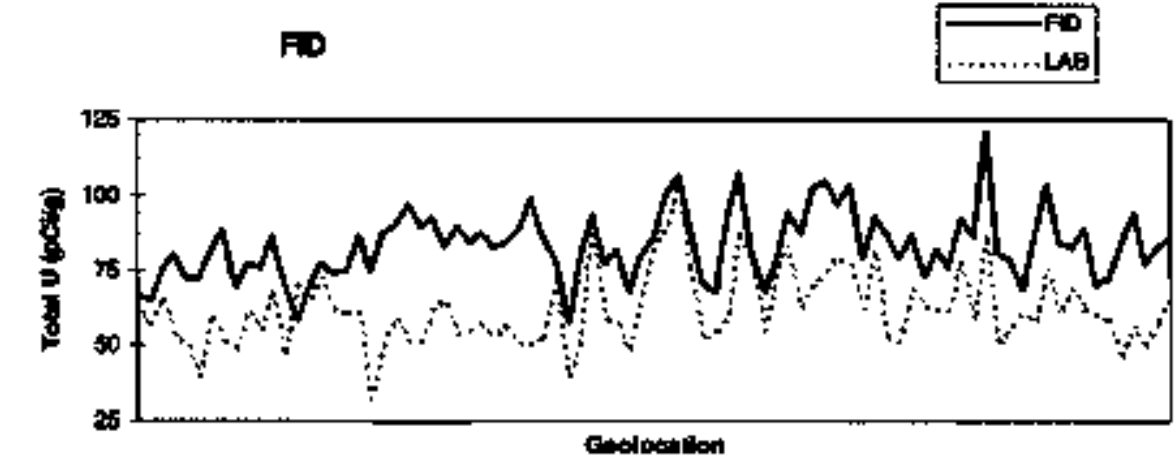

Floure 11. Field measurements of total uranium activity arranged sequentially by geolocation index code, as measured by (a) alpha-track detectors, (b) beta scintillometer. and (c) electret ionization chambers, and (c) FIDLEA scintillometer. 
(a)

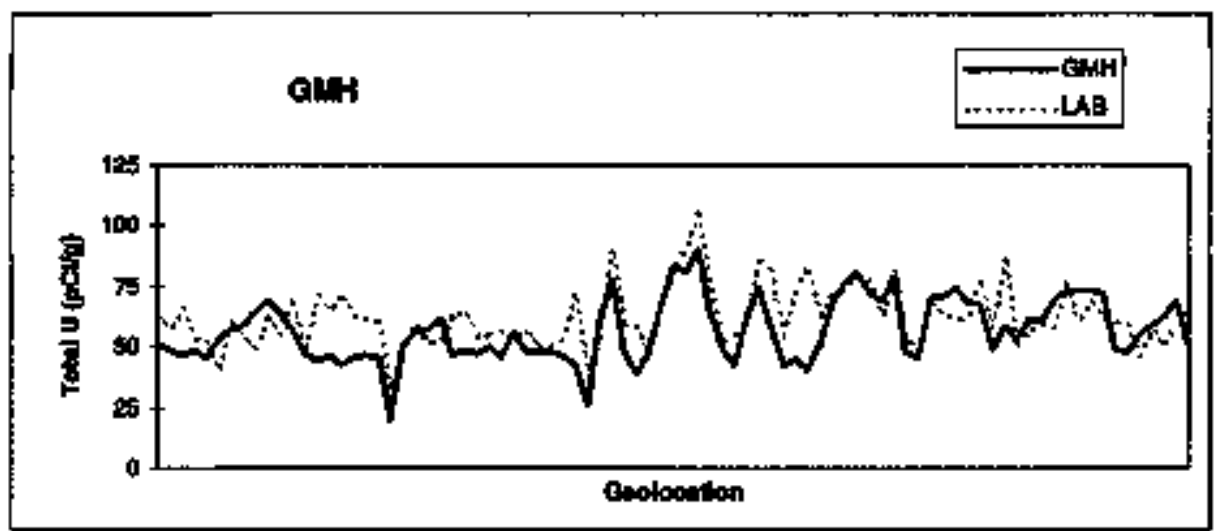

(b)

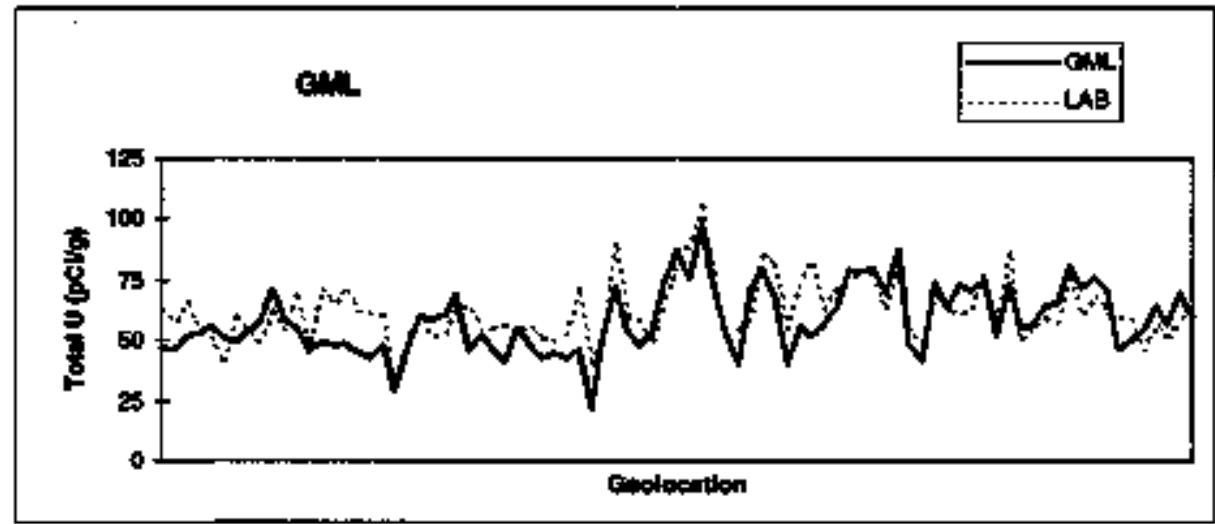

(c)

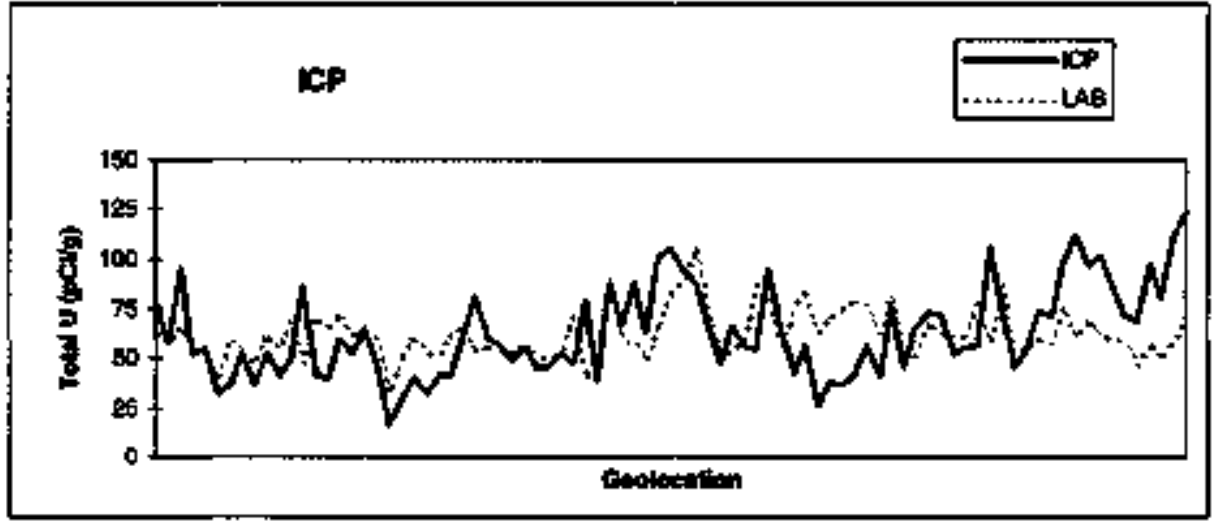

Figure 12 Field measuremenks of tolal uranium activity arranged sequentially by geotocation index code, as measured by (a) high-rnount gamme spectrometer, (b) lowmount gamma spectrometer, and (c) laser abłation-induretvely coupled plasme-atomic emission spectroscope. 
(a)

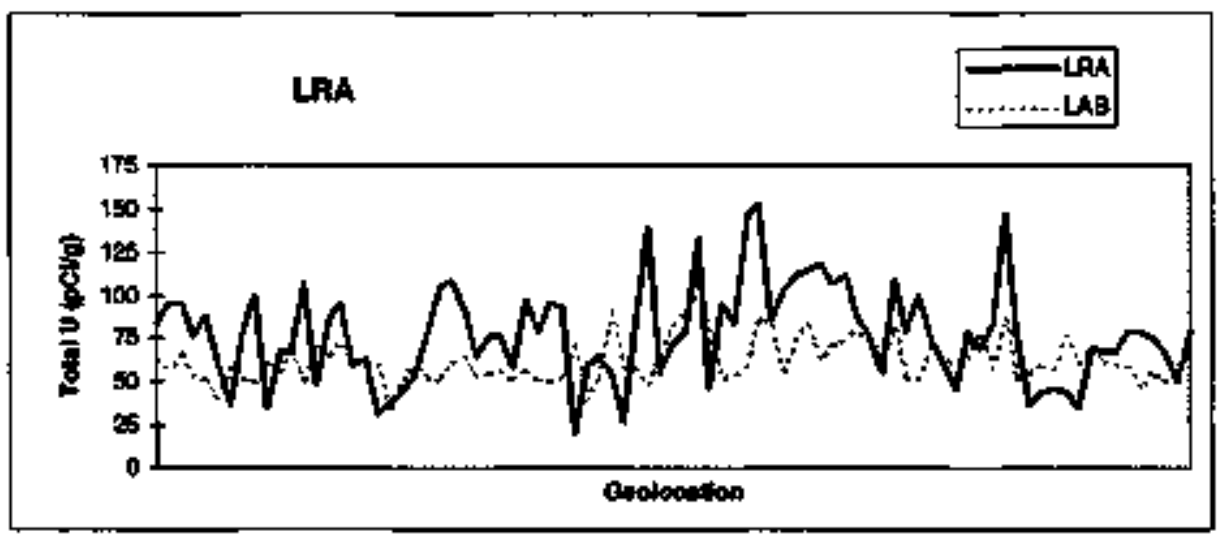

(b)

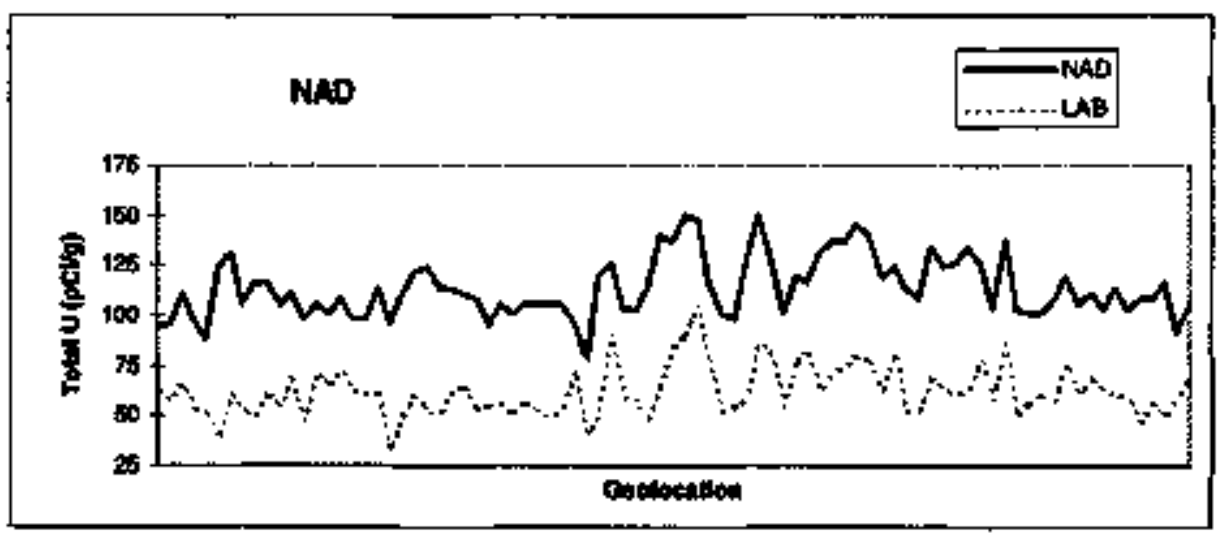

(c)

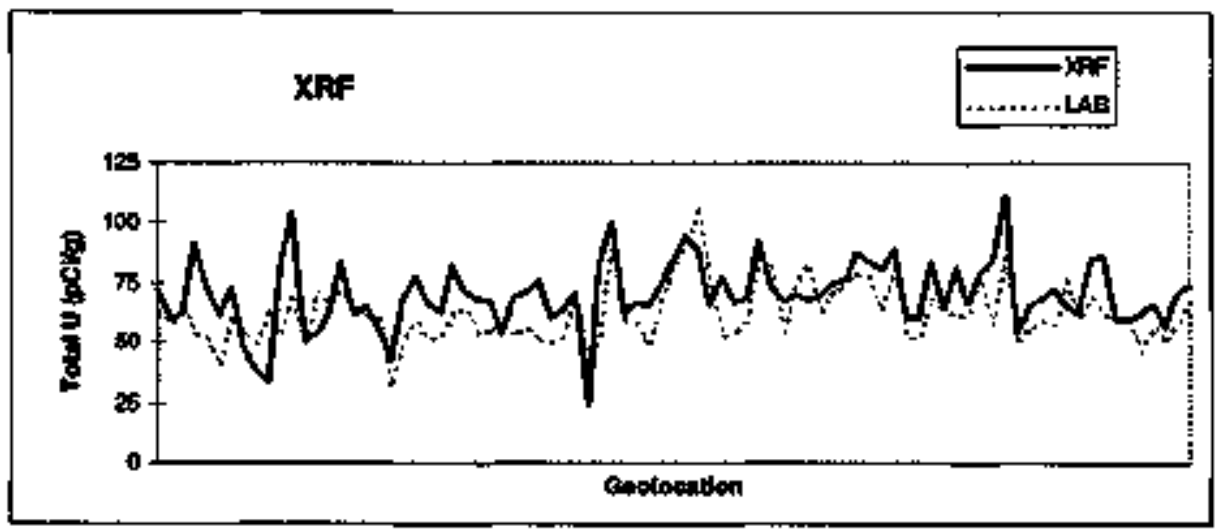

Figurs 13. Flekl measurements of total uranium activity antanged sequentially by geolocation index code, as measured by (a) long-range alpha detector, (b) sodum-toctiste scintillometer, and (c) ffeld x-ray Huorescence urit. 
(LAB) quite closely, whereas the NAD measurement curve tracks the shape of the LAB measurement curve but is vertically offset from it. In contrast, the measurement curve from the passive alpha-track detector [ATD; figure 11(a)] is both offset from the LAB measurement curve and sometimes indicates an inverse correlation with the relative high and low uranium activity peaks represented in the LAB data. Another notably different set of paired curves is represented by the electretionization chamber technology [EIC; figure 11 (c)]. Here, the alternative technology appears to be generating a uranium "signal" far out of proportion to the actual signal contained in the laboratory analyses. Similar to the passive alpha-track measurements, there is a suggestion of an inverse correlation with conventional soil sampling in figure 11(c).

The field-survey data for some technologies (ATD, EIC) exhibit a large number of negative values, despite the excellent (high- ${ }^{2}$ ) regression fits of the field calibration readings to the laboratory calibration-plot activities (table 4). For purposes of this baseline data report, negative values are interpreted as "below the detection limit" of the instrument involved. The ultimate cause of these negative total uranium activities is unclear, although the immediate cause obviously is the negative intercept ( $b_{0}$ coefficient) resulting from the least-squares regression. Forcing the regression curve to pass through the origin probably would not significantly reduce the number of negative calibrated measurements, as the difftcully does not appear to involve elevated background readings that could be subtracted from al] the field readings. Had elevated background readings been the problem, the regression-fitting procedure simply would have generated an appropriate positive intercept, and the background readings would have been incorporated into the caltbration automatically. More likely, some combination of field environmental and/or instrument conditions changed between the time the affected technologies obtained their calibration readings and the time the field survey(s) were conducted. The specific causes are uncertain; however, the overall effect is to have decreased field readings taken in a known contaminant field, relative to readings associated with the $\mathrm{Co}$ (near zero uranjum activity) calibration plot (table 2).

\section{Depth Distribution of Uranium}

Most of the uranium contamination at the incinerator area demonstration site, and at the Fernald site generally, is thought to be surficial in nature. A small number of soil-core samples were taken as part of the 1994 Fernald field characterization demonstration program to confirm this understanding for the demonstration data. A total of 15 eight-inch $(20 \mathrm{~cm})$ soil cores were collected. Five of these cores were sampled in two-inch (5-cm) increments to allow explicit evaluation of the depth distribution of uranium activity. The remaining ten cores were collected as one sample each. Core

Table 8: Uranium contarination measurements for selected depth intervals in soil cores

[Urandum measorements by ICP mass spectrometry; sample IDs tire prefixed by "LAB." Dats ane total uranium values in picocurtes per gam]

\begin{tabular}{|c|c|c|c|c|c|c|c|c|c|c|}
\hline \multirow{2}{*}{ Depth, } & \multicolumn{2}{|c|}{ AA7 } & \multicolumn{2}{|c|}{$\overline{A A 9}$} & \multicolumn{2}{|c|}{$w 7$} & \multicolumn{2}{|c|}{ W9 } & \multicolumn{2}{|c|}{$\mathrm{Yo}$} \\
\hline & $\mathbf{w}$ & Total U & 10 & Total U & 10 & Total U & 10 & Total U & 10 & Toted U \\
\hline $0-2$ & 136 & 40.94 & 140 & 50.46 & 148 & 77.09 & 152 & 46.60 & 144 & 52.26 \\
\hline $2-4$ & 137 & 16.85 & 141 & 32.60 & 149 & 22.83 & 153 & 24.76 & 145 & 30.31 \\
\hline $4-6$ & 138 & 6.27 & 142 & 16.03 & 150 & I2.08 & 154 & 11.85 & 146 & 16.99 \\
\hline $6-8$ & 139 & 6.39 & 143 & 4.88 & 151 & 13.64 & 155 & $\$ 4.46$ & 147 & 4.97 \\
\hline
\end{tabular}


Table 9: Comparison of Total Uranium Activities for a-inch

Core Samples and Standard Field Grab Samples

[Uraminn activities is picacuries per gram by ICP mass speciromery]

\begin{tabular}{|c|c|c|c|c|c|}
\hline $\begin{array}{l}\text { Locotion } \\
\text { Code }\end{array}$ & $\begin{array}{l}\text { Cons: } \\
\text { Acthily }\end{array}$ & $\begin{array}{l}\text { Fioldt } \\
\text { 8timplo } \\
\text { Acthity }\end{array}$ & $\begin{array}{l}\text { Location } \\
\text { code }\end{array}$ & $\begin{array}{l}\text { Core } \\
\text { Activity }\end{array}$ & $\begin{array}{l}\text { Field } \\
\text { Semple } \\
\text { Aottity }\end{array}$ \\
\hline AA10 & 22.25 & 53.89 & U7 & 46.26 & 89.03 \\
\hline AA6 & 21.68 & 59.80 & UB & 57.75 & 105.50 \\
\hline AA8 & 29.87 & 61.79 & U9 & 33.30 & 76.02 \\
\hline CC10 & 12.23 & 60.74 & w 10 & 3050 & 75.26 \\
\hline $\operatorname{cc} 6$ & 25.81 & 59.33 & W6 & 31.46 & 70.52 \\
\hline$C C 7$ & 25.09 & 52.48 & WB & 22.08 & 62.32 \\
\hline $\mathrm{CC8}$ & 21.35 & 51,36 & Y10 & 15.10 & 57.80 \\
\hline CC9 & 18.19 & 61.59 & Y6 & 18.46 & 55.32 \\
\hline U10 & 23.33 & 59.77 & $Y 7$ & 20.29 & 57.33 \\
\hline U6 & 45.80 & 65.60 & Y9 & 22,42 & 62.19 \\
\hline
\end{tabular}

samples were analyzed only by the standard laboratory analysis process.

The vertical distribution of uranium in two-inch (5-cm) soil-core segments taken from five separate spatial locations is given in table 8, and these data are displayed graphically in figure 14. These diagrams indicate that the majority of the uranium activity at the Fernald incinerator area is confined to the uppermost 2 inches $(5 \mathrm{~cm})$ of the soil and that the activity decreases markedly to a depth of at least 8 inches $(20 \mathrm{~cm})$ Schilk and others (1993a) have reported down-hole measurements of uranium activity, using a modification of the high-resolution gamma spectrometer technique, that are compatible with this conclusion of surficial concentration of uranium contaminants. Their measurements extended to depths of nearly 10 feet $(3 \mathrm{~m})$.

A somewhat less-definitive, but stil! instructive, evaluation of uranium activity with depth is possible by comparing composite 8-inch $(20-\mathrm{cm})$ soil-core results (COR in table G-8) with the results of standard "grab" field sampling (FLD in table G-8) that repre- sents soil from only the top inch $(2.5 \mathrm{~cm})$ or so. These data are presented in table 9 and the corresponding cross plot is illustrated in figure $\mathbf{1 5}$. Without exception, the 8-inch composite core activities are markedly lower than the corresponding field-sample activity. This relationship is compatible with the vertical activity profiles of figure 14, which suggest that high surficial activities are being mixed and diluted with lesscontaminated subsurface materials.

\section{Dupllcate Fleld Sampling and Laboratory Analyoes}

A number of replicate soil samples were collected at selected field locations for duplicate laboratory analyses. These duplicated data are identified by a sample type of "DUP" in the Appendix (table G-8), and these specific values have been extracted and reproduced ia table 10 . These paired analyses are plotted in figure 16. These replicate values fall very close to the 1:1 line that would indicate perfect reproducibility. A least-squares regression equation fitted to these data produces coefficients that are indistinguishable from a perfect $45^{\circ}$ line; the coefficient 


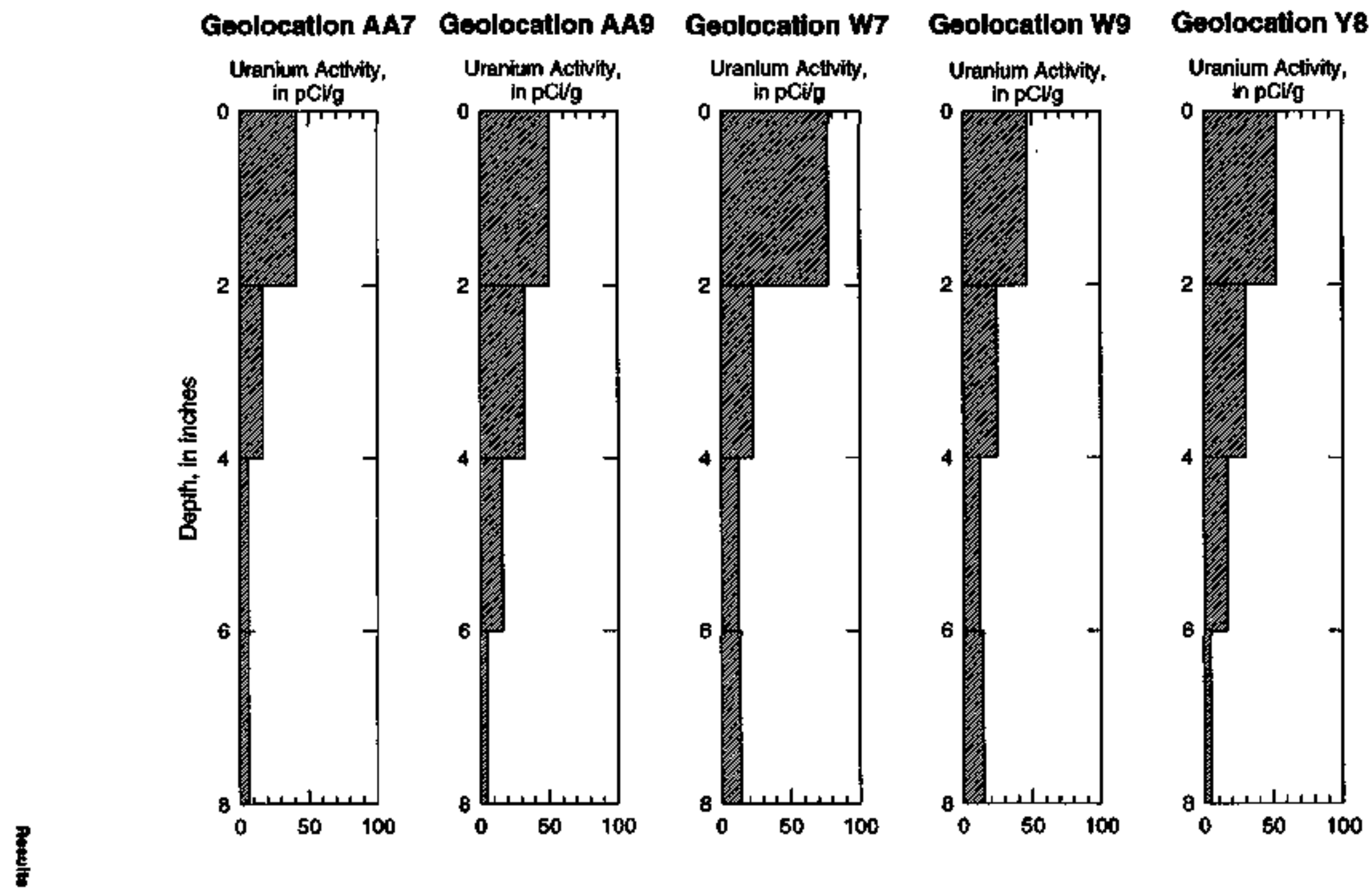

Figure 14. Depth protiles of total uranlum activity for five $\theta$-inch $(20-\mathrm{cm})$ soli cores. Analyses by KCP mass spectrometry 


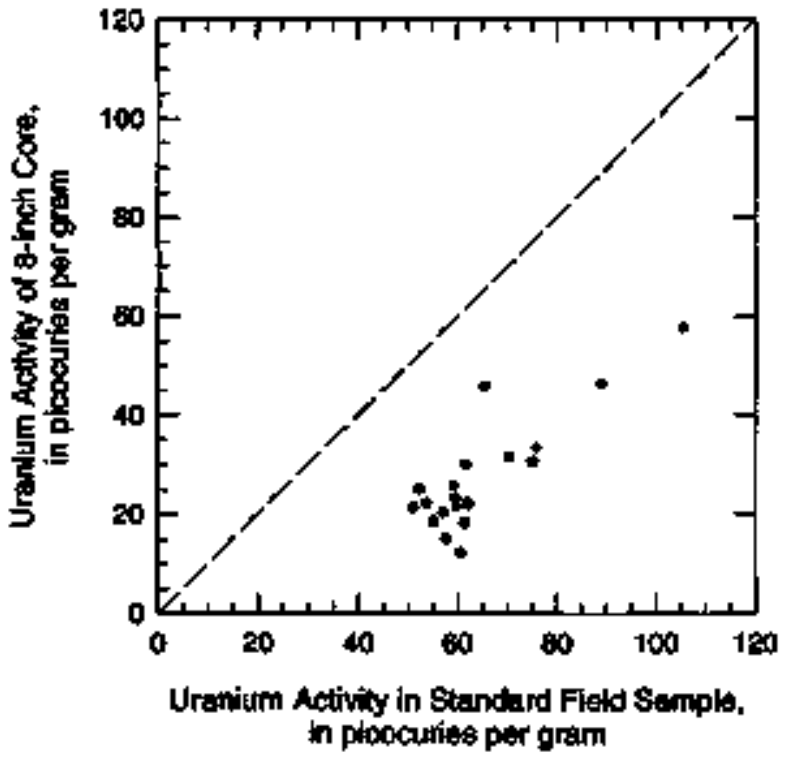

FIgre 15. Cross plot thowing total uranium activites of 8-inch compostte soil core samples compared to the activity of standard "surficiap" field (FLD) samples taken at the same spatial localion. All sample pairs plot below the indlcated 1:1 line (equal activites). Analyses by ICP mass spectrometry.

of determination for these paired samples is essentially equal to 1.0 .

Although the total suite of replicate samples is too limited for large-scale generalizations, the 17 available replicate analyses do provide some confirmation that the distribution of surficial uranium in the soil is relatively uniform over the very small-scale physical distances involved in this replicate sampling process.

\section{Further Analyses}

Analysis of the baseline Fernald fielddemonstration data, beyond presentation of simple location and value-comparison figures is beyond the scope of this data report. A future effort will evaluate the accuracy and precision of each demonstrated technology with respect to the replicate measurements of the two standard sites included as part of the demonstration. Preliminary results ${ }^{\dagger}$ suggest that some techniques are more precise than accurate, and vice-versa. Clearly, as indicated

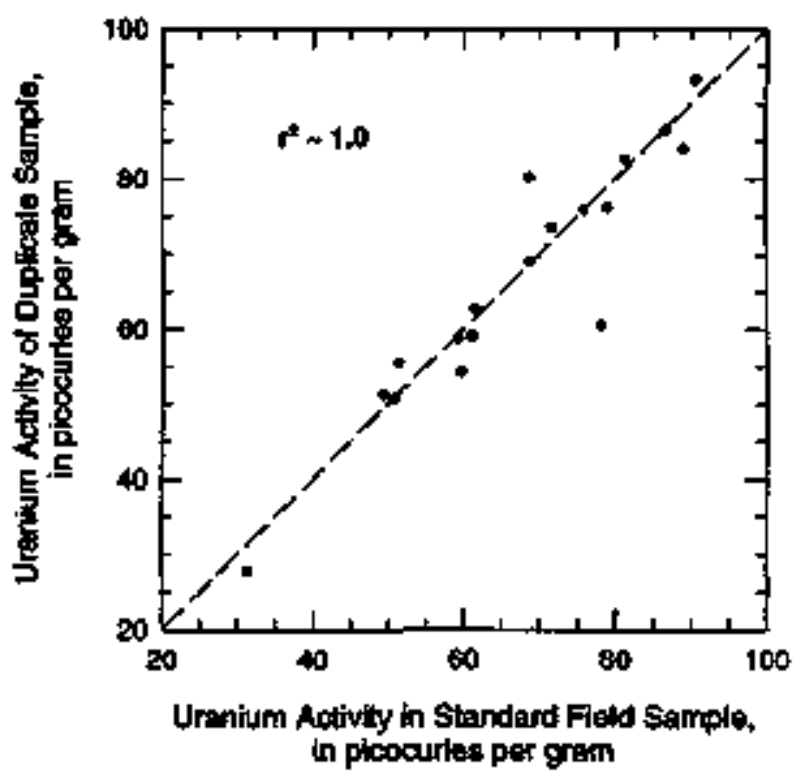

Finure 16. Closs plot comparing total uranium activities for replicate soil samples. Analyses by ICP mass spectrometry.

by the divergence between the paired curves representing the technology and laboratory geochemical uranium activities presented in figures 11 through 13, there are major questions of calibration accuracy represented by data from some of the different field methods.

The main set of field-survey data also will be evaluated separately, using statistical and geostatistical methods, such as those described by Rautman (1993) and by Rautman and others (1994). This latter evaluation will focus on the cost and risk decisions confronting a site operator: (1) What area(s) should be designated for remediation and which area(s) can be inferred to be "clean?" and (2) How should limited resources be allocated among additional characterization activities, treatment and remediation activities, and the potential costs of failure if all contaminated material is

'Rautman, C.A., in dtaft, Evaluation of standard-site measurements, 1994 Fernald field characterization desuonstration progrant being prepared as a Sandia Report, Sandia National Laboratcries, Albuquerque, N. Mex. 
Table 10: Replicate Soil Samples and Laboratory Analyses at Selected Srid Locations From Appendix Table G-8

(Measurements by ICP mass spectroscopy in pCi/g]

\begin{tabular}{|c|c|c|}
\hline $\begin{array}{l}\text { Guolocention } \\
\text { Index }\end{array}$ & FD & $\begin{array}{c}\text { DUP } \\
\text { In:urement }\end{array}$ \\
\hline$\overline{C 3}$ & 61.1 & 59.02 \\
\hline CCJ1 & 31.41 & 27.73 \\
\hline CC6 & 59.33 & 58.62 \\
\hline $\mathrm{cos}$ & 51.36 & 55.49 \\
\hline$\$ 10$ & 71.75 & 73.52 \\
\hline S5 & 50.98 & 50.58 \\
\hline U10 & $\$ 9.77$ & 54,18 \\
\hline U7 & 89.03 & 83.88 \\
\hline U9 & 76.02 & 75.82 \\
\hline w7 & 79.11 & 76.11 \\
\hline W8.5 & 81.23 & 82.55 \\
\hline$x 7$ & 68.76 & 80.17 \\
\hline X8.5 & 61.53 & 62.55 \\
\hline$\times 9$ & 60.46 & 57.80 \\
\hline Y11 & 86.77 & 86.51 \\
\hline Y8.5 & 68.69 & 68.95 \\
\hline 27 & 49.57 & 51.11 \\
\hline
\end{tabular}

not jdentified and remediated? (for example, Kaplan, 1993).

\section{Conclusions}

This data report contains the results of field demonstration of seven advanced-technology field-screening and four industry-standard methods for determining the total uranium activity of contaminated soils. The eleven individual data sets consist of raw field measurements at a number of manufactured calibration beds, two standard sites, and $\mathbf{8 5}$ field sample locations on a sequence of nested regular grids. The raw field measurements have been calibrated to laboratory measurements of total uranium activity obtained from a maximum of five calibration beds. A variety of meteorologic observations obtained episodically during the course of the field demonstration program are also included.

The data contained in this report will serve as the basis for future cost and perfor- mance evaluation of the eleven alternative characterization technologies demonstrated at the Fernald site. Preliminary comparison of simple graphical plots of results from the proposed alternatives to conventional soil sampling and laboratory measurement of uranium activity indicate that the beta scintillometer, the two mounting positions of gamma spectrometer, the laser ablation-inductively coupled plasma-atomic emission spectroscopy tool, and the field $x$-ray fluorescence technology performed best in terms of reproducing the laboratory data. The industry-standard FDLER and sodium-iodide detectors plus the innovative long-range alpha detector appear to reproduce the spatial variability of the laboratory data, but exhibit varying degrees of difference in the actual magnitude of the laboratory uranium activities. In general, all three of these technologies were conservative, reporting higher field uranium activities than those resulting from laboratory measurement. The passive alpha techniques, alpha-track detectors and electret-ionization chambers, appear to have performed worst in terms of both failing to reproduce the spatial variability of the laboratory measurements and underestimating those uranium activities. This underestimation could result in leaving contaminated soil in place without remediation. These data are also available for additional study of issues related to: (1) calibration of the technologies as potential functions of changing environmental conditions, (2) the overall accuracy and precision of the various technologies as captured by replicate measurements taken at the two standard sites, and (3) evaluation of the uranium contamination for a portion of the Fernald site.

\section{References}

Alter, H.W. and Fleisher, R.L., 1981, Passive integrating radon monitor for environmental monitoring; Healsh Physics, v. 40, p. 693-702.

Baldwin, D. Zamzow, D., Bajic, S.J., Weeks, S., D'Silva, A.P. Anderson, M.S., McIntosh, R., 
Pfeifle, J., Braymen, S., and Anderson, M.A. 1993. Report of Uraniwn Concentrations in Soil Deternitred by in-situ LA-ICP-AES, Report IS-5099, Ames Laboratory, Ames Iowa.

Caress, R.W., Allander, K.A., Bounds, J.A., MacArthur, D.W., Catlett, M.M., and Rutherford, D.A., 1993, Long-range alpha detection applied to soil surface monitoring, in Conference Record of the $26 \mathrm{th}$ Annual Topical Meeting of the Health Physics Soctety, Lake Coeur d'Alene, Jdatio, Jatuary 24-28, 1993.

Cunnane, J.C., Lee, S.Y., Perry, D.L., Tidwell, V.C., Schwing. J., Nuhfer. K.R., and Weigand, G. 1993. Field demonstration of technologies for characterization of uranium contamination in surface soils, in Proceedings of Waste Management 93, held in Tucson, Arizona, Fobruary 28-March 4, 1993, p. 803-809.

D'Silva, A.P., Zamzow, D., Jaselskis, E., and Weeks, S., 1992, Remote, teal-time analysis of hazardous wastes through laser ablation-inductively coupled plasma atomic emission spectrometry. in Praceedings of the International Topical Meeting on Nuclear and Hazardous Waste Management Spectrun 92, Boise, Idaho, Autgust 23 - 27, p. 409-413.

Kaplan, PG., 1993, Evaluation of soi] characterization technologies using a stochastic value of information approach, in Meeting the Chalknge, Praceedings of ER93 Environmental Remediation Conference, Augusta, Georgia, October 24-28, 1993, p. 129-132.

Kotrappa, P., Dua. S.K., Gupta, P.C., and Mayya, Y.S., 1981, Electret-A new tool for measuring concentrations of radon and thoron in air: Health Physics, v. 41, p. 35-46.

Kotrappa, P., Dempsey, J.C., Hickey, J.R., and Steiff, L.R. 1988, An electret passive environmental ${ }^{222} \mathrm{Rn}$ monitor based on ionization measurement: Health Physics, v. 54, p. 47-56.

MacArthur, D.W, Allander, KS., Bounds, J.A., Catlett, M.M., Caress, R.W., and Rutherford, D.A., 1992, Alpha contamination monitoring of surfaces, objects, and exclosed areas, in
IEEE Transactions on Nuclear Sctence, $v_{+} 40$, no. 4 , p. $840-845$.

Rantman, C.A., 1993, Direct Probability Mapping of Contaminants, in Meeting the Challenge. Proceedings of ER'93 Environnental Remediation Conference, Augusta, Georgia, October $24-28,1993$, p. 123-128.

Rautman, C.A., McGraw, M.A., Istok, J.D., Sigda, J.M., and Kaplan, P.G., 1994, Probabilistic comparison of altemative characterization technologies at the Femald urantum-in-soils integrated demtonstration project, in Proceed. ings of Waste Management-94, Febnuary 27. March 3, 1994, Tueson, Arizona, p. 21172124.

Schilk, A.J., Perkins, R W, AbeI, K.H., and Brodzinski, R.L., 1993a, Surface and subsurface characterization of uranium contamination at the Fermald Environmental Management Site, Report PNL-86I7. Pacific Northwest Laboratory, Richland, Wash., 43 p.

Schilk, A.J., Perkins, R.W., Abel, K.H., Brodzinski, R.L., Brown, D.P., Thompson, R.C., and Knopf, M.A., 1993b, Quantitative in-situ uranium contaminant mapping using high-resoluion gamma-ray spectrometry and beta scintillation counting, in Meeting the Chol. lenge, Praceedings of ER93 Environmental Remediation Conference, Augusta, Georgia, October 24-28, 1993, p. 155-158.

Tidwell, VC., Cunnane, J.C., Schwing, J, Lee, S.Y., Perry, D.L., and Morris, D.E., 1993, Field demonstration of technologies for delineating uranium contaminated soils, in Meeting the Challenge, Proceedings of ER93 Environmental Remediation Conference. Augusta, Geơgita, October 24-28, 1993, p. 147-154.

US EPA (U.S. Environmental Protection Agency), 1992, Characterization protocol for radioactive contaminated soils. Publication 9380.1-10FS, US EPA Office of Solid Waste and Emengency Response, Washington DC. 
Appendix A: Field Demonstration Project Plan 


\section{Projoct Plan}

The "Field Demonstration Project Plan-Uranium in Soils Integrated

Demonstration Program" dated May 1994 that follows was developed originally to document the various characterization technologies to be demonstrated during the 1994 Fernald Field Characterization Demonstration Program and to specify conduct of the actual field surveys. The plan is reproduced as it appeared at the beginning of field activities, with only those changes necessary to incorporate the plan into the overall report format. No editing or revisions has been done to modify this planning document to reflect in-field changes or grammatical errors.

Note that "Appendix F" of the project plan is duplicated by the Data Management Plan contained in Appendix B of this data report. The data management plan portion of the project plan has been omitted from this Appendix A to conserve space. The project plan continues with "Appendix $G$ " of the original document. The original table of contents has also been omitted because those page numbers are no longer relevant. 


\title{
FIELD DEMONSTRATION PROJECT PLAN URANIUM IN SOILS INTEGRATED DEMONSTRA- TION PROGRAM
}

\author{
MAY 1994
}

Host Site:

Fernald Environmental Restoration Management Corporation Fernald, Ohio 


\begin{abstract}
An Integrated Demonstration Program, hosted by the Fenald Envinonmental Restoration Management Corporation (FERMCO), has been established for investigating technologies applicable to the charactenzation and remediation of soils contarninated with uranium. An important part of this effort is the evaluation of field screening tools capable of acguiring high resolution information on the distribution of uranium contamination is surface soils in a cost-and-time efficient manner. Consistent with this need, five field sereening technologies will be demonstrated at a uranium contam. inated site at the FERMCO. The five technologies to be tested are gamma-ray spectrometry, beta scintillation counting. laser ablation-inductively coupled plasma-atomic emission spectroscopy (LA-ICP-AES), long-range alpha detection (LRAD), and passive radon monitoring. The goals of this field demonstration are to evaluate the capabilities of the five detectors and to demonstrate their utility within the Department of Energy's Environmental Restoration Program. To aid in the evaluation of detector performance similar field studies will be conducted using a sodium-iodide fetector (NaI), a low-energy scintillation detector (FIDLER), an X-ray fluorescence detector, and soil sampling/laboratory analysis. This second suite of tools represent the industrial standards for characterizing soils contaminated with uranium and other rudionuclides. Another important aspect of this program is the application of a cost/risk decision model to guide characterization of the site in real-time.
\end{abstract}




\section{INTRODUCTION}

One of the major problems facing the U.S. Department of Energy's (DOE) Environmental Restoration Program is the remediation of uranium-contaminated soils. In response to this problem the Office of Technology Development has initiated an Integrated Demonstration (ID) program to evaluate and compare the versatility, eftriciency, end economics of various technologies that may be combined into systems for the characterization and remediation of uranium contaminated soils. The Fernald Environmental Restoration Management Corporation (FERMCO), located 29 kilometers northwest of Cincinnati, Ohio, has been selected as the host site for this ID program (DOE, 1991) based on known envirommental problems stemming from past production of uranium metal for defense related applications. In support of the ID, a task group has been appointed to design and administer a program to address site characterization issues relative to uranium-contaminated soilk.

Costs and schedules associated with the characterization of soils bearing radionuclide contamination represent a significant obstacke in the remediation of such sites. Difficulties arise because current field detectors (i.e., scintillation detectors, Geiger counters, alpha detectors) do not offer the necessary sensitivity, hence site characterization prograns must rely heavily on soil sampling and laboratory analysis. However, a number of alternative technologies have recently been developed which appear to offer much better detection sensitivity (i,e., able to resolve contamination to a much lower concentration). These field screening technologies are garnma-ray spectronetry, beta scintillation counting, laser ablation-inductively coupled plasma-atomic emission spectroscopy (LA-ICP-AES), long-rang alpha detection (LRAD), and passive radon monitoring.

It is the interest of the ID program to evaluate the capabilities of each of these technologies and to demonstrate how these texhnologies might be integrated into the DOE's Environmental Restoration program. To meet these objectives a field demonstration program is scheduled for the spring of 1994. At this time each of these five technologies will be demonstrated at a uranium contaminated site at the FERMCO along with the current industrial standards (sodium-iodide detector [NaI], low-energy scintillation detector [FIDLER], $x$-ray fluorescence detector [XRF], and soil sampling). Reai-time analysis employing a cost/risk decision mode] will also be demonstrated and the merits of such an approach evaluated.

In this fiek demonstration project plan we cutline a program aimed at evaluating the capabilities of a saite of real-time radiation detectors and a costrisk decision model. We begin with a brief overview of each of the technologies to be dernonstrated. This is followed by a description of the field site and project schedule. Also included, is a description of the sampling strategy to be employed, details of how detector calibration will be conducted, and how the collected data will be analyzed and used in real-time to guide field demonstration activities. A Health and Safety Plan, Quality Assurance Plan, and Data Management Plan for the Field Demonstration are included as appendices to this document. Detailed descriptions of each of the technologies demonstrated as well as detailed operating procechunes are also provided in the appendices.

\section{MEASUREMENT AND ANALYSIS TECHNOLOGIES}

Five real-time field screening technologies for delineating uranjum contamination in surface and shallow sub-surface soils will be demonstrated along with the current industrial standards for soils characterization. It is important to note that each of these techniques measure uranium concentration in a different manner and each technique has a different window of observation, in an areal sense as well as in the effective depth to which the instrument is sensitive. In this section a brief description of each of the soil characterization technologies is given, along with a description of the cost/risk decision model used in the real-time analysis of the generated site characterization data.

Field demonstration of the gamma-ray spectrometry systern will be conducted by personnel 
from the Pacific Northwest Laboratories (PNL) (Schilk et al., 1993). The system is based on the use of a germanium detector that may be collimated by specialty shaped heavy metal shields. In the surface monitoring mode, an uncollimated detector is suspended one meter above the ground by a tripod. This crientation theoretically allows the detector to observe full $21 / 4 \mathrm{space}$. In this configuration, the spectrometer detects uranium in the exposed surface and subsurface soils to a maximum depth of approximately $15-20 \mathrm{~cm}$ to distances exceeding $10 \mathrm{~m}$, but the sensitivity decreases with odditional depth and radial distance due to gamma-ray attenuation. Other detector configurations will be investigated which yield data at a firer areal nesolution. Although the full gamma spectrum is measured the $1.0 \mathrm{MeV}$ gammm particles from protactinium- $234 \mathrm{~m}$, a daughter product of uranium238 decay, is used as the primary indicator of uranium concentration.

The beta scintillation counter was developed at PNL to measure uranium concentrations in surface soils on a real-time basis (Schilk et al., 1993). The system consists of multiple tayers of plastic scintillating material for the messurement of beta particles from surficial soils ( $\sim$ the top 1 $\mathrm{cm}$ ). The plastic scintillating layers are designed to measure uranium-238 surface concentration by detecting the $2.29 \mathrm{MeV}$ (maximum energy) beta particles from protactinium- $234 \mathrm{~m}$. The system is designed to discriminate between high-energy beta particles and other interfering backgronnd radiation by using coincidence counting techniques, which identify high-energy beta particles by the depth to which they penetrate into the fluor layer stack. The device used in the field tests is designed to monitor a surface area of approximately $0.2 \mathrm{mi}^{2}$.

The LA-ICP-AES technique is a proven Laboratory analytical method that has been adapted by Ames Laboratory for jeld applications (Baldwin et al., 1993: D'Silva et al., 1992). A neodymi. um YAG laser is focused directly on the soil surface to ablate in-situ a small sample $\left(-10^{+} \mathrm{s}\right.$ of $\mathrm{g}$ of soil), while an argon gas stream entrains the ablated sample particles and transports thenn directly into the ICP. The atomic emission from the ICP is transferred by fiber optics to a spectrometer for quantitative analysis of total elemental uranium. During the course of an infividual measurement, the ablating laser bear is rastered over a sampling area of about $6.5 \mathrm{~cm}^{2}$ affecting only the surficial layer of the soil $(\sim 100 \mu \mathrm{m})$.

LRAD system, which was developed at Los Alamos National Laboratory (LANL), detexts alpha particles (and other ionizing radiation) by collecting and measuring the ions that are produced when alphs particles are stopped in air (Caress et al., 1993; McArthur et al, 1992). Because the ambient air is the "detector gas," the field LRAD system was configured to be placed directly an the ground. In this configuration, it detects the uranium in the surface soil by monitoring the air ionization near the soil surface $(-10-20 \mathrm{jm})$. The LRAD system to be tested at FERMCO was designed to monitor contamination present on an $\sim 1 \mathrm{~m}^{2}$ surface.

Techniques currently available for the measurement of alpha activity in indoor air are being adapted for the task of screening soils contaminated with uranium. A group from Oak Ridge National Laboratory (ORNL) are evaluating commercially available passive radon monitors. Three types are being considered, efectret ionization chambers, alpha track detectors, and thin-layer thermoluminescence detector arrays. The detectors, measuring a few square centinieters in size, are sensitive to tokal alpha radiation emitted from near the soil surface $(\sim 10-20 \mu \mathrm{m})$.

To provide a means of comparison, soil samples will be collected and submitted for laboratory analysis. The collected samples will be submitted to an independent laboratory for analysis. The method of anslysis will be neutron activation.

The five field screening technologies under investigation will also be compared with those methods commonly employed in the field detection of radionuclide contaminated soils. Hand-held NaI, FIDLER, and XRF debtors will be employed as part of the tield demonstration program. The NaI, and FIDLER detectors are scintillation counters. The detectors count the total $x$ - and gammaradiation emitted from the soil. The active detection window measures 10 's of square centimeters 
in size and is sensitive to contamination in the upper few centimeters of the soil. The XRF is an active naclear tecinnigue in which a radioactive source is used to excite the target element. A simple spectrometer is then tised to detect and quantify the $x$-ray photons emitted by the excited atom. As such, the XRF is a point measurement technique sensitive to the tocal uranium concentration in the soil.

Also to be exploted is how the real-time analysis of field data might be used to improve the site characterization process. As data is gathered by a field technique it will be analyzed and a cost' risk decision model (Kaplan, 1992) will be used to help answer such questions as; where should the next measurement be made, is the information worth of the next sample greater than its cost to be collected, how uncertain are the predictions of contaminant concentrations at unsampled locations. A framework of geological decision analysis hes been adopted that quantifies the uncertainties inherent with samping natural materials and propagates those uncertainties through a decision model (Rautman, 1993). In this model, geologic uncertainty is described using standard geostatistical techiniques while decision analysis is approached through the optimization of a cost-risk-benefit objective function.

\section{FIELD DEMONSTRATION STTE DESCRIPTION}

A site with uranium contaminated soil located at the FERMCO has been selected for dernonstration of the tield screening technologies. The seketed site is known as the incinerator area, which is located just to the east of the production area. The field demonstration will be performed on a subsection of the site measuring approximately $10,000 \mathrm{~m}^{2}$. Uranivm contamination levels are believed to range from background to approximately $80 \mathrm{pCV} / \mathrm{g}$. Contarination at this site is primarily the result of emissions from the incineration of uranium-contaminated combustibles.

\section{FIELD DEMONSTRATION SCHEDULE}

The schedule for the field demonstration is contained in Table 1. The actual field demonstration is planned for May, Jure, and July 1994. It is expected that each detector technology will need to spend approximately three weeks at the FERMCO (about one whek for traiming and mobilizztion/demobilization, and two weeks to make field measurements). Multiple techmologies will be fielded at the same time in efforts to minimize the duration of the feeld demonstration. Some flexibility has been factored into this schedule; however, frolonged bad weather may cause the schedule to slide. As such the dates given here should only be viewed as approximate.

\section{SITE INVESTIGATION PLAN}

As previously noted the costs and schednles associated with the characterization of tranium contaminated soil present a significant problem to the DOE's Environtnental Restoration program. Five field screening technologies, each of which are currently at various stages of development. have been identified that may help address this problem. Each of these technologies are of interest because of their potential to detect radionuclide concentration at kevels lower than currently achievable with standard field detector methodologies. These detectors offer a number of advantages over the industrial standard for soils characterization; sampling and laboratory analysis. Probably the two most important are, 1) field detectors yield data in real-time as opposed to labofatory analysis which may take months to accomplish, and 2) fjekd measurements can be made at very high spatial resolution (i.e., many more field measurements can be made than can feasibly be sampled). With the development of sensitive field detectors, soil sampling will no long have to be relied upon for site characierization but simply be used as a means of verifying the results of the detector surveys.

In the summer of 1992, each of the new field screening technologies were demonstrated at the FERMCO (Cunnane, 1993; Tidwell, 1993). Except for the gamma-ray spectrometry system. this was the first time that the field detectors had been tested under actual field conditions. Several 
Table 1. Field Demonstration Schedule

\begin{tabular}{|ll|}
\hline Date & \multicolumn{1}{|c|}{ Activity } \\
\hline TBD & Meet with Regulators \\
\hline January 28 & Finglize Field Demonstration Site Selection \\
\hline March 27 & Finalize Field Demonstration Plan \\
\hline March 22-23 & $\begin{array}{l}\text { Perform initial site walkrover survey using NaI detector and per- } \\
\text { form dry-run test of real-time decision modeling }\end{array}$ \\
\hline April 18-May 6 & $\begin{array}{l}\text { Site preparation: survey initial grid, prepare callibration soills, 10- } \\
\text { cate on-site office space, till grass, etc. }\end{array}$ \\
\hline May 17-20 & Perform passive radon monitor survey \\
\hline May 23-June 3 & Perform NaI detector survey \\
\hline May 30-June 10 & Perform FIDDLER survey \\
\hline June 6-24 & Perform LRAD survey \\
\hline June 13-24 & Perform ICP-AES survey \\
\hline June 20-July 8 & Perforn garmma-ray spectrometryfbeta detector survey, EG\&G \\
\hline Suly 5-15 & Perform XRF survey, Perform passive radon motritor survey \\
\hline July 11-22 & Collect soil samples, Other \\
\hline September 2 & Cornplete soils anatyses \\
\hline September 20-22 & Hold Field Demonstration Open-House \\
\hline
\end{tabular}

important findings resulted from the field investigation. The most important finding was that each of the detectors showed promise for soils characterization applications; however, the need to improve detector sensitivity was identified (achievable simply through refinement of the prototype detectors). Difficulties were also experienced in comparing data collected by the tifferent measurement techniques. One reason is the vast difference in the scales of measurement. Each detector has a different window of observation in both an aneal sense as well as depth of penetration. Also, each technique relies on different physical laws for measuring uranium concentrations in the soil. To account for these differences, particular care must be given to the methodology governing the application of the field detector to a particular site characterization probiem. We also found that the site characterization process could be improved by developing the capability to perform realtime analysis of field data as wel] as involving regulators in the formulation of sitz characterization strategies.

A second field demonstration is scheduled for May, June, and July of 1994. The primary purpose of the study is to evaluate the capabilities of the refined field screening technologies and directly compare their performance with that of detectors currently used by the environimental industry (NaI, FIDLER, and XRF detectors). Also to be evaluated is the methodology governing the application of these techrologies to the characterization of radionuclide contaminated soils. In particular, care will be given to the manner in which detectors ane calibrated, data reduction is per- 
formed, and how the data are apalyzed. These precautions are necessary to facilitate interpretation of data generated by means of multiple measurement techmiques, ticluding soil sampting. Another important aspect of this fieid demonstration will be the use of real tirne analysis coupled with a cost risk decision modeling to guide the site characterization process. Efforts are also curently being made to involve state and federal regnlators in designing the field characterization strategies. In the following section, details conceming the fiedd demonstration program are given.

\section{Interview State and Local Repalators:}

Efforts will be made by the ID characterization task group and performance assessment task group to meet with state and federal EPA representatives. The purpose of the meeting will be to gain an understanding of how compliance measures are coutinely established for sites bearing soils contaminated with radionuclides. Regulatory decisions impacting the site characterization process include adoption of action levels, definition of the selective remediation unit (i.e., volume of soi] associated with the action level), treatment of "bot-spots", averaging or compositing practices, and how verification measures are enforced.

\section{Site Preparation:}

Site preparation is the responsibility of FERMCO persounel. Site preparation will include marking the site and restricting access to the site once the field demonstration begins. Prior to the initiation of the field program a base grid is to be marked and surveyed (consisting of approximately S0-75 locations). "Standards" plots (to be explained later) are also to be marked and access restricted. Three standards plots are needed, each measuring approximately 1.0 by 1.0 meter in size. Average uranium concentration in each plot should be background, $35 \mathrm{pCi} / \mathrm{g}$, and $100 \mathrm{pCi} / \mathrm{g}$, respectively. Grass on approximately $80 \%$ of the site is to be nemoved, either by mowing (i.e, crop grass off close to the ground) or killed, using an EPA approved defoliant. As such, this will allow assessment of the effect of grass on detector response. Subsequent growth of grass should be prevented for the duration of the fieid demonstration.

\section{Preparation of Calibration Soils:}

In efforts to normalize detector response a suite of spiked soils will be made and used to calibrate each of the field detectors. Preparation of the spiked soils will be the responsibility of FERMCO personnel. Four calibration soils, using soil of similar characteristics that found at the field demonstration site, will be prepared. Soils are to be homogenized and spiked (with uranium contaminated soil from the Fernald site) to yield concentrations of near background, 35, 100, and $200 \mathrm{pCV}$ g. Soils will then be dried and stored in sealed, marked dnums. Pans measuring $1.6 \mathrm{~m}$ on a side and $22.5 \mathrm{~cm}$ deep will be used to calibrate the detectors. To verify the soils, five sampies will be collected from each soil and analyzed.

\section{Site Investigation:}

Site surveys will be conducted using a wide suite of detectors. These technologies and the party responsible for their demonstration include:

- gamma spectrometry, PNL

- beta detector, PNL

- long range alpha detector, LANL

- LA-ICP-AES, AMES

- passive radon monitors, ORNL

- NaI detector, FERMCO

- FIDLER detector, FERMCO

- XRF detector, FERMCO 
- total station, FERMCO (for snrveying, in real-time, measnred locations)

To facilitale comparison among the different detector technologies, each detector strvey is to be perfonmed in exactly the same manner. Site surveys are to be performed according to the practices prescribed below. Any deviations to this program must first be approved by the ID characterization task group.

\section{Detector calibration:}

To improve comparability of the data derived by different measurement techniques, efforts are being made to assure consistency in the calibration of each detector. Consistency is achieved by calibrating each technique with the same soils, and by assuring that a consistent set of assumptions, coefficients, and parameters are osed in reducing measurement counts to a consistent unit (for this study pCi/g of total $\mathrm{U}$ ). As such, each detector will survey the calibration soik at least three times. These surveys will be conducted prior to the field demonstration, after completing the baseline survey, and following completion of the project. Prior to the fiekl demonstration, PT's representing each of the detector technologies will be responsible for providing the ID characterization task group with a detailed description of how raw detector data is converted to $\mathrm{pCi} / \mathrm{g}$ of total $\mathrm{U}$. The characterization task group will then decide upon a consistert set of assumptions, etc. to be used in detector date reduction.

\section{Quantification of Detector Precirion:}

To facilitate evaluation of the detectors, we also wish to standardize the way detector precision is quantified. This is accomplisted by identifying plots of undisturbed soil, called standards plots, at the test site. These standards plots will be used for making repeated detector measurements. Twice each day the standards plots ane to be surveyed by each detector being demonstrated. Environmental conditions at the time of the survey are also to be recorded. Hence, in addition to evaluating instrument precision, this data will also provide insight into the effects of the environment (i.e., hustidjty, rainfall, ambient temperature fluctuation) on detector performance.

\section{Field Sirveys:}

Surveys of the field demonstration site will be accomplished using eight independent detector technologies. Each survey witi begin by making measarements on a baseline grid marked prior to the field domonstration. Using this data and the cost/risk decision model additional measurement locations will be identified. Data will continue to be collected and anglyzed ontil the information worth of additional samples is less than the cost to collect them.

\section{Soil Sampling:}

Soil samples will be collected for comparison with each of the detector technologies. Both soi] cores, for comparison with the gamma-ray spectrometry system, and surface samples, for comparison with the other stricty surface sensitive techniques, will be collected. Soil cores will be colkected with a hand anger, driven to a depth of $20 \mathrm{~cm}$. A subset of these cores will be separated into $5 \mathrm{~cm}$ sections to provide insight into the distribution of uranjum with depth. Surface samples will be collected with a hand spade to depths not exceeding one centimeter. The collected samples will be homogenized and a $500 \mathrm{~g}$ sample extracted for analysis. Rocks, orgaric material, etc. is not to be removed from the samples.

Samples will be collected on the same baseline grid used for the detector surveys (approximately 50-75 surface samples and 25 core samples). An additional 10 samples will be collected 
from each of the standands plots (5 surface samples and 5 core samples). Spiked samples, teplicates, and blank samples are also to be analyzed. Foar sets of blanks and spiked samples $(35,100$ and $200 \mathrm{pCi} / \mathrm{g}$ ) are to be analyzed and $10 \%$ of the samples collected will be split for duplicate analysis.

Also of interest is how few soil samples would be necessary to verify the results of the field detector surveys. To address this question, data collected by the various detector technologies will be used with the cost/risk decision model to locate verification soil sampling sites. Sampling will be perfonmed and results compared to the baseline grid sampling as well as the detector survey data.

\section{Measurement Support Effects:}

One of the factors impacting the comparability of collected detector data is the vast difference in size of the soil surface area measured by each of the detector technologies. A number of methodologies have been developed in the mining industry to account for differences in the support size between core samples analyzed to determine ore grade and the support size of the selective mining unit. Similar methodologies will be applied here to determine whether such an approsch will help explain differences in the collected detector data. In order to make the necessary calcutations a timited number of samples need to be made on a very finely spaced grid. This will involve collecting nine closely spaced samples within a $3.3 \mathrm{~m}$ by $3.3 \mathrm{~m}$ area. Two sets of such data are to be collected. These fine scak grids will be incorporated into the larger baseline grid.

\section{Gamma-ray Spectrometry Surveys:}

Field surveys utilizing the gamma-ray spectrometry system will be performed in both a col. limated and uncollimated mode. In the uncollimated mode the gamma-ray spectroneter functions as a large area detector (sampling $>300$ square meters in a single measurement), which is valuable for initial site surveys. However, more detailed site surveys can be performed with the same instrument by simply collimating the detector (i,e, narrowing the field of view of the detector). The desined size of the detection anea, when operating in the collimated detector mode, will be $10 \mathrm{~m}^{2}$ (the detection area is set equal to the size of the selective remediation unit).

The gamma-ray spectrometer will also be used to infer the depth distribution of aranium contamination at the site. The depth distribution can be determined directly by analyzing different evergy photons and accounting for their differential absorption. The depti distribution can also be inferned through comparison of gamma-ray spectrometer data with data collected by detectors sensitive only to surface contamination.

\section{DataAnalysis:}

Analysis of the field demonstration data will be the responsibility of the ID characterization and performance assessment task groups. Detector performance will be judged in part on the re. peated data collected from the field standards pIots as weIl as the repeatability of meastrements made on the calibration soils. Data from the baseline grid, as collected by each of the measurement technologies, will be directly compared. Also to be compared are the final nraniurn isopleth maps generated by each of the measurement techniques. Where significant differences exist eftions will be made to identify physical reasons for the discrepancies. The product of the analysis will be a report docnmenting the findings of the field demonstration. In this report we will make recommendations concerning the use of these technologies in characterization programs as well as note the strengths and weaknesses of the different detector technologies. Evaluation of the cost benefits of the various detector technologies will be performed by the ID perfornatace assessment task group. 
Intersated Demonstration Open House:

As information and technology transfer are important aspects of this program, an oper house will be hosted by the ID characterization task group to publicize the results of the field demonstration. The basic format for the open house will include time for presentations, question-andanswer secessions, and technology demonstrations. Those invited to attend will include DOE officials, representatives of Environmental Restoration programs from various national labs, EPA representatives, representatives of private consulting firms, techmology vendors, and the local public. The open house is scheduled for late summer once the analysis of the field demonstration data is complete.

\section{REFERENCES}

D. BALDWIN, D.ZAMZOW, SJ.BAJC, S. WEEKS, A.P. DSLLVA, M.S. ANDERSON, R. MC INTOSH, J. PFEIFLE, S. BRAYMEN, and M.A. ANDERSON, "Report of Uraniam Cotcentrations in Soil Determined by In Situ LA-ICP-AES, "Ames Laboratory, IS-5099.UC-900 (1993).

R.W.CARESS, K.A. ALLANDER, J.A. BOUNDS, D.W.MAC ARTHUR, M. M. CATLETT, and D.A. RUTFERFORD, "Long-Range Alpha Detection Applied to Soil Surface Monitoring," Cont ference Record of the 26th Annual Topical Meating of the Heglth Physics Society Lake Coeur d'Alene, ID, January 24-28 (1993).

J.C. CUNNANE, S.Y. LEE, D.L. PERRY, V.C. THDWELL, J. SCHWING, K.R. NUHFER, and G. WEIGAND, "Field Demonstration of Technologies for Characterization of Uranium Contamination in Surface Soils," in Proceedings of Waste Management 93. Tucson, AZ, February 28-March 4 (1993).

U.S. DOE, "Integrated Technology Demonstration; Removal of Uranium Substances from Soils Management Plan," Prepared by Westinghouse Materials Company of Ohio for the U.S. Depart . ment of Energy, March 1991, DRAFT.

A,P. D'SIL VA, D. ZAMZOW, E. JASELSKIS, and S. WEEKS, "Remote, Real-Time Analysis of Hazardous Wastes Through Laser Ablation-Inductively Coxpled Plasma Atomic Emíssion Spectrometry," in Broceedings of the Intemational Topical Mezting on Nuckar and Hazardons Waste Management Spectrum 92, Boise, August 23-27, pp, 409-413 (1992).

P.G. KAPLAN, "Evaluation of Soil Characterization Techuologies Using a Stochastic Value of Information Approach," in Proceedings of ER'93. Agusta, GA (1993).

D.W. MAC ARTHUR, K.S. ALLANDER, J.A. BOUNDS, M.M. CATLETT, R.W. CARESS, and D.A. RUTHERFORD, "Alpha Contrmination Monitoring of Surfaces, Objects, and Enclosed Areas," IEEE Trinsfactions on Nuclear Science, Vol. 40, Number 4, p.840 (1993).

C. RAUTMAN, "Direct Probability Mapping of Contaminants," in Brocegdings of ER"93. Agusta, GA (1993),

A.J. SCHILK, R.W. PERKINS, K.H. ABEL, and R.L. BRODZINSKI, "Surface and Subsurface Characterization of Uramiun Contarination at the Fernald Environmental Management Site, " Pacific Northwest Laboratory, BNL_8617 (1993).

V.C. TIDWELL, J.C. CUNNANE, J. SCHWING, S.Y. LEE, D.L. PERRY, and D.E. MORRIS, "Field Dertonstration Of Technologies For Delineating Uranium Contaminated Soils," in Procedings of ER'93, Agosta, GA (1993). 


\title{
APPENDIX A: FIELD DEMONSTRATION OF IN SITU GAMMA-RAY SPECTROME- TER, AND HIGH-ENERGY BETA SCINTILLATION SENSOR
}

\author{
Alan Schilk (Pacific Northwest Laboratories) \\ Dick Perkins (Pacific Northwest Laboratories)
}

\section{DETECTOR THEORY}

\section{In Situ Gaunma-Rav Spectrometer}

In situ gamma-ray spectrometry has enjoyed widespread use around the world for the precise characterization of a multitude of radionuchides in the field due to its convenient transportability and rapid data-reduction capability. A high-purity germanium gamma-ray detector, suspended one meter from the ground in an uncollimated configuration, is sensitive to surface and shallow subsurface activity originating from hundreds of square meters, and effectively averages any horizontal heterogeneities that may exist within its field of view. Although in theory this type of system would monitor complete 2/4-space (i.e.. from horizon to horizon), the actual depth and expanse of contamination detected is strictly a function of the photon energy due to geometry factors and attenaation in the soil and air.

In practice, photons (i.e., gammas and $x$-rays) that are incident upon the germanium crystal lead to ionizations and excitations of myriad germanium atoms, thereby leading to the generation of an equivalent number of oppositely-charged species, viz., electrons (negatjve) and electron "holes" (positive). These charge-carrying species are swept to opposing regions of the germanium crystal dae to the presence of a strong electrical potential (generally on the order of a few thousand volts) where they are subsequenlly collected and quantified. The greater the amount of total energy deposited from an isolated event (i.e., due to the attenuation of a lone photon), the larger the total charge collected. Hence, by observing the magnitudes of individual charge pulses one may determine the various energies of the photons undergoing complete absorption in the crystal, and the specific photon energies serve as unique and immutable identifiers for various radionuclides of interest; e.g., 1.461-MeV ganma rays originate from the spontaneous decay of ${ }^{40} \mathrm{~K}, 0.662-\mathrm{MeV}$ gannmas represent ${ }^{137} \mathrm{Cs}$, and 1.001-MeV gammas are an indication of the presence of $234 \mathrm{mp} \mathrm{Pa}$ (a daughter of 239U). Furthermore, the total number of equivalent pulses per unit time is an indication of the actual amount of source material present.

The ${ }^{28} \mathrm{U}$ decay chain begins as follows:

${ }^{239} \mathrm{U}\left(4.47 \times 10^{9} \mathrm{y}\right) \rightarrow{ }^{234} \mathrm{Th}(24.1 \mathrm{~d}) \rightarrow{ }^{2344 \mathrm{~Pa}}(1.18 \mathrm{~m}) \rightarrow{ }^{234} \mathrm{U}\left(2.45 \times 10^{5} \mathrm{y}\right) \ldots$.

If secular equilibrium may be assumed, i.e., if no fractionation between $U$ and $P a$ has occurted within the past six months, then the decay rate of $234 \mathrm{mPa}$ is essentially equivalent to that of ${ }^{238}$ U. Consequently, one may utilize gamma-tay spectrometry to observe the rate of incidence of $1.001-\mathrm{MeV}$ garmmas from ${ }^{24 \mathrm{mPa}}$ to deternine the decay rate (and, therefore, the total activity) of 228U following system calibration.

An additional application of this technology is the ability to approximate the average uranium depth distribution in the soil volume viewed by comparing multiple photons from the usanium decay chain; viz., the 63-keV and $93-\mathrm{keV} \mathrm{x}$-rays from ${ }^{23} \mathrm{Th}$ and the $1.001-\mathrm{MeV}$ and $0.766-\mathrm{MeV}$ gammas from ${ }^{234} \mathrm{~Pa}$. Due to the differing attenuation properties of these photons, one may compare their observed intensities with those expected from various vertical distributions and determine, to a first-order, the behavior of the subsurficial contaminant. 


\section{Hith.Enerwy Beta Scintillation Sensor:}

A traditional mechanism for detecting charged particles (e.g., betas) is one that utilizes a substance which scintillates, or emits light. upon passage of such species through the sensitive material. The resulting light may then be used to simply indicate the presence of these charged particles or, under certain conxtitions, their relative energies as well. In particular, polystyrene-basted plastic fibers may be doped during their casting process with various fluorescent compounds that have been carefully selected to produce the desired scintillation, optical and radiation-resistance characteristics. The passage of charged particles through these individual fibers leads to the ionization and excitation of the fiuorescent dopants, which subsequently de-excite via the emission of visible light. The resulting light pulses are then partially transmitted down the length of the fiber and may eventualty be converted into lectrical signals (the intensities of which are directly proportional to the total energy deposited per event) via a light-sensitive device such as a photomultiplier uube (PMT).

With regard to the characterization of ${ }^{239} \mathrm{U}$ contamination, PNL has developed a prototype scintillation sensor that targets the 2.29-MeV (maximum energy) beta particke from the decay of 234mpa (see above decay scheme). This is accomplished through (1) the construction of flat ribbons that are composed of numerous square fibers $\left(0.25 \mathrm{~mm}^{2}\right.$ and $\left.1.0 \mathrm{~mm}^{2}\right)$, (2) the stacking of these rib. bons and the coupling of each bundled end to a PMT, and (3) utilizing custom-designed circuitry to interrogate the total number of scintillation events from each layer (as well as the coincident signals therefrom).

\section{DETECTOR DESCRIPTION}

\section{In Situ_Gammateray Spectrometer.}

The in situ spectrometry system is centered aroand a standard gemanium-crystal-based gamma-ray sensor that was purchased from EG\&G ORTEC (Oak Ridge, TN). This detector was specifically chosen for its enhanced sentitivity toward low-energy photons in order to facilitate the characterization of the $63-\mathrm{keV}$ and $93-\mathrm{keV} \mathrm{x}$-cays from ${ }^{234} \mathrm{Th}$. The germaninm crystal must be kept cold during normal operation to minimize the stray electronic noise inherent to this type of sensor, and such cocling is provided by the addition of liquid nitrogen (LN2) to a reservoir that is attached directly to the crystal housing. Hence, the overall sensor configuration consists of a cylindrical crystal housing (9-cm diameter $\times 28-\mathrm{cm}$ length) surmounted by a reservoir of the same basic shape (22 $\mathrm{cm} \times 28 \mathrm{~cm}$ ). This package is monnted to a sturdy tripod, in a down-looking orientation, such that the detector endeap is suspended one meter above the soil surface. The total combined weight (including full LN2 capacity, approximately 3 liters), is somewhat less than $15 \mathrm{~kg}$.

With regard to the supporting data-acouisition hardware, two individual options exist. In one, a remofe package contains all of the electronic hardware necessary for proper detector operation; this unit requires extemal AC power and includes a bias supply for the detector, an amplifier to shape and amplify the detector output signal, an analog-to-digital converter to tranklate this signal into usable form, and a memory buffer for storing the acquired data. The overall dimensions are approximately $30 \mathrm{~cm} \times 30 \mathrm{~cm} \times 30 \mathrm{~cm}$, and the unit is connected to the detector via a $10-\mathrm{m}$ power. supply/signal cable. Data display, accuisition control, and data reduction are performed by a star. dard laptop PC, which receives output from the hasdware unit and contains the necessary applica. tion-specific software (viz, Maestro-II from EG\&G ORTEC). The second hardware option eliminates the need for external power, remote hardware and cable, and laptop PC. With this option (currently under joint development at PNL and Los Alamos National Laboratory), all of the aforementioned electronics are condensed into an $11-\mathrm{cm} \times 8 \cdot \mathrm{cm} \times 24 \cdot \mathrm{cm}$ package that attaches directly to the LN2 reservoir and contains its own battery power. Data control and display are maintanned 
by a local palmtop PC (e,g, a Hewlett-Packard [Corvallis, OR] HPIOOL.X) and data reduction occurs ex situ at the operator's (or field supervisor's) convenience; acquired data is stored on convenient "flash-type" memory cards and transferred by hand as necessary.

\section{High-Energy Beta Scintillation Sensore}

The beta sensor represents new technology developed at PNL for the real-time, in sint characterization of ${ }^{238} \mathrm{U}$ or ${ }^{90} \mathrm{Sr}$ in surface soils and, as such, is not available commencially. The scintillating fiber ribbons, PMTs, power supplies, and associated electronic hardware are enclosed in an aluminum box measuring approximately $120 \mathrm{~cm} \times 35 \mathrm{~cm} \times 12 \mathrm{~cm}$ and weighing tess than $20 \mathrm{~kg}$. This package is composed of welded box-ube and sheet aluminum, and contains separate compartments for the ribbons/PMTs and supporting hardware. The light-sensitive fiber ribbons are shielded from ambient light by a thin layer of opaque plastic, and the effective observation window, which is centered on the detector base, measures $30 \mathrm{~cm} \mathrm{x} 60 \mathrm{~cm}$. This unil requires ckean AC power, although efforts to convert the system to a self-contained, battery-powered configuration are cintently underway and may be available at the time of the subject dernonstration.

Ratiation-induced scintillations within the individual ribbon layers are converted to proportionate electrical pulses by the PMTs, and the resulting signals are stbsequently processed as follows: (1) shaping and amplifying (first by a preamplifier and then by an amplification circuit), (2) filtering (to reduce the inherent electronic-noise contribution), (3) comparison with other contemporaneous PMT outputs (in order to establish intralayer and interlayer coincidences for mitigating individuad PMT noise and determining relative beta-particle energy, respectively), and (4) transmission via a signal cable to a local laptop or palmtop PC for final display. Although the only parameter of direct interest in the real-time in sita characterization of $230 \mathrm{U}$ is the total namber of triple-coincidences per unit time (i.e., the rate of incidence of high-energy ${ }^{234 \mathrm{mPa}}$ beta particles), the logic circuitry developed for the performance of step (3), above, also incicates the number of signals in each individual layer and the coincidences between layers I\&2 and layers $2 \& 3$; this additional information is useful for diagnostic and evaluation purposes.

\section{OPERATING PROCEDURE}

\section{In Situ Gamma=Ray Spectrometer.}

The following describes the necessary steps for the proper and safe operation of the in situ gamma-ray spectrometry system:

Remove the germanium-detector/reservoir unit (hereafter referred to as the "detector") from its shipping container and, using appropriate safety precautions, add LN2 to the fill port; a special funnel is supplied for this purpose. When handling LN2, long-sleeve shirts, jong pants, gloves and a full face shiedd (as a minimum) are to be wom for protection against frostbite słould spillage occur. This step is to be performed at least 8 hours prior to supplying power to the detector to ensure proper operation and preclude detector damage.

Assemble detector tripod and attach detector to faceplate. Adjust tripod legs so that the detector endcap is 1 meter above the ground. This step may be performed during the detector cool-down process.

When detector has reached normal operating temperature, connect the supporting electronics (remote of local unit) to the detector via the sopplied cable; this includes the detector bias supply (SHV connector), preamplifier power suppiy ( 9 pin D-type connector), detec- 
tor output (BNC connector), and bias shutdown signal (BNC connector). All cable connectors are clearly marked to prevent improper use.

Connect appropriate PC to the supporting electronics via the requisite cable (laptop PC for remote unit or HP100LX for local unit).

Provide power to the supporting electronic package and PC (clean AC power for the remote unit or battery power for the local urit).

Test proper operation of the in situ ganma-ray spectrometry system by placing a radioactive source (e.g+, a sealed ${ }^{4} \mathrm{Co}^{137} \mathrm{Cs}-2+1 \mathrm{Am}$ source) near the detector endcap and acquiring a preliminary spectrum for approximately five minutes. Adjust the amplifier gain and zeroadjust, if necessary, to obtain a 1-keV/channel spectrum.

Place uncollimated detector directly above each sampling point, ensure the endeap is located 1 meter above the surface, and initiate data acquisition via the controlling PC (this operation, and others, is perfomed by the accompanying software from EG\&O ORTEC). Acquisition times will be chosen at the discretion of the field supervisor. A unique sample identifier will be requested upon initiation, and individual spectra will be automatically saved to magnetic medium for subsequent data reduction.

Repeat above step following addition of tungsten or lead collimator.

After cessation of data acquisition, move detector to next sample location and repeat the two previous steps. Repeat until complete.

Through the course of, and following, each day of data collection, acquire adititional sealed-source spectra as above and compare with previous to evaluate stability of electronics.

Reduce data as convenient urilizing the accompanying software and provide results to FERMCO Site Engineer or ID Coordinator. This is to include hardcopy, magnetic medium, and photocopies of field notes.

\section{Hiph-Eneriy Beta Scintillation Sensogc}

The following describes the necessary steps for the proper and safe operation of the beta sensor:

Remove the sensor from its shipping container and place it on a sturdy sturface.

Connect the sensor to its PC via the accompanying cable and provide power to the system (either clean AC powar or battery power, if the latter capability is available).

Test the proper operation of the sensor by placing an extended, sealed source directly below the sensitive area and acquiring data for approximately ten minutes. Results are to be compared with previous laboratory suns to determine stability of sensor.

Place the sensor directly on the ground (a thin plastic sheet may be used to protect the sensor from contamination) at each sample Jocation and initiate data acquisition. A unigue sample identifier will be assigned at each point and data will be automatically saved to the PC's hard drive.

Move the sensor to the next sample location and repeat the previous step. Repeat until cont- 
plete.

Through the comse of, and following, each day of data collection, acquire additional sealed-sonrce spectra as above and compane with previoas to evaluate stability of electronics.

Reduce data as convenient and provide results to FERMCO Site Engineer or ID Coordinator. This is to include hardcopy, magnetic medium, and photocopies of field notes.

\section{CONVERSION OF FIELD DATA TO pCHE TOTAL URANIUM}

\section{In Situ Ganma-Ray Spectrometer:}

Prior to field deployment, the gemanium gamma-ray detector must undergo a thorough calibration process involving the observation of multiple radioactive sources in various orientations. Sealed ${ }^{60} \mathrm{Co},{ }^{137} \mathrm{Cs},{ }^{21} \mathrm{Am}$, and ${ }^{152}{ }^{5}$ sources are placed 1 meter from the endcap at a number of angles from the detector normal (e.g.every 10 degrees, from directly in front of the detector to directly alongside), and the sources are slowly rotated around the detector axis to determine its angular response function. Total gamma-ray counts for each source/orientation combination are compared with actual sonare strengths, and detector efficiencies for each scenario are calculated. This detector-specific information is combined with tabulated data that indicates the expected gammaray fluxes originating from soils exhibiting various vertical distributions. These data are entirely independent of the actual detector to be calibrated, and are easily calculated using radiation theory (e.g., attemuation coefficients) and simple mathematics.

The end result of this detector-specific and -independent collaboration is the generation of unique "calibration factors", with units of (pCi/g)/(counts per second), for all energies (or radionuclides) of interest; $n$.b., this is strictly toue only for uniform vertical distributions of contaminants, since the actual $\mathrm{pCi} / \mathrm{g}$ for a non-uniform distribution (e.g., one that decreases exponentially with depth) is a direct function of the depth in question -conversely, one may "assurne" a uniform distribution, despite evidence to the contrary, and obtain the "average" pCi/g for the soil volume viewed. As an example, to determine the specific activity of aged ${ }^{23} \mathrm{U}$ in soil one may obtain a gamma-ray spectsum (as above), determine the total number of counts in the $1.001-\mathrm{MeV}{ }^{2340 \mathrm{~Pa}}$ peak per unit time (i.e.. the total coumts per second), multiply this parameter by the unique calibration factor for this energy, and thereby obtain the total activity of ${ }^{238} \mathrm{U}$ per gram of soil. By doubling this value, one obtains the $\mathrm{pCi} / \mathrm{g}$ of total uranium.

\section{High-Encrgy Betascintillation Senkor}

The calibration process for the beta sensor is quite simple in relationship to the in situ gamma-ray spectrometer. In this case, the sensor is calibraled prior to field deployment by first mionitoring a series of medium-grained sands that have been "spiked" with various amounts of $2 * U$ (in nitrate form). These standard solls are (1) mixed thoroughly to ensure contaminant homogeneity, (2) slightly larger than the active area of the beta sensor, and (3) much thicker than the longest possible pathlength of a $2.29-\mathrm{MeV} 234 \mathrm{mPa}$ beta particle originating from within the source.

Triple-coincidences (see above) resulting from the observation of the standard sources, which generally span the range of $5 \mathrm{pCi} / \mathrm{g}$ to $200 \mathrm{pCi} / \mathrm{g}$ of totai uranium (i.e.. $2.5 \mathrm{pCi} / \mathrm{g}$ to $100 \mathrm{pCi}$ g of 23:U), are plotted versus activity to obtain a catibration curve; laboracory experience shows that the sensor response in this range is quite linear. Consequently, when triple-coincidences are obtained in the field they are simply multiplied by the previously determined calibration constant to establish total uranium activity per grom of soil at the ground surface. 


\title{
APPENDIX B: FIFLD DEMONSTRATION OF THE LASER-ABLATION, INDUCTIVE- LY COUPLED PLASMA-ATOMIC EMISSION SPECTROMETER
}

\author{
Marvin Arderson (AMES Laboratory)
}

\section{DETECTOR THEORY}

\author{
Laser Ablation
}

The laser ablation (LA) technique is used for direct sampling of soils. Laser radiation focused on the soil generates sample particles that range up to a few 10 s of fricrons $(\mu \mathrm{m})$ in size. The ablated sample particles are entroined in argon gas that is flowing through the ablation cell, transported through a 20 meter tabe, and introctuced into the ICP for excitation. This technigue eliminates the lengthy, approximately elght-hour sample dissolution and separation process needed to prepare a sample for analysis. Laser ablation has been successfully used for the direct sampling of metals and ceramics.

\section{Inductively Conpled Plasma - Atomic Empission.Spectroscopy}

The Inductively Coupled Plasma-Atomic Emission Spectrometry (ICP-AES) technique is used to analyze soil samples generated by the laser ablation technique. The sample is introduced into the high temperattre plasma, $8000 \mathrm{~K}$, of the ICP torch where it is vaporized, atomized, and ionized. The intense light from the ICP plasma is transfered via a fiber optic cable and introduced into the alomic emission spectrometer where it is resolved into wavelengths and intensities. The ICPAES is capable of rapidly detecting and quantitating several elements, op to 20 in the current configuration, simultaneous]y at the parts-per-million (ppm ( $\mu \mathrm{g} / \mathrm{g})$ ) level. This feature makes the ICPAES a valuable tool for the rapid simultaneous detection of total uraniom, tota] thorium, soil matrix elements, and other heavy metals.

\section{DETECTOR DESCRIPTION}

\section{Apparatus}

The LA-ICP-AES instrumentation used for laser sampling and rapid analysis of soil sarnples is located in the mobile demonstration Laboratory for environmental screening technologies (MDLEST) which is completely self-contained. Computers and control systems, electrical power, water, gases, and other utilities required to operate the LA-ICP-AES instrumentation are supplied by the MDLEST. In additton, a newly acquired Global Positioning System (GPS) is installed in the MDLEST to supply real-time coordinate infermation for mapping in situ sampling sites. The instrumentation and equipment installed in the MDLEST is under computer-control for tystem monitoring and actuation, and data acquisition and reporting. Thus, the operators have a minimal number of "manual tasks" to perform during the sampling and analysis operation.

The laser used for ablation sarnipling (Continnum model NY81-30 Nd:YAG laser, 30 Hz repetition rate, and $1064 \mathrm{~nm}$ wavelengti with frequency doubling and tripling capabilities) is located in the MDLEST. A fiber-optic cable $(600 \mu \mathrm{m}$ core diameter silica fiber, 25 meters in length -Polymicro Technologies model FVP-600660690) transmits the laser tadiation ( $5.5 \mathrm{~mJ}$ ) to the sampling probe. The fiber-optic cable is one component in the 20 meter umbilical connecting the MDLEST and the sampling probe. The umbilical also contains the aerosol transport tube, the power and control wiring for the electronic systems in the sampling probe, and the GPS antenna wire. The sampling probe is equjpped with a GPS antenna for locating in situ sampling sites, the ablation cell 
that is mechanically sealed to the soil surface, and the mechanism that focuses and rasters the laser beam over the soil surface. Argon gas flowing through the aenosol transport tube carries the ablated sample particles from the ablation cell to the remote ICP (RF Plasma Products model ICP. $36 \mathrm{~L}$ ) which is connected by fiber-optic bundle to the AES (Themo Jarrell Ash model ICAP 61-E Atomic Emission Spectrometer). The spectrometer is configured to detect and analyze 20-channels (elements) simultaneously, and is configured for the detection and analysis of uranium, thorium, and the soil matrix elements $\mathrm{Si}, \mathrm{Fe}, \mathrm{Al}, \mathrm{Ca}, \mathrm{Na}, \mathrm{K}$, Ti.

A Global Positioning System (GPS) (Ashtech model M-XII receiver and associated software) is installed in the MDLEST to supply real-tume condinate information for mapping in situ sampling sites. This mapping information is acquired during the sampling process, and can be directly plotted on site maps provided a common bench mark location is used. This feature altows off-grid locations to be sampled and the results plotted directly on the site map. This system will allow innovative sampling strategies to be tested. ing if necessary:

A microwave oven (CEM model MDS-2100) in the MDLEST will be used for sample dry-

\section{Safecy Precautions}

\section{Laser}

A Continuum Nd:YAG laser is utilized for the ablation sampling. The laser is capable of producing $100 \mathrm{~mJ}$ of $1064 \mathrm{~nm}$ laser light, $25 \mathrm{~mJ}$ of $532 \mathrm{~nm}$ second hantionic light, or $12 \mathrm{~mJ}$ of 355 nin third harmonic light in 10 nanosecond pulses at a $30 \mathrm{~Hz}$ repetition rate. These power, wavelength, and operating parameters define this as a class IV laser as defined in ANSI Z136.1-1986. A Class IV taser is capable of causing eye and skin damage through direct or specular reflection exposure, and is capable of jgniting flammable materials. During the alignment of the Nd: YAG Jaser beam to the optical fiber, class IV Jaser cperation, the access doors to the MDLEST are controlled, and only Ames Laboratory personnel wearing appropriate laser safety eye wear and possessing current laser safety training and eye exam will be allowed in the MDLEST. During nomal sampling operations with the laser beam path in the MDLEST enclosed, the laser energy emitted frotn the end of the fiber optic cable in the sampling probe is defined as a class I laser. There is no exposed laser radiation when the sampling probe is seated in the groumd seal ring.

\section{ICP}

The ICP requires high power levels at radio frequencies (RF) and high voltage for proper operation, and the torch emits intense ultraviolet and visible light. The operator is prevented from accessing the radio frequency and high voltage components during normal operation by safety interdocks and shielding. Additional installed shjelding prevents eye injury from the intense ultraviolet and visible light being emitted from the ICP toreh during operation.

\section{Lquid Argon}

A pressurized liquid argon dewar and manifold system distribute gas to the ICP, the sampling probe, and the spectrometer. This dewar and gas distribution system is equipped with pressure relief valves and gas regulators to prevent system over-pressurization. Cryogenic liquids are handled in accordance with safe handling practices to prevent skin and eye tissue contact that wil] result in burns. 
The microwave oven will be used for soil sample drying if necessary. This microwave oven complies with the U.S. Code of Federal Regulations Title 21, part 1030 for microwave leakage, and is equipped with safety intedocks that prevent operation while the door is open.

\section{Somple Handling}

The MDLEST is designed to take LA-ICP-AES instrumentation into the field for in situ sampling of contaminated sites. The data acquisition occurs without the operator physically handing the sample. The sampling probe is set over the site to be sampled; laser radiation is delivered to acquite the sample; flowing argon gas transports the ablated sample material to the ICP: the emisston generated in the ICP is imaged into the AES for analysis. The entire operation, in principle, can be performed by an operator in minimal contact with the contaminated site.

\section{Decontaminating Egutphent}

The ground seal ring will be decontaminated by washing with wator between successive sample sites. The ablation cell will be washed as needed. The flexible tubing connecting the ablation cell to the ICP will becone contaminated during operation and will be cleaned or replaced as needed. The ICP torch box is fitted with a high efficiency particulate air (HEPA) filter, located on the MDLEST roof, to trap sample residue that passes through the ICP. The HEPA filters are in situ certified to be operating within specifications by the Ames Labotatory ES\&H personnel. The HEPA filters will be surveyed before leaving the site, and if contamingted they will be removed and left at the site for disposal. The components of the Thermo Jarnell Ash ICAP-6IE Spectrometer will not be exposed to radioactive material.

\section{Geiger Counter}

A Geiger counter (Aware Electronics model RM-70 or equivalent) is available in the MDLEST for radiation monitoring and surveying purposes.

\section{OPERATTNG PROCEDURES}

\section{LA-ICR-AES Operation}

There are two methods of introducing a sample into the LA system. The primary method is in situ, this is the direct placement of the sample probe over the location to be sampled. The second method involves digging _10 grams of sample and placing it in a polypropylene bottle. This bottle then is manually placed under the sample probe for sampling and anajysis. The second nethad will be used if the soil to be sampled is too wet and will need to be dried before sampling and analysis.

The following steps outline the procedure for acquiring and analyzing an in situ sample:

- Position MDLEST near the location to be sampied

- Power "on" equipment and utilities

- Laser on shutter closed

- Prepare site by removing vegetation, tamping, and positioning the ground seal ring

- Set the sampling probe in the ground seal ring

- Initiate 'Coatrol' computer programming that prompts the following steps:

- Initiate GPS position system

- Check the gas seal to the soil surface

- Adjust the argon gas flow through the abtation cell to the required level

- Ignite the ICP torch; set the operating power aud acquire background emission data

- Initiate the automatic sampling sequence that performs the following steps 


Adjust the laser energy for the focus noutine
Open the laser shutter
Focus the laser energy on the soil
Close the laser shutter and adjust the laser energy for sample
ablation
Open the laser shutter
Start the programmed raster of the laser energy across the soil
surface
Acquire and store the ICP-AES emission data
Close the laser shutter
- Store GPS sample site location information
- Analyze ICP-AES emission data, print the results and save on optical disk
- Remove the ground seal ring, decontaminate. and place at the next sample iocation
- Repeat the sampling and analysis steps for multiple sites within reach of the urnbilical
Move the MDLEST to a oew location and repeat the sampling and analysis steps

\section{Microwave Dryins}

In situ soil samples that contain too much moisture will not produce enough sample material during the ablation sampling process to be quantitated with a high level of confidenxe. For this case, _ 10 grams of sample will be dug and placed into a polypropylene bottle and dried_8 minutes in the microwave oven. The botle containing the dried sample will be placed in the calibration fixsure for laser ablation sampling and analysis.

\section{Interferences}

Spectral interferences of analyte emisston lines in ICP-AES result from the overlap of emission lines, nnnesolved lines or molecularband emission, backgronind enission from the ICP, or stray light from strong emission lines of high concentration elements in the sample. Spectral overlap can be compensated for by measuring the concentration of interfering element(s). Unresolvable spectral interference requires the use of an alternate emission line for the element. Background and stray light can be compensated for by background corrections. The ICP-AES is tested to ensare that the detection channels for the elements of interest do not have any spectral interference from elements in the sample for which there are no detection chanels.

Chemical interferences in ICP.AES include molecular compound formation and tonization effects that occur within the ICP, and ane highly dependent on the matrix of the soil sample and dae specific element being detected. These effects are normally insignificant; however, if chemical interferences are observed, they can be minimized by using soil standards that are matrix-matched.

Physical and chemical interferences can occur during the laser ablation sampling, particularly at low laser energy densities, where selective vaporization may occur. These interferences shoukd be minimal since Femald blank soil, with a matrix similar to the soils that will be analyzed ot-site, was used to prepare the "artificial" soil standards for instrument calibntion.

\section{Standardization}

The Fernald soil standards will be used to calibrate the LA-ICP-AES and for determining inter-element and background correction factors. Altematively, NIST and NRM certified standard soils will be used. 
The steps in the standartization procedure are:

- Start the system, using standard operating procectures

- Profile and calibrate the LA-ICP-AES response for uranium, thonium, and matrix elements by sampling and analyzing the soil standards

- 5 replicate measurements will be made on each sample from which the meav and standard deviation will be calculated

- Repeat the sampling and analysis of one soil standard sample after tho more than five unknown site soil samples are analyzed. Use the results from the repeat soil standard to recalibrate the LAICP-AES response

- Report the instrument calibration in terms of the total U/Si ratio vs the activity in PCV/g

\section{DERIVATION OF pCig}

\section{Calculation}

An LA-ICP-AES calibration curve for the total U/Si ratio vs the activity in $\mathrm{pCi} / \mathrm{g}$ will be determined using the Femald soil standards. This calibration curve will then be used to quantitate the $U$ activity in the Fernald soil samples analyzed. The concentrations of individual isotopes, if needed, will be calcolated from their natural abmindance percentages.

\section{Alternative Method}

Alteruatively, the ICP-AES can be calibrated in terms of concentration (ppm ( $\mu \mathrm{g} / \mathrm{g}$ )) of total U. The resulting quantitation is reported in terms of the concentration that must be converted to activities (pCi/g) using the half life values of the particular radioisotope.

\section{Brecistonand Accuracy}

- Data averages and standard deviations will be calculated and reported for the elements of interest in terms of activities or altematively in concentrations

- Matrix elements, e.g. Si, Al, and Fe, will be quantitated within $30 \%$

- The accuracy of the quantitation of the total $U$ is unknown at this time but will be determined in the field

\section{REFBRENCDS}

- Operation and Maintenance Manual for Continuum NY81-30 Nd:YAG Laser

- Operation and Mainuenance Manual for Thermo Jarrell Ash ICAP-6IE Simultaneous Spectrometer

- Operation and Maintenance Manual for CEM MDS-2100 microwave digestion system

- Laser-Indiced Plasmas and Applications; LJ. Radziemsti and D.A. Cremers (eds.); Marcel Dekker, Inc., New York, 1989

- Laser Microanalysis; L. Moenke-Blankenbart (ed.); John Wiley \& Sons, Hew York, 1989

- Mobile Laboratory 5th Wheel Trailer Minimurn Specification Summary, Ames

Laboratory and Iowa State University 


\title{
APPENDIX C: FIEID DEMONSTRATION OF THE LONG RANGE ALPHA DETECTOR
}

\author{
John Bounds (Los Alarnos National Laboratories) \\ Duncan MacArthur (Los Alamos National Laboratories)
}

\section{DETECTOR THEORY}

Long-Range Alpha Detector (LRAD) technology relies on measuring radioactivity not by counting the rariation particles directly but by measuring the amount of air ionization caused by the radiation. In one type of LRAD, the ions created can be transported by an airflow and have been observed and measured at distances from a few centimeters to a few meters from the original alpha source. In another type of LRAD, ar electrostatic field separaites the ion pairs as they are formed. In both types of LRAD, the collected ions form an electrical current which can be measured. High sensitivities over extended area can be obtained. Alpha radiation is preferentially detected, since although all radiation tends to ionize air; neutron, beta and gamma radiation tend to deposit less energy per onit distance in air per incident energy. Alpha radiation has both short range and high energy, creating many ions near the source of the radiation. The LRAD takes its name for its high sensitivity towards detecting alpha radiation and the relatively long distances at which the actual ion collection occurs from the source.

Uranium decays by alpha enission and so is an ideal candidate for detection by an LRAD.

\section{DETECTOR DESCRIPTION}

For monitoring soils in situ, the electrostatic LRAD was chosen over the airflow types for the electrostatic detector's lower power requirements, simpler and more rugged construction, and higher efficiency at monitoring flat surfaces - the applied electric field allows fewer radiation-produced ton pairs to recombine before being collected. Unlike traditional hated held probes, the LRADs have no mylar or thin wires to break. The LRADs tse no special detection gases, the air itself is the medium for ion transport. The LRADs are so ngged, the largest measure one square meter and are mounted on the front end of a tractor, withstanding the beating obtained by driving over rough terrain and being placed on the ground with occasional hydraulic pressure. The figure shows the construction.

The LRAD soil surface monitor is essentially a large, flat box whose open end is placed on top of the soil to be mesusured. Inside the box, a signal plane of either copper or aluminum sheet is biased at $300 \mathrm{~V}$ and creates an electric field between itself and the soil. Ions created above the soil are collected by the field, restlong in an electrical current which is measured by the electrometer. Readings can be obtained directly from the electrometer or from an attached computer which averages the readings over thirty seconds and graphically displays the results. A guard plane between the signal plane and the detector box prevents leakage currents in and across the lexan standoffs from being misread as a signal. The entire unit, including computer, is powered in the field by its own car battery and de to ac inverter.

Al] LRAD soil surface monitors with a four-jnch signal plane to ground distance and $\mathbf{3 0 0}$ $\mathrm{V}$ bias have a response of one femtoamp $\left(10^{-15} \mathrm{~A}\right)$ per $6 \mathrm{dpm}$ of ${ }^{239} \mathrm{Pu}$. For other alpha emitters the LRAD has a response which varies as the average energy of the alpha particle. Response linearity is excellent and hes been measured from $100 \mathrm{dpm}$ to $300,000 \mathrm{dpm}$. Linearity is expected to continwe until space charge effects begin or until the current draw of the battery becomes a factor.

\section{OPERATING PROCEDURE}

The LRAD large soil surface monitor is mounted on a farm tractor. Experience has shown 


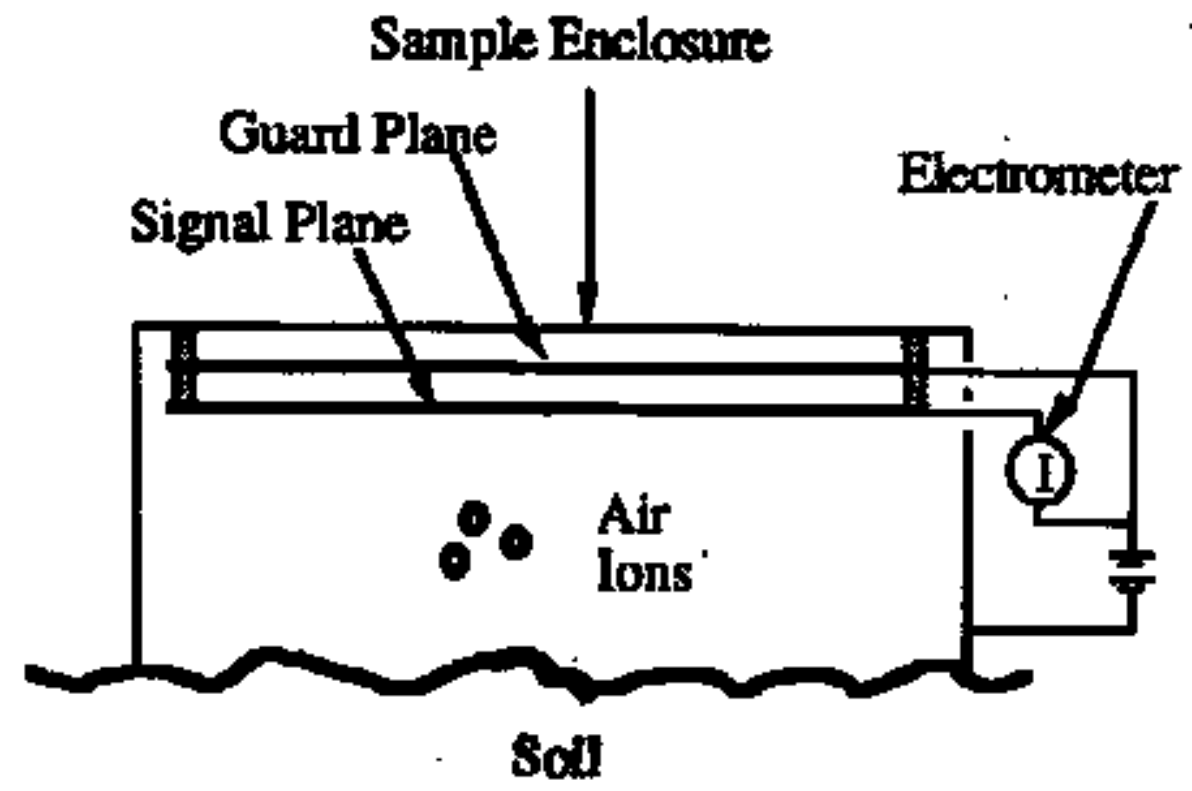

that the detector operation can be learned in less than half an hour, including how to dive the tratetor. The general procedure other than how to drive the tractor is as follows:

The tractor is operated only to move the detector and not while measurements are being made. The detector electronics are powered up at least the night before measurements are to be made to allow for thorough wamm-up time. The electronics shoutd be powered by supplied AC outlets and the detector's car battery should be recharged if necessary. The detector's $300 \mathrm{~V}$ battery should be checked on the furst day and be not lower than $295 \mathrm{~V}$. The detector should be on a reasonably clean (not spotless) aluminum plate to obtain an intrinsic background reading for the detector. An aluminum plate reading of 200 to $400 \mathrm{fA}$ is normal. In the morning, the electronics should be switched from the overnight $A C$ supply to self contained and recharged battery supply. As the first reading of the day, the reference spot should be re monitored, or one chosen if it is the first day of field woik. Repeatability of background and the reference point is sufficjent to show the detector is operating correctly and additional source checking is not required under normal operating conditions. Once the aluminum plate and reference spot readings are made, new monitoring may be performed.

To monitor a new spot, the spot should be four feet square and must be within a couple of inches of being planar. Its vegetation must be scalped as close to the ground as practical and clippings removed. This is typically accomplisled with a WeedEater style cutter or with band shears. Best results are obtained in two person operation, one to drive the tractor and one to direct placement of the detector on the cleared spot using preartanged hand signals. Since personnel oftent take turns driving the tractor, both should be wearing safety shoes to protect their toes during detector placement. The detector should be placed as nearly paralkel to the ground as possible and pushed down slightly with the tractor hydraulics to assure a good seal. The tractor should be stopped and dismounted since vibrations will cause noisy signals. The detector has a four inch wide foam seal around the cutside lower edge of the box -there should be few or no gaps between the foam and the soil (outside air contains about $10^{7}$ ions per $\mathrm{cm}^{3}$ during the day, a fA is only about 6000 electronsi sec). Once the detector is placed, computer acquisition is started and attention is paid to the intitial readings to note any problems with the placement. A shorted signal plane or air leaks are the two most common problems and easy to notice; all problems ever encountered, their signs and solutions, are listed on a one page sheet which deploys with the tractor. With practice the person directing the placement can spot potential troubłes before they occur and correct the situation before the detector 
is placed.

Once the detector is placed and data acquisition started, the data is allowed to collect for 8 to 15 minutes. This gives tine for transient conditions to subside and usually results in data with a discemible plateau in readings. After at least 8 minutes and once a plateau is evident, the data may be saved to the computer hand fisk and the platean value manually recorded in a logtook. The computer acquisition is halted and the tractor is remounted to be moved to the next cleared spot.

At the end of the day or when desired, the reference spot shoald be re monitored. The detector should be retumed to its aluminum background plate ovemight and the electronics switched over to AC power. The battery should be recharged as needed It is easiest to let the detector acquire data overnight so that it wil] be ready to thke out the next morning without waiting the time for a new data set to be acquired.

It is desirable to make a contour plot of the day's data nightly to observe trends and catch untusual readings. In addition the piot gives a sense of accomplishment to those taking the data.

\section{CONYERSION OF FIELD MEASUREMENTS}

The LRAD soil surface motitor measumes the ionization of air in its active volume. By using NIST-traceable sources, jt has been determined that the monitor collects about $40 \%$ of the airborne ion pairs produced by an alpha source beneath it (less within $3 \mathrm{~cm}$ of the sides of the box). The current reading in the LRAD can then be directly converted from fA to roentgen per unit time since the latter is defined in terms of the rate of ion production in air. Unfortunately, alpha contamination has historically been described by activity rather than exposure rate: DOE order 5400.5 states contamination limits in the more common form of $\mathrm{dpm} / 100 \mathrm{~cm}^{2}$.

In order to maice the LRAD readings more comprehensible to a wider audience, we prefer to report readings in $\mathrm{dpm} / 100 \mathrm{~cm}^{2}$. To convert to $\mathrm{dpm} / \mathrm{t} 00 \mathrm{~cm}^{2}$ we take the measured current, subtract the background reading of the detentor on a clear alumisom plate (typically 350 fA), and multiply by the measured conversion rate of $6 \mathrm{dpm} / \mathrm{fA}$ to get total dpm. The conversion is precise for plutonium-239 (5.10 MeV average alpha energy) and is very nearly the same for the average alpha energy of each of the natnral decay chains starting with ${ }^{238} \mathrm{U}$, ${ }^{235} \mathrm{U}$, and ${ }^{232} \mathrm{Th}(5.36,6.08$, and 6.14 $\mathrm{MeV}$ respectively). Fabricated ${ }^{238 \mathrm{~g}}$ metal has a lower average alpha energy of only $4.19 \mathrm{MeV}$. Since most sites that the LRAD have surveyed involved uranium contamination on natural background soit, the 6 dpm/fA corresponding to $5.10 \mathrm{MeV}$ alphas has been chosen as the best compromise to cover the range of 4.19 to $6.14 \mathrm{MeV}$ when converting to more common units. Dividing this tocal dpw measured over one square meter by 100 gives the reported $d p m / 100 \mathrm{~cm}^{2}$.

Several groups prefer to know contamination levels in terms of $\mathrm{pCi} / \mathrm{g}$ or ppm. The conversion from measured current to one of these units requires many assimptions. We do not litke to make all of these assumptions because each assumption gives reason to cast doubt on the accuracy and value of the measurement. The LRAD monitors make very accurate readings of relative activity, but contain no spectroscopic information from which to obtain isotope ratios or absolute concentrations. In fact, all in situ measurements on soil must make assumptions about the soil composition and homogeneity ì order to determine either isotope ratios or absolute concentrations. For completeness only, the LRAD conversion from current to $\mathrm{pCV} / \mathrm{g}$ and $\mathrm{ppm}$ is included here and goes as follows. The range of alpha particles can be used to get an effective depth of soil from which all upwardly directed alphas are collected and below which none are collected. For typical soil densities this depth works out to be $36 \mathrm{~mm}$. Multiptying by the one square meter surface area of the detector gives an effective volume of $36 \mathrm{~cm}^{3}$. At $2.7 \mathrm{~g} / \mathrm{cm}^{3}$, this implies an effective $100 \%$ monitored mass of $100 \mathrm{~g}$. Each $\mathrm{pCi} / \mathrm{g}$ of ${ }^{23 \mathrm{BU}}$ equals $2.22 \mathrm{dpm} / \mathrm{g}$ of $23 \mathrm{~g} \mathrm{U}$. Muhtiplying by the effective soil mass of $100 \mathrm{~g}$ gives $220 \mathrm{dpm}$ in the detector per $1 \mathrm{pCi} / \mathrm{g}{ }^{33} \mathrm{U}$. Taking into account the lower energy of ${ }^{23} \mathrm{U}$ alphas compared to ${ }^{29} \mathrm{Pu}$ alphas then gives a conversion of $7.4 \mathrm{dpm} / \mathrm{fA}$, and there- 
fore $30 \mathrm{fA}$ per pCi $\mathrm{U} / \mathrm{g}$. Since in most cases ${ }^{23} \mathrm{U}$ is in equilibrium with the ${ }^{238} \mathrm{U}$, the same stept must be followed and yield $34 \mathrm{fA}$ per $\mathrm{pCi}^{23} \mathrm{U} / \mathrm{g}$. The detector will see both of these decays for a total of $64 \mathrm{fA}$ per $\mathrm{pCi} / \mathrm{g}$ of $23 \% \mathrm{U}$. The higher beth and gamma activity for uranium add to this number slightly. Once the $\mathrm{pCi} / \mathrm{g}{ }^{2 \mathrm{r}} \mathrm{U}$ are detemined, the total uranium $\mathrm{ppm}$ is obtained by multiplying by (3 ppm total $\mathrm{U}) /\left(\mathrm{pCi} / \mathrm{g}{ }^{238} \mathrm{U}\right.$ ). This calculated conversion number of $64 \mathrm{fA}$ per $\mathrm{pCi} / 8$ of ${ }^{238} \mathrm{U}$ is smaller than what we have been using based on our oxiginal calculations and supported by the results at the Femald STP area. In our previous derivations and reporting of results we obtained a value of $108 \mathrm{fA}$ per $\mathrm{pCC} / \mathrm{g}$ of ${ }^{23 \mathrm{t} U}$ and obtained reasonabte agreement with core samples in the STP area. We determined empirically a total contribution of $2000 \mathrm{fA}$ from the detector background on an aluminum plate plus the natural activity other than uranium at the STP area, i.e., this background, subtracted from the measured current, gave nranium concentrations consistent with background. At this point we carnot select between the empirical and theoretical calculations as to which is more accurate. We look forward to the proposed well characterized plots for the spring demo to settle the issue once and for all. 


\title{
APPENDIX D: FIELD DEMONSTRATION OF PASSIVE ALPHA DETECTORS FOR CHARACTERIZATION OF URANIUM CONTAMINATION IN SOILS
}

\author{
C. S. Dudney, K. E. Meyer, and R. B. Gammage, \\ Oak Ridge National l aboratory, Oak Ridge, TN; \\ P. Kotrappa, Rad Elec Ine, Frederict, MD; \\ R. Wheeler and M. Salasky, Landaner, Inc, Glenwood, IL.
}

\section{DETECTOR THEORY AND DETECTOR DESCRIPTION}

\section{Alpha Traxk Detector (ATD) Technolon:}

ATDs are the basis of a technology that can achieve large numbers of inexpensive surface and aear-surface soil measurements that are boch accurate and simple to make. Alter and Fleisher (Health Physics 40:693-702, 1981) described the application of ATDs to the measurement of indoor aitbone alpha activity. The underlying prixciples of the measmement are that damage tracks in the plastic material are incuced by the passage of alpha particles through the material, that the damage tracks can be subsequently enlarged by exposure to potassium hydroxide solution, that the enlarged tracks can be counted with a microscope, and that the density (per unit area) of tracks is proportiona! to the alpha activity. Plastic ATDs are about $70 \%$ efficient in detecting alpha rays while being almost completely insensitive to gamma and beta ratiztions. The technology has alrearty been commercialized for the monitoring of environmental radon. Millions of detectors of the ATD type have been sold both to individual homeowners and to federal agencies mandated to screen their facilities for radon. The ATD technology has passed the stringent test criteria, blind testing, and quality assurance procedures set under EPA's Radon Measurement Proficiency Program.

ATDs are fabricated from LANTRACK. material, which is a polymer that has been cast using proprietary methods from an allyl diglycol carbonate monomer. Typically, the material is mapufactured in $1 \mathrm{~mm}$ thick sheets which are easily cut or formed to suit a particular appilication. The most frequently used detector format is small slabs, $1 \mathrm{~cm} \times 2 \mathrm{~cm}$ in size, that have an identificaton number laser-scribed on one face for chain-of-custody and tracking purposes.

\section{Electret Ionization Chamber (EIC) Textmology:}

ElCs provide another inexpensive measurement technique that is very easy to implement. Kotrappa and coworkers (Health Physics 41:35-46, 1981;Health Physics 54:47-56, 1988) have described the application of EICs to the measurement of indoor alpha activity. The underlying principle of the measurement is that ionizing particles that pass through the air in the sensitive volume of the detector create electron showers that are attracted to the positively charged face of the electret, neutralizing the charge. The rate at which the charge is neutralized is proportional to the activity concentration in the topmost centimeters of soil beneath the EIC. The technology has already been commercialized for the monitoring of environmental radon. Hundreds of thousands of detectors of the EIC type have been sold both to individual homeowners and to governmental agencies (pribcipally school systems) mandated to sereen their facilities for radon. The EIC technology has passed the stringent test criteria, blind testing, and quality assurance procedures set under EPA's Radon Measurement Proficiency Program.

EICs are passive ionization chanbers that consist of a charged Teflon electret mounted in a holder constnucted of a condacting polymer. The assembled detector stands $4 \mathrm{~cm}$ talt and samples a $47 \mathrm{~cm}^{2}$ araa. The charge on the Teflon is nniform and very stable, resulting in a long detector shelf life. When the electret is screwed into its holder a static electric field is established. The chamber is then placed on the contaninated soil surface. 
Results (tracks per sq $m m$ per h)

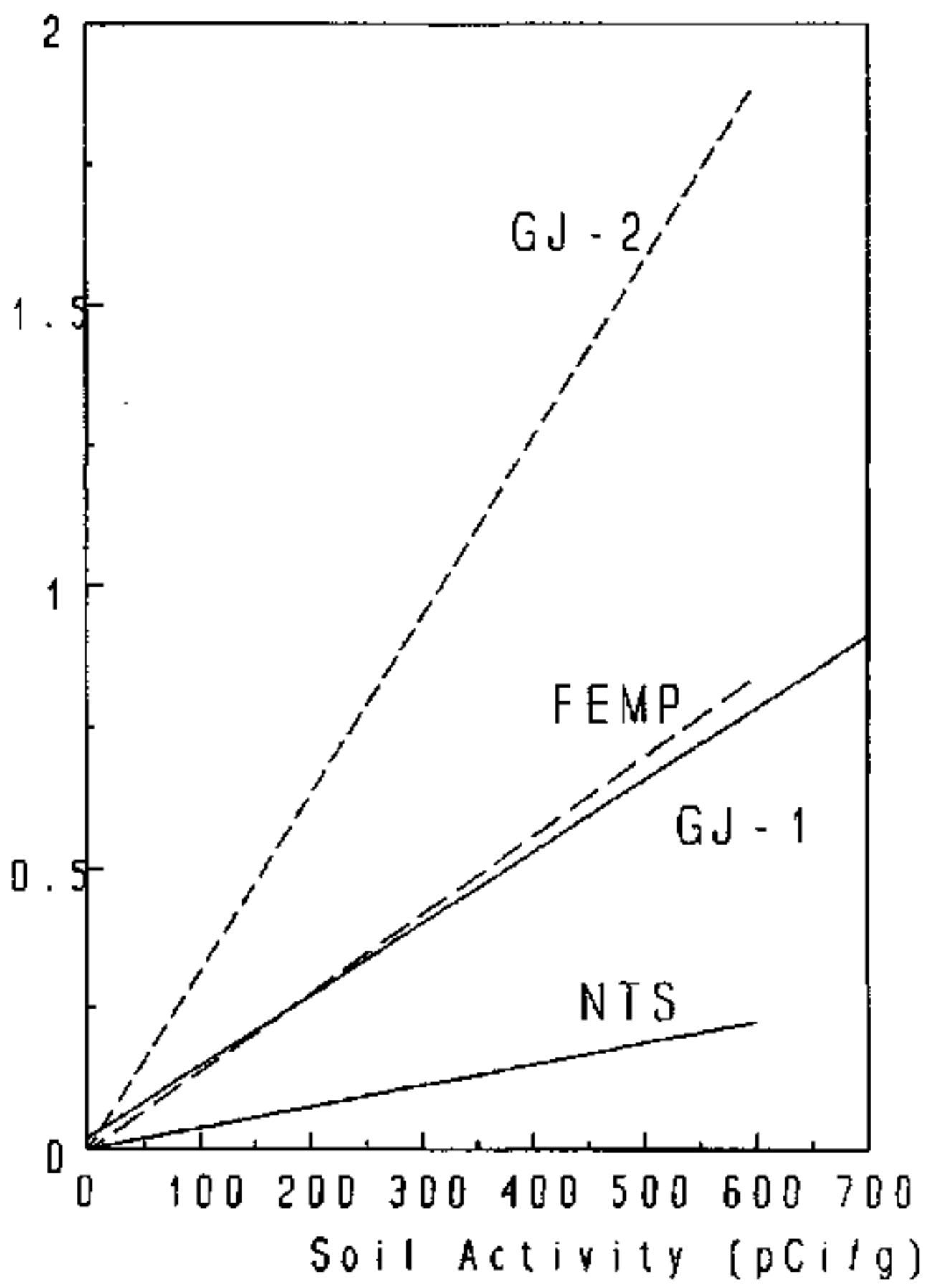

Figure 1. ATD calibration curves (determined by regression) are shown for soil sample sets from four different sites 


\section{OPERATING PROCEDURE}

The protocol for deployment of ATDs on contaminated soil surfaces is:

1) Record detector number, deployment location, and time;

2) Open sealed Mylar bag; strip protective polyethylene films off of detector face and back; place detector (number side down) on the contaminated surface;

3) After desired exposure time ( $1 \mathrm{~min}$ - 24hours), retrieve detector and record retrieval time;

4) Decontaminate detector (if necessary) by rinsing with clean water; allow to air-dry; return to Mylar bag; re-seal the bag;

5) Ship batch of detectors to Landaner, Inc. for analysis;

6) Convert tracks/mm $2 /$ hour to soil activity concentration.

The detector face in proximity to the surface will measure alpha emission due the surface contamination plus environmental radon. The other, or distal, face will measure only alpha emission due to environmental mon. For most situations, Landauer Inc. can provide the results of detector analysis within 48 hours of receipt of the detectors. A prototype mobile field-deployable ATD processing/analysis system is being developed at ORNL for those applications which require more immediate data analysis.

Protocols have also been developed for the proper handling, deployment, and calibration of EICs and a brief summary will be given here. The recommended procedure is:

1) Remove protective electret cap; place electret in voltmeter; record initial voltage, detector number, deployment location, and time.

2) Serew electret into holder and place chamber on contaminated soil surface.

3) In mixed fields (radon, beta, and/or gamma), deploy a paired detector shielded with porous Tyvek material.

4) After the desired exposure time ( $1 \mathrm{~min}$ - 24hours, depending on the centamination level), netrieve detector and record final electret voltage(s) and time(s).

5) Convert net rate of voltage drop to soil activity concentration.

The unscreened detector responds to surface alpha emission, environmental radon, and environmental beta and gamma ractiations, while the screened detector responds to all of these except the surface alpha emission. Therefore taking the difference between the screened and unscrened readings yields the detector response due to the surface alpha contamination alone.

\section{DATA REDUCTION PROCEDURES}

\section{Site-spacific Calibration;}

Preliminary results have shown that there is a generally linear rejationship between EIC or ATD response and bulk soil activity (expressed in $\mathrm{CCi} / \mathrm{g}$ ) when the devices are exposed in the laboratory. As seen in Figure 1, there can be substantial variation among ATD responses to soils froin different sites. Similar results have been obtained with EIC exposures. Therefore, a required element for data analysis is the collection of a set of soit samples from the measurement site. The set of samples should reflect a range of activity concentrations so that after radiochenical analysis is complete, site-spexific calibration exposures can be performed in the laboratory. are taken:

Once a set of soil samples from the site are returned to the laboratory, the following steps

1). The samples are ground in a jar mill to a very fine powder, ensuring uniform distribution of radioactive species. 
2). Petri dishes are filled to a depth of about one inch with ground soil from each sample. ATDs and EICs are exposed to each sample and the response recorded.

3). One or two aliquots from each ground sample is analyzed radiochemically.

4). The ATD responses are regressed (inearly) onto the radiochemical results to determine the linear relationship between ATD response and bulk soil activity. The EIC responses are regressed onto the radicchemical results in the sante manner. Ongoing research is investigating why we find non-zero intercepts in some regression anabyses.

\section{ATD Calculations;}

At the time of the field exposure, the following information must be recorded: the identification number of the ATD, the location of the measurement, and the times at which exposure begar and ended. After laboratory processing, the average track density on the proximal (i.e., toward the soil surface) and distal faces must be recorded. The expression for the relationship between the ATD track deusity measurements and the bulk soil activity is:

$$
\frac{\left(\frac{D-D_{\text {back }}}{T_{f}-T_{i}}\right)-b}{m}=(p C i g)
$$

where

$$
\begin{aligned}
& \text { D = measurement track density }\left(\text { tr/mtm }{ }^{2}\right) \text { on proxinal face } \\
& \mathrm{D}_{\text {back }} \quad=\text { background track density }\left(\mathrm{t} / \mathrm{mm}^{2}\right) \text { on distal face } \\
& \mathrm{T}_{t}-\mathrm{T}_{\mathrm{i}} \quad=\text { elapsed exposure time (minutes) } \\
& \text { b } \quad=\text { site-specific intercept ( } \mathrm{t} / \mathrm{mm}^{2} \text { per minute) } \\
& \text { m } \quad \text { = site-specific slope coefficient }\left(t / \mathrm{mm}^{2} \mathrm{per} \text { mirute } \mathrm{per} \mathrm{pCi} / \mathrm{g}\right)
\end{aligned}
$$

\section{EIC Calculations:}

At the time of the field exposure, the following information must be reconded: the identification namber of the EIC, the location of the measurement, the electret voltages before and after exposure, and the times at which exposure began and ended. The expression for the relationship between the electret voltage readings and the source activity is:

$$
\frac{\left(\left[\frac{V_{f}-V i}{T_{f}-T_{i}}\right] \times N L_{\text {open }}-\left[\frac{V_{f}-V i}{T_{f}-T_{i}}\right] \times N L_{\text {ghielded }}\right)-b}{m}=(p C i / g)
$$

where

$$
\begin{aligned}
& \text { open = open electret measurement } \\
& \text { shielded = electret/Tyvek paper measurement } \\
& \text { NL = nonlinearity correction factor (dimensioniess, see Table 1) } \\
& \mathbf{T}_{1}-\mathbf{T}_{\mathrm{i}}=\text { elapsed exposure time (minutes) } \\
& V_{t}-V_{1}=\quad \text { change in voltage during exposure (V) } \\
& \text { b = site-specific intercept (volts per minute) } \\
& \text { m = site-specific slope coefficient ( volts per minute per } \mathrm{pCi} / \mathrm{g} \text { ) }
\end{aligned}
$$

The mid-point voltage that is used in the nonlinearity correction factor reference tabie (Table 1) is given by: 


$$
v_{\mathrm{mpv}}=\frac{v_{t}-v_{1}}{2}
$$

The nonlinearity correction factors were estimated from experiments using a $29 \mathrm{Pu}$ source with an activity of $7700 \mathrm{dpm}$ (4\%). The correction derived here can be applied for any source. Thirteen electret voltage measurements were made at exposure time intervals of 5.5 minutes. The voltage drop for each time interval was plotted versus the mid-point voltage for each measorement. The measurements were then normalized to the measurement at $V_{\mathrm{MrV}}=400 \mathrm{~V}$. This data was then fit with a polynomial curve of the form:

$$
y=a+b x+c x^{2}+d x^{3}+c x^{4}+f x^{5}
$$

where:

$$
\begin{aligned}
& y=N L \\
& x=V_{\text {Min }}
\end{aligned}
$$

and the fitted coefficients were found to be: $a=1.9555, b=-0.0099419, c=4.487317 \mathrm{e}-5, \mathrm{~d}=$ $1.03644 \mathrm{e}-7, \mathrm{e}=1.18166 \mathrm{e}-10$, and $\mathrm{f}=-5.27881 \mathrm{e}-14$.

Table 1. Nonlinearity Correction Factors

\begin{tabular}{|l|l|l|l||l|l|}
\hline $\begin{array}{l}\mathrm{V}_{\text {MFv }} \\
\text { (volts) }\end{array}$ & $\mathrm{NL}$ & $\begin{array}{l}\mathrm{V}_{\mathrm{MPV}} \\
\text { (volts) }\end{array}$ & $\mathrm{NL}$ & $\begin{array}{l}\mathrm{V}_{\mathrm{MPV}} \\
\text { (volts) }\end{array}$ & $\mathrm{NL}$ \\
\hline 100 & 1.3176 & 325 & 1.0331 & 550 & 0.9739 \\
\hline 125 & 1.2387 & 350 & 1.0250 & 575 & 0.9704 \\
\hline 150 & 1.1798 & 375 & 1.0172 & 600 & 0.9670 \\
\hline 175 & 1.1366 & 400 & 1.0097 & 625 & 0.9360 \\
\hline 200 & 1.1050 & 425 & 1.0025 & 650 & 0.9573 \\
\hline 225 & 1.0820 & 450 & 0.9953 & 675 & 0.9482 \\
\hline 250 & 1.0652 & 475 & 0.9888 & 700 & 0.9336 \\
\hline 275 & 1.0523 & 500 & 0.9830 & 725 & 0.9110 \\
\hline 300 & 1.0419 & 525 & 0.9781 & 750 & 0.8769 \\
\hline
\end{tabular}




\section{APPENDIX E: FIELD DEMONSTRATION OF THE NaI, FIDDLER, and XRF DETEC TORS}

Fernald Enviormmental Restoration Management Co.

\section{DISCUSSION OF DETECTOR THEORY}

\section{NaI and FIDDLER Detects.x;}

Thallium activated sodium iodide [NaI(TI)\} scintillation material has been used since the early 1950 s and remains the most popolar scintillation material used for photon detection. Scintilbation detectors rely on the uncharged photon undergoing an interacticn that transfers the photon energy to an electron in the absorbing material. The electron's kinetic energy is then converted to a detectable flash of light. The light or seintilation is detected by a photomultiplier tube. The photomultiplier tube is required to convert the light into an electrical pulse which can then be courted on an appropriate meter. A schematic exhibiting this theory is shown in

Figure 1.

Although uranium is primarily an alpha emitter, it also emits characteristic $\gamma$-rays when it decays. These photons are of low energy, ranging from $48 \mathrm{keV}$ to $205 \mathrm{keV}$, which may be attenuated by surface soils, limiting the depth at which the detector is effective.

Figure 1.

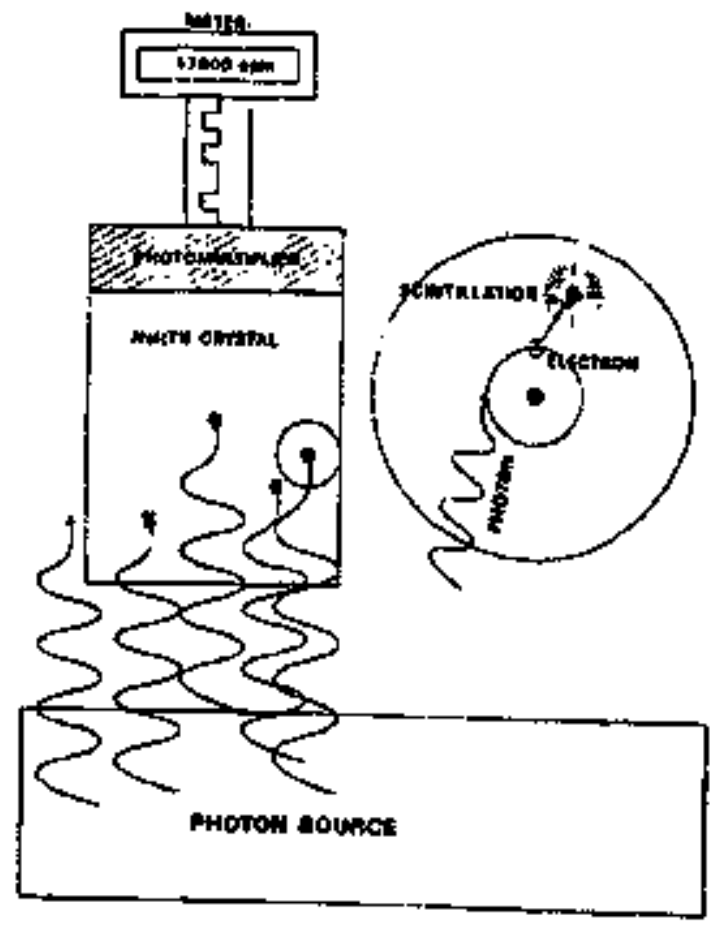

\section{X*ay Fluoresence Detector}

The Spectrace $9000 \mathrm{X}$-ray fluorescence andlyzer (XRF) is a field portable instrument capable of real-time in-situ qualitative and quantitative determination of elements above and including sulfur (with the exception of transuranics) in the periodic table, any of which may be present in a solid, liquid, or powder sample. The sample analysis quantifies the detected elements in parts per million (ppm) for the primary sample matrix applications. Parts per million of uraning can effectively be converted to picocuries per gram $(\mathrm{pCi} / \mathrm{g})$ by multiplying the value in $\mathrm{ppm}$ by 0.6757 . 
During analysis, one or mone of the three sources ( ${ }^{55} \mathrm{Fe},{ }^{109} \mathrm{Cd}$, and $\left.{ }^{24 i} \mathrm{Am}\right)$ may be exposed to the sample one at a time, thereby emitting $x$-radiation of sufficient energies to cause affected atoms to fluoresce or emit $x$-ray photons of characteristic energy. An $x$-ray photon striking the biased mercuric iodide crystal loses energy in the crystal through producing electron-hole pairs. The electric charge produced is collected and provides a current pulse that is directly proportional to the energy of the $x$-ray photon absorbed by the crystal. By anatyzing this current, both the identity and the quantity of the elements present in the sample can be detenmined by the XRF electronics unit. The minimun detection limit (MDL) for most analytes falls between 50-100 pprn. Typically, the larger the atomic number ( $($ ) the lower the MDL, for the XRF. For example, the MDL for cobalt ( $Z=27)$ is $101 \mathrm{ppm}$, for thorium $(Z-90)$ is $15 \mathrm{ppm}$, and for uranium $(Z-92)$ is $10 \mathrm{ppm}$.

\section{DETECTOR DESCRIPTION}

\section{NaICTI) $2 \times 2$ Detector}

The NaI(Tl) $2 \times 2$ Detector is a NaI(Tl) erystal with the shape of a right cylinder 2 inches high by 2 inches in dianieter. This crystal is optically coupled to a photomultiplier tube. The output of tie photomaltiplier is connected to a survey meter. This detector is small enough, $2 \mathrm{lbs}$ (.91 kg), to be used as a portable detector. The specifications for the scintillation probe used for the survey are listed in Table 1.

The NaI(Tl) detector with the above dimensions is able to detect photons with energies ranging from $60 \mathrm{keV}$ and above. This detector is limited in its ability to differentiate radiation sources. This detector will count all energies of $\psi$-rays inclading cosmic radiation and shine. In order minimize the effect of shine and cosmic radiation on the gamma measurements, a $3 / 16^{\circ}$ thick lead shield is placed around the circumference of the active portion of the detector.

\section{FIDLER (Field Instrument for Detecting Low Energy Radiation)}

The FIDLER operates with the same theory as the NaI(T) $2 \times 2$ detector with the exception of the NaI(T1) crystal dimensions. The NaI(T) crystal used in the FIDLER is only .063" (1.6 mm) thick. This decreases the probability of a high energy Fhoton from interacting in the scintillation material. This allows for the detector to count low energy photons without the unnecessary counting of high exergy photons. The FIDLER radiation ertrance window is $5^{n}$ diameter. The specifications for the FIDLER probe are listed befow:

The FIDLER is used in the same manner as the $2 \times 2$ detector. The difference is that the FIDLER can detect photons with energies as low as $10 \mathrm{keV}$. The efficiency of this detector decreases as the photon energy increases. This allows for increased detectabjlity of uranium. The problems associated with the "shine" from surrounding radiation sources are not evident when the FIDLER is used due to the FDLER being a thin crystal detector.

\section{X-ay Elumesence Detectio:}

The XRF is composed of two primary components incluting a probe and an electronics unjt. The probe consists of a sealed aluminum enclosure containing a high resolution mercuric iodide detector and three sealed radioisotope $x$-ray excitation sources. Also included in the probe is a pre-amplifier and bias supply for the detector and a mechanism to move the radjoisotope 8ourtes from their shielded location during analysis.

The electronics unit of the Spectrace 9000 provides data acquisition, processing, and display capabilities. The unit utilizes a fundamental parameter XRF calibration derived from theoretical considerations (as opposed to empirical data). The ment driven software supports multiple 
Table 1.

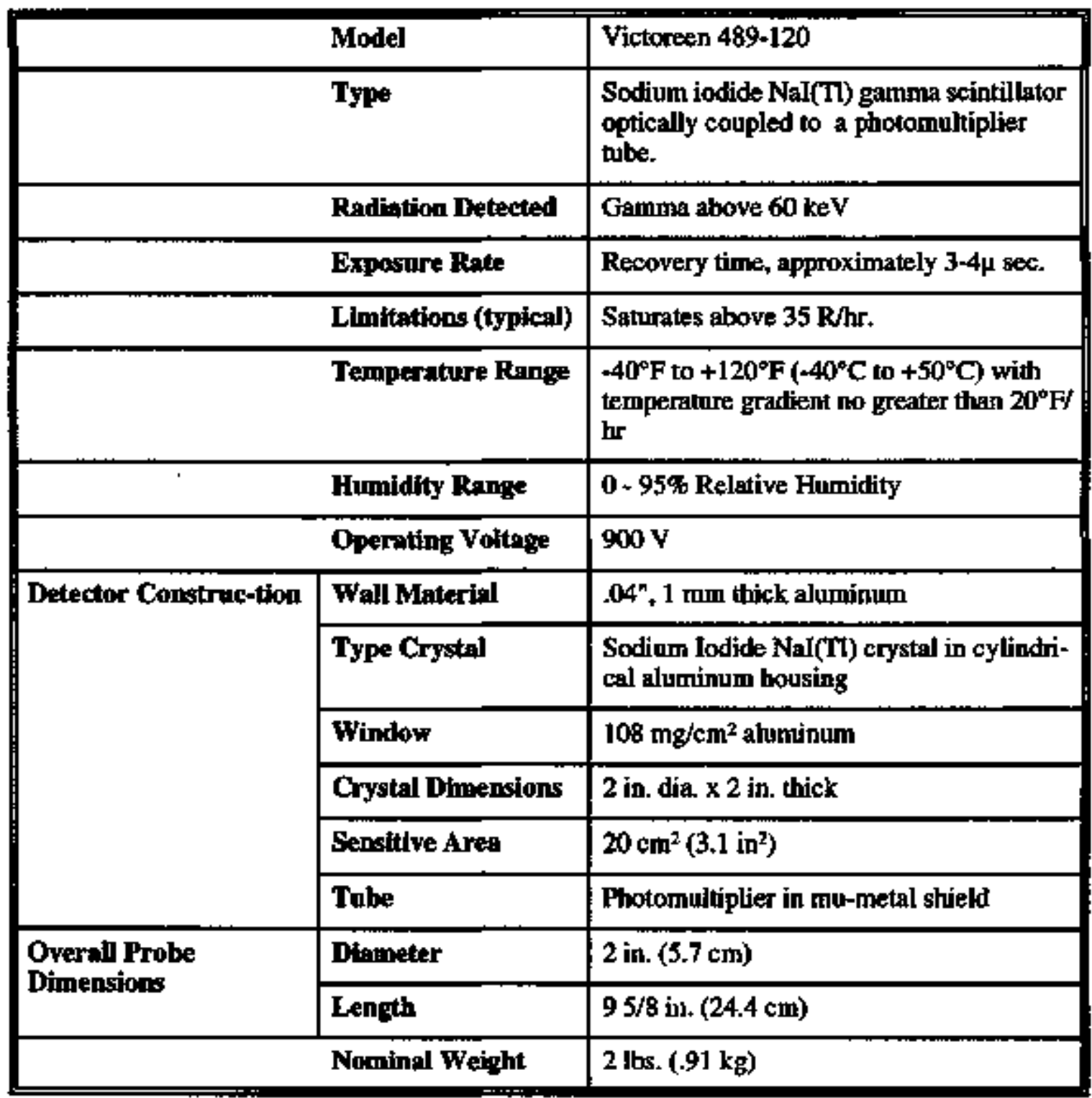

XRF calibrations called "Applicatioas." Each Application is a complete anslysis configuration including elements to be measured, interfering elements in the sample, and a set of fundamental parameter calibration coefficients. The Applications cutrently available on the XRF include "Soils with $U$ and Th", "Asphalt", "Water", "PbK in Paint", and "Pt in Paint."

\section{OPERATING PROCEDURE}

Specific details for the operation of the NaI and Fiddler detectors are contained in FERMCO Procedure EP-REM-001, "Use of Victoreen Thyac V Survey Meter Model 190 with Communicator and NaIT(T) Probes for use in Surface Soil Surveys."

Specific details for the operation of the X-ray Fluorescence Analyzer is contained in FERMCO Procedure EP-CRU3-006, "Operation of XRF Analyzer."

\section{CONVERSTON OF FIELD MEASUREMIENTS}




\section{Table 2.}

\begin{tabular}{|c|c|c|}
\hline \multicolumn{2}{|c|}{$\begin{array}{l}\text { Model } \\
\end{array}$} & \multirow{2}{*}{$\begin{array}{l}\text { Rexon } \\
\text { Sodium iodide NaI(Tl) gamma scintilator op- } \\
\text { tically coupled to a photomultiplier tube. }\end{array}$} \\
\hline & Type & \\
\hline & Radiation Detected & $\begin{array}{l}\text { Gamma and } X \cdot r a y>10 \mathrm{keV} \text { to approx. } 200 \\
\text { keV }\end{array}$ \\
\hline & Detectobility & $\begin{array}{l}330 \mathrm{cpm} / \mu \mathrm{CV} / \mathrm{m}^{2} \text { for } 60 \mathrm{keV} \text {, and } 640 \mathrm{cpm} / \mu \mathrm{CV} / \\
\mathrm{m}^{2} \text { for } 17 \mathrm{keV}\end{array}$ \\
\hline & Temperature Ronge & $-40^{\circ} \mathrm{F}$ to $120^{\circ} \mathrm{F}\left(-40^{\circ} \mathrm{C}\right.$ to $\left.50^{\circ} \mathrm{C}\right)$ \\
\hline & Operating Voltage & $120 \mathrm{~V}$ \\
\hline \multirow[t]{5}{*}{$\begin{array}{l}\text { Detector } \\
\text { Constraction }\end{array}$} & Type Crystal & $\begin{array}{l}\text { Sodfum Iodide NaI(Tl) erystal in cylindrical } \\
\text { aluminum housing }\end{array}$ \\
\hline & Crystal Dituensions & $5^{\prime}$ dis $\times 0.060^{\prime \prime}$ thick \\
\hline & Window & $.002 "$ alominum \\
\hline & Trube & $\begin{array}{l}\text { Photomultiplier 3" dia. SRC\#875801 or Equiv- } \\
\text { alent }\end{array}$ \\
\hline & Wㅔ Material & Light shield mu-metal .040" thick \\
\hline Overall Probe & Ditumeter & $6 \mathrm{in.}$ \\
\hline Dimenstons & Length & $83 / 4$ in. \\
\hline
\end{tabular}

In general, field measurements are converted to pCV/g total Uranium through detector calibration. Appropriate calsbration curves will be developed using the calibration soils provided by the ID Demonstration Program. 


\section{APPENDIX F: DATA MANAGEMIENT PLAN}

(This section has been omitted from this data neport; see Appendix B.) 


\subsection{Sampling Plan}

Randomization of sample information is necessary to make probability or confidence statements about the results of statistical analyses. Pure random sampling with a limited number of points faces the possibility of localized spatial clustering of points (purely by charxe) that produces information redundancy. Yet, systematic sampling with a random initial point provides for a distribution of samples over the entire study area because the sample points follow a simple pattern and are separate by a fixed distance.

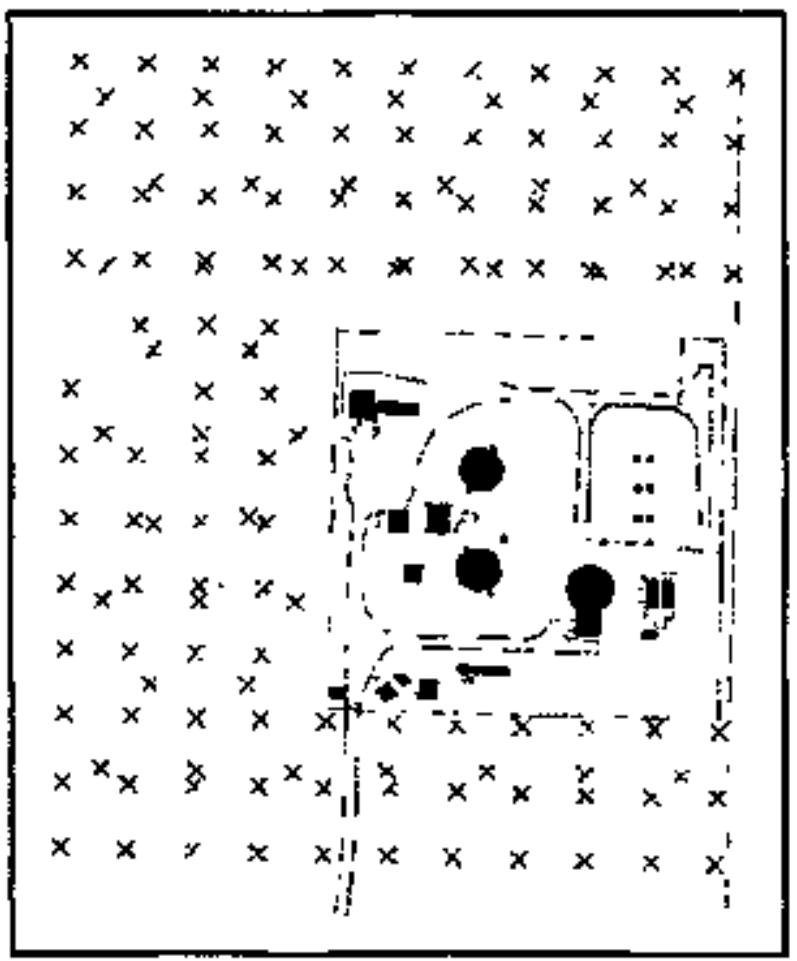

Figure 1.0 Sampling locations (example only)

Although "traditional" statistical approaches to sample analyses impose strict requirements pertaining to grid design and number of samples collected, this is not the case with the geostatistical/decision analysis approach proposed to be used during the USW. Althought, as an initial point of reference and to provide options for future "traditional" analyses, the sampling grid network proposed will follow a traditional, but modified, systematic sampling pattern. In this sense the number of exploratory sampling locations will be slifficient to provide a 95-percent probability that the maximum value sampled will equal or exceed the 95th percentile of the unknown underlying distribution, using a robust method presented by Barnes (1988). Of course, these are requirements that satisfy only one statistical test, but this test serves the purpose of investigating a site like Femald where the point of the investigation is to determine the extreme values with some degree of confidence. These extreme values are considered to be associated with some degree of 
failure, such as exceeding a regulatory cutoff criteria. Of course, like most statistical tests, the samples that describe the system are assumed to be independent (uncorrelated), whereas previous work at Fernald (1993) has already identified spatial correlation among Uranium contaminated soil samples.

The systematic sampling network will be modified in the sense that specific spatial scaks for sampling need to be examined to define the geostatistical variogram models used to characterize the correlational structure between saraples. The number of exploratory samples required is currently anticipated to range from $50-70$ samples for an area between 10-15 acres. It is anticipated that a sampling configuration similar to that shown in Figure 1.2 will be used to evaluate each texhnology at the exploratory level of this study. The results of the geostatistical/decision analysis will goide the collection of any subsequent samples, as required specifically by each technology to complete contaminate characterization of the site.

\subsection{Data Analysis and Interpretation}

All the geostatistical software pakages mentioned earlier require structured ASCII data files, yet data are read without specific format criteria (i.e. free-format, space delimited). The basic required database line structure for each sample location, therefore, is as follows: $x$ (easting) coordinate, $y$ (northing) coordinate, attribute. The database may be developed in any convenient manner so that extracting this structure is a simple task.

\begin{tabular}{|c|c|c|c|}
\hline SampleID & $x$-coord. & Y-coord. & Total UpCig \\
\hline Fsơfi & $148725 \times 6.13$ & $5 \overline{2913.68}$ & 4522 \\
\hline F\$0012 & 1487356.34 & 535013.92 & 30.97 \\
\hline FSO013 & 1487466.65 & 53511412 & 100.32 \\
\hline
\end{tabular}

Figure 2.0 Required data format for geostatistical anatysis

There are four field data components that must maintain a high level of precision and accuracy throughout the entire analysis process. First, the coordinate location of the field measurement must be verifjed and maintained throughout the analysis process. Cortuption of this key component would be extremely detrimental due to the spatiat emphasis of the analysis procedures. Secondly, the reported field measurements must be reduced to a consistent unit of measurement for direct comparison between sample locations and competing technologies. This plan assumes that all transformations/reductions in the field measurements required to meet these consistencies will be performed by the field technician and also that these values ate accurate, following verification of felecommunication transmission. Thirdly, each sample must be identified by a unique and distinguishing name that will have nomenclature that is conducive to database queries and general visual screening. Finally, if the technology used in sampling cannot be identified through the naming convention, then it must be indicated and maintained as a separate field for each sample collected. 
Following the completion of the exploratory sampling for a given technology, sample results will be received and verified via a telecommunication link between the Fernald Site and SNL. Geostatistical analyses will then be performed on the data set. This approach will typically involve developing univariate summary statistics and probability (histogram) plots from the raw information and evaluating any potential errant or cutlier values. The data will then be transformed into normal-scores space to giarantee the gaussian (normal) distribution required for stochastic modeling of the areal distribution of contamination.

Depending upon the selected study site, the surficial soil contamination may have an anisotropic component to the spatial correlation of samples. Such characteristics may be attributed to such natural processes as prevailing wind directions or preferential erosional patterns. If this anisotropy is deemed to be significant, it will have to be characterized and incorporated into the spatial correlation (variogram) model for the specific technology under study.

Data analysis mentioned above will be accomplished using a number of geostatistical software and other specifically developed programs including EPA's GEO-EAS, FSS TOOLBOX, and GSLIB. Following the variogram model development, several stochastic models will be developed to reflect the areal distribution of contamination as defined by the exploratory sampling from the specific technology. Each stochastic model, or realization, will be developed using the Sequential Gaussian Simulation technique contained in the GSLIB software package and each will equally reflects the spatial and statistical attributes of the available data. Because each stochastic model is equiprobable, generating a large number of model outcomes allows for developing a probability frequency in the modeled autcome for any particular unsampled lacation within the study domain, thereby assessing the uncertainty resulting from the model given the current data representation.

Potentially 3 to 5 stochastic realizations will be mapped with accompanying summary statistics in the form of graphs, tables, and/or plots to provide validation of the simulation model for each technology. The resulting uncertainty assessment provided through postprocessing of the stochastic modeling, as prevecusly mentioned, will be used to drive the decision analysis portion of the study and determine the need for additional sampling efforts and their optimal location for collection.

\subsection{Performaance. Assessment/cost Risk Analysis}

As discussed in Section 2.0, the data will be analyzed within a geostatistical framework to ultimately provide maps reflecting uncertainty in the modeling of surficial soil contamination. These maps will then be used in conjunction with decision analysis methodologies to determine optimal selection of additional samples, with the ultimate goal being a reduction in the risk of a wrong interpretation based on limited data.

The geostatistical component of this study requires fundamental statistical data analysis, an exercise in data transformation, and two levels of modeling. Summary statistics from the exploratory sampling information will be developed to evaluate basic behavior of the population characterized by the data. These surmmaries will reflect such things as the mean, 


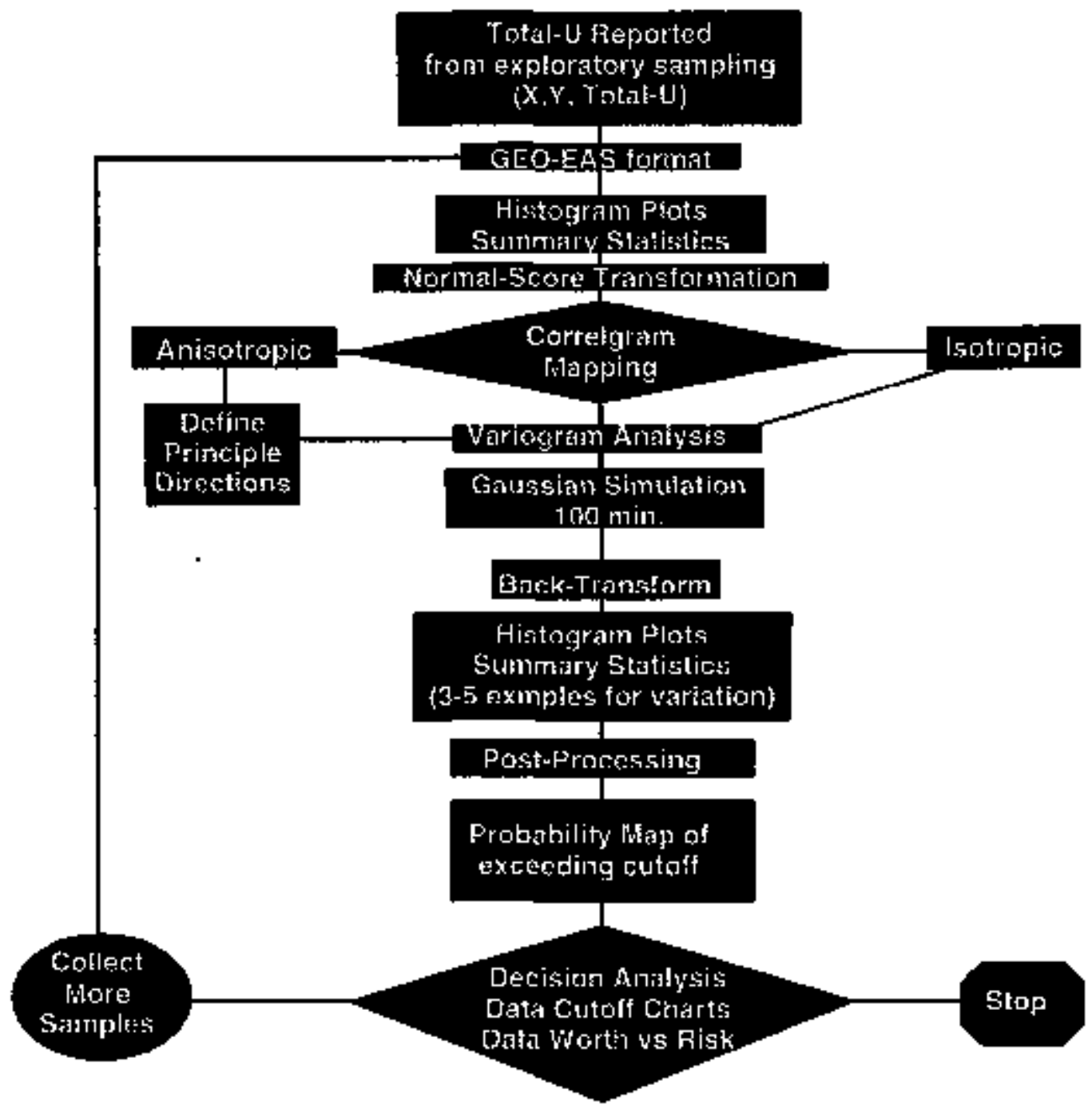

Figure 2.1 Geastatistical data analysis process flow

standard deviation, the sample frequency distribution (histogram) and it's behavior (skewness, quartile ranges, etc.). Figure 2.1 exhibits the geostatisitcal data analysis process flow,

The current intent is to employ a gaussian-related simulation algorithm to provide stochastic modeling of the sample data. This procedure requires that the population described by the data have a normal distribution. This normality will not likely be the case in the raw field data, but a simple transformation (normal-score) can insure the condition. The transformed data will then be subjected to an analysis of their spatial correlation (variography) to determine how the variance between all sample points can be expected to change as a function of their separational distance and direction. This information is analyzed graphically in the form of a variogram and subsequently a linear model is fit to the graph to reflect the variogram behavior.

The parameters that define the variogram model are then used to constrain the stochastic modeling (sequential gaussian simulation) of the areal distribution of contamination. 
Currently a minimum of 100 simulations are proposed to model "reality" as presented by each competing technology. Each simulation is conditioned to the existing data and provides an equiprobable representation of spatial distribution of contamination.

Following back-transformation of the data, the suite of simulations will be processed to develop an understanding of the probability that any particular location could exceed a predetermined cutoff (performance) criteria. It is this appreciation of uncertainty that will be used to optimize additional sampling efforts and also provide quatifying information on the performance of the technology via decision analysis methods.

\subsection{Data Eyaluation and Transfer to EERMCO}

Following the evaluation of uncertainty in the exploratory sampling modeling results, additional data may be required by the field technology to complete the interpretation for a desired degree of confidence. In these instances, the performance assessment team will direct FERMCO as to the number and location of any subsequent sampling efforts. Locations for additional sampling will be provided through appropriate coordinates. 


\section{Sandia National Laboratories \\ Albuquerque, New Mexico 87185}

date: April 1, 1994

from: V.C. Tidwell

to: atstribution

subject: FY-94 Field Demonstration Project Plan

Enclosed you will find a copy of the FY.94 Field Demonstration Projext Plan. The denonstration plan was developed based on our past diseussions, meetings, and review comments. If there are questions or comments concerning the plan please contact me. I will be in cootact with each of you as time nears for the demonstration.

copy to:
A. Arustrong (ORNL)
M. Anderson (Ames)
J. Bounds (LANL)
J. Cunnane (ANL)
C. Dudney (ORNL)
P. Kaplan (SNLA)
K. Nahfer (FERMCO)
D. Mortis (LANL)
S. Lee (ORNL)
D. Perry (LBL)
A. Schilk (PNL)

(Copy of original letter transmitting Project Plan to technology developers.) 
Appendix B: Data Management Plan 


\section{Data Management Plan}

The "Uranium in Soils Integrated Demonstration Field Characterization - Spring 1994 Data Management Plan" that follows was developed originally to guide the collection and transmission of data from the Fernald site to Sandia National Laboratories and back. The report is reproduced as it appeared at the beginning of the field characterization demonstration program. No editing of revisions have occurred to modify this planning document to reflect in-field changes or grammatical errors. 


\section{Uranium in Solis Integrated Demonstration Field Characterization - Spring 1994 \\ Draft Data Management Plan}

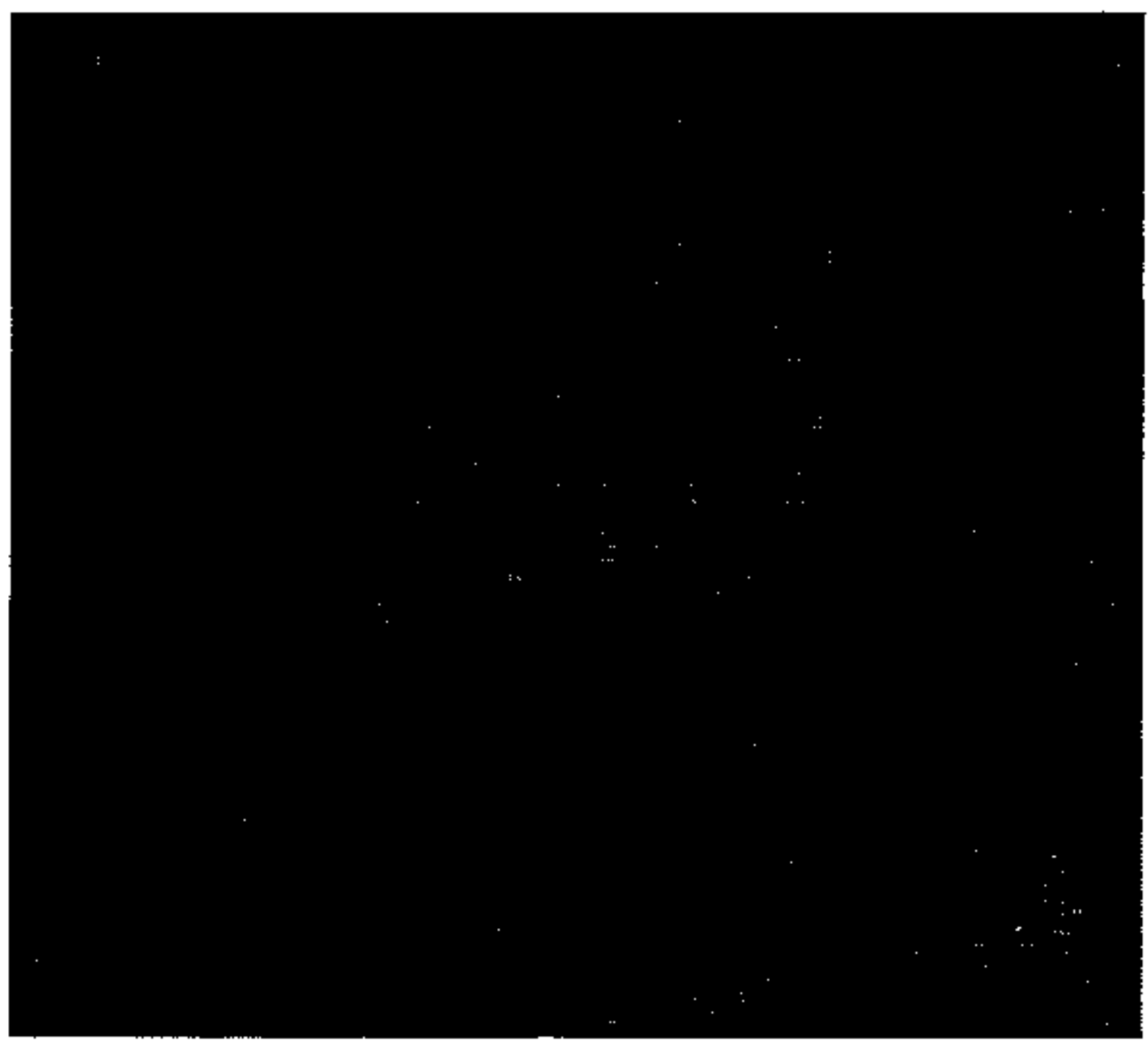

Figure I. I. I Femald Site.

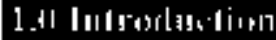

The Uranium in Soils Integrated Demonstration (USID) program was developed to help improve the detection and remediation of uraniurn cantaminated soils by demonstrating reliability, effectiveness, cost savings, and applicability under various environmental conditions. How each techrology performs influences the risk level, which will in turn influence how it is accepted by the public and the regulator. 
The majority of data collected for the USID 1994 Field Characterization Demonstration will be directly from various technologies" field measurements of surface uranium concentrations. Other collected data will be based on laboratory analysis of soil samples. A description of the technologies and methodologies used to detect uramium in soil is contained in the Measurement and Analysis Technologles section of the Field Demonstration Project Plan (May 1994). The quality objective for data management of the USD Field Characterization program is to provide a framework for maintaining validated and verifiable information.

The collection and analysis of data from the field and laboratory needs to be scientifically accurate and legally defensible. This requires the development of a data base that maintains and links both raw and transformed data. The procedures and requirements for assuring data quality are outlined in this data management plan. The plan is drafted in accondance with the guidance contained in Appendix F of the DOE Environmental Survey Mankal (DOE 1987).

\subsection{Sill IJ:v'rijution}

Fomaidd Environmental Management Project (FEMP) is located in southwestern Ohio approximately 18 miles northwest of Cincinnati near the communities of Mamitown and Ross. The site covers an area of 1050 acres of which 850 acnes are in Hamilton County and 200 acres are in Butler County. Of the 1050 acres, 136 acres encompass the former processing plant area. Figure 1.1.1 is a 1988 aerial photo of the Femald Site. Figure 1.1.2 is the approximate location of the USID Field Characterization Denonstration.

Fernald was built in the early 1950s' for the purpose of processing uranium and its compoumds from natural ore for use in government defense programs. Full operation of the processing plant began in 1952 with peak production occuring in the early 1960s. By the mid-1960's production declined and by 1989 production of uranium ore stopped. Since 1991 the mission of Fernald has focused on waste managetnent and environmental restoration of the sitc.
The majority of soils containing uranium exceeding $35 \mathrm{pCi} / \mathrm{g}$ are located within the top 1.5 feet of surficial material which consists predominantly of glacial till and includes sand, silt and clay. Approximately 50 percent of the production area soils contain contamination exceeding $35 \mathrm{pCi} / \mathrm{g}$.

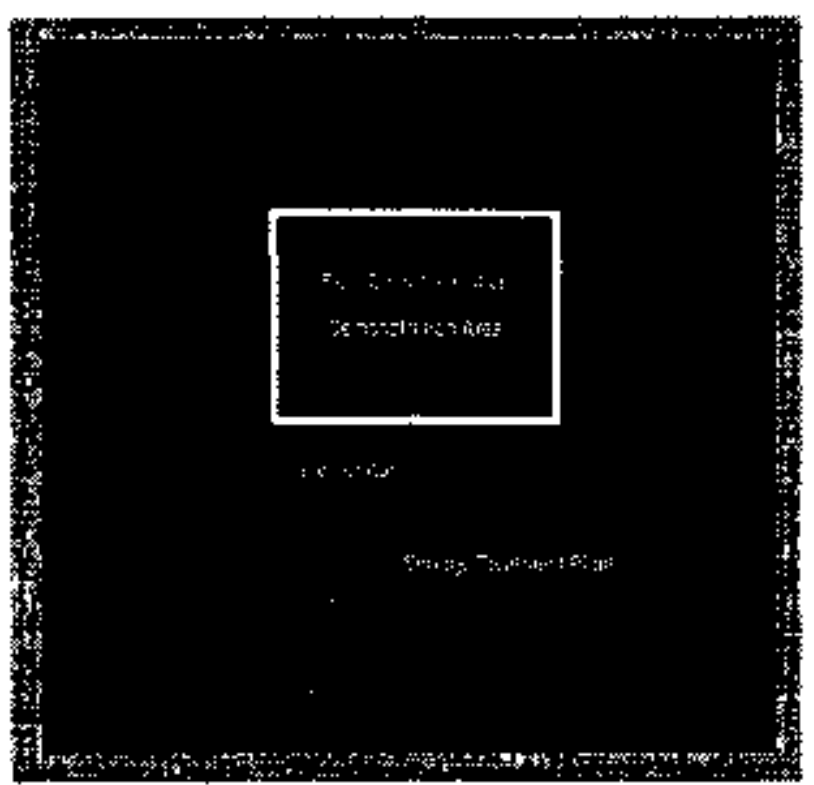

Figure J.J.2 Field characterization location.

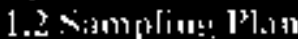

Randomization of sample information is necessary to make probability or confidence statements about the results of statistical analyses. Pure random sampling with a linited number of points faces the pessibility of localized spatial clustering of points (purely by chance) that produces information redundancy. Yet, systematic sampling with a random initial point provides for a distribution of samples over the entire study area because the sample points follow a simple pattem and are separated by a fixed distance.

Although "traditional" statistical approaches to sample analyses impose strict requirements pertaining to grid design and number of samples collected, this is not the case with the geostatistical/decision aralysis approach to be used during the USID. Although, as an initial point of reference and to provide options for future 
"traditional" analyses, the sampling grid network proposed will follow a traditional, but modified, systematic sarrpling pattem. In this sense the nurnber of exploratory sampling locations will be sufficient to provide a 95-percent probability that the maximum value sampled will equal or exceed the 95th percentile of the unknown underlying distribution, using a robust method presented by Bames (1988). These requirements satisfy only one statistical test, but this test serves the purpose of investigating a site like Femald where the purpose of the investigation is to determine the extreme values with some degree of confidence.

These extreme values are considered to be assspciated with sonne degree of failure, such as exceeding a regulatory cutoff criteria. Like most statistical tests, the samples that describe the system ane assumed to be independent (uncorrelated), whereas previous work at Fernald (1993) has already identified spatial correlation arpong uraniurm contarninated soil samples.

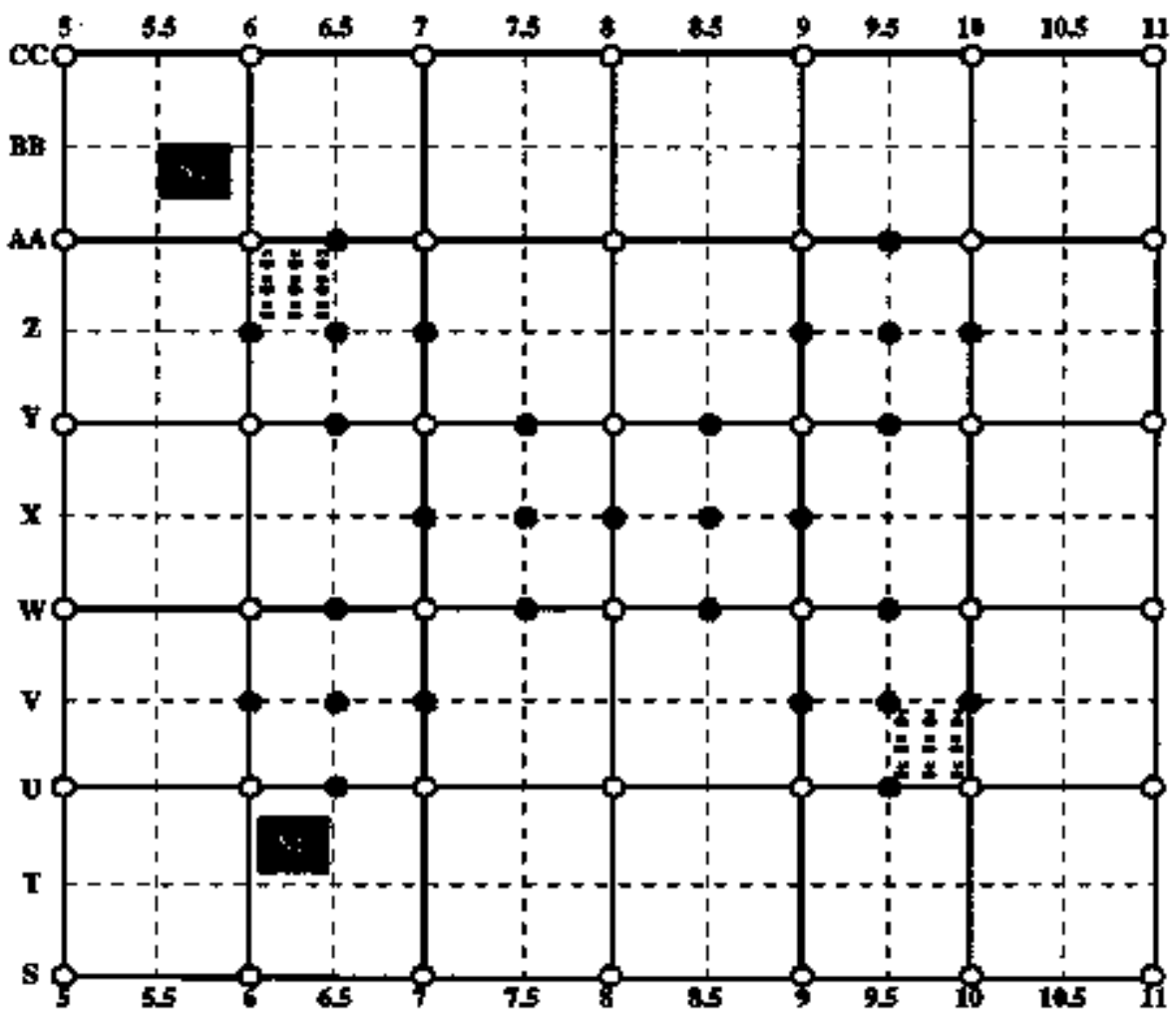

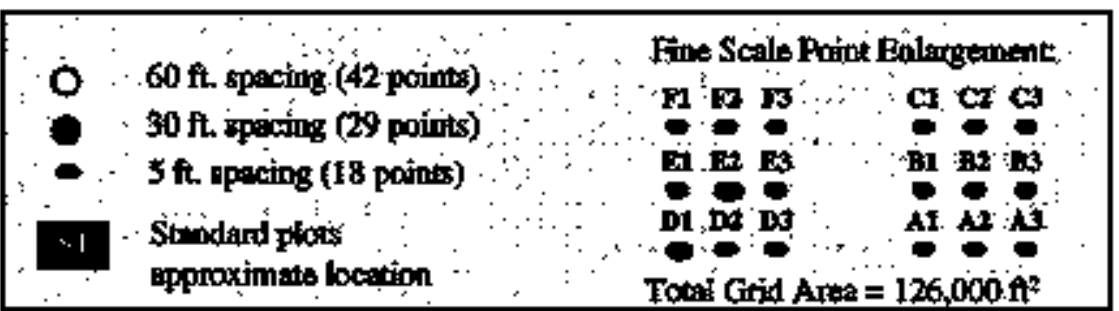

Figure J.2 Field characterization measurement locations. 
The systematic sampling network will be modified in the sense that specific spatial scales for sampling need to be examined to define the geostatistical variogram models used to characterize the correlational structure between samples. The number of exploratory measurements requirod is curremtly anticipated to 89 over an anea approximately 2.9 acres. It is anticipated that a sampling configuration simitar to that shown in Figure 1.2 will be used to evaluate each technology at the exploratory level of this study. The results of the geostatistical/decision analysis will guide the collection of any subsequent samples, as required for each technology to complete contaminate characterization of the site.

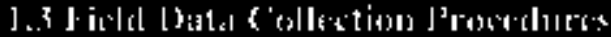

Field data will be collected from three separate instrument measurements (calibration of instruments, standards plots measurements and field (grid) measurements) and from field candition readings. Requirements for instrument measurement data collection, ircluding a description of each data field, naming conventions, data units, data precision, and frequency of reporting are in Appendix A. Specifications and Guidelines for Instrument Measurement Data Collection.

Calbration bed measurements. First, data are collected during calibration of detectors. Calibration is necessary to improve comparability of data derived by different measurement techniques. Each detector will measure the four calibration bed soils at least three times during the course of the survey - 1) prior to field measurements, 2) ofter completing the baseline survey, and 3) following completion of the field characterization exercise. Figure 1.2 exhibits the general location of the four calibration beds.

It is very important that we know bow the data is converted from the instrument counts to total uranium in $\mathrm{pCV} / \mathrm{g}$ and how it is converted between total uranium and U-238. Al] data collected from calibration bed measurements must show formula for any converșion applied to the raw dati.

Field conditions will be reconded at the time calibration plots are measured. The following field condition data will be obtained by FERMCO staff from mensurements routinely recortied at the FEMP meterrological tower. temperature, bumidity, wind speed, wind direction, and time. Figure 1.3.1 summarizes the frequency of instrument measurements and field condition data associated with each measurement.

Standands plots measurements. The second instrument measurement will be from standards plots measurements recorded twice daily. The standards plots will be used for making nepeated detector measurements, thus quantifying detector precision as affected by instnument drift and changing environmental conditions. Figure 1.2 exhibits the genernl location of the two standards plots.

It is very important that we know how the data is converted from the instrument counts to total uranium in $\mathrm{pCl} / \mathrm{g}$ and how it is converted between total uranium and U-238. All data collected from standands plots measurements must show formulae for any conversion applied to the raw data.

Field conditions will be recorded at the time standards plots are measured. The following field condition data will be obtained by FERMCO staff from measurements routinely reconded at the FEMP meteorological tower: tempersture, humidity, wind speed, wind direction, and time. Figure 1.3.I summarizes the frequency of instrument messurements and field condition data associated with each measurement.

Fleld (grid) measurements. The third event where data will be generated is during the field (grid) measurements. Prior to initiation of field dats collection a baseline grid will be marked and surveyed consisting of 89 measurement points. Fineld measurements will be taken on the 89 baseline grid points and will continue to be collected and analyzed until information worth of additional samples is less than cost to collect them. 
Figure 1.2 exhibits the layout of the grid points and grid point names.

It is very important that we know bow the data is converted from the instrument counts to total uranium in pCifg and how it is converted between total uranium and U-238. All data collected from field measurements must show formulat for any conversion applied to the raw data.

\begin{tabular}{|c|c|c|c|}
\hline $\begin{array}{c}\text { Meanourement } \\
\text { Typa }\end{array}$ & $\begin{array}{l}\text { Dato } \\
\text { Type }\end{array}$ & Frequency & $\begin{array}{l}\text { Flald Condhlons: } \\
\text { Reoonded }\end{array}$ \\
\hline calbration aede & cal & 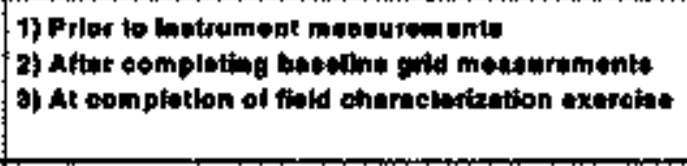 & 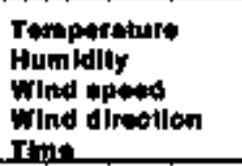 \\
\hline Standarde Plota & STD & Twlos wath day & 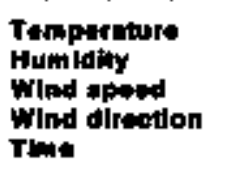 \\
\hline 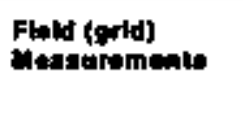 & FLD & 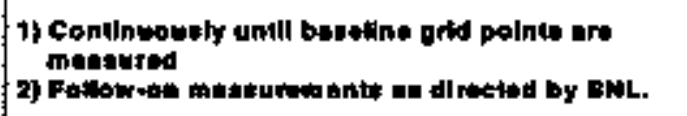 & $\begin{array}{l}\text { Linked to Fedep } \\
\text { Notepr, tower } \\
\text { fireld conditione }\end{array}$ \\
\hline $\begin{array}{l}\text { Letal Fild } \\
\text { Condition: }\end{array}$ & & Ones weoh day & 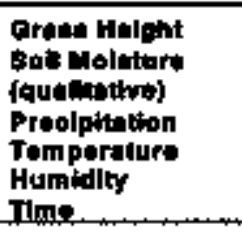 \\
\hline $\begin{array}{l}\text { Uot:par-ofogled| } \\
\text { Iower inld } \\
\text { eonditions }\end{array}$ & & 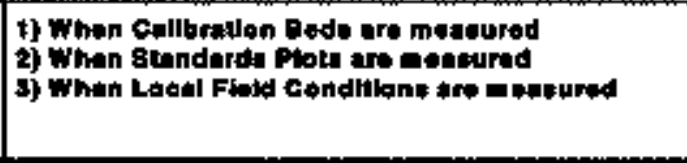 & $\begin{array}{l}\text { Tamporature } \\
\text { Mumbelty } \\
\text { Wind apend } \\
\text { Wind directlon } \\
\text { Time }\end{array}$ \\
\hline
\end{tabular}

Figure 1.3.1 Sumnary of data collection.

Field condition measurements. In addition to field condition data obtained during calibtation bed measurements and standards plots measurements, grass height, soil moisture (qualitative), ternperature, bumidity, and precipitation (over a 24 hour period) will be measured locally at the field characterization site once each day by the Project Engineers. The Project Engineers will compile a list of times that correspond to these measurements so that field condition data can be related to instrument measurements. Figure 1.3.1 summarizes the frequency of instrument measurements and field condition data associated with each megsurement. The technology developers are responsible for obtaining calibration plots measurements, standards plots measurements and field (grid) measurements. The Project Engineer is responsible for accurately recording field conditions at the speciffed intervals. Instrument measurement data and field condition data must be provided to the Field Data Coordinator at the end of each day on

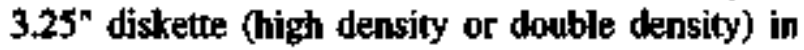
ASCII format and follow all requirements described in Appendix $A$. The Field Data Coordinator must verify the data files meet the required described in Appendix A. Figures 1.3.2 and 1.3.3 exhibit the data collection templates for instrument measurements and field conditions. 


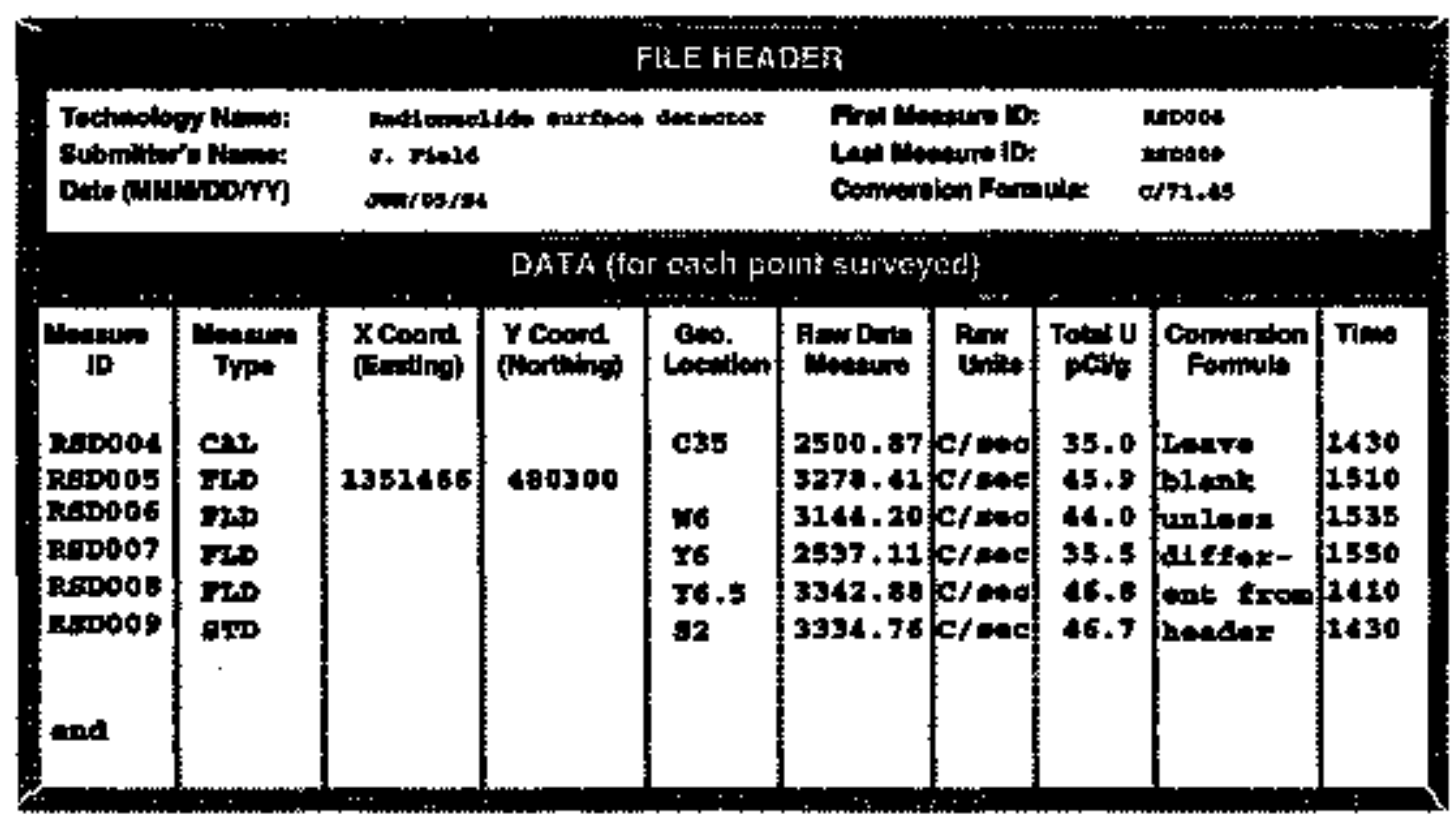

Figure 1,3.2 Instriment measurement data collection template.

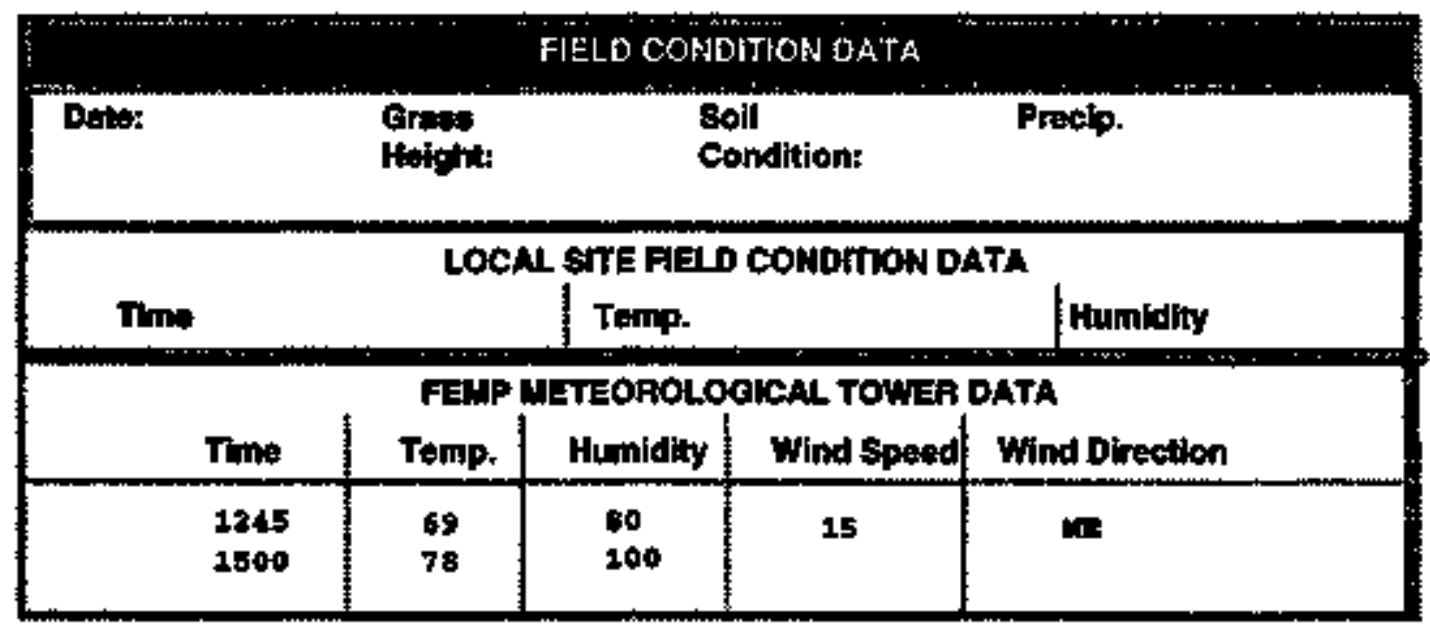

Figure 1.3.3 Field condition data collection template.

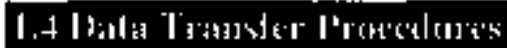

Instrument measurement data will be provided at the end of each day to the Field Data Courdinator in the format specified in Appendix A. The data will then be transferred to Lane Yarrington at SNL via modem by the Field Data Coordinator at the FEMP. The field condition data will be transferred, as a single electronic file, once each week to SNL via modern. The communications software used to transfer the data from the field must be compatible with a $14.4 \mathrm{~K}$ modem and QModen Pro for Windows software. Data will be transferred as follows:

The instrument measurement data and field condition data ayailable at the end of each day will be transferred to Sandia National Laboratories by 
the Freld Data Coordinator. The Sandia host computer will be left in HOST mode (acting as a Bulletin Board Service) so the data can be uploaded from a remote system. The phone number of the transfer host is (505) 848-0682.
The login name and password will be provided separately to the Field Data Coordinator. Figure 1.4 exhibits the SNL data transfer HOST mode screen.

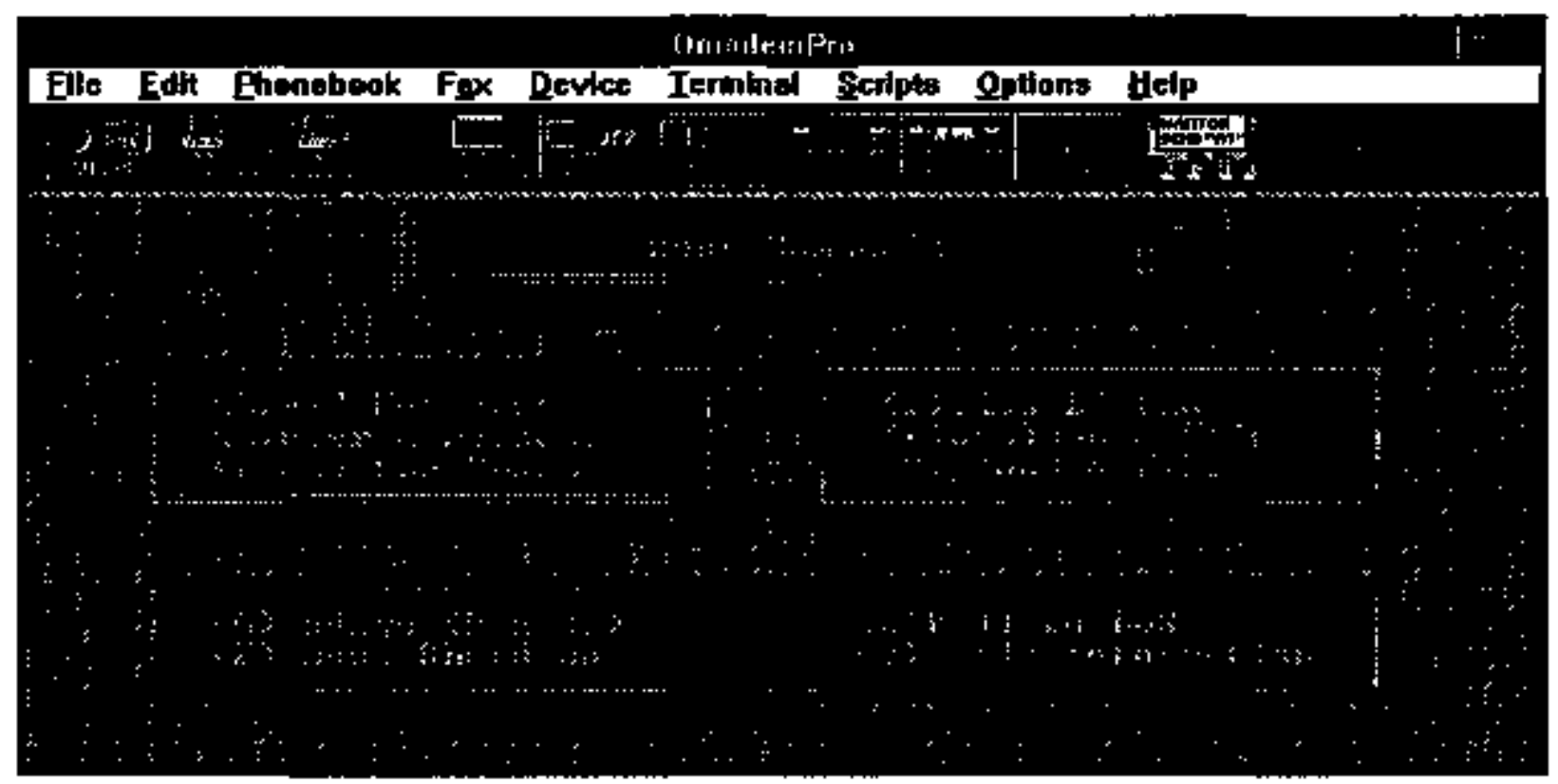

Figure 1,4. Data transfer procedures.

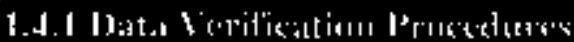

Once the instrument measurement and field condition data files have been oploaded to the SNL hrst cormputer, the data file shall be downloaded from the SNL data transfer host to the Fernald transfer bost. An electronic file comparison shall be made using the antomated 'packet checking' feature of the transfer communication software to cnsure that data is not altexed during transmission.

The Field Data Coordinator will provide hardcopies of instrument measurement data to the technology developers on the day following submittal of electronic data (e.g. electronic data submitted Monday will be will be provided in hardcopy format on Tuesday). The technology developers will be asked to sign a deplicate of the hardcopy (to acknowledging receipt of a hardcopy) and retien to the Field Data Coordinator.
If the technology developers find discrepancies in the hardcopy data it will be their responsibility to notify the Field Data Coordinator within two working days.

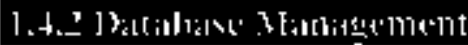

All dats received from instrument calibrations, standards ploks, and field measurements will be entered into Microsofi ACCESS's relational database management system. The database is being constructed and customized snch that data can be entered, manipulated, updated, and retrieved using buttons, pul|-down menus and point-and-click features. The database is being designed as a user-friendly tool making the data easily accessible to analysts, technicians, and managers. 
All data required for antlyses, visualization, and display will be retrieved from the USW ACCESS database. This will ensure data consistency and integrity.

Electronic instrument measumement data and field condition data will be continuously archived throughout the acquisition (instrument measurements and field condition data transferred to SNL), construction (ACCESS database format), and analysis (GSIIB output) processes.

Paper copies of the original instnment Ineasurement and field condition data will be kept on file at the FEMP by the Field Data Coordingtor. At the conclusion of the field characterization exercise a paper copy of will be forwarded to SNL by the Field Data Coordinator.

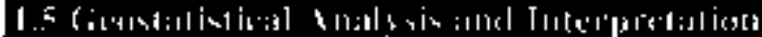

All the geostatistical software packages mentioned earlier require structured ASCII data files, yet data are read without specific format criteria (i,e. freefomtat, space dellmited). The basic required database lime structure for each sample location, therefore, is as follows: $X$ (easting) Coordinate, $Y$ (northing) Coordinate, and Total $U$ expressed in $\mathrm{pCi} / \mathrm{g}$. Figure 1.5 exhibits the required data format. The database may be developed in manner that allows for simple extraction of this data stnucture.

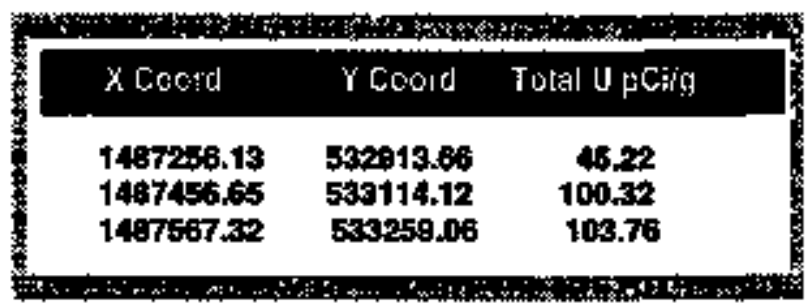

Figure 1.5. Required data format for geostatistical aralysis.

There are four field dath components that must maintain a high level of precision and accuracy throughout the entire analysis process. First, the coordinate location of the field messurement must be verified and naintained throughout the analysis process. Corruption of this key component would be extremely detrimental due to the spatial emphasis of the analysis procedares. Secondly, the reported field measurements must be reduced to a consistent unit of measurement for firect comparison between sample locations and competing technologies. This plan assumes that all transfomationstrectuctions in the field measurements required to meet these consistencies will be perforned by the field technicians and also that these values are accurate, following verification of telecommunication transmission. Thirdly, each sample must be identified by a unique and distinguishing name that will have nomenclature that is conducive to database queries and general visual screening. Finally, if the technology used in sarnpling cannot be identified through the naming convention, then it must be indicated and maintained as a separate field for each simple collected.

Following the completion of the exploratory sarnpling for a given technology, sample results will be received and verified via a telecommanication link between the Femald Site and SNL. Geostatistical analyses will then be performed on the data set.

This approach will typically involve developing univariate summary statistics and probability (histogram) plots from the raw information and evaluating any potential errant or outlier values. The data will then be transformed into normalscores spaced to guarantee the gaussian (nomal) distribution required for stochastic modeling of the areal distribution of contamination.

Depending upon the selected study site, the surficial soil contamination may have an anisotropic component to the spatial conelation of samples. Such characteristics may be attributed to such natural processes as prevailing wind directions or preferential erosional patterns. If this anisotropy is deemed to be significant, it will have to be characterized and incorporated into the spatial correlation (variogram) model for the specific technology under study.

Daka analysis will be accomplished using a number of geostatistical software and other specifically developed programs including EPA's GEO-EAS, FSS TOOLBOX, and GSLIB. Following the 
variogram model development, several stochastic models will be developed to reflect the areal distribution of contamination as defined by the exploratory sampling from the specific technology. Each stochastic model, or realization, will be developed using the Sequential Gaussian Simulation technique contained in the GSLIB software package and each will equally reflects the spatial and statistical attributes of the available data. Because each stochastic model is equiprobable, generating a large number of model outcomes allows for developing a probability frequency in the modeled outcome for any particular unsampled location within the study domsin, thereby assessing the uncertainty resulting from the model given the current data representation.

Potentially 3 to 5 stochastic realizations will be mapped with accompanying summary statistics in the form of graphs, tables, and/or plots to provide validation of the simulation model for each technology. The resulting uncertainty assessment provided through post-processing of the stochastic modeling, as previously mentioned, will be used to drive the decision analysis portion of the study and determine the need for additional sampling efforts and their optimal location for collection.

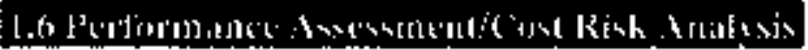

As discussed in Section 1.5, the data will be analyzed within a geostatistical framework to ultimately provide maps reflecting uncertainty in the modeling of surficial soil contamination. These maps will then be used in conjunction with decision analysis methodologies to determine optimal selection of additional samples, with the ultimate goal being a reduction in the risk of a wrong interpretation based on limited data.

The geostatistical component of this study requires fundamental statistical data analysis, an exercise in data transformation, and two levels of modeling. Summary statistics from the exploratory sampling information will be developed to evaluate basic behavior of the population characterized by the data. These summaries will reflect such things as the mean, standard deviation, the sample frequency distribution (histogram) and it is behavior (skewness, quartile ranges, etc.). Figure 1.6 exhibits the geostatistical data analysis process flow.

The current intent is to employ a gaussian-related simulation algorithm to provide stochastic modeling of the sample data. This procecture requires that the population described by the data have a normal distribution. This normality will not likely be the case in the taw field data, but a simple transformation (nombal-scorc) can insure the condition. The transformed data will then be subjected to an analysis of their spatial correlation (variography) to determine how the variance between all sample points can be expected to change as a function of their separational distance and direction. This information is analyzed graphically in the form of a variogram and subsequently a linear model is fit to the graph to reflect the variogram behavior.

The parameters that define the variogram model are then used to constrain the stochastic modeling (sequential gaussian simulation) of the areal distribution of contamination. Currently a minimum of 100 simulations are proposed to model "reality" as presented by each competing technology. Each simulation is conditioned to the existing data and provides an equiprobable representation of spatial distribution of contarnination.

Following back-transformation of the data, the suite of simulations will be processed to develop as understanding of the probability that any particular location could exceed a pre-determined cutoff (perfomance) criteria It is this appreciation of uncertainty that will be used to optimize additional sampling efforts and also provide qualifying information on the performance of the technology vja decision analysis methods.

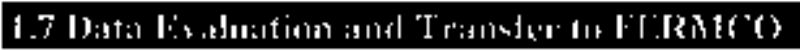

Following the evaluation of uncertainty in the exploratory sampling modeling results, additional data may be required by the field technology to complete the interpretation for a desired degree of confidence. In these instances, the SNL Performasce Assessment team will direct 
FERMCO as to the number and location of any subsequent sampling efiorts. Locations for additional sampling will be provided through appropriate coordinates.

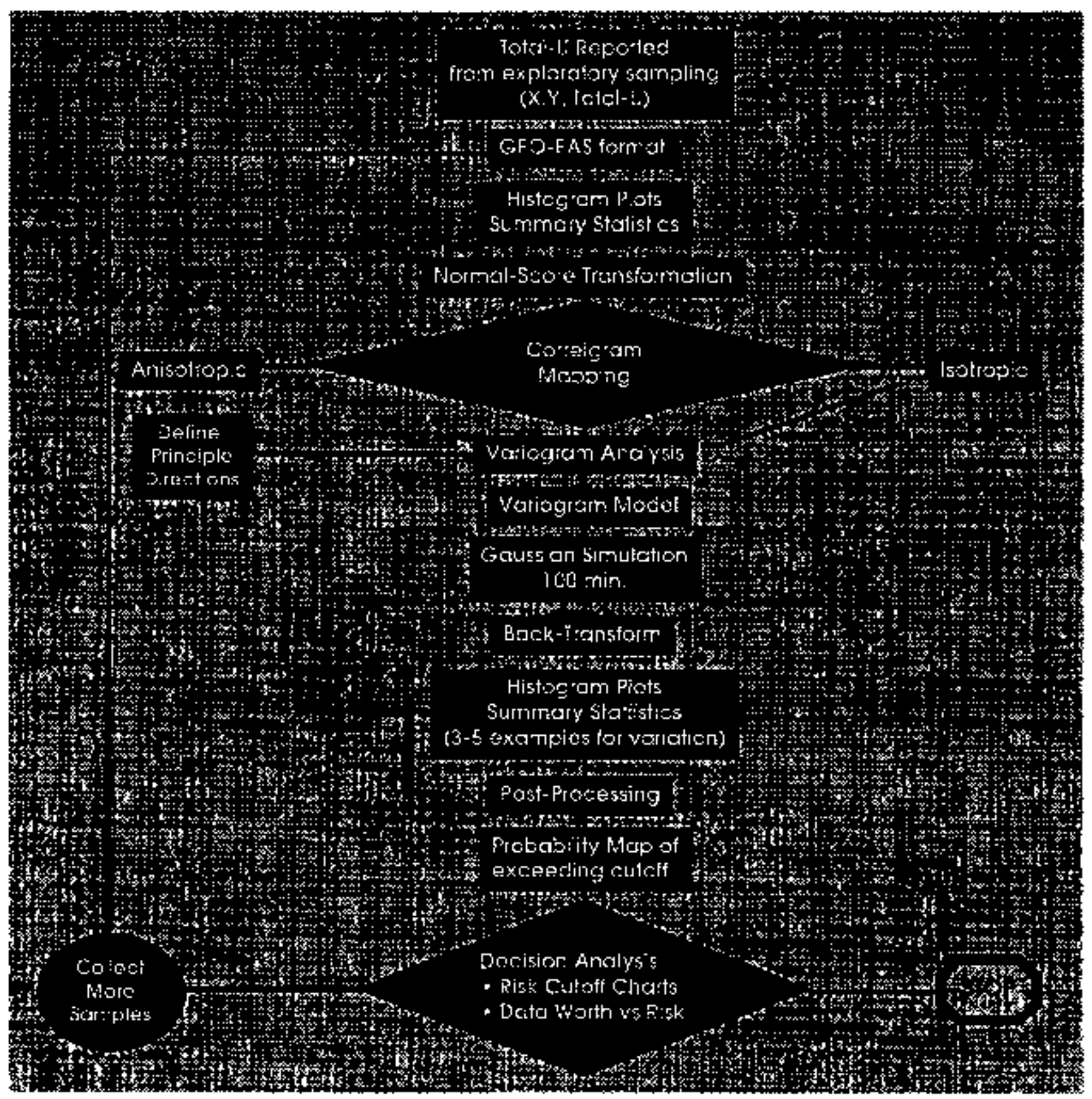

Figure J.6. Conceptual data anatysis process flow. 


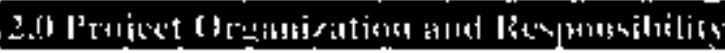

The following parties are responsible for the indicated tasks of the Spring 1994 USID Field Characterization program.

\section{- USID Coordinator - K. Niebfer}

A FERMCO employed responsible for managing, coordinating and funding the USID.

- Program Manager - V. Tidwell

A Sandia National Laboratory member will serve as the principal manager for the USID Fiejd Characterization program. The program manager is responsible for developing and irmplementing the field sampling and analysis effort. The manager is responsible for preparing the Work Plan which describes technical requirements for the field demonstration.

\section{- Project Engineers - J. Schwing and K. Pylka} FERMCO employees who will provide USID Field Characterization engineering support. The Project Engineer will provide full-time on-site support for all field activitias inchoding preparation of calibration test beds and standards plots, and engineering/logistic support for all Field Characterization program requirements. The Project Engineer is also responsible for obtaining field condition data and maintaining a field notebook.

\section{- Field Data Coordinator - $R$ Chernikoff}

An FEMP employee will be responsible for the coordination of all data acquisition activities. This will include verifying instrument measurement locations, transferring instrument measurement and field condition data to SNL in electronic format, and assuring compliance with procedures outlined in this document and it the Specificotions and Guidelines for Instrument Measurement Data Collection.

\section{- Database Management - (D. Beiso, G. Newman)}

The data manager is an SNL contractor responsible for developing and majntaining a data management plan which describes the process flow for the data received from the instrument reasurentents and field condition measurements. The data manager will develop a relational database repository for the data which will serve as the source for all calculations and analyses of the data.

\section{- Performance Assessment Arabyst (M. Cromer)}

The performance assessment amalyst is an SNL contract employee responsible for defining data specifications, ensuring data received from field measurements meets those specifications and for producing simulations of the data using the GSLIB software tools. The anatyst is also responsible for data transferal back to the field.

\section{- Computer Support Engineer (L Yarrington)}

The computer support engineer is a SNL employee responsible for performance assessment software development (automation) and maintenance, for cstablishing data transfer and verification procedures, and for establishing data tracking procedures such that information presented in the final report can be traced back to the original fueld data entry.

\section{- Computer Viswalization Analyst (J. Flinn)}

The computer visualization amalyst is a FERMCO employee responsible for generating graphical outputs of analyzed data using Intergraph software tools. 


\section{APPENDIX A. \\ URANIUM IN SOILS INTEGRATED DEMONSTRATION - FELD CHARACTERIZATION SPECIFICATIONS AND GUIDELINES FOR INSTRUMENT MEASUREMENT DATA}

\section{Conoral:}

At the end of each day of field characterization the Technology Developers will provide instrument measurement data to the Field Data Coordinator on a DOS formatted $3.5^{b}$ double or high density diskette. All measurement dala for a given day must be includiod in a sinole Ascl_comma-delimited file containing no hidden or special characters as ilustrated in Figure 1.

The ASCll file name will be in accordance with the following convention: A three character technology abbreviation (abbreviation list contained in item \#7), three character abbreviation for month, two dglt character day, and a "DAT" file exteneion. For example, the ASCll data file containing measurement data for the FIDLER survey on June 5 would be named FIDJUN05.DAT. The file name for Figure 1 would be RSDJUN05.DAT.

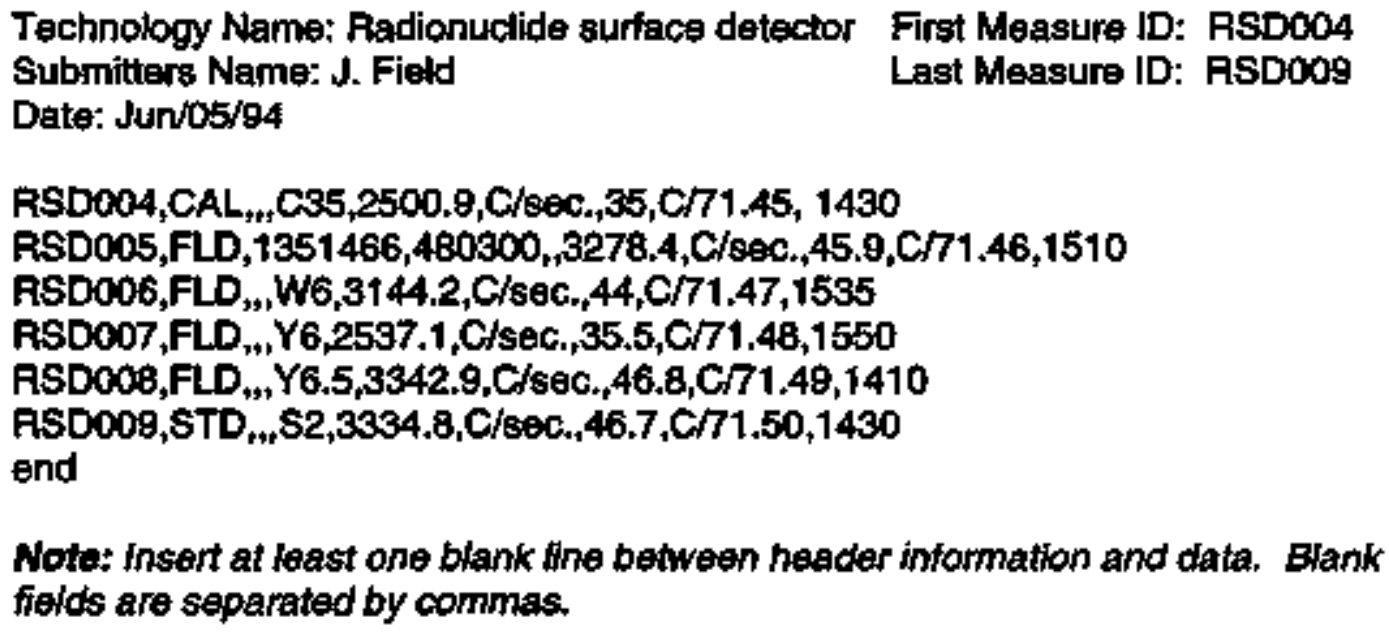

Note: Insert at least one blank fine between header information and data. Blank fields are separated by commas.

Figure 1. Comma delimited-ASCII data file format.

\section{Flle Specifications:}

The following defines the data ltems, naming conventions, data units, precision and frequency of reporting required for the anstrument measurements data file. Figure 2 illustrates items 1-17 described below.

\section{Flle Header: Items $1-5$}

The following information will be provided at the top of each data measurement file. 
Field Name

1. Technology Name

2. Submitter's Name

3. Data

4. Frrat Measure ID

5. Laet Measure ID

6. Conversion Formula

\section{Field Description}

Name of the instrument from which date is obtained. Be consistent with the technology name, for example, if you chose Gammeray spectrometer do mot later refer to the instrument as a Gamma spec.

Name of the individual(s) collecting and submitting data for that day.

Date the data was collected in the following format:

MMMDDMY (ex. MAY, JUN, JUL, AUG)

The Measure ID (using the naming conventlons described in item 47) of the first data point measured that day. This information will used to verify that all information has not been lost.

The Measure ID using the naming conventions described in item \#7) of the last data point measured that day.

Formula applied to convert raw data into totel uranium in pCíg. If the same formula is used to convert all measurements to Total $U$ $(\rho \mathrm{C} / \mathrm{g} / \mathrm{b}$ ) indicate the formula in the header portion of the file. If different formulae are used, provide the formula in column 15 for the corresponding measurement.

\section{Data Point: Items 7-17}

The following information will be captured with each instrument measurement.

7. Measure D
A unique six character identification for each instrument measurement, including calibration plots, standards plots and field (grid) measurements. The naming convention for Measure ID is a three character (alpha) abbreviation of the technology followed by a three character sequential number. For example, the first measurement recorded by the Sodium lodide Detector woukd be represented in the Measure ID field as follow: NADOO1 followed by NADOO2 and so on. Technology abbreviations have been assigned as follows:

ATD - Alpha Track Detector

BET - High Energy Beta Scintillation Sensor

EIC - Electret lonization Chamber

FID - FIDLER SUrvey

GMH - In Sltu High-Mounted Gamma-Ray Spectrometer

GML - In SItu Low-Mounted Gamma-Riay Spectrometer

ICP - Laser-Ablation, Inductively Coupled Plasma-Atomic

Emission Spectrometer 


\author{
LAB - Laboratory Analysis \\ LRA - Long Range Alpha Detector \\ NAD - Sodium lodide Detector \\ XFF - X-Ray Fuorescence Detector
}

Note: Every maasurement must have a unique Measure $\mathrm{ID}$ in order for the relational clatabase links to be established. Each technology will use sequential numbering for Measure iD beginning with 001 . The numbering will continue throughout the course of obtaining filed measurements. (Sequential numbering will no t begin with 001 each day. For example, if the Last Measure ID recorded on Monday is LRA067, the First Measure ID on Tuesday will begin with LRA068.) Therefore it is important to make a note of the Last Measure ID. The Fiekd Date Coordinator is responsible for verifying this has been done comectiy.

\section{Megordre Type}

Note:

9. $x$ Coord

10. Y Coord

11. Ceoloceation
Indicate what type of measurement is being recorded using the following designators:

CAL - Calibration bed measurement. Each detector will measure the four calibration bed soils at least three times during the course of the survey - 1) prior to field measurements, 2) after completing the baseline survey, and 3) following completion of the field data measurements.

STD - Standards plots measurement. Standards plots measurements will be taken twice daily unless field conditions or other factors require additional measurements.

$F L$. Fleld measurement (baseline grid and interstitial)

Do not include any "mistaken" measurements in the data file.

NAD-83 Ohio State plane coorcinate for the easting value of measurement location. State plane coordinates may be used when measurements are not taken on baseline (pre-assigned) grid locations. Coordinate values should not contain more then two cifilts after the dectmal point.

NAD-83 Ohio State plane coordinate for the northing value of measurement location. State plane coordinates may be used when measurements are not taken on baseline (pre-assigned) grid locations. Coordinate values should not contain more than two digits after the decimal point.

A naming convention has been established to ciscriminate between the three measurement types and their pre-defined locations. 
Figure 3 illustrates calibration beds, standards plots, and baseline grid measurement locations.

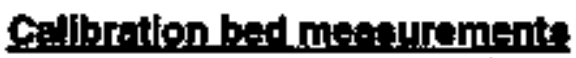

Measurements taken at the four calibration becs will have geolocation designations as follows:

Co- Measurements from background calibration bed

C35 - Measurements from 35 pClig calibration bed

C100 - Measurements from $100 \mathrm{pCl} / \mathrm{g}$ calibration bed

C200 - Measurements from $200 \mathrm{pCV} / \mathrm{g}$ calibration bed

\section{Standarch olote megelurements}

S1 - Measurements from standard plot \#1

S2 - Measurements from standard plot \#2

\section{Basellna ord and inter itifil mengurenents}

Measurements from the baseline grid will use the pre-assigned geolocation designations shown in Figure 3. Measurements taken between taseline grid polnts (that is, locations with no pre-assigned geolocation) record $X$ Coord (as defired in item $\# 9$ ) and $Y$ Coord (as defined in item $\# 10$ ) values instead of geclocation (item $\# 11$ ).

12. Raw Data Measure

13. Raw Units

14. Total $U$ (pcig)

15. Converslon Formula

16. Time

17. End
The measurement values as reported by the instrument prior to any conversions or transformations

Customary units for the raw data.

Raw data comverted to total uranitum expressed in pCVg. Single decimal place precision will be used for reporting total uranium.

Formula applied to convert raw date in to total uranium in $\mathrm{pCV} / \mathrm{g}$. If the same formula is used to convert all measurements to Total U (pCi/g) indicate the formula in the header portion of the file. If dilferent formulae are used, provide the formula in column 15 for the corresponding measurement.

Approximate time that measurement was taken expressed in 24 hour militery time units (local Femald time - EST). Example: 1430 is $2: 30 \mathrm{pm}$.

Text added to the end of the fife to verify end of data. 


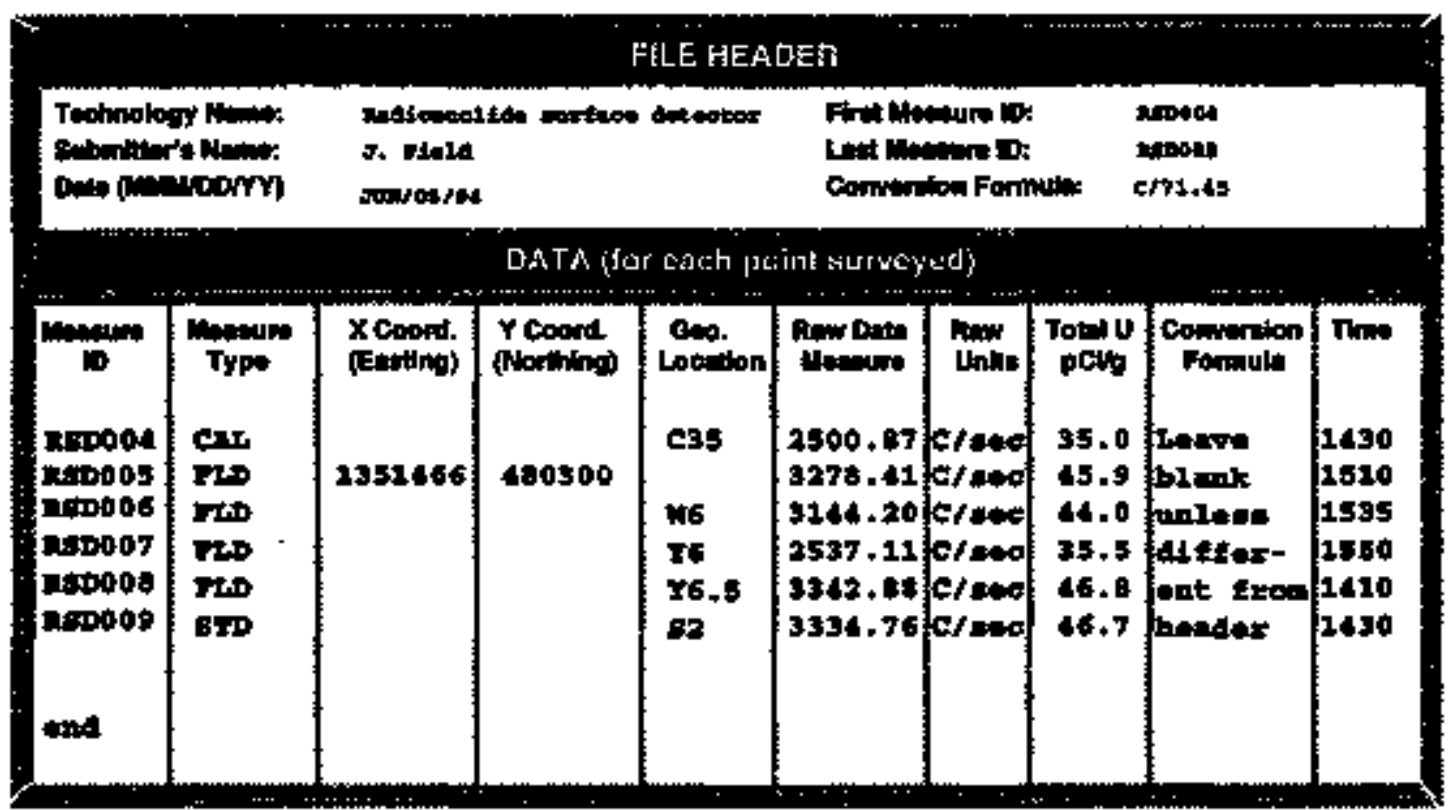

Figure 2. Instrument measurement data fiedds. 


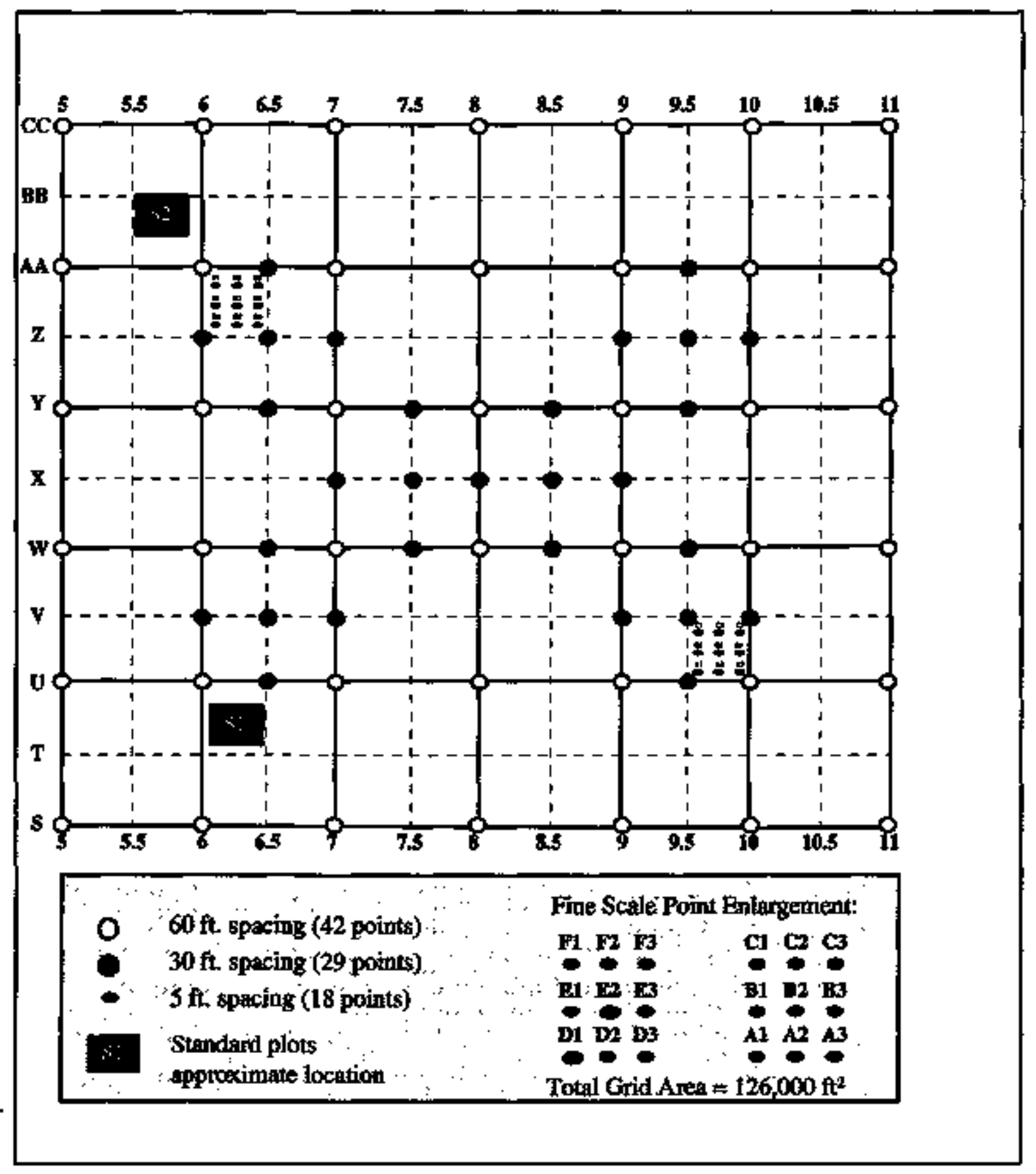

Figure 3. Geolocation references 
(This page intentionally left blank.) 
Appendix C: Ohio State Plane X-Y Coordinates for Geolocation Grid 
Tabla C-1: Ohlo State Plane X-Y Coondinates for Geolocation Grid

[Coordinate values in fret Leaders (-) not applicable]

\begin{tabular}{|c|c|c|c|c|c|c|c|c|c|c|c|}
\hline Geo LoG & $X$ Coord & Y coord & $\begin{array}{l}600 \\
\text { Loc }\end{array}$ & X Coord & Y Coond & $\begin{array}{l}\text { Goo } \\
\text { Loc }\end{array}$ & X Coord & $Y$ coord & $\begin{array}{l}\text { Goo } \\
\text { Loc }\end{array}$ & X Coond & $Y$ Coord \\
\hline A1 & 1351748.16 & 480363.18 & $\overline{\bar{D} 1}$ & 1351542.69 & $480 \$ 18.53$ & V6 & 1951528.87 & 480393.83 & $\overline{Y Y 7}$ & 1351591.04 & 480477.26 \\
\hline$A^{2}$ & 1351753.15 & 480363.05 & D2 & 1351547.09 & 480518,40 & V6.5 & I351559.12 & 480403,06 & $Y 75$ & $535162 \mathrm{t}, 03$ & 480476,49 \\
\hline $\mathrm{A}^{3}$ & 1351758.15 & 480362.92 & D3 & 1351552.09 & 480518.28 & $v 7$ & 1351588.72 & 480386.29 & Y8 & 1351651.02 & 480475.71 \\
\hline AAS & 1351472.63 & 480540.33 & El & 1351542.22 & 480523.53 & $\mathrm{vg}$ & 1351708.68 & 480384,20 & Y8.5 & $135168 \mathrm{t} .01$ & 480474.94 \\
\hline AA6 & 1351532.61 & 480538.78 & E2 & 1351547.22 & 480523.40 & v9.5 & 1351738.67 & 480383.43 & Y9 & 1351711.00 & 480474.17 \\
\hline AA6.5 & 1351562,60 & 48053801 & E3 & 1351552.21 & 480523.27 & $\mathrm{~V} 10$ & 1351768.66 & 480382.65 & Y9.5 & 1351725.00 & 480473.81 \\
\hline AA7 & 1351592.59 & 480537.24 & $\mathbf{F 1}$ & 1351542.35 & 480528.53 & ws & 1351469.54 & 480420.37 & Y10 & 1351770.98 & 480472.62 \\
\hline$A A B$ & 1351652.57 & 480535,69 & $\mathbf{F} 2$ & 1351547,34 & 480528.40 & w6 & 1351529.52 & 480418.82 & Y11 & 1351830.96 & 490471.08 \\
\hline AAG & 1351712.55 & 480534.15 & F3 & 1351552.34 & 480528.27 & W6.5 & 1351559.51 & 480418.05 & Z6 & $1351531+83$ & 480508.79 \\
\hline AA9.5 & 1351742.54 & 480533.38 & ss & $135 t 466.45$ & 480300.41 & $w 7$ & 1351589.50 & 480417.28 & Z6.5 & 1351561,82 & 480508.02 \\
\hline AA10 & 1351759.53 & 480532.94 & 56 & 1351526.43 & 480298.86 & w7.5 & 1351619.56 & 480419.51 & ZJ & I351591.81 & 480507.25 \\
\hline AA11 & 1351832.51 & 480531.06 & 57 & 1351586.41 & 480297.32 & w8 & 1351649.81 & 480428.73 & 29 & [35171).77 & 480504.16 \\
\hline B1 & 1351748.29 & 480368.17 & \$8 & 1351646.39 & 480295.77 & W8.5 & 1351679.08 & 480399.97 & 29.5 & 1351741.76 & 480503,39 \\
\hline B2 & 1351753.28 & 480368.05 & $s 9$ & 1351706.37 & 480294.23 & w9 & 1351709.41 & $4804 \backslash 2.19$ & $\mathrm{Z} 10$ & 1351786.75 & 480502,23 \\
\hline B3 & 1351758.28 & 480367.92 & $\$ 10$ & 1351766.35 & 480292.68 & W9.3 & 1351739.45 & 480413.42 & - & -- & - \\
\hline C1 & 1351748.41 & 480373.17 & StI & 1351826.33 & 480291.14 & $w_{10}$ & 1351769.44 & 480412.64 & -- & -- & - \\
\hline $\mathrm{C} 2$ & 1351753.41 & $4803+3.04$ & U5 & 1351468.12 & 480365.39 & w11 & 1351829.42 & 480411.10 & - & - & - \\
\hline $\mathrm{C3}$ & 1351758.41 & 480372.91 & U6 & 1351527.84 & 480353.85 & $x 7$ & 1351590.27 & 480447.27 & - & - & - \\
\hline $\cos$ & 1351474.17 & 480600031 & U6.5 & 1351557.96 & 480358.07 & $X 7.5$ & 1351620.26 & 480446.50 & - & - & - \\
\hline cc6 & 1351534.15 & $480 \$ 98.76$ & v7 & 1351588.06 & 480361.30 & $\mathbf{X 8}$ & 1351650.25 & 480445.72 & - & - & - \\
\hline $\mathrm{CC} 7$ & 1351594.13 & 480597.22 & U8 & 1351648.19 & 480365.75 & $\mathrm{X} 8.5$ & 1351680.24 & 480444.95 & -- & - & - \\
\hline $\operatorname{ccs}$ & 1351654.11 & 480595.67 & U9 & 1351707.91 & 480354.21 & $\mathrm{X} 9$ & 1351710.56 & 480457.17 & - & -- & -- \\
\hline $\operatorname{Cc9}$ & 1351714,09 & 480594.13 & U9.5 & 1351737,90 & 480353.44 & Y5 & 1351471.08 & 480480.35 & - & -- & -. \\
\hline $\mathrm{CC} 10$ & 1351774.07 & 480692.58 & U10 & 1351767.89 & 480352.66 & Y6 & 1351531.06 & 480478.80 & - & - & -- \\
\hline CC11 & 1351834.05 & 480591.04 & U11 & 1351827.87 & 480351.12 & $\mathrm{Y} 65$ & 1351561.05 & 480478.03 & - & $=$ & -- \\
\hline
\end{tabular}


Appendix D: Meteorologic Data 
Table D-1: Meterologic Date for 1994 Ferneld Field Characterization Demongtration Program

[EDT: Eastem Dayligin Time; EST: Eastem Standard TIme; eat: estimsted; mphr miles per hour]

\begin{tabular}{|c|c|c|c|c|c|c|c|c|c|c|c|c|c|}
\hline \multirow[b]{2}{*}{ Date } & \multicolumn{5}{|c|}{ LOCAL } & \multicolumn{7}{|c|}{ TOWER } & \multirow[b]{2}{*}{$\begin{array}{l}\text { WeatherfCloud Height } \\
\text { (100's (A.) }\end{array}$} \\
\hline & 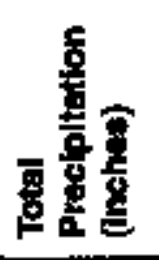 & 点点 & 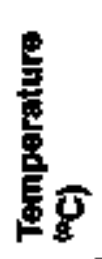 & $\begin{array}{l}\text { 吾京 } \\
\text { 至8 }\end{array}$ & 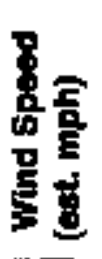 & 兽点 & 兽豆 & 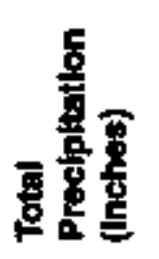 & $\begin{array}{l}\frac{6}{3} \\
\frac{8}{8} \\
\frac{8}{6}\end{array}$ & 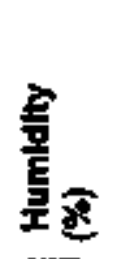 & 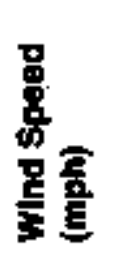 & 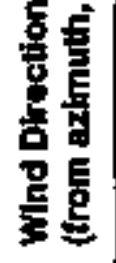 & \\
\hline $05 / \overline{194}$ & 0.00 & & & & & & & 0.00 & & & & & \\
\hline $05 / 02 / 94$ & 0.00 & 14:10 & 14.0 & 48 & 5 & 13:10 & 14:10 & 0.00 & [3.5 & 49 & 3.4 & 34 & 50 Set 250 Set \\
\hline $05 / 03 / 94$ & 0.05 & $13: 18$ & I2.I & 57 & 4 & 12:15 & 13:15 & 0.04 & 11.8 & 53 & 7.4 & 69 & Vry lgt. rain; 35 Sct $600 \mathrm{ve}$ \\
\hline $05 / 04 / 94$ & 0.00 & $14: 20$ & 13.3 & 72 & 4 & $13: 20$ & 14:20 & 0.00 & 13.1 & 73 & 7.0 & & 50 Owc \\
\hline $05 / 05 / 94$ & 0.00 & $07: 55$ & 6.8 & 100 & 3 & $07: 00$ & 08:00 & 0.00 & 6.2 & 100 & 2.] & 267 & Heavy fog $w /, 13$ and visibility \\
\hline $05 / 06 / 94$ & 0.28 & $07: 49$ & 11.0 & 98 & $\mathbf{I}$ & $06: 49$ & 9:49 & 0.27 & 10.8 & 100 & 2.7 & 349 & Lgt. rain \\
\hline $0507 / 94$ & 1.05 & & & & & & & 1.03 & & & & & \\
\hline $0508 / 94$ & 0,00 & & & & & & & 0.00 & & & & & \\
\hline $05 / 09 / 94$ & 0.00 & & & & & & & 0.00 & & & & & \\
\hline $05 / 10 / 94$ & 0.00 & $13: 23$ & 18.6 & 36 & 4 & $12: 23$ & $13: 23$ & 0.00 & 18.5 & 37 & 5,0 & 354 & S0 Set \\
\hline $05 / 11 / 94$ & 0.13 & $14: 05$ & 22.8 & 36 & 6 & $13: 05$ & $14: 05$ & 0.12 & 22.0 & 33 & 9.6 & 221 & 120 Sct $250 \mathrm{Bkn}$ \\
\hline $05 / 12 / 94$ & 0.05 & $09: 08$ & 13.3 & 66 & 7 & $08: 08$ & $09: 08$ & 0.04 & 12.9 & 70 & 4.8 & 298 & 60 Set 250 Sct \\
\hline $05 / 13 / 94$ & 0,00 & $14: 48$ & 20.8 & 35 & 5 & $14: 00$ & $15 \div 00$ & $0 . \infty$ & 19.6 & 39 & 5.0 & 95 & 60 Set 200 Sct \\
\hline $05 / 14 / 94$ & 0.35 & & & & & & & 0.37 & & & & & \\
\hline $05 / 15 / 94$ & 0.29 & & & & & & & 0.31 & & & & & \\
\hline $05 / 16 / 94$ & 0.00 & $11: 00$ & 16.6 & 74 & 6 & $10 \times 00$ & $11: 00$ & 0.00 & 15.6 & 65 & 11.2 & 323 & $45 \mathrm{Sct}$ \\
\hline $05 / 17 / 94$ & 0.00 & $13: 45$ & 18.5 & $\$ 7$ & 9 & $12: 45$ & $13: 45$ & 0.00 & 17.3 & 49 & 10.9 & 29 & \\
\hline $05 / 18 / 94$ & 0.00 & $15: 22$ & 18.7 & 34 & 11 & $14: 22$ & $15 \div 22$ & 0.00 & 17.8 & 34 & 14.0 & 8 & $60 \mathrm{Sct}$ \\
\hline $05 / 19 / 94$ & 0.00 & $13: 35$ & 17.9 & 53 & 3 & $12: 35$ & $13: 35$ & 0.00 & 17.2 & 48 & 6.5 & 46 & $60 \mathrm{sct}$ \\
\hline $05 / 20494$ & 0.00 & $13: 49$ & 21.0 & 46 & 6 & $12: 49$ & $13: 49$ & 0.00 & 20.0 & 39 & 6.8 & 21 & $60 \mathrm{Sct} 250 \mathrm{Sct}$ \\
\hline $05 / 21 / 94$ & 0.00 & & & & & & & 0.00 & & & & & \\
\hline $05 / 2294$ & 0.00 & & & & & & & 0,00 & & & & & \\
\hline $05 / 23 / 94$ & 0.00 & $09 \div 52$ & 23.3 & 56 & 1 & $08: 50$ & $09: 50$ & 0.00 & 22.5 & 58 & 2.3 & 308 & 120 \$ct \\
\hline $05 / 24 / 94$ & 0.00 & $13: 22$ & 28.5 & 50 & 8.5 & $12: 22$ & $13: 22$ & 0.00 & 27.9 & 48 & 9.8 & 240 & ${ }^{n} 60$ Sct 200 Sct $250-\mathrm{Bkn}$ \\
\hline $05 / 25 / 94$ & 0.08 & $13: 25$ & 25.7 & 52 & 4 & $12: 54$ & $13: 54$ & 0.08 & 24.7 & 53 & 7.5 & 250 & 60 Sct $120 \mathrm{Sat}$ \\
\hline
\end{tabular}


Table D-1: Metorologic Data for 1994 Fernald Field Characterization Demonatration Program (continued)

[EDT: Eastem Daylight Timo; EST. Eastero Standard Tinc; est; estimated; mph; miles per hoor]

\begin{tabular}{|c|c|c|c|c|c|c|c|c|c|c|c|c|c|}
\hline \multirow[b]{2}{*}{ Date } & \multicolumn{5}{|c|}{ LOCAL } & \multicolumn{7}{|c|}{ TOWER } & \multirow[b]{2}{*}{$\begin{array}{c}\text { Weather/Clowd Hoight } \\
\text { (100's ft) }\end{array}$} \\
\hline & 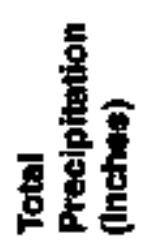 & 悬它 & 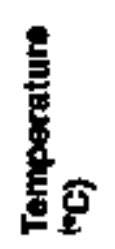 & 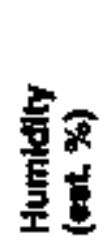 & 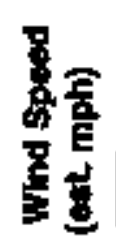 & 官点 & 틀유 & 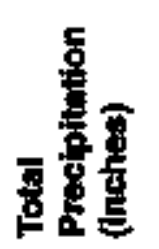 & $\begin{array}{l}\frac{8}{3} \\
8 \\
\end{array}$ & 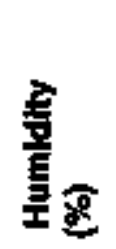 & 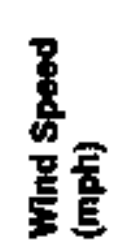 & 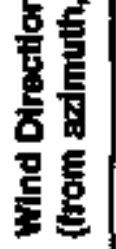 & \\
\hline $05 / 26 \sqrt{94}$ & 0.02 & & & & & & & 0.02 & & & & & \\
\hline $05 / 27 / 94$ & 0.00 & $08: 25$ & 9.3 & 67 & 6 & 07:25 & 08:25 & 0.00 & B.3 & 65 & 7.9 & 3] & 60 Sct \\
\hline $05 / 28 / 94$ & 0.00 & & & & & & & 0.00 & & & & & \\
\hline $05 / 29 / 94$ & 0.00 & & & & & & & 0.00 & & & & & \\
\hline $05 / 30 / 94$ & 0.00 & & & & & & & 0.00 & & & & & \\
\hline $05 / 31 / 94$ & 0.00 & $09: 30$ & & & & $08: 45$ & $09: 45$ & 0.00 & 23,4 & 67 & 5.5 & 232 & \\
\hline $0 \$ / 31 / 94$ & & $10: 14$ & & & & $9: 00$ & $10: 00$ & & 23.7 & 65 & 7.5 & 219 & \\
\hline $05 / 31 / 94$ & & $10: 27$ & & & & $09: 30$ & $10: 30$ & & 24.6 & 61 & 79 & 217 & \\
\hline $05 / 31 / 94$ & & $13: 20$ & 28 & 46 & 8.5 & $12: 20$ & $13: 20$ & & 27.9 & 44 & & & \\
\hline $06 / 01 / 94$ & 0.00 & 08.50 & & & & $07: 45$ & $08: 45$ & 0.00 & 20.2 & 58 & 4.0 & 304 & \\
\hline $06 / 01 / 94$ & & $08: 59$ & & & & & & & & & & & \\
\hline $06 / 01 / 94$ & & $09: 54$ & & & & $08: 45$ & $09: 45$ & & 22.8 & 43 & 7.0 & 331 & \\
\hline $06 / 01 / 94$ & & 10:01 & & & & $09: 00$ & $10: 00$ & & 22.9 & 40 & 6.5 & 325 & \\
\hline $06 / 01 / 94$ & & $10: 16$ & & & & $09: 15$ & $10: 15$ & & 23.4 & 39 & 7.3 & 327 & \\
\hline $06 \times 01 / 94$ & & $10: 27$ & & & & & & & & & & & \\
\hline $0601 / 94$ & & $10: 50$ & & & & $09: 45$ & $10: 45$ & & 23.7 & 37 & 7.9 & 318 & \\
\hline $06 \% 1 / 94$ & & $10: 57$ & & & & & & & & & & & \\
\hline $0601 / 94$ & & $13: 00$ & & & & $12: 00$ & $13: 00$ & & 25.5 & 33 & 7.5 & 278 & \\
\hline $0601 / 94$ & & $13: 17$ & & & & $12: 15$ & $13: 15$ & & 25.5 & 32 & 8.9 & 287 & \\
\hline $0 \times 101 / 94$ & & $13: 26$ & & & & & & & & & & & \\
\hline $06 \times 1 / 94$ & & $13: 31$ & & & & $12: 30$ & $13: 30$ & & 25.5 & 31 & 10.5 & 304 & \\
\hline $06 / 01 / 94$ & & $13: 36$ & & & & & & & & & & & \\
\hline $0601 / 94$ & & $13: 39$ & & & & & & & & & & & \\
\hline $06102 / 94$ & 0.00 & 08:08 & & & & $07: 00$ & $08: 00$ & 0.00 & 13.2 & 43 & 4,1 & 6 & \\
\hline $06102 / 94$ & & $08: 10$ & & & & & & & & & & & \\
\hline
\end{tabular}


Table D-1: Meterologic Data for 1994 Fernald Fleld Characterizatlon Demonatration Program (Continued)

[EDT: Eastem Daylight Time; EST. Eastern Standard Time; est: estimstect, mptr: villes per hour]

\begin{tabular}{|c|c|c|c|c|c|c|c|c|c|c|c|c|c|}
\hline \multirow[b]{2}{*}{ Date } & \multicolumn{5}{|c|}{ LOCAL } & \multicolumn{7}{|c|}{ TOWER } & \multirow[b]{2}{*}{$\begin{array}{c}\text { Weathericloud Helght } \\
\text { (100's ft.) }\end{array}$} \\
\hline & 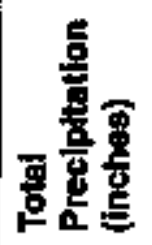 & 을휴 & $\frac{2}{5}$ & 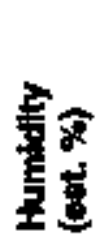 & 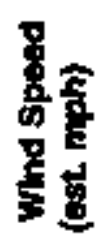 & 息量 & 를룰 & 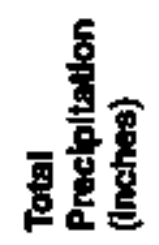 & $\begin{array}{l}\frac{2}{3} \\
\frac{5}{8} \\
\end{array}$ & 龺 & 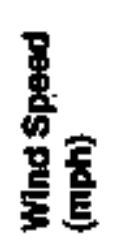 & 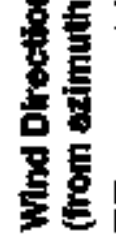 & \\
\hline $0602 / 94$ & & $08: 14$ & & & & & & & & & & & \\
\hline 0602994 & & $08: 16$ & & & & $07: 15$ & 08:15 & & 13.5 & 43 & 4.9 & 6 & \\
\hline $06 / 02 / 94$ & & $08: 19$ & & & & & & & & & & & \\
\hline 060294 & & $08: 22$ & & & & & & & & & & & \\
\hline $06 / 02 / 94$ & & $08: 24$ & & & & & & & & & & & \\
\hline $0602 / 94$ & & $08: 27$ & & & & & & & & & & & \\
\hline 060294 & & $08: 29$ & & & & & & & & & & & \\
\hline $06 \times 02 / 94$ & & $08+31$ & & & & $07: 30$ & $08 \div 30$ & & 13.4 & 43 & 5.3 & 0 & \\
\hline 060284 & & $09: 00$ & & & & $08: 00$ & 09:00 & & 13.6 & 43 & 4.9 & 359 & \\
\hline $0602 \% 4$ & & $09: 05$ & & & & & & & & & & & \\
\hline $06 / 10 / 94$ & & $13: 21$ & & & & 12:15 & $13: 15$ & & 16.9 & 33 & 5.1 & 9 & \\
\hline $06 / 02 / 94$ & & $13: 24$ & & & & & & & & & & & \\
\hline $06 / 03 / 94$ & 0.00 & $09: 50$ & & & & $08: 45$ & $09: 45$ & 0.00 & 17.3 & 55 & 4.2 & 74 & \\
\hline 06\%03/94 & & $10: 06$ & & & & $09: 00$ & $10 \times 00$ & & 17.8 & 53 & 4.2 & 53 & \\
\hline $06 \% 03 / 94$ & & $10: 16$ & & & & $09: 15$ & 10:15 & & 18.5 & 49 & 4.1 & 66 & \\
\hline O6FOA94 & & $10: 34$ & & & & $09: 30$ & $10 \div 30$ & & 19.0 & 45 & 4.5 & 67 & \\
\hline $06 / 0394$ & & $10: 46$ & & & & 09:45 & $10: 45$ & & 19.5 & 41 & 5.6 & 83 & \\
\hline $06 / 03 / 94$ & & 11:0? & & & & $10 ; 00$ & 11:00 & & 19.8 & 39 & 5.9 & 67 & \\
\hline $0603 / 94$ & & $13: 2 \mathrm{l}$ & & & & 12:15 & 13:15 & & 21.7 & 33 & 5.7 & 27 & \\
\hline $06003 / 94$ & & $13: 36$ & 22.2 & 39 & 2 & $12: 36$ & $13: 36$ & & 22.4 & 36 & & & \\
\hline 0603/94 & & $14: 51$ & & & & $13: 45$ & $14: 45$ & & 22.6 & 32 & 4.9 & 67 & \\
\hline $06 \% 0484$ & 0.00 & & & & & & & 0.00 & & & & & \\
\hline $0600 / 44$ & 0.00 & & & & & & & 0.00 & & & & & \\
\hline 060694 & 0.62 & $09 \div 30$ & & & & $08: 30$ & $09: 30$ & 0.65 & 24.2 & 77 & 6.3 & 203 & \\
\hline 0606094 & & $09: 45$ & & & & $08: 45$ & $09 \div 45$ & & 24.6 & 77 & 6.5 & 202 & \\
\hline
\end{tabular}


Table D-1: Moterologic Data for 1994 Fernald Fleld Characterization Demonstration Progrram (continued)

[EOT: Eastem Daylight Time; EST: Eastern Standard Time; est; estimaled; mpb: miles per hour]

\begin{tabular}{|c|c|c|c|c|c|c|c|c|c|c|c|c|c|}
\hline \multirow[b]{2}{*}{ Date } & \multicolumn{5}{|c|}{ LOCAL } & \multicolumn{7}{|c|}{ TOWEA } & \multirow[b]{2}{*}{$\begin{array}{c}\text { Weather/Cloud Helght } \\
\text { (100's ft.) }\end{array}$} \\
\hline & 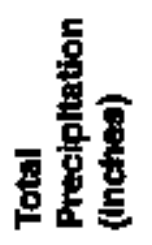 & 量苞 & $\frac{8}{8}$ & 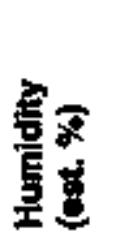 & 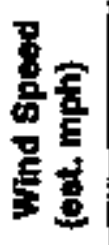 & 量䕗 & 墨总 & 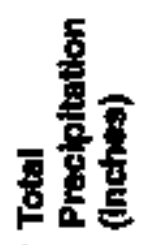 & 量 & 趌 & $\begin{array}{l}\frac{7}{8} \\
\frac{5}{6} \\
\frac{2}{5} \\
\frac{5}{5}\end{array}$ & 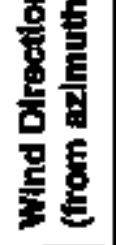 & \\
\hline $06106 / 94$ & & $10: 28$ & & & & $09: 15$ & $\overline{100: 15}$ & & 25.2 & 75 & 7.4 & 199 & \\
\hline $06 / 06 / 94$ & & $10: 30$ & & & & $09: 30$ & $10: 30$ & & 25.8 & 73 & 7.1 & 202 & \\
\hline $06 / 06 / 94$ & & $11: 16$ & & & & $10: 15$ & 11:15 & & 27.1 & 70 & 7.2 & 198 & \\
\hline $06106 / 94$ & & 11:28 & & & & & & & & & & & \\
\hline 0606194 & & 13:28 & & & & $12: 15$ & $13: 15$ & & 29.2 & 62 & 8.1 & 196 & \\
\hline $06 / 06 / 94$ & & $13: 31$ & & & & $12: 30$ & $13: 30$ & & 29.6 & 61 & 8.8 & 204 & \\
\hline $06 / 06494$ & & $13: 40$ & & & & & & & & & & & \\
\hline (W606494 & & $13 \div 55$ & & & & $12: 45$ & $13: 45$ & & 29.5 & 61 & 8.5 & 203 & \\
\hline $06 / 06 / 94$ & & $14 \div 01$ & & & & $13: 00$ & $14 ; 00$ & & 29.6 & 60 & 9.5 & 201 & \\
\hline $06 / 07 / 94$ & 0.00 & $09: 50$ & 24.4 & 84 & 2.5 & $08: 54$ & $09: 54$ & 0.00 & 23.8 & 88 & 4,0 & 341 & -X 250-Bkn Haze \\
\hline $06 / 07 / 94$ & & $10: 49$ & & & & $09: 45$ & $10: 45$ & & 24.7 & 85 & 1.6 & 16 & \\
\hline $06 / 07 / 94$ & & $11: 30$ & & & & 10:30 & $11: 30$ & & 26.2 & 79 & 3.I & 86 & \\
\hline $0607 / 94$ & & $12: 02$ & & & & $11: 00$ & $12: 00$ & & 26.9 & 75 & 1.7 & 69 & \\
\hline $06108 \times 4$ & 0.01 & $08+55$ & & & & $07: 45$ & $08: 45$ & 0.01 & 15.8 & 84 & 7.9 & 16 & \\
\hline $06 / 08 / 94$ & & $09: 10$ & & & & $08: 00$ & $09: 00$ & & 16.0 & 83 & 10.4 & 30 & \\
\hline O6os/94 & & $09: 29$ & & & & $08: 15$ & $09: 15$ & & 16.2 & 83 & 105 & 33 & \\
\hline OGOS/94 & & $14: 40$ & & & & $13: 30$ & $14: 30$ & & 21.0 & 63 & 9.9 & 54 & \\
\hline 0610894 & & $14: 43$ & & & & & & & & & & & \\
\hline 0610894 & & 18:11 & & & & $17: 00$ & $18: 00$ & & 19.4 & 69 & 7.9 & 51 & \\
\hline $06 / 08 / 94$ & & $18: 23$ & & & & $17: 15$ & 18:15 & & 19.2 & 69 & 7.3 & 65 & \\
\hline $06 / 09 / 94$ & 0.02 & $09: 16$ & & & & $08: 15$ & $09: 15$ & 0.02 & 14,9 & 69 & 6.2 & 60 & \\
\hline $0609 / 94$ & & $09: 32$ & & & & $08: 30$ & $09: 30$ & & 15.0 & 69 & 4.9 & 44 & \\
\hline $06 / 09 / 94$ & & $09: 46$ & & & & $08: 45$ & $09: 45$ & & 15.3 & 68 & 7.2 & 66 & \\
\hline $06109 / 94$ & & $09: 58$ & & & & & & & & & & & \\
\hline $06109 / 94$ & & $10: 45$ & 16.9 & 67 & 2.5 & $09: 45$ & $10: 45$ & & 16.6 & 66 & 5.6 & 61 & 100 Bkn \\
\hline
\end{tabular}


Table D-1: Meterologlic Data for 1994 Femald Fleld Characterizetion Demonstration Program (continued)

[EDT: Eastern Daylight Time; EST: Eastern Stantard Time; est.: estimatod; mph: ubles per hour]

\begin{tabular}{|c|c|c|c|c|c|c|c|c|c|c|c|c|}
\hline \multirow[b]{2}{*}{ Date } & \multicolumn{4}{|c|}{ LOCAL } & \multicolumn{7}{|c|}{ TOWJ } & \multirow[b]{2}{*}{$\begin{array}{c}\text { WeathesfCloud Hoight } \\
\text { (100's it) }\end{array}$} \\
\hline & 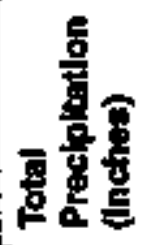 & 基豆 & 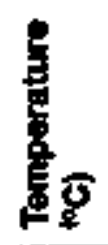 & 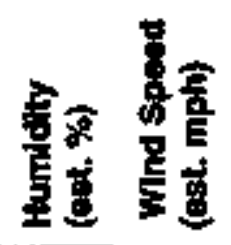 & 量点 & 톹뮴 & 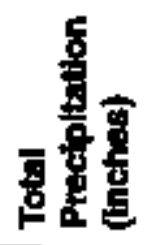 & $\frac{9}{8}$ & 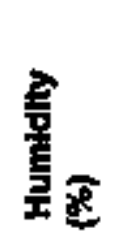 & 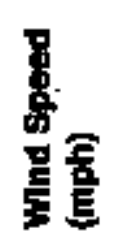 & 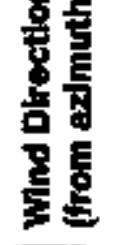 & \\
\hline $06109 / 94$ & & $10: 47$ & & & & & & & & & & \\
\hline $06109 / 94$ & & 11:07 & & & $10: 00$ & $11: 00$ & & 17.0 & 64 & 7.1 & 56 & \\
\hline $0609 / 94$ & & $14: 00$ & & & $13: 00$ & 14:00 & & 22.6 & 5s & 4.8 & 78 & \\
\hline 060994 & & $14: 10$ & & & & & & & & & & \\
\hline $0609 / 94$ & & $14: 12$ & & & & & & & & & & \\
\hline $06 / 09 / 94$ & & $14: 16$ & & & 13:15 & $14: 15$ & & 22.5 & 55 & 3.0 & 42 & \\
\hline $06 / 09 / 94$ & & $14: 25$ & & & & & & & & & & \\
\hline $06 / 09 / 94$ & & $18: 30$ & & & $17: 30$ & $18: 30$ & & 25.0 & 48 & 4.3 & $4 !$ & \\
\hline $06 / 09 / 94$ & & 18:45 & & & $17: 45$ & $18: 45$ & & 24.8 & 49 & 3.2 & 68 & \\
\hline (x)/10/94 & 0.00 & $09: 22$ & & & $08: 15$ & $09: 15$ & 0.00 & 19.2 & 54 & 3.8 & 59 & \\
\hline $06 / 10 / 94$ & & $09: 34$ & & & $08: 30$ & $09: 30$ & & 20.0 & 51 & 4.0 & 56 & \\
\hline $06 / 1094$ & & $09: 36$ & & & & & & & & & & \\
\hline $06 / 10994$ & & $09: 48$ & & & $08: 45$ & $09: 45$ & & 20.5 & 50 & 4.1 & 54 & \\
\hline $06 / 10 / 94$ & & $09: 50$ & & & & & & & & & & \\
\hline $06 / 10 / 94$ & & $09: 56$ & & & & & & & & & & \\
\hline $06 / 10 / 94$ & & $09: 58$ & & & & & & & & & & \\
\hline $06 / 10 / 94$ & & $10: 04$ & & & 09000 & $10 ; \infty$ & & 20.8 & 49 & 4.2 & 72 & \\
\hline $06 / 10,94$ & & $10: 13$ & & & & & & & & & & \\
\hline $06 / 10 / 94$ & & $10+15$ & & & $09: 15$ & 10:15 & & 21.4 & 50 & 3.7 & 76 & \\
\hline $06 / 10 / 94$ & & $10 \div 17$ & & & & & & & & & & \\
\hline $06 / 10 / 94$ & & $10 \div 20$ & & & & & & & & & & \\
\hline $06 / 1094$ & & $10: 26$ & & & & & & & & & & \\
\hline $06 / 10 / 94$ & & $10+28$ & & & & & & & & & & \\
\hline $06 / 1094$ & & $10: 30$ & & & $09: 30$ & $10: 30$ & & 22.0 & 48 & 3.5 & 91 & \\
\hline $06 / 10 / 94$ & & $10+31$ & & & & & & & & & & \\
\hline
\end{tabular}


Table D-1: Meterologle Data for 1994 Fernald Fleld Characterization Demonetration Program (continued) [EDT: Eastem Daylightk Time; EST: Esstem Standard Time; est: estimated; mptri miles per how]

\begin{tabular}{|c|c|c|c|c|c|c|c|c|c|c|c|c|c|}
\hline \multirow[b]{2}{*}{ Date } & \multicolumn{5}{|c|}{ LOCAL } & \multicolumn{7}{|c|}{ TOWER } & \multirow[b]{2}{*}{$\begin{array}{l}\text { WoatherfCloud Heigh } \\
\text { (too's it.) }\end{array}$} \\
\hline & 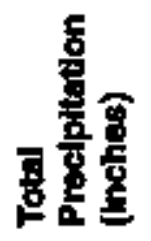 & 点点 & 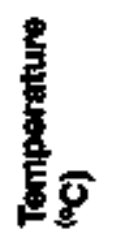 & 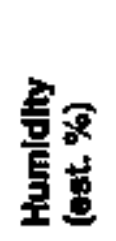 & 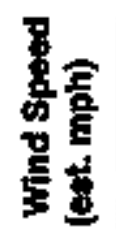 & 点点 & 点点 & 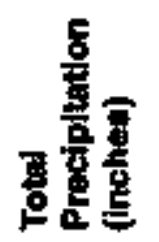 & $\frac{5}{85}$ & $\begin{array}{l}\mathbf{3} \\
\frac{3}{2}\end{array}$ & $\begin{array}{l}8 \\
\frac{8}{5}= \\
\frac{8}{2}\end{array}$ & 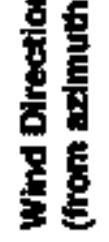 & \\
\hline 061094 & & $\overline{10: 34}$ & & & & & & & & & & & \\
\hline $0610 / 44$ & & $10: 36$ & & & & & & & & & & & \\
\hline 061094 & & $10: 40$ & & & & & & & & & & & \\
\hline $06 / 10,94$ & & 10,42 & & & & & & & & & & & \\
\hline $06 / 1094$ & & 10.45 & & & & $09: 45$ & $10: 45$ & & 22.5 & 48 & 3.6 & 86 & \\
\hline $06 / 10094$ & & $10: 47$ & & & & & & & & & & & \\
\hline $06 / 1094$ & & $10: 49$ & & & & & & & & & & & \\
\hline $06 / 10 / 94$ & & $10: 53$ & & & & & & & & & & & \\
\hline $06 / 1094$ & & $10 \div 56$ & & & & & & & & & & & \\
\hline $06 / 10 / 94$ & & 10.58 & & & & & & & & & & & \\
\hline $06 / 1094$ & & $11: 01$ & & & & 10:00 & 11:00 & & 22.8 & 48 & 3.4 & 43 & \\
\hline $04 / 1094$ & & $11: 03$ & & & & & & & & & & & \\
\hline $06 / 1094$ & & 13:50 & 27.6 & 34 & 0.0 & $12: 50$ & $13: 50$ & & 26.8 & 32 & 3.5 & 220 & 60 Sct 100 Sct 250 Sct \\
\hline $06 / 1094$ & & $14: 00$ & & & & $13: 00$ & $14: 00$ & & 26.7 & 28 & 4.4 & 308 & \\
\hline 061094 & & 14:15 & & & & $13: 15$ & $14: 15$ & & 26.7 & 29 & 5.0 & 341 & \\
\hline $06 / 1394$ & 0.04 & $13: 13$ & & & & $12: 00$ & $13: 00$ & 0.04 & 30 & 6] & 8.8 & 203 & \\
\hline $06 / 13 / 94$ & & $13: 30$ & & & & $12: 30$ & [3:30 & & 30.3 & 61 & 12.2 & 185 & \\
\hline $06 / 13 / 94$ & & $14: 35$ & & & & $13: 30$ & 44:30 & & 31.1 & 56 & 105 & 213 & \\
\hline $06 / 13 / 94$ & & $16: 08$ & & & & $15: 00$ & $16: 00$ & & 31.1 & 55 & 10 & 200 & \\
\hline $06 / 13 / 94$ & & $16: 28$ & & & & t5:15 & $16: 15$ & & 31.3 & 54 & 9.6 & 210 & \\
\hline 061494 & 0.00 & $09: 37$ & & & & $08: 30$ & 09:30 & 0,00 & 25.2 & 85 & 7.5 & 202 & \\
\hline $0 \times 14 / 94$ & & $09: 46$ & & & & $08: 45$ & $09: 45$ & & 25.7 & 84 & 6.5 & 206 & \\
\hline $06 / 14 / 94$ & & $10: 11$ & & & & $09: 00$ & 1000 & & 25.7 & 84 & 7.2 & 187 & \\
\hline $06 / 14 / 94$ & & $10: 12$ & & & & & & & & & & & \\
\hline $06 / 14 / 94$ & & $12: 56$ & & & & 11:45 & $12: 45$ & & 29.3 & 72 & 6.1 & 201 & \\
\hline
\end{tabular}




\begin{tabular}{|c|c|c|c|c|c|c|c|c|c|c|c|c|c|}
\hline \multirow[b]{2}{*}{ Dete } & \multicolumn{5}{|c|}{ LOCAL } & \multicolumn{7}{|c|}{ TOWEA } & \multirow[b]{2}{*}{$\begin{array}{l}\text { Wenther/Cloud Hielght } \\
\text { (100's ti) }\end{array}$} \\
\hline & 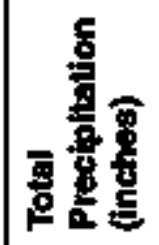 & 롤를 & $\frac{5}{8}$ & 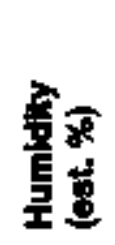 & 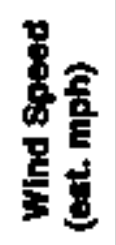 & 官蒠 & 量豆 & 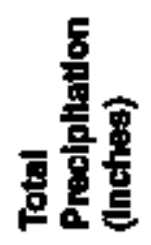 & $\begin{array}{l}3 \\
\frac{3}{5} \\
5\end{array}$ & 急 & 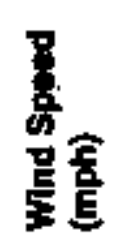 & 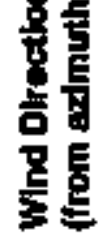 & \\
\hline $06 / 14 / 94$ & & $13: 08$ & & & & $12: 00$ & $13: 0$ & & 29.4 & 74 & 6.5 & 181 & \\
\hline $06 / 14 / 94$ & & 13:38 & & & & $12: 30$ & $13: 30$ & & 30.1 & 71 & 5.9 & 179 & \\
\hline $0614 / 94$ & & 13:55 & & & & $12: 45$ & $13: 45$ & & 30.5 & 68 & 6.6 & 194 & \\
\hline $06 / 15 / 94$ & 0.00 & $09: 24$ & & & & $08: 15$ & $09: 15$ & 0.00 & 26.3 & 83 & 4.0 & 257 & \\
\hline $06 / 15 / 94$ & & $09: 38$ & & & & 0830 & $09+30$ & & 26.8 & 81 & 3.9 & 238 & \\
\hline $06 / 15 / 94$ & & $10: 46$ & & & & $09: 45$ & 10:45 & & 29.3 & 71 & 3 & 235 & \\
\hline O6rISA34 & & II:0I & & & & $10: 00$ & 11:00 & & 29.7 & 69 & 3.9 & 233 & \\
\hline $0615 / 94$ & & $11: 33$ & & & & $10: 30$ & $11: 30$ & & 30.1 & 65 & 5.6 & 276 & \\
\hline $06 r 15 / 94$ & & $11: 44$ & & & & & & & & & & & \\
\hline $06 / 15 / 94$ & & $14: 53$ & & & & $13: 45$ & 14:45 & & 32.8 & $\$ 4$ & 4,1 & 187 & \\
\hline $06 / 15 / 94$ & & $15+08$ & & & & $14: 00$ & $15: 00$ & & 32.7 & 53 & 3.9 & 176 & \\
\hline $06 / 15 / 94$ & & $15: 23$ & & & & $14: 15$ & $15: 15$ & & 32.8 & 55 & 3.9 & 205 & \\
\hline $\left.06^{\prime}\right] 5 / 94$ & & $15: 41$ & & & & $14: 30$ & $15 \div 30$ & & 33.3 & 53 & 4,5 & 171 & \\
\hline $06 / 15 / 94$ & & $16: 22$ & & & & $15: 15$ & $16: 15$ & & 33.4 & 49 & 2.9 & 183 & \\
\hline $06 / 16 / 44$ & 0.01 & $09: 00$ & & & & 08:00 & $09: 00$ & 0.01 & 24.5 & 89 & 0.7 & 249 & \\
\hline 061694 & & $09 \div 15$ & & & & 0 os:15 & 03:15 & & 25.2 & 86 & 1.7 & 237 & \\
\hline $06 / 1694$ & & $09: 20$ & & & & $08: 15$ & $09: 15$ & & 25.2 & B6 & 1.7 & $23 ?$ & \\
\hline $0616 / 44$ & & $09+22$ & & & & & & & & & & & \\
\hline 0616944 & & $09 \div 24$ & & & & & & & & & & & \\
\hline 0611694 & & $09: 32$ & & & & $08: 30$ & $09: 30$ & & 25.8 & 85 & 1,5 & 192 & \\
\hline $06 / 16 / 94$ & & $69: 94$ & & & & & & & & & & & \\
\hline $06 / 16 \times 4$ & & $09: 38$ & & & & & & & & & & & \\
\hline $06 / 16 / 94$ & & $11: 25$ & & & & $10: 15$ & 11:15 & & 23.8 & 83 & 11.1 & 123 & \\
\hline $06 / 16 / 94$ & & $11: 44$ & & & & $10 \times 30$ & $11 \div 30$ & & 23.5 & 83 & 8.4 & 112 & \\
\hline $0616 / 94$ & & I5:15 & & & & $14: 15$ & $15 * 15$ & & 30.8 & 50 & 4.1 & 184 & \\
\hline
\end{tabular}




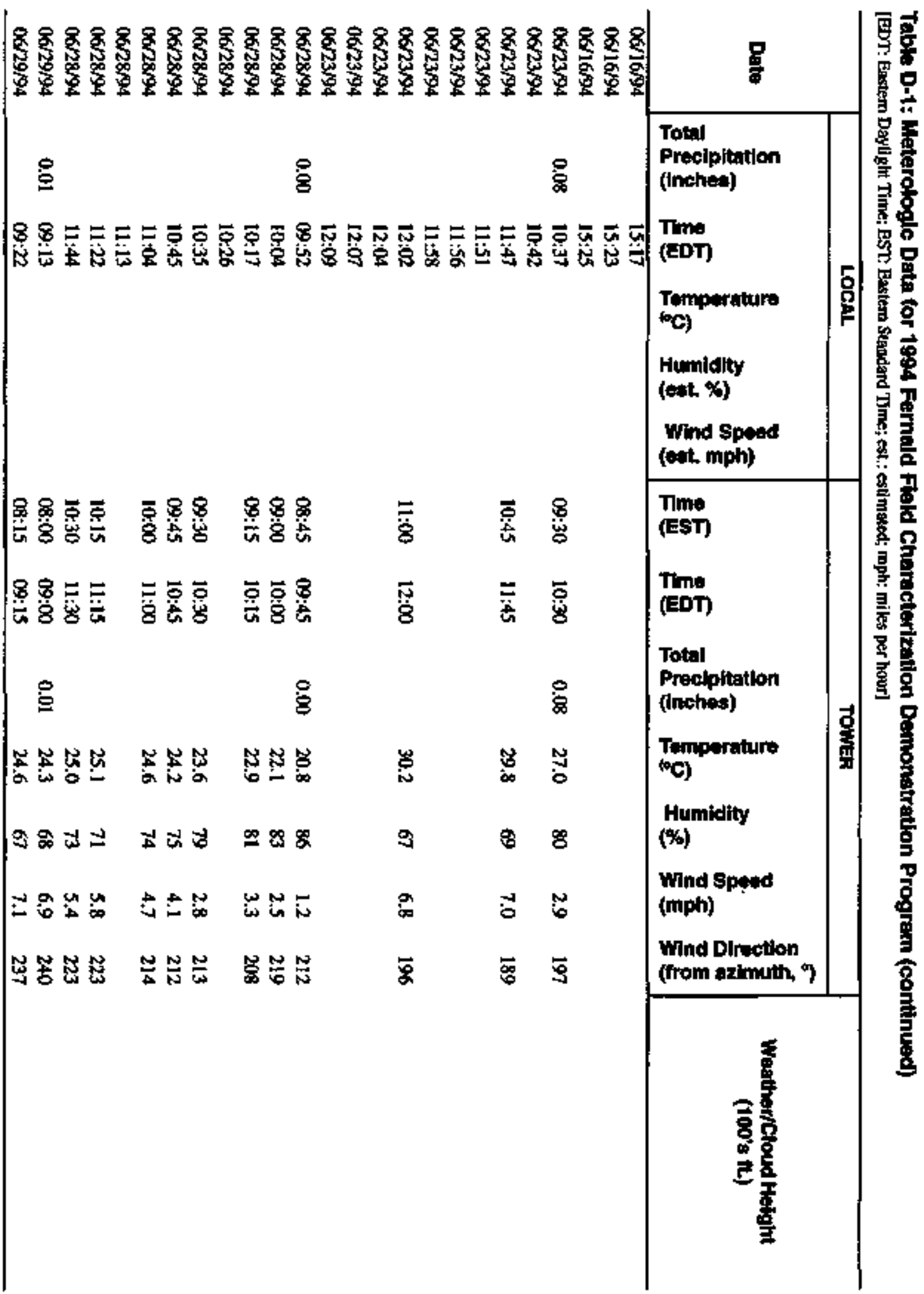


Table D-1: Meterologic Data for 1994 Fornald Field Characterlzation Demonstration Program (continued)

[EDT: Eastern Dayligłx Time; EST: Eastenn Standard Time; est: estimated; mpti miles per hour]

\begin{tabular}{|c|c|c|c|c|c|c|c|c|c|c|c|c|}
\hline \multirow[b]{2}{*}{ Date } & \multicolumn{4}{|c|}{ LOCAL } & \multicolumn{7}{|c|}{ TOWER } & \multirow[b]{2}{*}{$\begin{array}{c}\text { Weathow/Ckoud Helght } \\
\text { (100' n.) }\end{array}$} \\
\hline & $\begin{array}{r}\frac{5}{5} \\
\frac{5}{5} \overline{8} \\
\frac{5}{8} \\
0\end{array}$ & 흘 & $\begin{array}{l}\frac{2}{5} \\
\frac{E}{2} \\
\frac{2}{2}\end{array}$ & 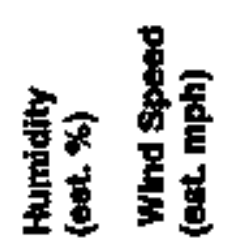 & 音鼻 & 点㗐 & 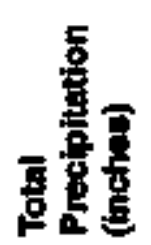 & $\begin{array}{l}\frac{9}{7} \\
\frac{7}{8} \\
\frac{8}{6}\end{array}$ & 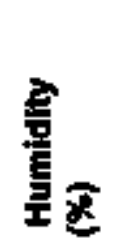 & $\begin{array}{l}\frac{8}{6} \\
\frac{5}{5}\end{array}$ & 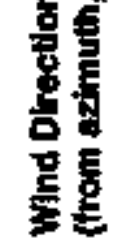 & \\
\hline $0629 / 94$ & & $09+32$ & & & $08 \% 30$ & $09: 30$ & & 25.0 & 65 & 7.4 & 235 & \\
\hline $06 / 29 / 94$ & & $09: 41$ & & & & & & & & & & \\
\hline $06 / 29 / 94$ & & $09: 53$ & & & $08: 45$ & $09: 45$ & & 25.2 & 64 & 8.3 & 240 & \\
\hline $0629 / 94$ & & 10:02 & & & $09: 00$ & $10: 00$ & & 25.4 & 69 & 8.0 & 241 & \\
\hline $06 / 29 / 94$ & & $10: 11$ & & & & & & & & & & \\
\hline $06 / 29 / 04$ & & $10 \div 23$ & & & $09: 15$ & $10: 15$ & & 25.6 & 61 & 7.9 & 252 & \\
\hline $06 / 29 / 94$ & & $10: 32$ & & & $09: 30$ & $10: 30$ & & 26.0 & 60 & 8.2 & 231 & \\
\hline $06 / 29 / 94$ & & $10: 40$ & & & & & & & & & & \\
\hline $07 / 07 / 94$ & 0.00 & $13: 30$ & & & $12: 30$ & $13: 30$ & 0.00 & 30.6 & 57 & 5.2 & 211 & \\
\hline $07 / 07 / 44$ & & $13: 50$ & & & $12: 45$ & $13: 45$ & & 30.7 & 58 & 6.2 & 216 & \\
\hline $07 / 07 / 94$ & & $14: 15$ & & & [3:15 & 14:15 & & 30.9 & 58 & 6.7 & 210 & \\
\hline $07 / 07 / 94$ & & 14:35 & & & 13:30 & $14: 30$ & & 30.9 & 57 & 5.7 & 183 & \\
\hline $07 / 07 / 94$ & & $15: 00$ & & & $14: 00$ & $15: 00$ & & 31.2 & 59 & 5.6 & 169 & \\
\hline $07 / 07 / 94$ & & $15: 15$ & & & $14: 15$ & $15: 15$ & & 31.2 & 57 & 6.5 & 182 & \\
\hline $07 / 07 / 94$ & & $15: 35$ & & & $14: 30$ & $15: 30$ & & 31.0 & 58 & 4.9 & 209 & \\
\hline $07 / 07 / 94$ & & $15: 50$ & & & $14: 45$ & $15: 45$ & & 31.1 & 58 & 59 & 200 & \\
\hline $07 / 07 / 94$ & & $17 \div 25$ & & & $16 \div 15$ & $17: 15$ & & 30.4 & 65 & 3.7 & 203 & \\
\hline $07 / 07 / 94$ & & 19:49 & & & $18: 45$ & $19: 45$ & & 30.2 & 68 & 2.1 & 181 & \\
\hline $07 A 08194$ & 0.41 & $08: 56$ & & & $07: 45$ & $08: 45$ & 0.38 & 24.4 & 83 & 7.2 & 201 & \\
\hline 0710894 & & 09:36 & & & 08:30 & $09: 30$ & & 24.3 & 85 & 7.7 & 212 & \\
\hline $07 / 08 / 94$ & & $16: 06$ & & & $15: 00$ & $16: 00$ & & 29.5 & 70 & 9.0 & 188 & \\
\hline $07 / 09 / 94$ & 0.00 & $09: 06$ & & & 08:00 & $09: 00$ & 0.00 & 21.0 & 76 & 3.4 & 299 & \\
\hline $07 / 09 / 94$ & & $09: 31$ & & & $08: 30$ & $09: 30$ & & 21.3 & 73 & 3.5 & 274 & \\
\hline $07 / 99 / 94$ & & $09: 57$ & & & $08: 45$ & $09: 45$ & & 21.3 & 74 & 3.2 & 263 & \\
\hline $07 / 09 / 94$ & & $10: 21$ & & & 09:15 & $10: 15$ & & 22.1 & 71 & 3.1 & 243 & \\
\hline
\end{tabular}


Table D-1: Weterologic Data for 1994 Femald Fleld Characterization Demongitration Program (continued)

[EDT: Eastem Daytight Time; EST: Eastem Standard Time; est: : estimated; mph: miles per hour]

\begin{tabular}{|c|c|c|c|c|c|c|c|c|c|c|c|c|}
\hline \multirow[b]{2}{*}{ Dati } & \multicolumn{4}{|c|}{ LOCALL } & \multicolumn{7}{|c|}{ TOWEA } & \multirow[b]{2}{*}{$\begin{array}{c}\text { Wonther/Cloud Hoight } \\
\text { (100/4 fi) }\end{array}$} \\
\hline & 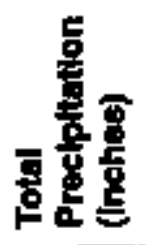 & 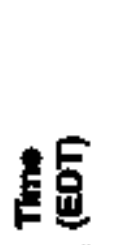 & $\begin{array}{l}\frac{9}{2} \\
\frac{8}{5} \\
5 \\
\end{array}$ & 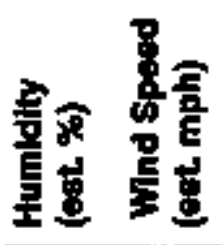 & 春营 & 를 & 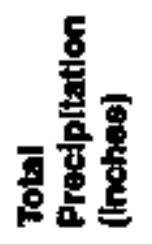 & 㟒量 & 点 & $\frac{8}{8} \frac{8}{8}$ & 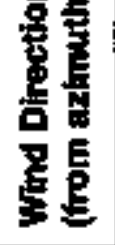 & \\
\hline $07 / 6 / 94$ & & $11: 13$ & & & $10 \div 00$ & $11: 00$ & & 23.2 & 64 & 5.4 & 242 & \\
\hline $07 / 09194$ & & 12:21 & & & $11: 15$ & $12 ; 15$ & & 24.8 & 67 & 6.3 & 234 & \\
\hline $07 / 09 / 94$ & & $35 ; 48$ & & & $14: 45$ & $15: 45$ & & 26.6 & $\$ 6$ & 8.9 & 253 & \\
\hline $07 / 09 / 94$ & & $16: 06$ & & & $15: 00$ & $16: 00$ & & 26.6 & 56 & 7.4 & 265 & \\
\hline $07 / 09 / 94$ & & $17 \div 35$ & & & $16: 30$ & $17: 30$ & & 26.6 & 52 & 8.3 & 256 & \\
\hline $07 / 09 / 94$ & & $17: 57$ & & & $16 \div 45$ & $17: 45$ & & 26.1 & 55 & 6.8 & 256 & \\
\hline $07 / 09 / 94$ & & $19: 43$ & & & $18: 30$ & $19: 30$ & & 25,2 & 59 & 4.6 & 246 & \\
\hline 0709194 & & $20: 02$ & & & $15: 30$ & 16:30 & & 24.6 & 64 & 2.4 & 235 & \\
\hline $07 / 10 / 94$ & 0.00 & $11: 25$ & & & $10 \div 15$ & $11: 15$ & 0.00 & 22.5 & 67 & 5.5 & 315 & \\
\hline 07/10/94 & & $12: 00$ & & & $1 t: 00$ & $12: 00$ & & 23.2 & 63 & 5.6 & 324 & \\
\hline $07 / 1094$ & & $12: 31$ & & & $11: 30$ & $12: 30$ & & 23.1 & 60 & 6.1 & 321 & \\
\hline $07 / 10 / 94$ & & $13 \times 00$ & & & $12: 00$ & 13:00 & & $23 . t$ & 61 & 6.3 & 312 & \\
\hline $07 / 10 / 94$ & & $16: 15$ & & & $15: 15$ & 16:15 & & 24,2 & 53 & 6.7 & 3I] & \\
\hline $07 / 10 / 94$ & & $16: 35$ & & & $15: 30$ & $16: 30$ & & 24.2 & 53 & 7.2 & 337 & \\
\hline $07 / 11 / 94$ & 0.00 & $09: 30$ & & & $08 \div 30$ & $09: 30$ & 0.00 & 18.7 & 79 & 2.6 & 75 & \\
\hline $07 / 11 / 94$ & & $10: 18$ & & & $09: 00$ & $10 \times 00$ & & 20.2 & 75 & 2.0 & 51 & \\
\hline $07 / 11 / 94$ & & $16: 34$ & & & $15: 30$ & $16: 30$ & & 26.2 & 49 & 5.4 & 264 & \\
\hline $0 / 111 / 94$ & & $17: 01$ & & & $16 \div 00$ & $17: 00$ & & 26.6 & 48 & 2.3 & 264 & \\
\hline $07 / 11 / 94$ & & $18: 21$ & & & $17: 15$ & $18: 15$ & & 26.5 & 47 & 2.9 & 278 & \\
\hline $07 / 11 / 94$ & & $18: 48$ & & & $17: 45$ & $18: 45$ & & 26.8 & 46 & 1.9 & 217 & \\
\hline $07 / 12 / 94$ & 0.00 & $09: 54$ & & & $08 \div 45$ & $09: 45$ & 0.00 & 22.5 & 79 & 2.6 & 189 & \\
\hline $0 / / 2 / 94$ & & $10: 00$ & & & $09: 00$ & $10 \div 00$ & & 23.6 & 75 & 2.0 & 159 & \\
\hline $0 / / 12 / 94$ & & $10: 20$ & & & $09: 15$ & $10: 15$ & & 24.2 & 72 & 3.2 & 206 & \\
\hline $07 / 12 / 94$ & & $10: 27$ & & & & & & & & & & \\
\hline $0 / / 12 / 94$ & & 19:28 & & & 18:15 & 19:15 & & 29.1 & 45 & 2.5 & 221 & \\
\hline
\end{tabular}




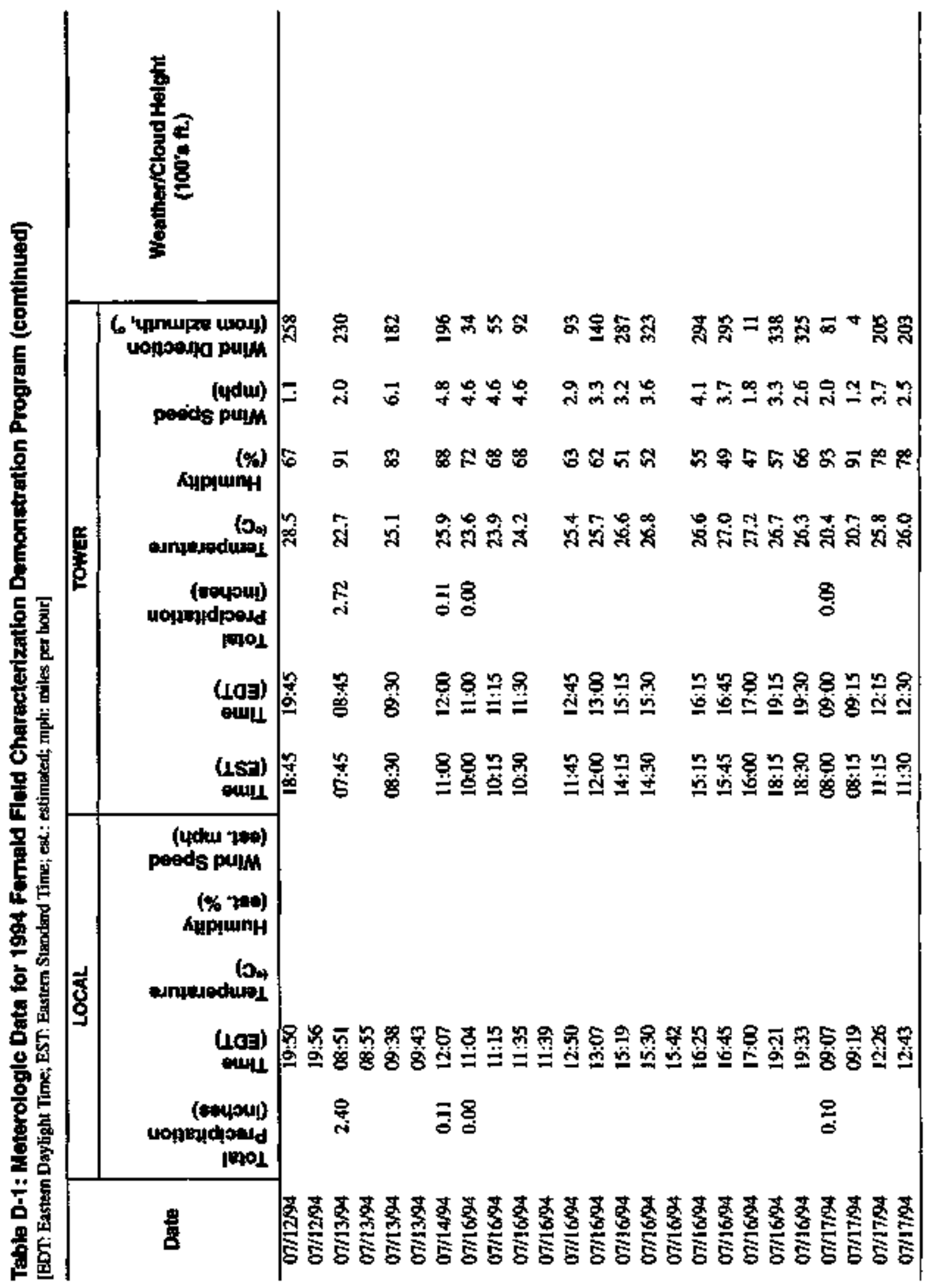


Tabla D-1: Meterologle Data for 1994 Femald Field Characterization Demongtration Program (continued)

[EDT: Eastem Daylight Time; EST: Esstem Standard Time; est: extimated; mph; miles per hoer]

\begin{tabular}{|c|c|c|c|c|c|c|c|c|c|c|c|c|c|}
\hline \multirow[b]{2}{*}{ Date } & \multicolumn{5}{|c|}{ LOCAL } & \multicolumn{7}{|c|}{ TOWER } & \multirow[b]{2}{*}{$\begin{array}{c}\text { Weather/Cloud Height } \\
\text { (100's ft.) }\end{array}$} \\
\hline & 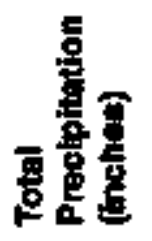 & 垔哥 & 量 & 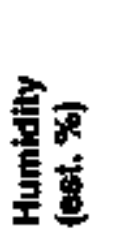 & 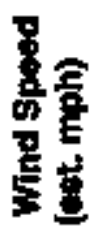 & 吾量 & 点 & 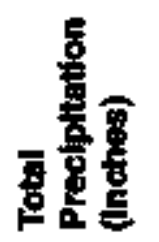 & $\begin{array}{l}0 \\
\frac{8}{8} \\
8\end{array}$ & 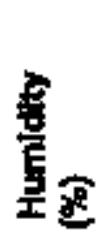 & 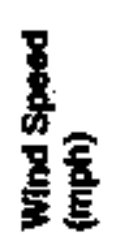 & 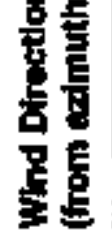 & \\
\hline$\overline{07 / 17 / 94}$ & & $19: 02$ & & & & $18: 00$ & $19: 00$ & & 27.5 & 76 & 3.9 & 224 & \\
\hline $07 / 18 / 94$ & 0.00 & 11: 12 & & & & 10:00 & 11:00 & 0.00 & 26.0 & 68 & 5.5 & 310 & \\
\hline $97 / 18 / 94$ & & $11: 31$ & & & & $10: 30$ & $11: 30$ & & 26.5 & 61 & 5.3 & 303 & \\
\hline $07 / 18994$ & & $14: 31$ & & & & 13:30 & $14: 30$ & & 28.6 & 54 & 3.7 & 227 & \\
\hline $07 / 18 / 94$ & & $14: 43$ & & & & & & & & & & & \\
\hline $07 / 18 / 94$ & & $15: 05$ & & & & 14:00 & $15: 00$ & & 28.3 & 52 & 5.0 & 307 & \\
\hline $07 / 18 / 94$ & & $15: 17$ & & & & $14: 15$ & $15: t 5$ & & 28.6 & 50 & 4.4 & 274 & \\
\hline $07 / 18 / 94$ & & $15: 28$ & & & & & & & & & & & \\
\hline $07 / 19 / 94$ & 0.00 & $09: 04$ & & & & $08 ; 00$ & C9:00 & 0.00 & 20.8 & 88 & 1.9 & 101 & \\
\hline $07 / 19 / 94$ & & $09: 12$ & & & & & & & & & & & \\
\hline $07 / 19 / 94$ & & $09: 16$ & & & & $08: 15$ & $09: 15$ & & 21.9 & 89 & 1.3 & 108 & \\
\hline $07 / 19 / 94$ & & $09: 21$ & & & & & & & & & & & \\
\hline $07 / 19 / 94$ & & $09: 29$ & & & & & & & & & & & \\
\hline $07 / 19 / 94$ & & $13: 39$ & & & & $12: 30$ & $13: 30$ & & 30.3 & 56 & 4.7 & 162 & \\
\hline $07 / 19 / 94$ & & $13: 50$ & & & & 12:45 & $13: 45$ & & 30.3 & 55 & 4.8 & 178 & \\
\hline $07 / 19 / 94$ & & $14: 01$ & & & & $13: 00$ & $14: 00$ & & 30.6 & 56 & 4.5 & 195 & \\
\hline $07 / 19 / 94$ & & $15: 00$ & & & & 14:00 & 14:10 & & 30.6 & 56 & 5.3 & 233 & \\
\hline
\end{tabular}


(This page intentionally left blank.) 
Appendix E: Calibration Data 
Table E-1: Callbration Measurements tor Altemative Characterization Technologies [Leaders (-); not epplicable]

\begin{tabular}{|c|c|c|c|c|c|c|c|}
\hline \multirow{2}{*}{ ID } & \multirow{2}{*}{ Dats } & \multirow{2}{*}{ Time } & \multicolumn{5}{|c|}{ Cullbration Plot Nume } \\
\hline & & & $\mathbf{c o}$ & $c 35$ & 0100 & C200 & $\mathbf{C P}$ \\
\hline \multicolumn{8}{|c|}{$\begin{array}{c}\text { Alpha-Track Detector } \\
\text { (umits are tracks per mul } \text { m }^{2} \text { hour) }\end{array}$} \\
\hline ATD167 & 01-Jun-94 & $16: 00$ & 0.1567 & 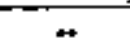 & - & - & - \\
\hline ATD168 & 01-Jun-94 & $16 \times 0$ & -- & - & 0.1875 & - & $\rightarrow$ \\
\hline ATD170 & 01-Jun-94 & $16+00$ & - & 0.2450 & - & 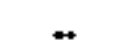 & - \\
\hline ATD222 & 02-Jun-94 & 0830 & 0,0405 & -- & $\cdots$ & - & - \\
\hline ATD2233 & 02-Jun-94 & $09 \div 00$ & - & -- & 0.1993 & - & - \\
\hline ATD224 & 02-Jun-94 & $09: 00$ & $=$ & - & - & 0.3756 & .. \\
\hline ATD225 & $02-J u n-94$ & 0900 & -- & 0.1196 & -- & -- & - \\
\hline ATD226 & O2-Jun-94 & 15700 & 0.0387 & - & + & - & $\rightarrow$ \\
\hline ATD227 & 02-Jun-94 & $15: 00$ & - & - & 0.2073 & -. & -- \\
\hline ATD228 & 02-Jun-94 & $15: 00$ & -- & 0.0970 & - & -- & .. \\
\hline ATD229 & O2-Jun-94 & $15: 00$ & $\cdots$ & - & - & 0.3094 & -. \\
\hline ATD321 & 18-Jul-94 & $13: 41$ & 0.0578 & $=$ & $\leftrightarrow$ & $=$ & .. \\
\hline $\operatorname{ATD} 322$ & 18.Jul-94 & $13: 41$ & -- & 0.1405 & - & - & - \\
\hline ATD323 & 18-Jul-94 & $13: 55$ & - & - & 0.1639 & -- & - \\
\hline ATD324 & 18-Jut-94 & $13+55$ & ** & - & - & -- & 0,0892 \\
\hline ATD401 & 19-Jut-94 & $09 \div 07$ & 0.0504 & - & -. & .. & -- \\
\hline ATD402 & 19-Jn-94 & $09 \times 07$ & -- & - & 0.1675 & -- & .. \\
\hline ATD403 & 19-Jul-94 & 09:07 & - & 0.1468 & - & -- & - \\
\hline ATD40? & 19-Jol-94 & $09: 07$ & - & - & - & .. & 0.0990 \\
\hline \multicolumn{8}{|c|}{$\begin{array}{l}\text { Beta Stintillometer } \\
\text { (units are counts per second) }\end{array}$} \\
\hline BETOO] & 07-Jul-94 & 13.28 & 5.98 & $\leftarrow$ & - & $*+$ & 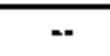 \\
\hline BETOD2 & 07-Jul-94 & $13: 48$ & 6,30 & - & -- & -- & -- \\
\hline BET003 & 07-Jul-94 & $14: 15$ & - & 18.78 & - & -- & -- \\
\hline BETO04 & 07-Jut-94 & $14 \div 34$ & - & 20.14 & - & $=$ & .+ \\
\hline BETO0S & 07-Jul-94 & $14: 54$ & - & - & 26.37 & $=$ & $*$ \\
\hline BETOO6 & 07-J미-94 & $15: 14$ & - & . & 26.75 & - & .. \\
\hline BETOOT & 07-Ja-94 & $15: 34$ & -- & -- & -- & - & 16.06 \\
\hline BETOOS & 07-Ju]-94 & $15: 50$ & - & -- & -- & - & 15.80 \\
\hline BET127 & 11-Jut-94 & $17: 56$ & 7.09 & .. & -. & - & - \\
\hline BET128 & $11-J \mathrm{~b}]-94$ & $18: 12$ & 6.91 & -- & -- & - & - \\
\hline BET729 & 11-Jvl-94 & $18: 50$ & - & 24.68 & + & - & - \\
\hline BET130 & Il-Jul-94 & 19:06 & - & 25.62 & - & -- & - \\
\hline BETI31 & I1-Jul-94 & $19: 24$ & - & .. & 34.41 & - & - \\
\hline BET132 & |1-Jul-94 & $19: 41$ & -- & $\cdots$ & 32.42 & - & - \\
\hline BET144 & 56-Ju\}-94 & $15: 19$ & 6.97 & -- & $=$ & - & -. \\
\hline BET 45 & 16-Ju1-94 & $15: 30$ & 6.85 & - & - & -- & - \\
\hline BET146 & 16-Jul-94 & $15: 42$ & .. & 23.98 & - & .. & - \\
\hline BET147 & 16-Ju1-94 & $16: 25$ & -- & 25.60 & - & - & ** \\
\hline BET 148 & [6-Ju]-94 & $16: 45$ & -- & -- & 33.27 & - & - \\
\hline BET149 & |6-Ju|-94 & 1700 & $\cdots$ & $\rightarrow$ & 33.80 & .. & - \\
\hline
\end{tabular}


Table E-1: Calfbration Meaeurements for Alternative Characterization Technologies (continued)

[Leaders (-): nat applicabte]

\begin{tabular}{|c|c|c|c|c|c|c|c|}
\hline \multirow{2}{*}{ ID } & \multirow{2}{*}{ Dato } & \multirow{2}{*}{ Time } & \multicolumn{5}{|c|}{ Callbration Plot Name } \\
\hline & & & $\mathbf{c o}$ & C35 & $\mathrm{C} 100$ & $\cos$ & $\mathbf{C P}$ \\
\hline \multicolumn{8}{|c|}{$\begin{array}{l}\text { Electret Iotization Chamber } \\
\text { (umits are volts per hour) }\end{array}$} \\
\hline $\mathrm{E} 1 \mathrm{C} 426$ & 02-Jun-94 & $15: 35$ & - & - & - & 14.617 & - \\
\hline $\mathrm{EIC427}$ & 02-Jun-94 & $08: 13$ & - & - & - & 13.559 & - \\
\hline ERC428 & $02-50 n+94$ & $15: 40$ & - & - & 12.056 & - & - \\
\hline EFC429 & 0l-Jun-94 & 1557 & - & - & 8.591 & - & - \\
\hline EIC430 & 01-Jun-94 & 17,02 & $\rightarrow$ & - & - & 11.739 & - \\
\hline EIC435 & O2-Jun-94 & $08: 12$ & - & -- & 15.134 & - & - \\
\hline $\mathrm{EIC} 436$ & O2-Jun-94 & $15: 43$ & -- & 4.310 & - & - & - \\
\hline $\mathrm{EIC437}$ & Q2-Jun-94 & $08: 11$ & - & 3.834 & - & - & - \\
\hline EIC438 & 01-Jun-94 & $16: 50$ & - & 6.158 & $\leftrightarrow$ & - & - \\
\hline EIC439 & 02-Jan-94 & $08: 10$ & 2.834 & - & -- & -- & - \\
\hline EIC440 & O2-Jun-94 & $16: 32$ & $2.84 !$ & - & - & - & -- \\
\hline EIC441 & 01-Jun-94 & $16: 42$ & 3.988 & $\cdots$ & - & - & - \\
\hline EIC534 & 18-Jul-94 & $1374 t$ & 0.630 & - & - & - & - \\
\hline EICS35 & 18-Jul-94 & $13: 41$ & 0.520 & $=$ & -- & - & - \\
\hline EIC536 & 18-Jul-94 & $13: 41$ & -- & 1.300 & $\cdots$ & - & - \\
\hline EIC537 & 18-Jul-94 & $13: 41$ & -- & 3.750 & - & - & - \\
\hline EIC538 & 18-Jul-94 & $13: 41$ & - & $\cdots$ & 1.200 & - & -- \\
\hline EICS39 & 18-Ju1-94 & $13: 41$ & 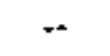 & -- & 2.030 & - & - \\
\hline EIC\$40 & ]B-Jul-94 & $13: 55$ & $*$ & -- & - & -- & 6.250 \\
\hline EIC541 & 18-Jul-94 & $13 \div 55$ & - & -- & $=$ & $=$ & 2.290 \\
\hline \multicolumn{8}{|c|}{$\begin{array}{c}\text { FIDLER Scintillometer } \\
\text { (units are counts per minute) }\end{array}$} \\
\hline FIDOOÓ & 02-Jvn-94 & $08: 08$ & 469 & + & $=$ & 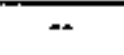 & 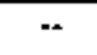 \\
\hline FIDO07 & 02-Jun-94 & $08: 10$ & 440 & - & $m$ & $=$ & - \\
\hline FIDO08 & 02-Juo-94 & $08: 12$ & 440 & - & -- & -- & - \\
\hline FIDOO9 & 02-Jun-94 & $08: 14$ & -- & 808 & -- & 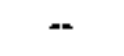 & - \\
\hline FID010 & 02-Jun-94 & $08: 16$ & $\rightarrow$ & 783 & $*$ & - & - \\
\hline FID011 & 02-Jun-94 & $08: 18$ & - & 782 & $=$ & -- & $=$ \\
\hline FIDOI2 & 02-Jtun-94 & $08: 20$ & 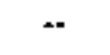 & -- & 918 & -. & -- \\
\hline FIDOI3 & 02-Jun-94 & $08: 22$ & $=$ & -- & 940 & $=$ & - \\
\hline FIDO14 & 02-Jun-94 & $08: 24$ & $-r$ & - & 969 & -- & - \\
\hline FID015 & 02-Jun-94 & 08:26 & - & - & +- & 1633 & -- \\
\hline FID016 & 02-Jun-94 & $08: 28$ & - & - & - & 1622 & - \\
\hline FIIDO17 & 02-Jun-94 & $08: 30$ & 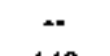 & -- & -- & 1582 & - \\
\hline FIII76 & 06-Jun-94 & $13: 43$ & 449 & - & - & - & 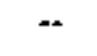 \\
\hline FDD177 & O6-Jun-94 & $13: 45$ & 442 & -- & - & -- & $=$ \\
\hline FID178 & 06-Jun-94 & $13: 55$ & - & 781 & - & -- & - \\
\hline FID179 & 06-Jun-94 & $13: 57$ & $=$ & 735 & - & - & -- \\
\hline FP180 & 06-Jum-94 & $13: 59$ & 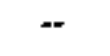 & -- & 964 & - & - \\
\hline FIDI81 & O6-Jun-94 & 14.01 & - & - & 909 & $\rightarrow$ & - \\
\hline FID182 & 06-Jun-94 & 14:03 & - & - & 913 & - & $=$ \\
\hline FP183 & O6-Jun-94 & 14:06 & $=$ & - &.- & 1519 & -- \\
\hline
\end{tabular}


Table E-1: Calfbration Meauurements for Atternetlve Characterization Technologie: (continued)

[Leaders (--): not applicable]

\begin{tabular}{|c|c|c|c|c|c|c|c|}
\hline \multirow{2}{*}{$\mathbf{1 0}$} & \multirow{2}{*}{ Date } & \multirow{2}{*}{ Time } & \multicolumn{5}{|c|}{ Callbration Plot Name } \\
\hline & & & $\mathbf{c o}$ & $\cos 5$ & C100 & $\cos 00$ & $\mathrm{CP}$ \\
\hline FiD184 & $06-\operatorname{Jun}-94$ & $14: 08$ & $\overline{-\sigma}$ & - & 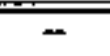 & 1541 & 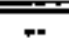 \\
\hline FID2J4 & J0-Jun-94 & $10: 13$ & 463 & - & - & - & $=$ \\
\hline FID215 & 10-Jun-94 & $10: 15$ & 481 & -- & -- & - & - \\
\hline FID216 & $10-3 u n-94$ & $10: 17$ & 479 & .. &.. & -- & - \\
\hline FID217 & 10-Јип-94 & 10.20 & 465 & - & - & - & - \\
\hline FID 218 & 10-J เип-94 & $10: 23$ & 475 & - & - & $\rightarrow$ & - \\
\hline FID219 & 10.Jun-94 & $10: 26$ & - & 785 & $\cdots$ & - & $\leftarrow$ \\
\hline FID220 & 10-Jun-94 & $10: 28$ & - & 767 & -- & - & - \\
\hline FiD221 & 10-Jun-94 & $10: 31$ & - & 748 & .. & - & - \\
\hline FID 222 & 10-Jun-94 & $10: 34$ & $*$ & 764 & - & - & - \\
\hline FID223 & 10-Jun-94 & 10.36 & -- & 762 & - & - & - \\
\hline FID224 & $10-J u p-94$ & $10: 38$ & .. & 797 & - & - & - \\
\hline F1D225 & $10-J u n-94$ & $10: 40$ & - & - & 909 & - & -. \\
\hline FID 226 & 10-Jun-94 & $10: 42$ & - & - & 937 & - & $\omega$ \\
\hline FII227 & 10-Jun-94 & $10: 45$ & -- & -- & 897 & - & - \\
\hline FD228 & $10-5 u n-94$ & $10: 47$ & -. & -- & 953 & -- & -- \\
\hline FD229 & 10-3un-94 & $10: 49$ & $=$ & -- & 921 & - & - \\
\hline FID230 & 10-Jun-94 & 10.53 & - & $=$ & - & 1556 & 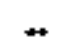 \\
\hline FID231 & $10-J u n-94$ & $10-56$ & -. & -- & - & 1561 & - \\
\hline FID232 & 10-Jun-94 & $10: 58$ & 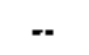 & $=$ & $=$ & 1638 & $\Rightarrow$ \\
\hline FID233 & 10-Jun-94 & 11:01 & - & - & -- & 1543 & $=$ \\
\hline FID234 & 10-Jun-94 & $11: 03$ & -- & -- & -- & 1581 & - \\
\hline FID 303 & 23-Jua-94 & $11: 47$ & 454 & - & -- & - & -- \\
\hline FID304 & 23-Juv-94 & $11: 49$ & 440 & -- & -- & - & - \\
\hline FID 305 & 23-Jvn-94 & 11:51 & 455 & - & $*$ & - & - \\
\hline FID306 & 23-Jun-94 & $11: 56$ & - & 748 & - & $=$ & - \\
\hline FID307 & 23-Jyn-94 & $11: 58$ & -- & 794 & - & -- & -- \\
\hline FID 308 & 23-Jun-94 & $12: 00$ & .. & 773 & .. & - & .. \\
\hline FID309 & 23-Jun-94 & $12: 02$ & -- & - & 898 & - & - \\
\hline FID310 & 23-Jan-94 & $12: 04$ & .. & -. & 928 & - & - \\
\hline FIDS1t & 23-Jun-94 & $12: 07$ & $=$ & $=$ & - & - & $\$ \$ 1$ \\
\hline FID312 & 23-Jun-94 & 1209 & -- & $=$ & - & - & 513 \\
\hline FID313 & 23-Jun-94 & $12: 11$ & -- & - & - & - & 534 \\
\hline \multicolumn{8}{|c|}{$\begin{array}{l}\text { High-Mount Gamma Spectrometer } \\
\text { (units are picocuries per gram of }{ }^{238} \mathrm{U} \text { ) }\end{array}$} \\
\hline GMHO01 & 10-Jul-34 & $11: 25$ & 1.94 & $=$ & - & - & $=$ \\
\hline GMHOO2 & $10-J u l-94$ & $12: 00$ & .. & 34.60 & - & -- & - \\
\hline GMHOO3 & 10-Jul-94 & $12: 31$ & - & 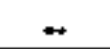 & 46.00 & \# & - \\
\hline \multicolumn{8}{|c|}{$\begin{array}{l}\text { Low Mount Garmma Spectrometer } \\
\text { (units are picocuries per tram of }{ }^{238} \mathrm{U} \text { ) }\end{array}$} \\
\hline GMLO01 & 10-Jv1-94 & $11: 25$ & $\rightarrow$ & 36.70 & + & -- & -- \\
\hline GMLOO2 & $10-\mathrm{J}=1-94$ & $12: 00$ & $1.9 \mathrm{~J}$ & -- & -- & - & - \\
\hline GMLOO3 & 10-Jul-94 & $13: 00$ & - & - & 50.90 & +- & - \\
\hline GML108 & 18-Jut-94 & 15.05 & 0.70 & - & - & - & - \\
\hline
\end{tabular}


Table E-1: Calibration Measurements for Aftemative Characterization Technologiles (continued)

[Leaders ( - ) not applicabie]

\begin{tabular}{|c|c|c|c|c|c|c|c|}
\hline \multirow{2}{*}{$\boldsymbol{D}$} & \multirow{2}{*}{ Date } & \multirow{2}{*}{ Time } & \multicolumn{5}{|c|}{ Carlbration Plot Name } \\
\hline & & & Co & $\cos 5$ & C160 & 0200 & $\mathbf{C P}$ \\
\hline GMLi09 & 18-Jw-94 & 15:17 & $\overline{-1}$ & 33.80 & - & 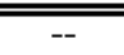 & 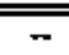 \\
\hline GML110 & 18-Jut-94 & $15: 28$ & - & - & 49.50 & - & - \\
\hline GML111 & 19-Jul-94 & $13: 39$ & 4.10 & -- & -- & -- & -- \\
\hline GML112 & 19-Jul-94 & $13: 50$ & $\cdots$ & 36.90 & $\cdots$ & - & - \\
\hline GML113 & 19-5u1-94 & $14: 01$ & - & - & 47.60 & - & -- \\
\hline \multicolumn{8}{|c|}{$\begin{array}{l}\text { Laser Ablation-Fnductively Coupled Plasuna Spectrontetter } \\
\text { (units are counts of uranium per count of silicon) }\end{array}$} \\
\hline ICPOO1 & 15-Sun.94 & $11: 20$ & .0051 & - & - & - & - \\
\hline ICPOON & 15-Jun-94 & $11: 40$ & - & .0367 & - & - & - \\
\hline ЕСРOO3 & 15-Jun-94 & $12: 02$ & -- & -- & .0508 & - & - \\
\hline ICPOO4 & 15-Jun-94 & $12: 20$ & .0041 & - & 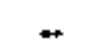 & - & - \\
\hline ICPOOS & 15-Јшп-94 & $12 \div 34$ & - & .0397 & - & - & - \\
\hline ICPOO6 & 15-Jun-94 & $12: 50$ & - & - & .0504 & - & - \\
\hline ICP0O7 & 15-Jun-94 & 13.06 & .0046 & - & - & - & - \\
\hline ICPOOS & 15-Jun-94 & $13: 21$ & -- & .0394 & - & - & - \\
\hline КСРО09 & 15-Jun-94 & 13.35 & - & - & .0502 & - & - \\
\hline ICPO20 & 16-Jum-94 & $08: 45$ & - & .0367 & + & - & - \\
\hline ICPO34 & 17-Jコน-94 & $10: 50$ & - & $.034 \mathrm{I}$ & - & - & - \\
\hline ICPO42 & 18-Jan-94 & $10: 51$ & .0040 & -- & - & -- & -- \\
\hline ICPO43 & 18-Jun-94 & $11: 00$ & +2 & .0247 & -. & - & - \\
\hline ICPO44 & 18-Jun-94 & 11:08 & - & - & .0304 & - & - \\
\hline ICPOSS & 18-Jun-94 & $14: 38$ & - & .0211 & - & - & - \\
\hline IClo7s & 19-Jun-94 & $13: 43$ & - & .0298 & - & - & $*$ \\
\hline ICPQ96 & 19-Juท-94 & $09: 12$ & - & .0221 & - & $=$ & - \\
\hline ICP1I2 & 20-Juo-94 & 10,06 & - & .0206 & - & - & - \\
\hline ICP125 & 20-Jun-94 & 11:16 & - & .0265 & - & - & - \\
\hline ICP130 & 20-Jun-94 & $13: 48$ & - & .0248 & - & - & $=$ \\
\hline ICP14I & $20-\mathrm{Jun}-94$ & $07: 27$ & .. & .0248 & - & - & -- \\
\hline ICP158 & 21-Jua-94 & $10: 11$ & - & .0241 & - & - & - \\
\hline ICP159 & 21-Jun-94 & $10: 23$ & .0068 & - & - & - & - \\
\hline ICP176 & 12-0cl-94 & $08: 40$ & .0018 & - & - & - & - \\
\hline ICP177 & $12-0 \mathrm{ct}-94$ & 08.51 & - & .0212 & - & - & - \\
\hline ICP192 & 12-Oct-94 & $13: 24$ & .0029 & - & - & - & - \\
\hline ICP193 & $12-0 \mathrm{ct}-94$ & 13:35 & - & .0264 & - & - & - \\
\hline \multicolumn{8}{|c|}{$\begin{array}{l}\text { Long-Range Alpha Dettctor } \\
\text { (units are fempto-amperes) }\end{array}$} \\
\hline$\overline{\text { LRAOO1 }}$ & 07-Jun-94 & 10.49 & 5700 & - & $=$ & - & - \\
\hline LRA002 & 07-Jun-94 & $11: 30$ & - & 7600 & -- & - & -- \\
\hline LRA003 & 97-Jun-94 & $11: 44$ & $\rightarrow$ & - & 9800 & - & - \\
\hline LRAOO4 & 07-Jun-94 & $12: 02$ & - & - & - & 19000 & - \\
\hline LRA101 & 10-Jun-94 & 10.11 & - & - & 9600 & - & - \\
\hline LRA102 & 10-Jun-94 & $10: 27$ & 6400 & - & - & - & -- \\
\hline LRA103 & 10-Jun-94 & $10: 41$ & - & 7800 & - & -. & -- \\
\hline
\end{tabular}


Table E-1: Caflbration Measurements for Alternative Characterlzation Fechnologles (continumd)

[Leaders (-c): not Ipplicabte]

\begin{tabular}{|c|c|c|c|c|c|c|c|}
\hline \multirow{2}{*}{$\mathbf{0}$} & \multirow{2}{*}{ Dete } & \multirow{2}{*}{$\operatorname{Tim}$} & \multicolumn{5}{|c|}{ Calbration Plot Name } \\
\hline & & & $\mathbf{c o}$ & $\cos$ & C100 & C200 & $\mathbf{C P}$ \\
\hline \multicolumn{8}{|c|}{$\begin{array}{l}\text { Sodium-lodide Scintillotreter } \\
\text { (tunits pete counts per minute) }\end{array}$} \\
\hline NADO06 & 31-May-94 & $10: 50$ & 3717 & $\ldots$ & - & 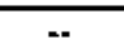 & 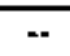 \\
\hline NADOO7 & 31-May-94 & $10: 52$ & 3724 & $\ldots$ & - & - &.- \\
\hline NADO08 & 31-May-94 & $10: 55$ & - & 5361 & $\cdots$ & - & -- \\
\hline NADO09 & 31-May-94 & 10:57 & - & 5420 & - & -- & -- \\
\hline NADOIO & 3]-May-94 & $10: 59$ & -- & 5420 & - & -- & - \\
\hline NATOOII & 31-May-94 & $11: 02$ & - & - & 6340 & -- & - \\
\hline $\mathrm{NADO12}$ & 31-May-94 & $11: 04$ & - & -- & 6250 & -- & -- \\
\hline NADO13 & 31-May-94 & $11: 07$ & $*$ & $\rightarrow$ & 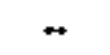 & 9970 & -- \\
\hline NAD014 & 31-May-94 & $11: 09$ & - & -. & -- & 9870 & -- \\
\hline NAD119 & 01-Jun-94 & 13:17 & 3704 & - & - & .. & .. \\
\hline NADI20 & 01-Jun-94 & $13: 26$ & 3703 & - & - & - & - \\
\hline NADI21 & $01-J n n-94$ & $13: 28$ & -- & 5360 & - & -- & - \\
\hline NAD122 & 01-Jon-94 & $13: 31$ & $\ldots$ & 5210 & - & - & - \\
\hline NAD123 & 01-Jon-94 & $13: 34$ & $\leftrightarrow$ & $\cdots$ & 6050 & - & - \\
\hline NADI24 & O1-Jun-94 & $13: 36$ & - & -- & 6200 & -- & - \\
\hline NADI2S & (01-Jon-94 & $13: 39$ & $\ldots$ & - & - & 9820 & - \\
\hline NAD126 & 01-Jun-94 & $13: 41$ & -- & - & - & 10020 & - \\
\hline NAD 127 & O1-Jan-94 & $13: 43$ & -- & -- & - & 9870 & - \\
\hline NADI38 & 03-Jun-94 & 1000 & 3571 & $*$ & 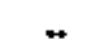 & $\leftrightarrow$ & - \\
\hline NAD139 & O9-Jun-94 & 1004 & 377 & - & - & - & - \\
\hline NAD 40 & 6)-Jan-94 & 10.06 & 3720 & -. & - & - & - \\
\hline NAD 141 & 03-Jun-94 & 1009 & 3735 & - & - &.- & - \\
\hline NAD142 & 03-Jun-94 & 10.14 & 3856 & -- & - & -- & - \\
\hline NAD 143 & 03-Jun-94 & $10: 16$ & -. & 5400 & - & - & - \\
\hline NAD144 & 03-Jun-94 & $10: 19$ & $\cdots$ & 5400 & - & - & - \\
\hline NAD145 & 03-Jyn-94 & $10: 21$ & - & 5450 & - & - & - \\
\hline NAD146 & 03-Jun-94 & 1025 & -- & $\$ 400$ & - & -. & - \\
\hline NAD147 & 03-Jun-94 & $10 \div 27$ & -- & 5650 & - & -- & -. \\
\hline NAD148 & 03-Jun-94 & $10 \div 30$ & $\cdots$ & - & 6100 & 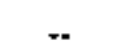 & -. \\
\hline NAD149 & 13-Jun-94 & $10 \div 34$ & .. & - & 6300 & - & - \\
\hline NAD150 & 03-Јил-94 & $10: 36$ & - & $\rightarrow$ & 6400 & $\cdots$ & $*$ \\
\hline NAD1S1 & 03-Jun-94 & $10: 40$ & - & - & 6430 & - & -- \\
\hline NAD152 & 03-Jun-94 & $10+43$ & - & - & 6450 & - & -- \\
\hline NAD 153 & 03-Jun-94 & 10,46 & - & - & - & 10000 & -- \\
\hline NAD154 & 03-Jun-94 & $09-45$ & - & - & .. & 9970 & -- \\
\hline NAD1S5 & 03-Jun-94 & 09550 & - & - & - & 10050 & $=$ \\
\hline NAD156 & 03-Јил-94 & $09: 55$ & - & - & -- & 10030 & -- \\
\hline NAD157 & 03.Jun+94 & 09:58 & - &. & - & 10170 & $=$ \\
\hline \multicolumn{8}{|c|}{$\begin{array}{l}\text { X-Ray Fluorescence Unit } \\
\text { (units are parts per million) }\end{array}$} \\
\hline XRFO01 & 03-Jun-94 & $10: 08$ & 1.5065 & $\overline{-}$ & - & - & - \\
\hline $\mathrm{XRF} O \mathrm{OM}$ & 03-Jun-94 & $10: 18$ & 7.1392 & -- & - & - & - \\
\hline
\end{tabular}


Table E-1: Caltbration Meesurements for Alternative Character|zetion Technologies (Continued)

[Leaders (-); not applicable]

\begin{tabular}{|c|c|c|c|c|c|c|c|}
\hline \multirow{2}{*}{$\mathbf{0}$} & \multirow{2}{*}{ Dato } & \multirow{2}{*}{ Thros } & \multicolumn{5}{|c|}{ Cadibretion Plot Name } \\
\hline & & & Co & $\cos 5$ & C100 & $\cos$ & $\mathbf{C P}$ \\
\hline XRF00 & 03-Jun-94 & $10: 28$ & 2.4741 & - & 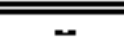 & - & $\overline{-1}$ \\
\hline XRF004 & 03-Jun-94 & 10:38 & 5.0143 & - & - & -. & - \\
\hline XRF00S & 03-Jun-94 & $10: 48$ & -3.128 & - & - & - & - \\
\hline XRFO06 & 03-Jum-94 & $10: 59$ & - & 87.620 & - & - & -- \\
\hline XRFON7 & 03-Jun-94 & 11:09 & $\rightarrow$ & 87.092 & - & - & -- \\
\hline XRFO08 & 03-Jun-94 & $11: 21$ & - & 83.774 & - & $\leftarrow$ & - \\
\hline XRFO09 & 03-Jun-94 & $11: 31$ & -- & 83.227 & - & - & - \\
\hline XRF010 & 03-Jun-94 & $11: 41$ & -- & 80.580 & - & - & - \\
\hline XRE011 & 03-Jun-94 & 11:51 & - & $\leftarrow$ & 131.23 & - & - \\
\hline XRF012 & 09-Jun-94 & $12: 01$ & - & - & 130.38 & - & - \\
\hline XRF013 & 03-Ju-144 & $12 ; 10$ & .. & - & 126.26 & - & - \\
\hline XRF[0]4 & 03-Jun-94 & $12: 20$ & - & - & 134.51 & -. & -- \\
\hline XRF015 & 03-Jun-94 & $12 \div 30$ & - & - & 137.20 & - & - \\
\hline XRF016 & 03-h1m-94 & $12: 41$ & - & -- & - & 297.76 & - \\
\hline XRF017 & 03-Jun-94 & $13: 01$ & $=$ & $*$ & - & 469.40 & - \\
\hline XRF018 & 03-Juด-94 & $09-57$ & - & - & - & 330.44 & - \\
\hline XRFD19 & (66-J山-94 & 10.09 & - & -- & -. & 293.20 & - \\
\hline XRF020 & O6-Jan-94 & $09: 58$ & - & - & - & 320.06 & - \\
\hline XRF134 & 28-Jun-94 & $10: 04$ & -.3322 & - & -- & - & - \\
\hline XRF135 & 28-Jun-94 & 10:17 & 8.0806 & -- & -- & - & - \\
\hline XRF136 & 28-Jon-94 & $10: 26$ & 11.063 & - & - & -- & -- \\
\hline XRF137 & 2\&-Jun-94 & 10.35 & +14989 & - & - & -- & -. \\
\hline XRF138 & 28.Jun-94 & 10.45 & 6.3455 & -- & -- & $=$ & - \\
\hline XRF139 & 28-J壮-94 & 11:04 & - & 81.606 & - & - & - \\
\hline XRF140 & 28-Jun-94 & $11: 13$ & -- & 60.776 & - & - & - \\
\hline XRF141 & 28-Jun-94 & $11: 22$ & -- & 82.830 & - & - & - \\
\hline XRFI42 & 28-Jun-94 & $11: 44$ & -. & 72.294 & - & - & - \\
\hline XRP143 & 28-Jũ-94 & 09.52 & - & 97.769 & - & - & - \\
\hline XRF144 & 29-Jun-94 & $10: 02$ & -- & -- & 150.49 & - & - \\
\hline XRF145 & 29-Jun-94 & $10: 11$ & .. & - & 110 & - & -- \\
\hline XRP146 & 29-Jun-94 & 10.23 & - & - & 107.17 & - & - \\
\hline XRPJ47 & 29-Jun-94 & $10: 32$ & - & - & 119.15 & - & .. \\
\hline XRFI48 & 29-Jun-94 & $10: 40$ & - & - & 133,93 & - & - \\
\hline XRFI49 & 29-Jun-94 & $09: 13$ & - & - & - & - & 45.716 \\
\hline XRFI50 & 29-Jun-94 & $09: 22$ & - & - & $\leftarrow$ & - & 62.459 \\
\hline XRF $] 51$ & 29-Jun-94 & $09: 32$ & - & - & - & - & 74.296 \\
\hline XRFl52 & 29-Jun-94 & $09: 41$ & - & - & - & -- & 56.234 \\
\hline XRF153 & 29-Jun-94 & $09: 53$ & - & - & - & - & 59.668 \\
\hline XRF173 & 01-Jut-94 & 10.03 & 5.1425 & - & - & - & - \\
\hline XRF174 & 01-Jut-94 & $10: 12$ & 9.5908 & - & - & - & -- \\
\hline XRF175 & 01-Ju1-94 & $10: 23$ & 1.9863 & - & - & - & - \\
\hline XRF176 & 01-Juf-94 & $10: 33$ & 8.0542 & -- & - & - & - \\
\hline XRF177 & 01-Jul-94 & $10: 44$ & 3.7396 & - & - & - & - \\
\hline XRF178 & 01-Jul-94 & $10: 56$ & - & 78.945 & - & - & -. \\
\hline
\end{tabular}


Table E-1: Calbration Measurements for Altemative Characterization Technologies (continued)

[Leaders (-): not applìcable]

\begin{tabular}{|c|c|c|c|c|c|c|c|}
\hline \multirow{2}{*}{$\mathbf{D}$} & \multirow{2}{*}{ Dots } & \multirow{2}{*}{ Time } & \multicolumn{5}{|c|}{ Callbration Plot Name } \\
\hline & & & $\mathbf{C o}$ & C35 & 6100 & Cogo & $\mathbf{C P}$ \\
\hline 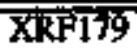 & 61-J़ी-94 & $=0$ & $\overline{---}$ & 69.607 & $\overline{-}$ & 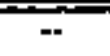 & $=$ \\
\hline XRF180 & 01-Juj-94 & 13:02 & $\rightarrow$ & 66.563 & - & .. & $\rightarrow$ \\
\hline XRF181 & 01-Ju\}-94 & 13:13 & $*$ & 69.512 & • & + & $\omega$ \\
\hline XRP182 & 01-Jul-94 & $13: 21$ & -- & 78.027 & - & -- & - \\
\hline XRF183 & 01-Ju-94 & $13 ; 30$ & -- & -- & 120.03 & -- & - \\
\hline XRF184 & 01-Ju]-94 & $13: 40$ & -- & - & 113.09 & -- & -- \\
\hline XRF185 & $01-J u t-94$ & $13: 49$ & -- & - & 119.54 & - & - \\
\hline XRF186 & 01-Jw1-94 & 13:59 & -- & - & 118.09 & -- & - \\
\hline XRF187 & 01-Ju1-94 & 14:07 & 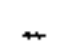 & $*$ & 139.24 & - & - \\
\hline XTF188 & 01-Jul-94 & $14: 18$ & -- & - & - & -- & 43.615 \\
\hline XRF189 & 01-Jul-94 & $14: 27$ & -- & - & - & -- & 68.619 \\
\hline XRF190 & 01.Jul-94 & $09: 32$ & - & $=$ & - & - & 71.211 \\
\hline XRF191 & 01-Ju1-94 & $09: 43$ & -- & - & - & - & 39.051 \\
\hline XRF192 & 0|-Jul-94 & 09.53 & -. & - & - & - & 52.116 \\
\hline
\end{tabular}


Appendlx F: Standard Sites Data 
Table F-1: Standard-Sitea Reasurements by all Technologles Except ICP

[Times ate Eastern Daylight Time; fow data measurememt units vary by technology; total uranibm in picocuries per gram.

Leaders (-) ined cate no data]

\begin{tabular}{|c|c|c|c|c|c|c|c|c|c|}
\hline \multicolumn{5}{|c|}{ Stanchard stite 1} & \multicolumn{5}{|c|}{ Standard Stto 2} \\
\hline Date & Time & 10 & $\begin{array}{l}\text { Raw } \\
\text { Data }\end{array}$ & $\begin{array}{c}\text { Total } \\
\text { Uranitum }\end{array}$ & Datso & Tims & ID & $\begin{array}{l}\text { Paww } \\
\text { Donta }\end{array}$ & $\begin{array}{c}\text { Total } \\
\text { Uranium }\end{array}$ \\
\hline \multicolumn{10}{|c|}{$\begin{array}{l}\text { Alphe-Track Detector } \\
\text { (raw dute units are tracks/mm }\end{array}$} \\
\hline 02-Jun-94 & $07: 55$ & ATD215 & 0.0752 & 18.86 & 02-Jum-94 & $07: 57$ & ATD217 & 0.0747 & 18.28 \\
\hline 18-Ju1-94 & $12: 00$ & ATD319 & 0.0711 & 14.08 & 18-Jul-94 & $12 \div 00$ & ATD320 & 0.0631 & 4.77 \\
\hline 19-Jul-94 & $14: 10$ & ATD440 & 0.2192 & 186.53 & 19-Jn1-94 & $14: 10$ & ATD441 & 0.1033 & 51.58 \\
\hline \multicolumn{10}{|c|}{$\begin{array}{c}\text { Beta Seintillonseter } \\
\text { (ray dets units are counts per second) }\end{array}$} \\
\hline $07 \cdot 501-94$ & $19: 49$ & B̈ET0I 6 & 19.82 & 77.80 & 07.501 .94 & $17: 25$ & BET009 & 16,30 & 5758 \\
\hline 08-Jul-94 & $08: 56$ & BET017 & 20.58 & 82.17 & 08-Jul-94 & $09: 36$ & BETO18 & 18.11 & 6798 \\
\hline 09-Ju1.94 & $09: 06$ & BET0S0 & 16.78 & 60.34 & 08-5:1-94 & $16: 06$ & BET042 & 16.39 & 58.10 \\
\hline 09-Jul-94 & $09: 57$ & BET052 & 16.11 & 56.49 & 09-Jut-94 & $09: 31$ & BETDSI & 14.17 & 4534 \\
\hline 09-Jul-94 & 11:13 & BETOS4 & 16.82 & 60.57 & 09-Ju1-94 & $10: 21$ & BET053 & 13.96 & 44.14 \\
\hline 09-Ful-94 & $12: 21$ & BETOS\$ & 16,00 & 55.86 & 09-Jul-94 & $16: 06$ & BETO70 & 16.12 & 56.55 \\
\hline 09-Jul-94 & $14: 04$ & BETQ63 & 16.69 & 59.82 & $09 . \mathrm{Jul}-94$ & $17: 35$ & BET075 & 16.53 & 58.90 \\
\hline 09-Jal-94 & $15: 48$ & BETOGS & 18.79 & 71.88 & 69-Jul-94 & $20: 02$ & BET083 & 16.04 & 56.09 \\
\hline 09-Ju1-94 & $17 \div 57$ & BET076 & 18.63 & 70.97 & 10-Jul-94 & $09: 37$ & BET085 & 14.62 & 47.93 \\
\hline 09-Jut-94 & $19: 43$ & BETOS2 & 18.82 & 72.06 & 10-Ju[-94 & $11: 24$ & BET09J & 16.24 & 57.24 \\
\hline 10-Jul-94 & $09: 16$ & BETO\$4 & 18.10 & 67.92 & 10-Jul-94 & $12+55$ & BETO96 & 15.49 & 52.93 \\
\hline 10-Jul-94 & $13: 29$ & BETO9? & 18.03 & 67.52 & 10-JuL-94 & $16: 21$ & BET106 & 15.67 & 53.96 \\
\hline 10-Juk-94 & $15+39$ & BET1OS & 18.86 & 72.29 & 11-Jul-94 & $10: 35$ & BET109 & 21.33 & 86.48 \\
\hline 11-Ju1-94 & $09: 17$ & BET10? & 18.53 & 70.39 & 11-Jul-94 & $13: 25$ & BET118 & 15.20 & 51.26 \\
\hline 11-Jul-94 & $10 \times 09$ & BET108 & 18.53 & 70.39 & 11-Jul-94 & $16: 56$ & BET12S & 14.52 & 47.35 \\
\hline $11-3|1|-94$ & $13+00$ & BET117 & 18.42 & 69.76 & 16-Jul-94 & $11 \div 39$ & BET134 & 12.89 & 37.99 \\
\hline 1]-Jul-94 & $17 \div 26$ & BET126 & 17.48 & 64.36 & 16.Jul-94 & $12: 50$ & BET139 & 12.23 & 34.20 \\
\hline |6-Jn|-94 & 11:04 & BET133 & 17.22 & 62.87 & -- & - & - & - & - \\
\hline 16-Ju1-94 & $13: 07$ & BET I 40 & 16.03 & 56.03 & + & * & - & - & - \\
\hline \multicolumn{10}{|c|}{$\begin{array}{l}\text { Electret lonization Chamber } \\
\text { (raw data units are volts per bour) }\end{array}$} \\
\hline 01-Jun-94 & $17: 25$ & EIC363 & 4.41 & 73.37 & 01-Junt-94 & $17: 28$ & EIC365 & 2.61 & 22.81 \\
\hline 18-Jul-94 & $12: 00$ & EIC518 & 1.62 & $-4.9]$ & 18-Jal-94 & 12:00 & EICS19 & 2.08 & 8.01 \\
\hline \multicolumn{10}{|c|}{$\begin{array}{c}\text { FIDLER Detector } \\
\text { (raw data units are couns per minute) }\end{array}$} \\
\hline 02-Jun-94 & $09: 00$ & FID018 & 775 & 103.78 & 02-Jun-94 & $09: 05$ & $\mathbf{F L D O 2 0}$ & 674 & 75.18 \\
\hline 02-5un-94 & $09: 02$ & FIDO19 & 752 & 97.27 & 02-Jun-94 & $09: 07$ & FIDO21 & 755 & 98.12 \\
\hline 02-Jun-94 & $13: 24$ & FID083 & 740 & 93.87 & C2-Jun-94 & $13: 27$ & FID084 & 698 & 81.97 \\
\hline 03-Јup-94 & $13 \div 21$ & FW095 & 752 & 97.27 & 03-Jun-94 & $13: 26$ & FID096 & 729 & 90.75 \\
\hline 03-Jun-94 & $14: 51$ & FID124 & 751 & 96.98 & 03-Jan-94 & $34 \div 57$ & FID126 & 676 & 75.74 \\
\hline
\end{tabular}


Table F-1: Standard-Sites Measurrements by all Technologles Except ICP (continued)

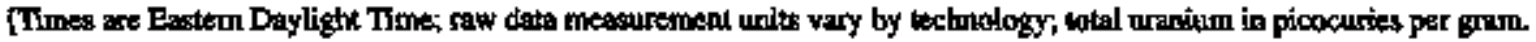
Leaders (-) indicate no dab]

\begin{tabular}{|c|c|c|c|c|c|c|c|c|c|}
\hline \multicolumn{5}{|c|}{ Standend Stte 1} & \multicolumn{5}{|c|}{ Standard Slte 2} \\
\hline Dete & Tinto & ID & Raw & $\begin{array}{c}\text { Total } \\
\text { Uranium }\end{array}$ & Date & Thine & 10 & $\begin{array}{l}\text { Raw } \\
\text { Data }\end{array}$ & $\begin{array}{l}\text { Total } \\
\text { Uranhim }\end{array}$ \\
\hline 03-Jun-94 & $14 \div 54$ & FID125 & 740 & 93.87 & $06-J u n-94$ & $10 \div 31$ & FD138 & 716 & 87.07 \\
\hline O6-Jun-94 & $10: 28$ & FID 137 & 763 & 100.38 & 06-รип-94 & $13 \div 31$ & FID 175 & 732 & 91.60 \\
\hline 06-Jun-94 & $13 \div 28$ & FID174 & 705 & 83.96 & 09-J斻-94 & $11: 03$ & F1D197 & 638 & 64.98 \\
\hline $09-J u n-94$ & $10-5]$ & FW195 & 683 & 77.73 & 09-Jnמ-94 & $11: 05$ & FIDI98 & 613 & 57.90 \\
\hline 09-Jun-94 & $10+53$ & FIDI96 & 711 & 85.66 & I0-Jun-94 & $09: 57$ & FD212 & 683 & 77.73 \\
\hline 10-Jun-94 & $09 \div 49$ & FID210 & 77 & 104,35 & 10-Jun-94 & $09: 59$ & FID 213 & 668 & 73.48 \\
\hline 10-Jư-94 & $09 \div 51$ & FID 211 & 769 & 102.08 & 13-Jun-94 & $09: 49$ & Flb247 & 600 & 54.22 \\
\hline 13-Jun-94 & $09 \div 36$ & FD245 & 678 & 76.31 & 13-Jun-94 & $09: 51$ & FID248 & 627 & 61.87 \\
\hline $13-J u t-94$ & $09: 39$ & F1D246 & 650 & 68.38 & 14-Jun-94 & $13: 20$ & $\mathrm{FID26!}$ & 632 & 69.28 \\
\hline 14-Jun-94 & $13: 07$ & FID259 & 660 & $\gamma 1.21$ & 14-Jun-94 & $13 \div 22$ & FID262 & 642 & 66.11 \\
\hline 14-Jun-94 & 13:09 & FID260 & 686 & 78.58 & 16-Jun-94 & $09: 32$ & $\mathrm{~F}[\mathrm{D} 275$ & 668 & 73.48 \\
\hline 16-Jun-94 & $09: 20$ & $\mathrm{FID} 273$ & 745 & 95.28 & 16-Jun-94 & $09: 34$ & $\mathrm{FID} 276$ & 705 & 83.96 \\
\hline 16-Jun-94 & $09: 22$ & $\mathrm{FID} 274$ & 740 & 93.87 & 17-Jun-94 & $10: 47$ & FID289 & 686 & 78.58 \\
\hline 17-Jun-94 & $10: 41$ & FD287 & 729 & 90.75 & $17-31 \mathrm{~m}-94$ & $10: 49$ & $\mathrm{~F} 1 \mathrm{D} 290$ & 722 & 88.77 \\
\hline 17-Jun-94 & $10: 43$ & FID288 & 728 & 90.47 & 23-Jun-94 & $10 \div 37$ & FID296 & 695 & 81.12 \\
\hline 23-Jun-94 & $10: 42$ & FID297 & 772 & 102.93 & $\cdots$ & -. & $\omega$ & - & -- \\
\hline \multicolumn{10}{|c|}{$\begin{array}{l}\text { High-Mount Gamma Spectrometer } \\
\text { (raw data units are picocuries per gram) }\end{array}$} \\
\hline 11-Ivl-94 & $69: 30$ & GMHOOS & 27.7 & 82.73 & 11-Jul-94 & $18: 48$ & GMHO23 & 17.9 & 5251 \\
\hline 11+Jul-94 & $16: 34$ & GMH018 & 28.6 & 85.51 & 12-Jul-94 & $09: 54$ & GMHO26 & 18.5 & 54.36 \\
\hline 12-Jul-94 & $10: 20$ & GMH027 & 28.7 & 85.81 & 12-Jul-94 & $19: 28$ & GMH045 & 18.7 & 54.97 \\
\hline 12-Jol-94 & $19: 50$ & GMH046 & 28.8 & 86.12 & 13-Jul-94 & 08:55 & GMH047 & 19.1 & 56.21 \\
\hline 13-Jul-94 & $09: 43$ & СМн048 & 28.0 & 83.66 & 16-Jul-94 & $11: 14$ & GMHOSO & 14.9 & 43.26 \\
\hline 16-5ul-94 & 12:07 & GMH059 & 23.3 & 69.16 & 16-Jut-94 & $19: 21$ & GMH094 & 14.6 & 42.33 \\
\hline 16-ful-94 & 11:35 & GMH061 & 23.1 & 68.54 & t7-Jul-94 & $09: 19$ & GMH097 & 15.5 & 45.11 \\
\hline 16-Jul-94 & $19: 33$ & GMH095 & 24.0 & 71.32 & - & + & $=$ & - & + \\
\hline 17-Jul-94 & $09: 07$ & GMH096 & 14.6 & 42.33 & - & - & - & - & $*$ \\
\hline \multicolumn{10}{|c|}{$\begin{array}{l}\text { Low Mount-Gamma Spectrometer } \\
\text { (raw data units are picocuries per gran) }\end{array}$} \\
\hline 11-Jut-94 & $10 \div 08$ & GMLOO6 & 29.9 & 84.42 & 11-Jul-94 & $18: 21$ & GMLO23 & 19.0 & 52.62 \\
\hline 11-Jul-94 & $17 \div 01$ & GMLOZO & 32.2 & 91.13 & 12-Jul-94 & $10: 27$ & GMLO28 & 20.0 & 55.53 \\
\hline 12-Ju]-94 & 10,00 & GMLO27 & 31.3 & 8851 & 12-Jul-94 & 19:56 & GMLO46 & 20.2 & 56.12 \\
\hline 12-Jul-94 & $19: 35$ & GMLO45 & 31.7 & 89.68 & 13-Jul+94 & 09:38 & GML048 & 20.0 & 55.53 \\
\hline 13-Jul-94 & $08: 51$ & GMLO47 & 32.5 & 92.01 & 17-Jul-94 & $12 \div 43$ & GMLO61 & 15.1 & 41.23 \\
\hline 17-Jul-94 & $12: 26$ & GMLO60 & 25.6 & 71.87 & 18-Jul-94 & $11: 12$ & GML094 & 13.4 & 36.27 \\
\hline 17-Jul-94 & 19,02 & GMLO93 & 25.8 & 72.46 & 18-jul-94 & $14: 43$ & GML107 & 14.7 & 40.07 \\
\hline 18-Jul-94 & $11: 31$ & GMLOSS & 26.8 & 75.38 & 19.Jul-94 & $15: 00$ & GMLI14 & 17,3 & 47.65 \\
\hline
\end{tabular}


Table F-1: Standard-Sltes Measurements by all Technologies Except ICP (continued) [Times aie Esstem Daylight Time; raw data meabufememt units vary by technology; total uraniom in picocuries per gram. Leaders (-) indicate no data]

\begin{tabular}{|c|c|c|c|c|c|c|c|c|c|}
\hline \multicolumn{5}{|c|}{ Standard stot 1} & \multicolumn{5}{|c|}{ Standard stto 2} \\
\hline Deto & Thue & ID & $\begin{array}{l}\text { Ran } \\
\text { Data }\end{array}$ & $\begin{array}{c}\text { Total } \\
\text { Uranium }\end{array}$ & Date & Thmo & ID & $\begin{array}{l}\text { Row } \\
\text { Datu }\end{array}$ & $\begin{array}{c}\text { Total } \\
\text { Uranlium }\end{array}$ \\
\hline 18-Jul-94 & $14: 31$ & GML106 & 25.6 & 71.87 & $=$ & - & - & - & - \\
\hline \multicolumn{10}{|c|}{$\begin{array}{l}\text { Long-Range Aloba Detector } \\
\text { (raw data units are fempto amperes) }\end{array}$} \\
\hline Q8-Jun-94 & $08: 55$ & LRAOOS & 6400 & 46.02 & 08-Jun-94 & $09: 10$ & LRAONG & 6800 & 55.39 \\
\hline Os-Jun-94 & $18+11$ & LRAO45 & 7700 & 76.49 & 08-Jun-94 & $18: 23$ & LRAO46 & 8700 & 99.93 \\
\hline 09-Jun-94 & $\phi 9: 32$ & LRA051 & 7300 & 67.11 & $09-\mathrm{Jun}-94$ & $09: 16$ & LRAOSO & 8400 & 92.90 \\
\hline (9-Јуш-94 & $18: 44$ & LRA097 & 7800 & 78.83 & 09-Јил-94 & $18+33$ & LRA096 & 8700 & 99.93 \\
\hline 10-Jan-94 & $09: 19$ & LRA098 & 7700 & 76.49 & 10-Jun-94 & $09: 41$ & LRA099 & 8500 & 95.24 \\
\hline 13-Jun-94 & $13: 13$ & LRAJOS & 3900 & -12.58 & 13-Jun-94 & $13: 30$ & LRA106 & 5000 & 13.20 \\
\hline 13-Jun-94 & $14: 35$ & LRA111 & 4300 & -3.21 & 13-Jun-94 & $16: 08$ & LRA118 & 6000 & 36.64 \\
\hline 13-Jon-94 & $16: 21$ & LRA119 & 5700 & 29.61 & 14-Jun-94 & $09 \div 46$ & LRA120 & 7200 & 64.77 \\
\hline 14-Jun-94 & $10 \div 11$ & LRA121 & 6500 & 48.36 & 14-Jun-94 & $12: 56$ & [RA]34 & 7100 & 62.42 \\
\hline 14-Jun-94 & $13: 08$ & LRA135 & 6500 & 48.36 & - & -- & -- & -- & -- \\
\hline \multicolumn{10}{|c|}{$\begin{array}{c}\text { Sodium-lodide Sciotillonktert } \\
\text { (raw data units art counts pet minnte) }\end{array}$} \\
\hline $01+J u a-94$ & $08: 51$ & NAD073 & 6250 & 139.67 & 0I-Jun-94 & $08+59$ & NADN74 & 6050 & 129.23 \\
\hline 01-Jun-94 & $13: 00$ & NAD116 & 6050 & 129.23 & 01-Jun-94 & $13: 07$ & NAD118 & 5850 & 118.79 \\
\hline 01-Jen-94 & 13:02 & NAD117 & 6200 & 137.06 & $m$-Jun-94 & $09: 50$ & NADl 69 & 5750 & 113.57 \\
\hline 07-Jun-94 & $09: 46$ & NAD168 & 6050 & 129.23 & O\&-Jun-94 & $14: 32$ & NADI80 & 5800 & 116.18 \\
\hline 08-Jun-94 & $14: 38$ & NAD182 & 6050 & 129.23 & 08-Jun-94 & $14: 34$ & NAD181 & 5850 & 118.79 \\
\hline 08-Jun-94 & $14: 40$ & NAD183 & 6050 & 129.23 & 09-Jun-94 & $14: 12$ & NAD191 & 5750 & 113.57 \\
\hline 09-Jun-94 & $14: 00$ & NAD189 & 5900 & 121.40 & 09-Jun-94 & $34: 14$ & NAD192 & 5800 & 116.18 \\
\hline 09-Jun-94 & $14: 02$ & NAD190 & 5850 & 118.79 & 10-Jun-94 & $09: 56$ & NAD2015 & 6000 & 126.62 \\
\hline 10-Jun-94 & $09: 48$ & NAD203 & 6300 & 142.28 & 10-Juய-94 & $09 \cdot 58$ & NAD206 & 6100 & 131.84 \\
\hline 10-Jun-94 & $09 \div 50$ & NAD204 & 6550 & 155.33 & 13-Jun-94 & $09: 44$ & NAD219 & 5750 & 113.57 \\
\hline 13-J!m-94 & $09: 30$ & NAD217 & 5800 & 116.18 & 13-Jun-94 & $09: 46$ & NAD220 & 5800 & 116.18 \\
\hline 13-Jun-94 & $09: 32$ & NAD218 & 5900 & 121.40 & 14-Jun-94 & $13: 14$ & NAD233 & 5700 & 11096 \\
\hline 14-Jun-94 & $13: 00$ & NAD231 & 5900 & 121.40 & 14-JUm-94 & $13: 16$ & NAD234 & 5650 & 108.35 \\
\hline 14-Jun-94 & $13 \div 02$ & $\mathrm{NAD}_{232}$ & 6050 & 129.23 & 16-Jun-94 & $15: 23$ & NAD243 & 5700 & 110.96 \\
\hline 16-Jun-94 & $15: 15$ & $\mathrm{NAD} 245$ & 6050 & 129.23 & 16-Jun-94 & $15: 25$ & NAD248 & 5760 & 114.09 \\
\hline 16-Jun-94 & $15: 17$ & NAD246 & 5900 & 121.40 & 17-Jun-94 & $10: 47$ & NAD261 & 6050 & 129.23 \\
\hline 17-Jun-94 & $10: 41$ & NAD259 & 6200 & 137.06 & 17-Jun-94 & $10: 49$ & NAD262 & 5900 & 121.40 \\
\hline 17-Jun-94 & $10: 43$ & NAD260 & 6400 & 147.50 & - & -- & - & -- & -- \\
\hline \multicolumn{10}{|c|}{$\begin{array}{l}\text { X+Ray Fluorescence Unit } \\
\text { (raw data usits are parts per million) }\end{array}$} \\
\hline 66-Jva-94 & $11 \div 21$ & $\mathrm{XRF024}$ & 84.71 & 90.32 & 06-Jun-94 & $11: 37$ & XRF025 & 31.00 & 38.54 \\
\hline 06-Jun-94 & $13: 43$ & XRFO29 & 69.93 & 76.07 & 06-Jun-94 & 1353 & XRF030 & 70.52 & 76.64 \\
\hline
\end{tabular}


Table F-1: Standard-Sites Meacurementa by all Technologios Except ICP (continued)

TTmes are Eastem Dayligtx Time; raw dats measurement unils vary by lechnolosy; total uranium in picocurtes per gram. Leaders ( - ) indicate no (data)

\begin{tabular}{|c|c|c|c|c|c|c|c|c|c|}
\hline \multicolumn{5}{|c|}{ Standard Stwa 1} & \multicolumn{5}{|c|}{ Standard Site 2} \\
\hline Datio & Time & ID & $\begin{array}{l}\text { Raw } \\
\text { Donta }\end{array}$ & $\begin{array}{c}\text { Total } \\
\text { Uranium }\end{array}$ & Dato & Time & ID & $\begin{array}{l}\text { Raw } \\
\text { Datta }\end{array}$ & $\begin{array}{c}\text { Total } \\
\text { Uranium }\end{array}$ \\
\hline 08-3ut-94 & $09: 13$ & XRFO3] & 68.70 & 74.89 & DR.Jun-94 & $09: 29$ & XRFO32 & 51.90 & 58.69 \\
\hline $08-J 415-94$ & $13: 49$ & XRFO47 & 83.80 & 89.45 & O8-Jun-94 & 14:01 & XRF048 & 60.93 & 67.39 \\
\hline 09-Jum-94 & $09: 50$ & XRF049 & 70.54 & 76.66 & 09-Jun-94 & 10:01 & XRFOS0 & 65.15 & 71.46 \\
\hline 09-Jum-94 & 14:08 & XRF068 & 68.48 & 74.68 & 09-Jun-94 & $14: 22$ & XRFO69 & 64.49 & 70.83 \\
\hline 10-jun-94 & $09: 36$ & XRFOT! & 72.19 & 78.25 & 10-Jun-94 & 10:06 & XRFOI2 & 63.94 & 70.30 \\
\hline 10-Jute-94 & $14: 06$ & XRFOB6 & 85.19 & 90.79 & 10-Jun-94 & $14: 17$ & XRFOB? & 55.50 & 62.16 \\
\hline 14-Jun-94 & $09: 37$ & XRF088 & 80.61 & 86.36 & 14-Jun-94 & $10 \times 12$ & XRFO\&9 & 58.36 & 64.92 \\
\hline 14-Jun-94 & 13:55 & XRF104 & 77.62 & 83.48 & 14-Jun-94 & $13 \div 38$ & XRF103 & 56.98 & 63.59 \\
\hline 15-Јит-94 & $09: 48$ & XRF1OS & 83.66 & 89.30 & 15.Jun-94 & $10 \times 05$ & XRF106 & 64.33 & 70.67 \\
\hline 15-Jun-94 & $13: 30$ & XRF119 & 80.09 & 85.87 & 15-Jun-94 & $13: 17$ & XRF118 & 58.82 & 65.36 \\
\hline 16-Јบแ-94 & $09: 24$ & XRF120 & 73.25 & 79.28 & $16-J \tan -94$ & $09: 38$ & XRF121 & 56.83 & 63.44 \\
\hline 16-Jun-94 & $11: 44$ & XRF133 & 98.53 & 103.64 & 16-Jum-94 & 11:33 & XRF132 & 60.35 & 66.84 \\
\hline 30-Jan-94 & $09 ; 02$ & XRF154 & 80.82 & 86.57 & 30-Jun-94 & $09: 13$ & XRF155 & 54.08 & 60.80 \\
\hline 30-Jun-94 & $12 ; 30$ & XRF169 & 89.53 & 94.97 & 01-Jul-94 & $\propto 8: 54$ & XRF171 & 60.13 & 66.69 \\
\hline 01-Jul-94 & $08: 44$ & XRF170 & 87.64 & 93.14 & 01-Ju|-94 & $15: 07$ & XRF194 & 36.35 & 43.70 \\
\hline 01-Jul-94 & $14: 51$ & XRF193 & 88.98 & 94.44 & - & - & - & - & - \\
\hline
\end{tabular}


Table F-2: Standard Stios Mansurements by Lacer Ablation-Inductively Coupled Plasma-Atomic Emiseion spectroscopy Technology

[Rew date in counts uranium per connt siticom; total uranimo in picocuries per gram. Negetive valnes interpeted as bekw dotection lintit]

\begin{tabular}{|c|c|c|c|c|}
\hline $\begin{array}{l}\text { Oate } \\
\text { (EDT) }\end{array}$ & Time & ID & Fanw Data & $\begin{array}{c}\text { Total } \\
\text { Uranium }\end{array}$ \\
\hline \multicolumn{5}{|c|}{ Calibration Plot CP } \\
\hline $15-J u n-94$ & $14: 42$ & ICPO12 & 0,0344 & 111.06 \\
\hline 15-Jun-94 & $14: 55$ & ICPO13 & 0.0436 & 142.58 \\
\hline 15-Jun-94 & $15: 09$ & ICPO14 & 0.0451 & 147.72 \\
\hline \multicolumn{5}{|c|}{ Calitration Ptot CO } \\
\hline $15-J u n-94$ & $14: 19$ & KCP011 & 0,0047 & 9.32 \\
\hline 15-Jun-94 & $17: 56$ & KCPOH8 & 0.0048 & 9.66 \\
\hline 16-Jun-94 & 09:05 & [CP02] & 0,0053 & 11.37 \\
\hline 16-Jun-94 & $18: 36$ & ICP052 & 0.0148 & 43.92 \\
\hline 17-Jnn-94 & $11 \div 36$ & КСР036 & 0.0046 & 8.98 \\
\hline 18-Jun-94 & $11: 13$ & 1CPO45 & 0.0037 & 5.89 \\
\hline 19-Jtut-94 & $67: 33$ & 1CPO67 & 0.0060 & 13.77 \\
\hline 20-Jun-94 & 08:07 & ICP115 & 0.0052 & 11.03 \\
\hline 20-5vo-94 & $14: 55$ & KCP147 & 0.0087 & 23.02 \\
\hline 21-J啔-94 & $08: 12$ & ICP149 & 0,0053 & 11.37 \\
\hline 21-Jus-94 & $13: 42$ & ICP174 & 0,0126 & 36.38 \\
\hline $12-0 \mathrm{ct}-94$ & 13:53 & ICP179 & 0.0019 & -0.27 \\
\hline 12-Oct-94 & $16: 16$ & ICP190 & 0.0026 & 2.12 \\
\hline $12-0 \mathrm{ct}-94$ & $17: 15$ & КCP19] & 0,0012 & -2.67 \\
\hline 12-Oct-94 & $08: 57$ & FP194 & 0,0035 & 5.21 \\
\hline $12-0 \mathrm{ct}-94$ & 11:29 & $\mathrm{ICP} 205$ & 0.0026 & 2.12 \\
\hline \multicolumn{5}{|c|}{ Calibration Plot C35 } \\
\hline $15-\overline{J u n}-94$ & $\overline{14}: 0 \overline{1}$ & ICP010 & 0.0357 & $\overline{115.52}$ \\
\hline 15-Jun-94 & $16: 54$ & ICPOIS & 0.0373 & 121.00 \\
\hline 15-Jun-94 & $17: 56$ & JCP019 & 0.0418 & 136.41 \\
\hline 16-Jun-94 & $09: 21$ & ICPOZ2 & 0.0362 & 117.23 \\
\hline 16-Jun-94 & $16: 44$ & $\operatorname{ICP} 029$ & 0.2627 & 893.15 \\
\hline 16-Jun-94 & 18:49 & ICP033 & 0.0637 & 211.44 \\
\hline 17.Jun-94 & $11: 21$ & ICP095 & 0.0346 & 111.75 \\
\hline 17.Jun-94 & $13: 15$ & ICP041 & 0.0400 & 130.25 \\
\hline 18-Jun+94 & $11: 21$ & ICP046 & 0.0242 & 76.12 \\
\hline 18-Jun-94 & $12: 42$ & ICP054 & 0.0212 & 65.84 \\
\hline 18-Jun-94 & $16: 33$ & ICP065 & 0.0236 & 74.06 \\
\hline 19-Jun-94 & $07: 19$ & ICPO66 & 0.0224 & 69.95 \\
\hline 19-Jum-94 & $09+22$ & ICPO76 & 0.0297 & 94.96 \\
\hline 19-Jun-94 & $10 \div 40$ & ICP083 & 0.0300 & 95.99 \\
\hline
\end{tabular}


Table F-2: Standard Sites Measurements by Laser Ablation-inductively Coupled Plasma-Atomic Emisston Spoctroscopy Technology (continued)

[Raw data in coemts uranium per count silicon; tolal unanium in picocuries per gram. Negetive values tanerpeted as bolow detection limit]

\begin{tabular}{|c|c|c|c|c|}
\hline $\begin{array}{l}\text { Date } \\
\text { (EDT) }\end{array}$ & Thme & ID & Raw Data & $\begin{array}{c}\text { Total } \\
\text { Untrilum }\end{array}$ \\
\hline 19-Jun-94 & $12: 18$ & ICP091 & 0.0297 & 94.96 \\
\hline 19-Jun-94 & $16: 06$ & ICP107 & 0.0228 & 71.32 \\
\hline 19-J!n-94 & 17,00 & ICP111 & 0.0225 & 70.30 \\
\hline $20-\mathrm{Jun}-94$ & $07: 44$ & ICP113 & 0.0188 & 57.62 \\
\hline 20-Jun-94 & $07: 55$ & ICP114 & 0.0211 & 65.50 \\
\hline 20-Jun-94 & $11: 49$ & ICP131 & 0.0224 & 69.95 \\
\hline 20-Jun-94 & $14: 45$ & 1CP146 & 0.0275 & 87.42 \\
\hline 21-Jun-94 & 07:58 & ICP148 & $0.022 \mathrm{I}$ & 68.93 \\
\hline 2l-Jun-94 & $09: 31$ & KCP155 & 0.0232 & 72.69 \\
\hline 21-Jun-94 & $\mathrm{t} 2: 30$ & KCP168 & 0.0234 & 73.38 \\
\hline 21-Jun-94 & $13: 30$ & KCPI73 & 0.0272 & 86.40 \\
\hline 2[-Jun-94 & $13: 54$ & LCP175 & 0.0329 & 105.92 \\
\hline $12-0 c t-94$ & $13 ; 40$ & KCP178 & 0.0214 & 66.53 \\
\hline 12-Oct-94 & $14: 46$ & KCP183 & 0.0267 & 84.68 \\
\hline 12-Oct-94 & $15: 59$ & КCP189 & 0.0266 & 84.34 \\
\hline 12-Oct-94 & $09: 08$ & ICP195 & 0.0233 & 73,04 \\
\hline 12-Oct-94 & 10:06 & ICPI99 & 0.0216 & 67.21 \\
\hline 12-0ct-94 & 01:14 & 1CP206 & 0.0213 & 66.19 \\
\hline
\end{tabular}


(This page intentionally left blank.) 


\section{Appendlx G: Technology Data}


Table G-1: Composfie Data Ustlng for Alphe-Track Detector Technology

[Negutive tofal uranimm values interpoted as below detection level. Leaders (-): not messured or not applicabie]

\begin{tabular}{|c|c|c|c|c|c|c|c|c|}
\hline Cwo Lod & $\begin{array}{l}x \text { Coord } \\
\text { (fiot) }\end{array}$ & $\begin{array}{l}Y \text { Coond } \\
\text { (fent) }\end{array}$ & ID & Type & Dine & $\operatorname{Tim}_{\text {(EDT) }}$ & $\begin{array}{l}\text { Row Dote } \\
\text { (trackst par } \\
\text { mminthour) }\end{array}$ & $\begin{array}{l}\text { Totol U } \\
\text { (pCV/g) }\end{array}$ \\
\hline$\overline{C C 10}$ & 1351774 & 480593 & ATDT01 & FLD & Ol-Jun-94 & $12: 43$ & 0.0597 & $0.8 \mathrm{I}$ \\
\hline AAS & 1351713 & 480534 & ATD102 & FLD & 01-Jun-94 & $12: 44$ & 0.0576 & -1.64 \\
\hline Y8 & 1351651 & 480476 & ATD109 & FLD & 01-Jan-94 & $12: 46$ & 0.0496 & -10.95 \\
\hline$x 7.5$ & 1351620 & 480447 & ATDl04 & FLD & $01-J u m-94$ & $12: 48$ & 0.0691 & 11.75 \\
\hline w7 & 1351590 & 480417 & ATDI0S & FLD & 01-Jun-94 & $12: 49$ & 0.0508 & -9.55 \\
\hline W6.5 & 1351560 & 480418 & ATD106 & FLD & 01-Jun-94 & 12:50 & 0.0678 & 10.24 \\
\hline V6.5 & $\$ 351559$ & 480403 & ATD 07 & FLD & 01-Jun-94 & $12: 51$ & 0.0688 & 11.41 \\
\hline V6 & 1351529 & 480394 & ATD108 & FLD & 01-Jun-94 & 12.57 & 0.0314 & -32.14 \\
\hline Us & 1351468 & 480365 & ATDI09 & FW & O1-Jun-94 & 1259 & 0.0738 & 17.23 \\
\hline ws & 1351470 & 480420 & ATD 10 & FLD & 01-Jua-94 & $13: 00$ & 0.0813 & 25.96 \\
\hline Y5 & 1351471 & 480480 & ATDll1 & FLD & Ol-Jun-94 & $13: 02$ & 0.0475 & -13.40 \\
\hline AAS & 1351473 & 480540 & ATD112 & FLD & 01-Jun-94 & 13.03 & 0.0597 & 0.81 \\
\hline $\operatorname{ccs}$ & 1351474 & 480600 & ATD113 & FLD & 01-Jun-94 & 13.05 & 0.0521 & $-8,04$ \\
\hline CCs & 1351534 & 480599 & ATDi 14 & FLD & 01-Juk-94 & 13,06 & 0.0662 & 8.38 \\
\hline $\mathrm{CC} 7$ & 1351594 & 480597 & ATDI15 & FLD & 01-Jun-94 & 13:08 & 0.0624 & 395 \\
\hline AA6 & 1351533 & 480539 & ATDI16 & FLD & 01-Jun-94 & 13.09 & 0.0451 & -16.19 \\
\hline Z6 & 1351532 & 480509 & ATDI17 & FLD & 01-Jun-94 & $13: 10$ & 0.0607 & 1.97 \\
\hline $\mathrm{Z6.5}$ & 1351562 & 480508 & AID118 & FLD & 01-Juo-94 & $13: 14$ & 0.0677 & 10.12 \\
\hline Y6 & 1351531 & 480479 & ATD119 & FLD & 01-Jug-94 & $13: 16$ & 0.0664 & 8.61 \\
\hline w6 & 1351530 & 480419 & ATD120 & FLD & 01-Jun-94 & $13: 17$ & 0.0634 & 5.12 \\
\hline Y6.5 & 1351561 & 480478 & ATD:21 & FLD & 01-Ju0-94 & $13: 19$ & 0.0522 & -7.92 \\
\hline F1 & 1351542 & 480529 & ATDI22 & FLD & 01-Jun-94 & $13: 21$ & 0.0638 & 5.58 \\
\hline $\mathbf{F} 2$ & 1351547 & 480528 & ATDI23 & FLD & 01-Jun-94 & $13: 22$ & 0.0681 & 10.59 \\
\hline F3 & 1351552 & 480528 & ATD124 & FLD & 01-Jun-94 & $13: 23$ & 0.0567 & -2.68 \\
\hline E1 & 1351542 & 480524 & ATD125 & FLD & 01-Jun-94 & $13: 24$ & 0.0572 & -2.10 \\
\hline E2 & 1351547 & $480 \$ 23$ & ATD 126 & FLD & 01-Jun-94 & $13: 25$ & 0.0588 & -0.24 \\
\hline $\mathrm{E3}$ & 1351552 & 480523 & ATDI27 & FLD & 01-Jun-94 & $13: 26$ & 0.0765 & 20.37 \\
\hline D1 & 1351542 & 480519 & ATD128 & FLD & 01-Jun-94 & $13: 27$ & 0.0624 & 3.95 \\
\hline D2 & 1351547 & 480518 & ATD129 & FLD & 01-Jan-94 & $13: 28$ & 0.0595 & 0.58 \\
\hline D3 & 1351552 & 480518 & ATD130 & FLD & 01-Jun-94 & 13:29 & 0.0439 & -17.59 \\
\hline AAT & 1351593 & 480537 & ATD131 & FL.D & 01-Jun-94 & 13:30 & 0.0546 & -5.13 \\
\hline 27 & 1351592 & 480507 & ATD132 & FLD & 01-Jun-94 & $13: 32$ & 0.0638 & 5.58 \\
\hline Y7 & 1351591 & 480477 & ATD133 & FLD & 01-Iun-94 & $13: 33$ & 0.0728 & 16.06 \\
\hline W7. & 1351620 & 480420 & ATD134 & FLD & 01-Jun-94 & 13:35 & 0.0796 & 23.98 \\
\hline Y7.5 & 1351621 & 480476 & ATD135 & FLD & 01-Jun-94 & $13 \div 37$ & 0.0696 & 12.34 \\
\hline $\cos$ & 1351654 & 480596 & ATD136 & FLD & 01-Jut-94 & $13: 38$ & 0.0726 & 15.83 \\
\hline $\mathbf{X 7}$ & 1351590 & 480447 & ATD13? & FLD & 01-5un-94 & 13:38 & 0.0480 & -12.81 \\
\hline
\end{tabular}


Table G-1: Compos/te Date Listing for Alpha-Track Detector Technology (continued)

[Negrifive total manium vakus interpreted as below detection level. Leaders (-); not measured or ant applicable]

\begin{tabular}{|c|c|c|c|c|c|c|c|c|}
\hline Coo leo & $\begin{array}{c}x \text { Coord } \\
\text { (feot) }\end{array}$ & $\begin{array}{l}\text { Y Coond } \\
\text { (teet) }\end{array}$ & 10 & Type & Date & $\underset{(15 D T)}{\operatorname{Tim}}$ & 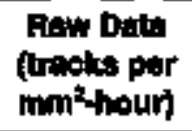 & $\begin{array}{l}\text { Toted U } \\
\text { (pci/g) }\end{array}$ \\
\hline$\overline{\text { AA8 }}$ & 1351653 & 480536 & ATD138 & FLD & $01-\sqrt{u n-94}$ & $13: 40$ & 0.0543 & -5.48 \\
\hline $\mathrm{X} 8$ & 1351650 & 480446 & ATD139 & FLD & 01-Jun-94 & I3:41 & 0.0749 & 18.51 \\
\hline Ws & 1351650 & 480429 & ATD140 & FLD & 01-Jun-94 & $13: 43$ & 0.0594 & 0.46 \\
\hline$X 8.5$ & 1351680 & 480445 & ATD14I & FLD & 0I-Jun-94 & $13: 44$ & 0.0677 & 10.12 \\
\hline Y8.5 & 1351681 & 480475 & ATD142 & FLD & 01-Jun-94 & $13: 46$ & 0.0762 & 20.02 \\
\hline W8.5 & 1351679 & 480400 & ATD143 & FLD & 0l-Jun-94 & $13: 48$ & 0.0581 & -1.05 \\
\hline Z9 & 1351712 & 480504 & ATD145 & FLD & 0โ-Јயा-94 & 13.53 & 0.0489 & -11.77 \\
\hline Y9 & 1351712 & 480474 & ATD146 & FLD & 01-Jun-94 & $13 \div 54$ & 0.0801 & 2456 \\
\hline$\times 9$ & 1351711 & 480457 & ATD147 & FLD & Of-Jun-94 & $13: 56$ & 0.0725 & 15.71 \\
\hline W9 & 1351709 & 480412 & ATD148 & FLD & 01-Jun-94 & $13: 57$ & 0.0399 & -22.25 \\
\hline v9 & 1351709 & 480384 & ATD149 & FLD & 01-Jum-94 & $13: 59$ & 0.0855 & 30.85 \\
\hline tg & 1351708 & 480354 & ATD150 & FLD & 01-Job-94 & $14 \div 00$ & 0.0660 & 8.14 \\
\hline$\$ 9$ & 1351706 & 480294 & ATDIS1 & ELD & $01-J u m-94$ & $14: 01$ & 0.1293 & 81.85 \\
\hline AA9.5 & 1351743 & 480533 & ATDI52 & FLD & 01-Jum-94 & $14: 06$ & 0.0650 & 6.98 \\
\hline 29.5 & 1351742 & 480503 & ATD 153 & FLD & D1-Jun-94 & $14: 07$ & 0.0484 & -12.35 \\
\hline W9.5 & 1351739 & 480413 & ATDI54 & FLD & $01-36 m-94$ & 14:09 & 0.0653 & 7.33 \\
\hline V9.5 & 1351739 & 480383 & ATDISs & FLD & $01-5 u n-94$ & $14: 10$ & 0.0590 & -0.01 \\
\hline U9.5 & 1351738 & 480353 & ATD 56 & FLD & 01-Jun-94 & $14: 11$ & 0.0867 & 32.25 \\
\hline C1 & 1351748 & 480373 & ATD157 & FLD & 01-Jum-94 & 14:12 & $0.0 \$ 99$ & 1.04 \\
\hline$C 2$ & $135 \pm 753$ & 480373 & ATDI58 & FLD & O1-Jun-94 & $14: 13$ & 0.0946 & 41.45 \\
\hline $\mathrm{C} 3$ & 1351758 & 480373 & ATD159 & FLD & 01-Jun-94 & $14: 14$ & 0.0616 & 3.02 \\
\hline B1 & 1351748 & 480368 & ATDI60 & FLD & 01-Jun-94 & $14: 15$ & 0.0770 & 20.95 \\
\hline B2 & 1351753 & 490368 & ATD161 & FLD & 01-Jun-94 & $14: 16$ & 0.0328 & -30.51 \\
\hline $\mathbf{B 3}$ & 1351758 & 480368 & ATD162 & FLD & 0I-Jun-94 & $14: 17$ & 0.0479 & -12.93 \\
\hline Al & 1351748 & 480363 & ATDI63 & FLD & 01-Jun-94 & $14: 18$ & 0.0828 & 27.71 \\
\hline $\mathrm{A} 2$ & 1351753 & 480363 & ATD164 & FLD & 0t-Jun-94 & $14: 19$ & 0.0852 & 30.50 \\
\hline A3 & 1351758 & 480363 & ATD165 & FLD & 01-Jun-94 & $14: 20$ & 0.0855 & 30.85 \\
\hline AAlO & 1351760 & 480533 & ATD166 & FLD & 01-Jun-94 & $14: 22$ & 0.0823 & 27.12 \\
\hline$\infty 0$ & -- & -- & ATDI67 & CAL & 0t-Jun-94 & $16: 00$ & 0.1567 & - \\
\hline $\mathrm{C} 100$ & -- & -- & ATD168 & CAL & 01-Jun-94 & $16 ; 00$ & 0.1875 & - \\
\hline C35 & $=$ & -- & ATD170 & CAL & 01-Јиภ-94 & $16: 00$ & 0.2450 & - \\
\hline AA11 & 1351833 & 480531 & ATD201 & FLD & 02-Jun-94 & $07 \div 38$ & 0.0463 & -14.79 \\
\hline Y11 & 1351831 & 480471 & $\mathrm{ATD} 202$ & FLD & (2)-Јап-94 & $07: 39$ & 0.1145 & 64.62 \\
\hline WI1 & 1351829 & 480411 & ATD203 & FLD & O2-Jun-94 & $07: 40$ & 0.0723 & 15.48 \\
\hline U11 & 1351828 & 480351 & ATD204 & FLD & Q2-Jun-94 & $n \div 41$ & 0.0846 & 29.80 \\
\hline S10 & 1351766 & 480293 & ATD205 & FLD & 02-Jun-94 & $07: 43$ & 0.0995 & 47.15 \\
\hline St1 & 1351826 & 480291 & ATD206 & FLD & 02-Jun-94 & $\varphi 7: 43$ & 0.0581 & -1.05 \\
\hline U10 & 1351768 & 480353 & ATD20 & FLD & 02-Jun-94 & $07: 45$ & 0.0622 & 3.72 \\
\hline
\end{tabular}


Table G-1: Composite Data Listing tor Alpha-Track Detector Technology (continued)

[Negative total uraninum values interpreted as below devection level. Leaders (-): not measured or uol applicable]

\begin{tabular}{|c|c|c|c|c|c|c|c|c|}
\hline cos los & $\begin{array}{c}x \text { coord } \\
\text { (tted) }\end{array}$ & $\begin{array}{c}Y \text { Coord } \\
\text { (fett) }\end{array}$ & 10 & Typo & Datio & $\underset{\text { Time }}{\text { (EDT) }}$ & $\begin{array}{l}\text { Raw Dets } \\
\text { (tracks per } \\
\text { mintholy) }\end{array}$ & $\begin{array}{l}\text { Tolet I } \\
\text { (pCN(g) }\end{array}$ \\
\hline$\overline{\text { V10 }}$ & 1351769 & 480383 & ATD208 & FLD & "02-Jun-94 & $\overline{07: 45}$ & 0.0509 & 9.4 .44 \\
\hline W10 & 1351769 & 480413 & ATD209 & FLD & 02-Jun-94 & $07: 46$ & 0.0598 & 0.93 \\
\hline Y10 & 1351771 & 480473 & ATD210 & FLD & 02-Jun-94 & $\omega ;: 47$ & 0.0590 & -0.01 \\
\hline cel1 & 1351834 & 480591 & ATD211 & FLD & O2-Jun-94 & $07: 49$ & 0.0779 & 22.00 \\
\hline บ7 & 1351588 & 480361 & ATD212 & FLD & 02-Jun-94 & 0,51 & 0.0853 & 30.62 \\
\hline s5 & 1351466 & 480300 & ATD214 & FLD & 02-Jun-94 & $07: 53$ & 0.0615 & 2.91 \\
\hline s1 & 1351541 & 480338 & ATD215 & \$TD & 02-Jun-94 & 0755 & 0.0752 & 18.86 \\
\hline AA6.5 & 1351563 & 480538 & ATD216 & FLD & -02-Jun-94 & $07: 56$ & 0.0684 & 10.94 \\
\hline \$2 & 1351508 & 480562 & ATD217 & STD & 02 -Jun-94 & $07: 57$ & 0.0747 & 18.28 \\
\hline U6.5 & 1351558 & 480358 & ATD218 & FLD & 02-Jnn-94 & $08: 00$ & 0.0882 & 33.99 \\
\hline U8 & 1951648 & 480366 & ATD219 & FLD & O2-Jun-94 & $08: 01$ & 0.0795 & 23.86 \\
\hline Y9.5 & 1351725 & 480474 & ATD 220 & FLD & Q2-Jun-94 & $08: 03$ & 0.0712 & 14.20 \\
\hline Z10 & 1351787 & 480502 & $\mathrm{ATD} 221$ & FLD & 02-Jan-94 & $08: 06$ & 0.0645 & 6.40 \\
\hline$\infty$ & - & - & ATD 222 & CAL & 02-Jnn-94 & $08: 30$ & 0.0405 & - \\
\hline $\mathrm{C} 100$ & - & + & ATD223 & CAL & 02-Jun-94 & $09: 00$ & 0.1993 & - \\
\hline $\mathrm{C}_{200}$ & - & - & ATD224 & CAL & 02-Jun-94 & $09 ; 00$ & 0.3756 & - \\
\hline $\mathrm{C} 35$ & - & - & ATD225 & CAL & (2)-Jnต-94 & 09.00 & 0.1196 & - \\
\hline$\infty$ & - & - & ATD226 & CAL & 02-Jun-94 & $15: 00$ & 0.0387 & - \\
\hline $\mathrm{Cl} 100$ & - & - & ATD227 & CAL & 02-Jעก-94 & $15: 00$ & 0.2073 & - \\
\hline C35 & - & - & ATD228 & CAL & 02-Jun-94 & $15: 00$ & 0.0970 & -- \\
\hline $\mathrm{C} 200$ & + & - & ATD229 & CAL & 02-Jur-94 & 15,00 & 0.3094 & - \\
\hline s1 & 1351541 & 480338 & ATD319 & STD & 18-Jul-94 & $12: 00$ & 0.0711 & 14,08 \\
\hline$s 2$ & 1351508 & 480562 & ATD320 & $\mathbf{S T D}$ & 18-Jut-94 & 12,00 & 0.0531 & 4.77 \\
\hline$\infty$ & - & - & ATD321 & CAL & 18-5ul-94 & $13: 41$ & 0.0378 & - \\
\hline C35 & - & - & ATD322 & CAL & $18-5 u 1-94$ & $13 ; 41$ & 0.1405 & - \\
\hline$C 100$ & - & .. & ATD323 & CAL & 18-Jul-94 & 13:5s & 0.1639 & - \\
\hline$C P$ & - & - & ATD324 & CAL & $18-\mathrm{Jul}-94$ & $13: 55$ & 0.0892 & - \\
\hline$\infty$ & - & .. & ATD401 & CAL & 19-Jul-94 & $09: 07$ & 0.0504 & - \\
\hline C100 & - & - & ATD 402 & CAL & 19-Jul-94 & $09: 07$ & 0.1675 & - \\
\hline $\mathrm{C} 35$ & - & - & ATD403 & CAL & 19-Jul-94 & $09: 07$ & 0.1468 & - \\
\hline $\mathrm{CP}$ & - & - & ATD 407 & CAL & 19-Jul-94 & $09: 07$ & 0.0990 & - \\
\hline U6 & 1351528 & 480354 & ATD421 & FLD & 19-Jul-94 & $10: 05$ & 0.0863 & 31.78 \\
\hline - & 1351465 & $4 \mathrm{~B} 0330$ & ATD428 & FLD & 19-Jnl-94 & 13:55 & 0.0715 & {$[4.55$} \\
\hline- & 1351475 & 480320 & ATD429 & FLD & 19-Jul-94 & 13:55 & 0.1226 & 74.05 \\
\hline- & $1 3 5 \longdiv { 4 7 3 }$ & 480315 & ATD430 & FLD & 19-Jut-94 & $14: 10$ & 0.1331 & $\$ 6.28$ \\
\hline- & 1351475 & 480310 & ATD431 & FLD & 19-Jul-94 & $14: 10$ & 0.0954 & 42,38 \\
\hline-- & 1351480 & 480310 & ATD432 & FLD & 19-Jul-94 & $14: 10$ & 0.1951 & $\begin{array}{r}158.4 \\
7\end{array}$ \\
\hline
\end{tabular}


Table G-1: Composite Data Llstlng for Alphe-Track Detector Technology (continued)

[Negrive total uranisum vahues Interpreted as below detection kevel. Leaders (-): not measured or not applicable]

\begin{tabular}{|c|c|c|c|c|c|c|c|c|}
\hline ext los & $x$ Coond & $\begin{array}{l}\text { Y coond } \\
\text { (teell) }\end{array}$ & $\mathbf{1 0}$ & Туре & Deto & $\begin{array}{l}\text { TIme } \\
\text { (EDT) }\end{array}$ & 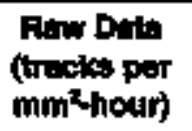 & $\begin{array}{l}\text { Totet U } \\
\text { (pCl/g) }\end{array}$ \\
\hline- & 1351480 & $\overline{480315}$ & $\overline{A T D 433}$ & $\overline{\mathrm{FLD}}$ & 19̈-Jul-94 & $14 \div \overline{10}$ & $0 \overline{0.1602}$ & $\begin{array}{r}117.8 \\
3\end{array}$ \\
\hline - & 1351480 & 490320 & ATD434 & FLD & 19-Ju]-94 & $14: 10$ & 0.1357 & 89.30 \\
\hline- & 1351485 & 480310 & ATD435 & FLD & 19-Ju\}-94 & $14: 10$ & 0.0753 & 18.97 \\
\hline- & 1351485 & 480315 & ATD436 & FLD & 19-Ju1-94 & $14: 10$ & 0,0851 & 30.38 \\
\hline- & 1351485 & 420320 & ATD437 & FLD & 79-Ja1-94 & 14:10 & 0.1473 & $\begin{array}{r}1028 \\
1\end{array}$ \\
\hline -- & 1351495 & 480300 & ATD438 & FLD & 19-Jol-94 & $14: 10$ & 0.0765 & 2037 \\
\hline- & 1351495 & 480330 & ATD439 & FLD & 19-Jol-94 & 14:10 & 0.0822 & 27.01 \\
\hline s1 & 1351541 & 480338 & ATD440 & STD & 19-Jut-94 & 14:10 & 0.2192 & $\begin{array}{r}186.5 \\
3\end{array}$ \\
\hline s2 & 1351508 & 480562 & ATD441 & STD & 19-Ju!-94 & 14:10 & 0.1033 & 51.58 \\
\hline- & 1351800 & 480595 & ATD442 & FLD & 19-Jol-94 & 14:53 & 0.0861 & 31.55 \\
\hline- & 1351815 & 480575 & ATD443 & FLD & 19-Jn|-94 & 14:53 & 0.1095 & 58.80 \\
\hline -- & 1351815 & 480580 & ATD444 & FL.D & 19-Jul-94 & $14: 53$ & 0.0689 & 11.52 \\
\hline- & 1351815 & 480585 & ATD445 & FLD & 19-Jw|-94 & 14:53 & 0.0450 & -16.31 \\
\hline- & 1351820 & 480575 & ATD446 & FLD & |9-Jul-94 & $14: 53$ & 0.1116 & 61.24 \\
\hline .- & 1351820 & 480580 & ATD447 & FLD & 19-Jal-94 & $14: 53$ & 0.2299 & $\begin{array}{r}198.9 \\
9\end{array}$ \\
\hline$\vec{P}$ & 1351820 & 480585 & ATD448 & FLD & 19-Jul-94 & $14: 53$ & 0.1222 & 73.58 \\
\hline- & 1351830 & 480565 & ATD449 & FLD & 19-Jul-94 & $14: 53$ & 0.0889 & 34.81 \\
\hline
\end{tabular}


Tablo G-2: Composits Datu Lating for Beta Seintlllometer Technology

FF": soil maisture correction fuctor (not applicable to sample type CAL), Adj.: adjusted (see texr). Negative total uramium values interpered us below detection level, Leaders (-.): not messumed or not applicable]

\begin{tabular}{|c|c|c|c|c|c|c|c|c|c|c|}
\hline Poo Loc & $\begin{array}{c}x \cos 0 \\
(100)\end{array}$ & $\begin{array}{c}Y \cos d \\
\text { (fodt) }\end{array}$ & ID & Туре & Dote & $\begin{array}{l}\text { Time } \\
\text { (EDI) }\end{array}$ & $\begin{array}{l}\text { Raw Dats } \\
\text { (coumita par } \\
\text { second) }\end{array}$ & $\begin{array}{l}\text { Toted U } \\
\text { (pcivo) }\end{array}$ & $F$ & 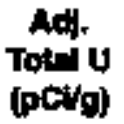 \\
\hline$\overline{C 0}$ & $\overline{-}$ & $\overline{-}$ & BETDO1 & CAL & 07-]ul-94 & $13: 28$ & 5.98 & + & 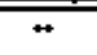 & 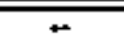 \\
\hline $\mathbf{C O}$ & - & - & BETOO2 & CAL & 07-Iv1-94 & $13: 48$ & 6.30 & $*$ & 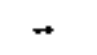 & - \\
\hline cas & - & - & BETW03 & CAl & 07-hnl-94 & $14: 15$ & 18.78 & -. & - & - \\
\hline cas & -- & - & BETOO4 & CAL & 07-hu-94 & $14: 34$ & 20.14 & - & -- & - \\
\hline $\mathrm{C} 100$ & - & -- & BETOOS & CAL & 07-Jol-94 & $14: 54$ & 26.37 & - & - & - \\
\hline Cloo & - & - & BETO06 & CAL & 07-Juk-94 & $15: 14$ & 26.75 & - & -- & - \\
\hline$C P$ & - & -- & BETOOr & CAL & (0)-Ju1-94 & $15: 34$ & 16.06 & - & -- & - \\
\hline CP & - & - & BETO08 & CAL & 07-Ju\}-94 & $15: 50$ & 15.80 & - & - & - \\
\hline $\mathbf{\$ 2}$ & j3\$1508 & 480662 & BETO09 & STD & $07-5 u 1-94$ & $17: 25$ & 16.30 & 57.58 & 1.000 & 57.58 \\
\hline $\operatorname{ccs}$ & 1351534 & 480599 & BET010 & FLD & 67-Jul-94 & $18: 03$ & 16.40 & 58.15 & 1.000 & 58.15 \\
\hline Cos & 1355474 & 480600 & BET012 & F.D & $07+J u]-94$ & $18: 36$ & 12.05 & 33.16 & 1.000 & 39.16 \\
\hline AAS & 1351479 & 480540 & BET013 & FLD & 07-Ju]-94 & $18: 54$ & 13.54 & 41.72 & 1.000 & 41.72 \\
\hline AA6 & 1351533 & 480539 & BET014 & FLD & $07+\mathrm{JuJ}-94$ & 19:1! & 14.90 & 49.54 & 1.000 & 49.54 \\
\hline Z6 & 1351532 & 480509 & BET01s & FLD & 07-Jul-94 & $19: 27$ & 15.04 & 50.34 & 1.000 & 50.34 \\
\hline s1 & 135154] & 480338 & BET016 & STD & 07-JuJ-94 & $19: 49$ & 19.82 & 77.80 & 1.000 & 77.80 \\
\hline \$I & 1351541 & 484338 & BET017 & \$TD & $08-\mathrm{J}(1 \mathrm{~d}-94$ & $08: 56$ & 20.58 & 82.17 & 1.000 & 82.17 \\
\hline $\mathbf{s} 2$ & 1351508 & 480562 & BET018 & STD & 08-Ju1-94 & $09: 36$ & 18.11 & 67.98 & 1.000 & 67.98 \\
\hline PI & 1351542 & 480529 & BET019 & FLD & 08-JuL-94 & $09: 53$ & 16.47 & 58.56 & 1.000 & 58.56 \\
\hline P2 & 1351547 & 480528 & BETOZO & FLD & 08-Ju1-94 & $10: 09$ & 16.11 & $\$ 6.49$ & 1.000 & 56,49 \\
\hline $\mathbf{F 3}$ & 1351552 & 480528 & BET021 & F.D & 08-Ju\}-94 & $10: 25$ & 15.51 & 53.04 & 1.000 & 53.04 \\
\hline E3 & 1351552 & 480523 & BET0Z2 & FLD & 08-Ju]-94 & $10: 4 i$ & 16.48 & 58.61 & 1.000 & 58.61 \\
\hline E2 & 1351547 & 480523 & BETOZ3 & FLD & $08 \cdot 5 n 1-94$ & 10.57 & 14.13 & 45.11 & 1.000 & 45.11 \\
\hline E1 & 1351542 & 480524 & BET024 & FLD & 08-Juk-94 & 11:12 & 14.65 & 48.10 & 1.000 & 48.10 \\
\hline DI & 1351542 & 480519 & BET025 & FLD & 08-Jul-44 & $11: 28$ & 16.16 & 56.78 & 1.000 & 56.78 \\
\hline $\mathbf{D}$ & 1351547 & 480518 & BET026 & FLD & 08-Jub-94 & $11: 44$ & 15.79 & 54.65 & 1.000 & 54.65 \\
\hline $\mathbf{D} 3$ & 1351552 & 480518 & BETOY? & FLD & 08-Ju-94 & $12: 00$ & 15.53 & 53.16 & 1.000 & 53.16 \\
\hline AA6.5 & 1351563 & 460533 & BETOZ2B & FUD & $08-5 u 1-94$ & $12: 16$ & 15.79 & 54.65 & 1.000 & 54.65 \\
\hline 26.5 & 1351562 & 490508 & BETO29 & FLD & 08-Jvl-94 & $12: 31$ & 17.13 & 62.35 & 1.000 & 62.35 \\
\hline Y65 & $135] 561$ & 460478 & BET030 & FID & 08-Jul-g4 & $12: 47$ & 16.71 & 99.94 & 1.000 & 59.94 \\
\hline Y6 & 1351531 & 480479 & BET031 & FD & 08-Jnl-94 & 13:03 & 16.17 & 56.83 & 1.000 & 56.83 \\
\hline Y5 & 1351471 & 480480 & BETOS2 & FLD & 08.Jul+\$4 & $13: 20$ & 14.99 & 50.05 & 1.000 & 50.05 \\
\hline ws & 1351470 & 480420 & EET033 & FLD & 08-Ju-94 & $13: 36$ & 16.16 & 56.78 & 1.000 & 56.78 \\
\hline us & 1351468 & 480365 & BET034 & FLD & \&-Jvl-94 & $13: 52$ & 15.32 & 51.95 & 1.000 & 51.95 \\
\hline Y6 & 1351529 & 480394 & BET035 & FLD & Q8-Jul-94 & 14:11 & 16.63 & 59.48 & 1.000 & 59.48 \\
\hline V6.5 & 1351559 & 480409 & BET035 & FUD & Q8s-Jou-94 & $14: 28$ & 19.40 & 75.39 & 1.000 & 75.39 \\
\hline w6.5 & 1351560 & 480418 & BETOS? & FLD & 08-JnL-94 & $14: 44$ & 17.70 & 65.62 & 1.000 & 65.62 \\
\hline W6 & 1351530 & 490419 & BET038 & FLD & 08-Jul-94 & $15: 00$ & 15.64 & 53.79 & 1.000 & 53.79 \\
\hline w7 & 1351590 & 480417 & BETOB9 & FLD & 08-Jul-94 & $15: 16$ & 19.11 & 73.72 & 1.000 & 73.72 \\
\hline whs & 1351620 & 480420 & BETO40 & FLD & 08-Jol-94 & $15: 32$ & 18.11 & 67.98 & 1.000 & 67.98 \\
\hline
\end{tabular}


Table G-2: Composite Data Lleting for Beta Scintillometer Technology (continued)

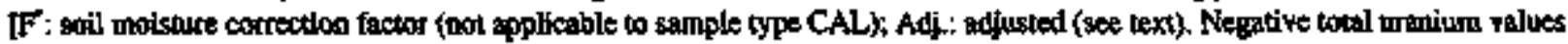
interpreted as below detection kevel. Leaders (-); not measured or nox applicable]

\begin{tabular}{|c|c|c|c|c|c|c|c|c|c|c|}
\hline Goo loo & $x$ coond & $\begin{array}{l}\text { Y Coord } \\
\text { (toit) }\end{array}$ & ID & Type & Date & $\begin{array}{l}\text { Tian } \\
\text { (EDT) }\end{array}$ & $\begin{array}{l}\text { Raw Date } \\
\text { (counts per } \\
\text { second) }\end{array}$ & $\begin{array}{l}\text { Tolial us } \\
\text { (pcils) }\end{array}$ & $F^{*}$ & $\begin{array}{l}\text { Adj } \\
\text { Toted U } \\
\text { (pctig) }\end{array}$ \\
\hline $\bar{W}$ & 3351650 & $\overline{4850459}$ & BEF & $\overline{F L D D}$ & 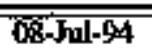 & $15: 48$ & $\overline{16.6 \mathrm{t}}$ & 5936 & 1.000 & 5936 \\
\hline$\$ 2$ & 1351508 & 480562 & BET042 & STD & 08-Jal-94 & $16: 06$ & 16.39 & 58.10 & 1.000 & 58.10 \\
\hline$\infty C 7$ & 1351594 & 480597 & BET043 & FLD & OB-Jul-94 & $16: 40$ & 16.15 & 56.72 & 1.000 & 56.72 \\
\hline $\mathrm{ccs}$ & 1351654 & 480596 & BET044 & FLD & as-Jul-94 & $17, \infty 0$ & 1630 & 57.58 & 1.000 & 57.58 \\
\hline$A A B$ & 1351653 & 480536 & BETOAS & FLD & 68-Jul-94 & $17: 16$ & 14.92 & 49.65 & 1.000 & 49.65 \\
\hline AA7 & $135 \$ 593$ & 480537 & BETQ46 & FLD & 08-Jus-94 & $17: 33$ & 15.30 & 51.84 & 1.000 & 51.84 \\
\hline $\mathbf{z 7}$ & 1351592 & 480507 & BETO47 & FLD & o8-Jul-94 & $17: 49$ & 15.23 & 51.43 & 1.000 & 51.43 \\
\hline Y7 & 1351591 & $4804 \pi$ & BET048 & FLD & 08-bul-94 & 18:05 & 15.94 & $55.5 \pm$ & 1.000 & 55.51 \\
\hline$x 7$ & 1351590 & 480447 & BET049 & FLD & 0A-Jol-94 & 18:22 & 17.01 & 61.66 & 1.000 & 61.66 \\
\hline s1 & 1351541 & 490038 & BETUSO & STD & os-bul-94 & 09.06 & 66.78 & 60.34 & 1.374 & 82.90 \\
\hline $\mathbf{s}$ & 1351508 & 480562 & BETOSI & STD & 09-Jtal-94 & $09: 31$ & 14.17 & 45.34 & 1.374 & 6230 \\
\hline SI & 1351541 & 480338 & BET052 & STD & 09-Jol-94 & 69.57 & 16.11 & 56,49 & 1.374 & 77.62 \\
\hline S2 & $\mathbf{1 3 5 1 5 0 8}$ & 480562 & BETOS3 & STD & OS-Sul-94 & $|0: 2|$ & 13.96 & 44.14 & 1.374 & 60.64 \\
\hline s1 & {$[35154]$} & 480338 & BET)S4 4 & STP & a9-Ju1-94 & $11: 13$ & 16.82 & 60.57 & 1.374 & 83.22 \\
\hline U6 & 1351528 & 480354 & BETOS5 & FLD & c9-Ju\}-94 & $11: 30$ & 14.19 & 45.46 & 1374 & 62.46 \\
\hline$\$ \$$ & $13 \$ 1466$ & 480300 & BETOS6 & PLD & (99-Jul-94 & $11: 47$ & 11.5t & 30.06 & 1.374 & 4131 \\
\hline U6.5 & 1351558 & 480358 & BETV57 & FLD & Q9-Jul-94 & 12.05 & 15.96 & 55.63 & 1.374 & 76.43 \\
\hline S1 & 135154] & 480338 & BETOS8 & STD & (9)-Jut-94 & $|2: 2|$ & 16.00 & 55.86 & 1374 & 76.75 \\
\hline$w$ & 1351588 & 480361 & BETOS9 & FLD & (9-It)-94 & $12: 39$ & 15.95 & 55.57 & 1.374 & 76.35 \\
\hline us & 1351648 & 480366 & BET060 & FLD & 09-hul-94 & $12: 57$ & 17.44 & 64.13 & 1374 & 88.J1 \\
\hline ug & 1351708 & 480354 & BET06I & FLD & 09-30l-94 & $13: 13$ & 1699 & 61.54 & 1.374 & 8456 \\
\hline 59 & 1351706 & 480294 & BET062 & FLD & 09-hol-94 & $13: 29$ & 18.92 & 72.63 & 1.374 & 99.80 \\
\hline sı & 1351541 & 480338 & BET063 & STD & 09-bul-94 & $14: 04$ & 16.69 & 59.82 & 1.374 & 82.19 \\
\hline w8.5 & 1351679 & 480400 & BET064 & FLD & 09.Jol-94 & 14:24 & 16.50 & 58.73 & 1.311 & 76.99 \\
\hline w9 & 1351709 & 480412 & BET065 & FLD & 09-501-94 & $14: 40$ & 15.86 & 55.05 & 1.272 & 70.03 \\
\hline v9 & 1351709 & 480984 & BETQ66: & FLD & 09-Ju1-94 & $14: 56$ & 17.35 & 63.61 & 1.236 & 78.62 \\
\hline V9.5 & 1351739 & 480383 & BETO67 & FLD & 09-Jul-94 & $15: 12$ & 15.81 & 54.77 & 1.201 & 65.77 \\
\hline W9.5 & 1351739 & 480413 & BET068 & FLD & 09-Jul-94 & $15: 27$ & 14.69 & 48.33 & 1.169 & 5650 \\
\hline SI & 1351541 & 480338 & BET069 & STD & O9-Jul-94 & $15: 48$ & 18.79 & 71.88 & 1.109 & 79.72 \\
\hline 52 & 1351508 & 480562 & BETC 70 & STD & o)-Jut-94 & $16: 06$ & 16.12 & 56.55 & 1.109 & 62.71 \\
\hline X7.5 & 1351620 & 480447 & BET07 & FLD & 09.hol-94 & $16: 28$ & 14.22 & 45.63 & 1.109 & 50.60 \\
\hline $\mathrm{x8}$ & 1351650 & 480446 & BETOT2 & PLD & og-Jal-94 & I6:44 & 16.13 & 56.60 & 1.109 & 62.77 \\
\hline Y8 & 1351651 & 480476 & BETO73 & FLD & 09-Jol-94 & $17: 00$ & 13.55 & 41.78 & 1.100 & 46.34 \\
\hline Y7.5 & 1351621 & 480476 & BETO74 & FLD & og-hal-g4 & $17: 16$ & 15.94 & $\$ 5.51$ & 1.109 & 61.56 \\
\hline$\$ 2$ & 1351508 & 480562 & BETOMS & STD & 09-Jul-94 & $17: 35$ & 16.53 & 58.90 & 1.109 & 65.32 \\
\hline S1 & 135154 & 480338 & BETO76 & STD & 09-Jul-94 & $17: 57$ & 18.63 & 70.97 & 1.109 & 78.70 \\
\hline$Y 8.5$ & $135[68 \mathrm{t}$ & $4 \$ 0475$ & BETW7 & FLD & 09-Jur-94 & $18:[9$ & 15.83 & 54.88 & 1.109 & 60.86 \\
\hline Y9 & 135171! & 480474 & BETO/8 & PLD & O9-Jul-94 & 18:36 & 14.40 & 46.67 & 1.109 & 51.75 \\
\hline Y9.S & $135 \$ 725$ & 480474 & BETO79 & F.D & 99-Jul-94 & $18: 52$ & 15.97 & 55.68 & 1.109 & 61.75 \\
\hline $\mathrm{Xg}$ & 1351711 & 480457 & BEJOSO & $\mathbf{F L}, \mathbf{D}$ & O9-Jul-94 & 19.08 & 16.81 & 60.51 & 1.109 & 67.11 \\
\hline
\end{tabular}


Table C-2: Composite Data Lating for Beta seintillometer Technology (continued)

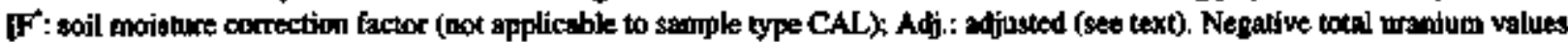
interpreted as below tetection lovel. Leaders ( - )t not measured or bot applicable]

\begin{tabular}{|c|c|c|c|c|c|c|c|c|c|c|}
\hline Ceo Lot & $\begin{array}{c}x \text { coond } \\
\text { (fiect) }\end{array}$ & $\begin{array}{l}Y \text { coord } \\
\text { (fed) }\end{array}$ & ID & Type & Depto & $\begin{array}{l}\text { Time } \\
\text { (ISDT) }\end{array}$ & $\begin{array}{l}\text { Fon Dote } \\
\text { (cournte per } \\
\text { second) }\end{array}$ & $\begin{array}{l}\text { Total U } \\
\text { (pCNo) }\end{array}$ & $F^{*}$ & $\begin{array}{l}\text { Acti. } \\
\text { Total U } \\
\text { (pcilg) }\end{array}$ \\
\hline$\overline{\mathrm{X} 8.5}$ & 1351680 & $4804 \overline{5}$ & $\overline{\text { BETQ81 }}$ & FLD & "09-3ul-94 & 19.24 & 15.33 & 52.01 & $\overline{1 . \overline{109}}$ & 57.68 \\
\hline s1 & 135 I54! & 480338 & BET082 & STD & 09-Jul-94 & $19: 43$ & 18.82 & 72.05 & 1.109 & 79.9I \\
\hline s2 & I351508 & 480562 & BET083 & STD & 09-Jut-94 & $20: 02$ & 16.04 & 56.09 & 1.109 & 62.20 \\
\hline s] & J35154] & 480338 & BET084 & STD & $10-3 u-94$ & $09: 16$ & 18.10 & 67.92 & 1.187 & 80.62 \\
\hline$\$ 2$ & 1351508 & 480562 & BET085 & STD & 10-knl-94 & $09: 37$ & 14.62 & 47.93 & 1.187 & 56.89 \\
\hline $\mathrm{cos}$ & 1351714 & 480594 & BETOB6 & FLD & 10-bul-94 & $10: 01$ & 17.29 & 63.27 & 1.987 & 75.10 \\
\hline CC10 & 1351774 & 480593 & BETOS7 & FLD & 10-hl-94 & $10: 18$ & 14,44 & 46.89 & 1.187 & $\$ 5.66$ \\
\hline AalO & 1351760 & 480533 & BET088 & FLD & $10-501-94$ & $10: 34$ & 17.67 & 65.45 & 1.187 & 77.69 \\
\hline AA9.5 & 1351743 & 480533 & BET089 & FLD & 10-3ul-94 & $10 \div 50$ & 1632 & 57.70 & 1.187 & 68.48 \\
\hline AAO & 1351713 & $4 \$ 0534$ & BETO90 & FLD & 10-Jul-94 & $11: 06$ & 14.21 & 45.57 & 1.187 & $\$ 4.10$ \\
\hline$\$ 2$ & 1351508 & 480562 & BET091 & STD & 10-Jul-94 & $11: 24$ & 16.24 & 57.24 & 1.187 & 67.94 \\
\hline 29 & 1351712 & 480504 & BETO $n$ & FLD & 10-JuL-94 & $11: 48$ & 14.90 & 49.54 & 1.187 & 58.80 \\
\hline 29.5 & 1351742 & 480503 & BET093 & FLD & 10-Jul-94 & $12: 04$ & 17.76 & 65.97 & 1.187 & 78.30 \\
\hline $\mathrm{ZlO}$ & 1351787 & 480502 & BETOS4 & FLD & 10-Jul-94 & $12: 20$ & 15.57 & 53.39 & 1.387 & 63.37 \\
\hline Y10 & 1351771 & 480473 & BET09S & FLD & 10-Jut-94 & $12: 36$ & 16.94 & 61.26 & I.187 & 72.71 \\
\hline s2 & 1351508 & 400562 & BETO\% 6 & STD & 10-Ju๋-94 & $12: 55$ & 15.49 & 52.93 & 1.187 & 62.82 \\
\hline St & 1351541 & 480538 & BET097 & STD & 10-Jul-94 & $13: 29$ & 58.03 & 67.52 & 1.187 & 80.14 \\
\hline Wuo & 1351769 & 480413 & BETQ98 & FLD & $10-5 n-94$ & $13: 34$ & 16.83 & 60.62 & 1.187 & 71.96 \\
\hline w1l & 1351829 & 480411 & BET099 & FLD & $10-1 u 1-94$ & $14 \times 06$ & 17.64 & 65.28 & 1.187 & 77.49 \\
\hline Y11 & $135183 I$ & 480471 & BETIOO & FLD & 10-Jut-94 & $14: 22$ & 16.90 & 61.03 & 1.187 & 72.44 \\
\hline AAll & 1351833 & 480531 & BETIOF & FLD & 10-Ju]-94 & $14: 39$ & 11.98 & 32.76 & 1.187 & 38.89 \\
\hline SI1 & 1351826 & 480291 & BETIOZ & $F L D$ & 10-Jur-s4 & $14: 58$ & 13.50 & $4[.49$ & 1.187 & 49.25 \\
\hline U1! & 1351828 & 480351 & BET103 & FLD & 10-Jul-94 & 15:19 & 17.66 & 65.39 & 1.187 & 77.62 \\
\hline U10 & 1351768 & 480353 & BETIOA & FLD & 10-Jul-94 & $15: 39$ & 17.43 & 64.07 & 1.187 & 76.05 \\
\hline si & 1351541 & 480398 & BETIOS & STD & 10-Ju-94 & $15: 59$ & 18.86 & 72.29 & 1.187 & 85.80 \\
\hline s2 & 1351508 & 480562 & BET106 & STD & $10-\mathrm{Jut}-94$ & $16: 2 !$ & 15.67 & 53.96 & 1.187 & 64.05 \\
\hline \$1 & $135154 \mid$ & 480338 & BET'TO7 & STD & 11-Juk-94 & $09: 17$ & 18.53 & 70.39 & 0.880 & 61.94 \\
\hline$\$ 1$ & 1351541 & 480338 & BET108 & STD & 11-Jut-94 & 10.09 & 18.53 & 70.39 & 0.880 & 61.94 \\
\hline 82 & 1351508 & 480562 & BET109 & STD & 11-Ju\}-94 & $10: 35$ & 2133 & B6.48 & 0.846 & 73.16 \\
\hline V10 & 1351769 & 490383 & BET110 & FD & 11-Jur-g4 & 10.59 & 16.61 & 59.36 & 0.883 & 52.42 \\
\hline $\mathrm{C} 3$ & $135 \$ 758$ & 480373 & BET1!1 & FLD & 11-Jur-94 & $11: 15$ & $16.3 \%$ & 58.10 & 0.908 & 52.75 \\
\hline $\mathrm{C} 2$ & 1351753 & 480973 & HET112 & FD & $11+5 u l+94$ & $11: 31$ & 15.15 & 50.97 & 0.933 & 47.56 \\
\hline $\mathrm{Cl}$ & 1351748 & 480373 & BETI13 & FLD & 11-Ju\}-94 & $11: 48$ & 17.19 & 6269 & 0.960 & 60.19 \\
\hline B1 & 1351748 & $4 \$ 0368$ & BET154 & FLD & 11-ful-94 & $12: 04$ & 15.72 & 54.25 & 0,965 & 53,43 \\
\hline B2 & 1351753 & 480368 & BETLSS & FLD & 1]-5ol-54 & $12: 20$ & 16.07 & 56.26 & 1.010 & 56.82 \\
\hline B3 & 1351758 & 480368 & BET116 & FLD & 11-Jul-94 & $12: 38$ & 15.65 & 53.85 & 1.038 & 55.89 \\
\hline s1 & 1351541 & 480338 & BET117 & STD & 11-Jul-94 & $13: 00$ & 18,42 & 69.76 & 1.073 & 74.85 \\
\hline S2 & 1351508 & 480562 & BETII8 & STD & | J-Jul-94 & $13: 25$ & 15.20 & 51.26 & 1.112 & 57.00 \\
\hline U9.5 & I351738 & 480353 & BET119 & FLD & 11-Jul-94 & $14: 07$ & 14,40 & 46.67 & 1.178 & 54.97 \\
\hline A1 & 1351748 & 480363 & BET120 & FLD & [1-Ju|-94 & $14: 24$ & 13.97 & 44.19 & 1.267 & 55.99 \\
\hline
\end{tabular}


Table G-2: Composite Data Llating for Beta Scintillometer Technology (continued)

[F: soil moisture competion factor (not applicable to sample type CAL); Adj.: adjusted (see text). Negative toend uraniuen rahues interprexed as below detection lovel. Leaders (-) not measumed or not applicable]

\begin{tabular}{|c|c|c|c|c|c|c|c|c|c|c|}
\hline Geo loc & $\begin{array}{l}x \text { Coond } \\
\text { (field }\end{array}$ & $\begin{array}{l}Y \text { coord } \\
\text { (fodif) }\end{array}$ & ID & Type & Datio & $\underset{\text { (ED) }}{\text { Tino }}$ & $\begin{array}{l}\text { Row Dota } \\
\text { (countia per } \\
\text { necond) }\end{array}$ & $\begin{array}{l}\text { Total U } \\
\text { (pcis) }\end{array}$ & $\mathbf{F}$ & 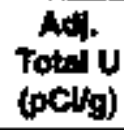 \\
\hline$\overline{A 2}$ & 1351753 & 460363 & BE'STI & FDD & II- $\sqrt{0.94}$ & $14: 40$ & 14.19 & $\overline{45 . \overline{46}}$ & $\overline{1.267}$ & 37.60 \\
\hline $\mathbf{A 3}^{3}$ & 1351758 & 480363 & BET'22 & FLD & 11-Ju1-94 & $15: 27$ & 18.19 & 68.44 & 1.267 & 86.71 \\
\hline 510 & 1351766 & 460293 & ВET123 & FLD & 11-Juk-94 & $15: 55$ & 16.91 & 61.08 & 1.267 & $\pi .39$ \\
\hline CCII & 1351834 & 480591 & BET124 & FLD & 1]-Jnl-94 & $16: 17$ & 11.97 & 3271 & 1.267 & 41.44 \\
\hline 52 & 1351508 & 480562 & BET125 & STD & |1-JuL-94 & $16: 56$ & 14.52 & 47.35 & t. 267 & 60.00 \\
\hline S1 & 1351541 & 480338 & BET126 & STD & I]-Ju[-94 & $17: 26$ & 17.48 & 64,36 & 1.267 & 81.54 \\
\hline$\infty$ & 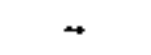 & 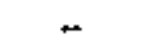 & BET127 & CAL & [1]-Jul-94 & $17: 56$ & 7.03 & 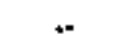 & -- & - \\
\hline $\mathrm{CO}$ & - & -. & BET128 & CAL & |1-Jol-94 & $18: 12$ & 6.91 & -- & - & - \\
\hline $\mathrm{C35}$ & - & -. & BET129 & CAL & 11-Jul-94 & $18: 50$ & 24.68 & - & - & - \\
\hline C35 & - & - & BET130 & CAL & 11-Jul-s/4 & $19: 06$ & 25.62 & - & - & + \\
\hline $\mathrm{Cl00}$ & -- & - & BET13] & CAL & 1I-hul-94 & 1524 & $34,4]$ & - & - & -- \\
\hline C100 & - & - & BET132 & CAL & [1-Jul-94 & $19: 41$ & 32,42 & - & - & - \\
\hline si & J35]\$41 & 480338 & BET133 & STD & 16-Ja|-94 & 11.04 & 17.22 & 62.87 & 1.276 & 8022 \\
\hline$\$ 2$ & 1351508 & 480562 & BET134 & STD & 16-Jul-94 & $11: 39$ & 12.89 & 37.99 & 1.580 & 60.02 \\
\hline- & 1351488 & 480598 & BET13S & FLD & 16-Jut-94 & $11: 58$ & 9.42 & 18.06 & 1.343 & 24.25 \\
\hline- & 1351474 & 480571 & BETI36 & FD & J6-Jnl-594 & $12: 11$ & 10.45 & 23.97 & 1.359 & 3258 \\
\hline- & 1351487 & 480540 & BET137 & FLD & 16-Jol-94 & $12: 25$ & 10.50 & 24.26 & $1.3 n$ & 33.41 \\
\hline- & 1351473 & 480523 & BETI38 & FLD & J6-Jul-94 & $\$ 2.38$ & 10.52 & 24.38 & 1.393 & 33.95 \\
\hline s2 & 1351508 & 480562 & BET139 & STD & 16-Jni-94 & $12: 50$ & 12.23 & 34.20 & 1.742 & 59.57 \\
\hline St & J351541 & 480338 & BET140 & STD & 16-Jul-94 & 13:07 & 16.03 & 56.03 & 1.425 & 79.84 \\
\hline - & 1351485 & 480300 & BET14] & FLD & ]6-Jul-94 & $13: 21$ & 10.55 & 24,55 & 1.816 & 44.58 \\
\hline- & 1351466 & 480312 & BET142 & FLD & J6-Jnl-94 & $13: 33$ & 8.69 & 13.86 & 1.844 & 25.56 \\
\hline- & 1351831 & 480550 & BET143 & FLD & 16-Jbl-94 & $13: 53$ & 7.98 & 9.78 & 1.690 & 16.53 \\
\hline$\infty$ & - & - & BET144 & CAL & $36-J y 1-94$ & $15: 19$ & 6.97 & $=$ & 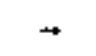 & - \\
\hline$\infty$ & - & - & BETI45 & CAL & $16-5 u 1-94$ & $15: 30$ & 6.85 & - & ـ & 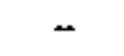 \\
\hline C35 & - & - & BET146 & $\mathrm{CAL}$ & $36-5101-94$ & $15: 42$ & 23.98 & - & - & - \\
\hline C35 & - & - & BET147 & CAL & If-Jul-94 & $16: 25$ & 25.60 & - & -- & - \\
\hline C100 & $\rightarrow$ & - & BET]48 & CAL & I6-Ju|-94 & $16: 45$ & 33.27 & $\because$ & - & $*$ \\
\hline $\mathrm{ClOO}$ & $-\cdot$ & - & BET149 & CAL & 16-Jul-94 & $17: 00$ & 33.80 &. & - & - \\
\hline
\end{tabular}


Table G-3: Compoalte Data Usting for Electret lonization Chamber Technology

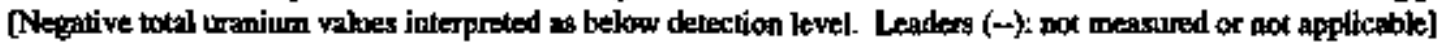

\begin{tabular}{|c|c|c|c|c|c|c|c|c|}
\hline Cot Loe & $\begin{array}{c}x \text { Coord } \\
\text { fioet }\end{array}$ & $\begin{array}{l}\text { Y Coond } \\
\text { (ive) }\end{array}$ & 10 & Type & Date & $\operatorname{Tim}_{\text {(EDT) }}$ & $\begin{array}{l}\text { Raw Deto } \\
\text { (volitemr) }\end{array}$ & $\begin{array}{l}\text { Total U } \\
\text { (pcl/g) }\end{array}$ \\
\hline AA11 & 1351833 & 480531 & EIC349 & FiLD & Oดl-Jับn-94 & 15.53 & 7.3820 & 156.94 \\
\hline Y11 & 1351831 & 480471 & EIC350 & FLD & 01-Jum-94 & 1534 & 3,6620 & 52.45 \\
\hline W11 & 1351829 & 480411 & EIC3S1 & FLD & 01-Jun-94 & $15: 56$ & 27070 & 25.62 \\
\hline U1t & 1351828 & 480351 & EIC3\$2 & FLD & 01-Jun-94 & $15: 57$ & 3.2860 & 41.88 \\
\hline s11 & 1351826 & 480291 & EIC353 & FLD & 01-5um-94 & $15: 58$ & 3,1790 & 38.88 \\
\hline s10 & 1351766 & 480293 & Elec354 & FLD & 01-Jun-94 & $16: 00$ & 3.2120 & 39.81 \\
\hline U10 & 1351768 & 480353 & EIC35s & FLD & 01-Jun-94 & $16: 01$ & 3.0970 & 36.57 \\
\hline V10 & 1351769 & 480383 & EIC3\$6 & FLD & 01-Jun-94 & $16 \times 03$ & 2.6550 & 24.16 \\
\hline W10 & 1351769 & 480413 & EIC357 & FLD & 01-Jun-94 & $16: 05$ & 59000 & 115.56 \\
\hline Y10 & 1351771 & 480473 & EIC358 & FLD & 01-Jun-94 & $16: 05$ & 9.1460 & 206.49 \\
\hline CC11 & 1351834 & 480591 & EIC359 & FLD & 01-Jun-94 & $16: 07$ & 3.6200 & 51.27 \\
\hline U & 1351588 & 480361 & EIC360 & FLD & 01-Jun-94 & $17: 10$ & 4.2750 & 69.66 \\
\hline V6 & 1351529 & 480394 & EIC361 & FLD & 01-Jun-94 & $17: 22$ & 1.0480 & -20.98 \\
\hline Ss & 1351466 & 480300 & EIC362 & FLD & 01-Jun-94 & $17: 24$ & 2.4060 & 17.16 \\
\hline$\$ 1$ & 1351541 & 480338 & EIC363 & STD & 01-Jun-94 & $17: 25$ & 4.4070 & 73.37 \\
\hline$\$ 2$ & 1351508 & 480562 & EIC365 & \$TD & O1-Jun-94 & $17: 28$ & 26070 & 22.81 \\
\hline U6.5 & 1351558 & 480358 & EIC366 & FLD & 01-Jun-94 & $17: 30$ & 4.1540 & 66.27 \\
\hline U8 & 1351648 & 480366 & ElC367 & FLD & 01-Jun-94 & $17: 31$ & 4.8070 & 84.61 \\
\hline Y9.5 & 1351725 & 480474 & EIC 368 & FLD & 01-Jun-94 & $17: 32$ & 2.9780 & 33.23 \\
\hline Z10 & 1351787 & 480502 & ElCэ69 & FLD & O1-Jun-94 & $17: 33$ & 4.4230 & 73.82 \\
\hline $\mathrm{CClO}$ & 1351774 & 480593 & EIC370 & FLD & 02-Jun-94 & $16: 01$ & 2,4940 & 19.64 \\
\hline $\mathrm{CC9}$ & 1351714 & 480594 & EIC371 & FLD & 02-Jun-94 & $16: 02$ & 1.0520 & -20.87 \\
\hline $\mathrm{CCB}$ & 1351654 & 480596 & EIC372 & FLD & $02-J a n-94$ & $16: 03$ & 0.5260 & -35.64 \\
\hline $\operatorname{cc} 7$ & 1351594 & 480597 & Eic373 & FLD & 02-Jun-94 & $16: 05$ & 2.2360 & 12.39 \\
\hline $\cos$ & 1351474 & 480600 & EIC375 & FLD & QQ-Јй-94 & $16: 07$ & 1.4510 & -9.66 \\
\hline AAS & 1351473 & 480540 & EIC376 & FLD & 02-Jun-94 & $16 \mathrm{x} 0 \mathrm{~s}$ & 2,3910 & 16.74 \\
\hline AA6 & 1351533 & 480539 & EIC377 & FLD & 02-Jun-94 & $16: 09$ & 25260 & 20.54 \\
\hline AA6.5 & 1351563 & 480538 & EIC 378 & FLD & 02-Jun-94 & $16: 10$ & 0.6660 & -31.71 \\
\hline AA7 & 1351593 & $480 \$ 37$ & EIC379 & FLD & $02-J u n-94$ & $16: 11$ & 2.6770 & 24.78 \\
\hline AAB & 1351653 & 480536 & EIC380 & FLD & $02-J u n-94$ & $16: 12$ & 1.7450 & -1.40 \\
\hline AA9 & 1351713 & 480534 & EIC381 & FLD & 02-Jun-94 & $16: 13$ & 26920 & 25.20 \\
\hline AA9.5 & 1351743 & 480533 & EIC382 & FLD & 02-Jun-94 & $16: 14$ & 1.7500 & -1.26 \\
\hline AA10 & 1351760 & 480533 & Eic383 & FLD & 02-hun-94 & $16: 14$ & 26960 & 25.31 \\
\hline 29.5 & 1351742 & 480503 & EIC384 & FLD & 02-Jun-94 & $16: 16$ & 2.8300 & 29.07 \\
\hline Z9 & 1351712 & 480504 & ElC385 & FLD & 02-Jun-94 & $16: 17$ & 3.2350 & 40.45 \\
\hline 27 & 1351592 & 480507 & EIC386 & FLD & 02-Jue-94 & $16: 18$ & 2.1620 & 10.31 \\
\hline $\mathrm{Z6.5}$ & 1351562 & 480508 & ElC387 & FLD & 02-Jun-94 & $16: 28$ & 0.9280 & -24.35 \\
\hline
\end{tabular}


Table Q-3: Composite Data Llsting for Electret lonization Chamber Technology (continuwd)

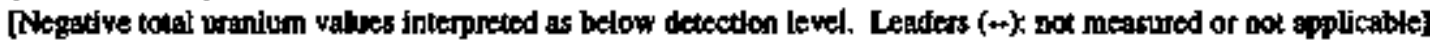

\begin{tabular}{|c|c|c|c|c|c|c|c|c|}
\hline Coo Loc & $\begin{array}{c}x \text { coord } \\
\text { (fipet) }\end{array}$ & $\begin{array}{c}Y \text { Coord } \\
\text { (itionis }\end{array}$ & ID & Type & Date & Tims & $\begin{array}{l}\text { Anw Dants } \\
\text { (roltehr) }\end{array}$ & $\begin{array}{l}\text { Tolal } \\
\text { (poig) }\end{array}$ \\
\hline$\overline{\mathrm{Z6}}$ & 1351532 & 480509 & EIC388 & $\overline{\text { FLD }}$ & 02-Jun-94 & $16: 29$ & 3.3110 & 42.59 \\
\hline Y5 & 1351471 & 480480 & EIC389 & FLD & 02-Jип-94 & $16: 30$ & 4.2390 & 68.65 \\
\hline Y6 & 1351531 & 480479 & EIC390 & FLD & 02-Jun-94 & $16: 31$ & 25230 & 20.45 \\
\hline Y6.5 & 1351561 & 480478 & EIC391 & FLD & 02-รun-94 & $16: 32$ & 3.7190 & 54.05 \\
\hline $\mathrm{Y7}$ & 1351591 & 480477 & $\mathrm{EIC} 392$ & FLD & 02-Jun-94 & $16: 33$ & 3.4580 & 46.72 \\
\hline Y7.5 & 1351621 & 480476 & EIC393 & FLD & $02-J u n-94$ & 1634 & 1.9940 & 5.59 \\
\hline$Y B$ & 1351651 & 480476 & EIC 394 & FLD & $02-J n n-94$ & $16: 36$ & 2.5230 & 20.45 \\
\hline Y8.5 & 1351681 & 490475 & EIC395 & FLD & 02 -Jun-94 & $16: 37$ & 1.5950 & -5.62 \\
\hline Y9 & 1351711 & 480474 & EIC396 & FLD & 02-Jun-94 & $16: 37$ & 4.4000 & 73.18 \\
\hline Y9.5 & 1351725 & 480474 & EIC397 & DUPT & 02-Jun-94 & 16:38 & 2.0060 & 5.93 \\
\hline $\mathbf{X 9}$ & 135t711 & 480457 & EIC398 & FLD & 02-Jur-94 & $16: 39$ & 3.8820 & 58.63 \\
\hline X8.5 & 1351680 & 480445 & ElC399 & FLD & $02-\operatorname{Jn}-94$ & $16: 40$ & 2.8460 & 29.52 \\
\hline$\times 7.5$ & 1351620 & 480447 & EIC401 & FLD & 02-Juo-94 & $16: 41$ & 1.6380 & $-4,41$ \\
\hline$x 7$ & 1351590 & 480447 & EIC402 & FLD & O2-Jua-94 & $16: 42$ & 5.3280 & 99.24 \\
\hline ws & 1351470 & 480420 & EIC403 & FLD & 02-Jun-94 & $16: 43$ & 3.4250 & 45.79 \\
\hline W6 & 1351530 & 480419 & EICAO4 & FLD & 02-Jur-94 & $16: 43$ & 5.8090 & I12.75 \\
\hline W6.5 & 1351560 & 480418 & EIC40S & FLD & 02-Jun-94 & $16: 44$ & 2.7060 & 25.59 \\
\hline W7 & 1351590 & 480417 & EIC406 & FLD & 02-Jun-94 & $16: 45$ & 5.3080 & 98.68 \\
\hline W7.5 & 1351620 & 480420 & EIC407 & FLD & 02-Jun-94 & $16: 45$ & 1.1560 & -17.95 \\
\hline Ws & 1351650 & 480429 & EICA08 & FLD & 02-Jun-94 & $16: 46$ & 2.1800 & 10.82 \\
\hline V6.5 & 1351559 & 480403 & EICAOS & FLD & 02-Jum-94 & $16: 48$ & 2.4640 & 18.79 \\
\hline V6 & 1351529 & 480394 & EIC4EO & DUP' & 02-Jun-94 & $16: 49$ & 1.3040 & -13.79 \\
\hline U9 & 1351708 & 480354 & ERC4II & FLD & O2-Jun-94 & $16: 53$ & 2.1990 & 11.35 \\
\hline U5 & 1351468 & 480365 & EIC412 & FLD & 02-Jun-94 & $16: 49$ & 2.7620 & 27.16 \\
\hline U7 & 1351588 & 480361 & EIC413 & DUP $\ddagger$ & 02-Jun-94 & $16: 51$ & 2.7540 & 26.94 \\
\hline W8.5 & 1351679 & 480400 & EIC4I4 & FLD & 02-Jun-94 & $16: 54$ & 1.8840 & 2.50 \\
\hline w9 & 1351709 & 480412 & EIC415 & FLD & 02-Jum-94 & 1655 & 2.6170 & 23.09 \\
\hline V9 & 1351709 & 480384 & EIC416 & FLD & 02-Iun-94 & $16: 55$ & 3.3480 & 43.63 \\
\hline S10 & 1351766 & 480293 & EIC417 & DUPA & 02-Jun-94 & $16: 57$ & 2.6670 & 24.50 \\
\hline U10 & 1351768 & 480353 & EIC418 & DUPt & 02-Jun-94 & $16: 58$ & 2.5260 & 20.54 \\
\hline U95 & 1351738 & 480353 & EIC419 & FLD & 02-Jun-94 & $16: 59$ & 3.5660 & 49.75 \\
\hline v9s & 1351739 & 480383 & EIC420 & FLD & 02-Jun-94 & $17: 00$ & 2.3810 & 16.46 \\
\hline vio & 1351769 & 480383 & EIC421 & DUP4 & 02-Jun-94 & $17: 01$ & 2.2320 & 12.28 \\
\hline W10 & 1351769 & 480413 & $\mathrm{EIC422}$ & DUPt & 02-Jun-94 & 17.01 & 4.1790 & 6697 \\
\hline w9.5 & 1351739 & 480413 & $\mathrm{EIC423}$ & FLD & 02-Jun-94 & $17: 02$ & 2.6870 & 25.06 \\
\hline Y10 & $\$ 35177$ & 480473 & $\mathrm{EIC424}$ & DUP' & $02-J u n-94$ & $17: 03$ & 1.7910 & -0.11 \\
\hline $\mathbf{2 1 0}$ & 1351787 & 480502 & EIC425 & DUPY & 02-Jun-94 & $17: 04$ & 2.5370 & 20.84 \\
\hline $\mathrm{C200}$ & - & - & EIC426 & CAL & $02+5 u n-94$ & $15: 35$ & 14.6170 & + \\
\hline
\end{tabular}


Table G-3: Composite Data Listing for Electret Ionization Chamber Technology (continued)

[Negative tonal uranimm values interpreted as below detection level. Leakers (-): not meaguned or nox appliegble]

\begin{tabular}{|c|c|c|c|c|c|c|c|c|}
\hline Cor LoG & $\begin{array}{c}x \text { coord } \\
\text { (tient) }\end{array}$ & $\begin{array}{c}Y \text { Coond } \\
\text { (10it) }\end{array}$ & D & Typo & Dente & $\operatorname{Tins}_{\text {(EDT) }}$ & $\begin{array}{l}\text { Paw Datia } \\
\text { (voltendi) }\end{array}$ & $\begin{array}{c}\text { Total U } \\
\text { (potto) }\end{array}$ \\
\hline C200 & $*$ & $\bar{\ldots}$ & EIC427 & CAL & 02 -Jun-94 & $8: 13$ & 13.5590 & - \\
\hline Cion & - & - & EIC428 & CAL & 02-Jun-94 & $15: 40$ & 12.0560 & -- \\
\hline C100 & - & - & EIC429 & CAL & 01-Jun-94 & 1557 & B.5910 & - \\
\hline$C 200$ & - & - & EIC430 & CAL & 01-Jun-94 & $17: 02$ & 11.7390 & - \\
\hline $\mathrm{Cl} 100$ & - & - & EIC435 & CAL & 02-Iưn-94 & $8 \div 12$ & 15.1340 & - \\
\hline c35 & - & - & EIC436 & CAL & 02-Jun-94 & $15: 43$ & 4.3100 & - \\
\hline C35 & - & -- & EHC437 & CAL & 02-Jun-94 & $8: 11$ & 3.8340 & $\omega$ \\
\hline C35 & - & -- & ElC438 & CAL & 01-Jun-94 & $16: 50$ & 6.1580 & - \\
\hline$\infty$ & - . & -- & Elc439 & CAL & 02.Jum-94 & $8+10$ & 2.8340 & - \\
\hline$\infty$ & - & -- & ElC440 & CAL & 02-Jum-94 & $16: 32$ & 2.8410 & - \\
\hline$\infty$ & - & -- & EKC441 & CAI & 01-Iun-94 & $16: 42$ & 3.9880 & -- \\
\hline F1 & $\$ 351542$ & 480529 & EICSOO & FLD & 18-Ju1-94 & $9: 36$ & 0.0000 & -50.42 \\
\hline $\mathbf{F} 2$ & 1351547 & 480528 & EICSOI & FLD & |8-Jt1-94 & $10: 34$ & 0.5100 & +36.09 \\
\hline $\mathbf{F 3}$ & 1351552 & 480528 & ElCs02 & FLD & 18-Jul-94 & $10: 34$ & 0.5400 & -35.25 \\
\hline E1 & 1351542 & 480524 & EKC503 & FLD & 18-Jul-94 & $10: 34$ & 0.7200 & -30.20 \\
\hline E2 & 1351547 & 480523 & ElCsO4 & FLD & 18-Jut-94 & $10: 34$ & 0.9100 & -24.86 \\
\hline $\mathbf{E 3}$ & 1351552 & 480523 & EKC505 & FLD & 18-Jul-94 & $10: 34$ & 1.4500 & -9.69 \\
\hline D1 & 1351542 & $4 \$ 0519$ & EACs06 & FLD & 18-Jut94 & $10: 34$ & 1.4500 & -9.69 \\
\hline $\mathrm{D} 2$ & 1351547 & 480518 & Excson & FLD & 18-Jul-94 & $10: 34$ & 0.1700 & -45.64 \\
\hline D3 & 1351552 & 480518 & ElCs08 & FLD & 18-Jul-94 & $10: 34$ & 0.5200 & -35.81 \\
\hline $\mathrm{Cl}$ & 1351748 & 480373 & $\operatorname{AICSOS}$ & FLD & 18-Jal-94 & $10: 48$ & 1.0900 & -19.80 \\
\hline$C 2$ & 1351753 & 480373 & EICS10 & FLD & 18-Ju1-94 & $10: 48$ & 2.7200 & 25.98 \\
\hline $\mathrm{C} 3$ & 1351758 & 480373 & EIC511 & FLD & 18-Ju1-94 & 10.48 & 2.7200 & 25.98 \\
\hline B1 & 1351748 & 480368 & EIC512 & FLD & 18-Jul-94 & $10: 48$ & 0.3600 & -40.31 \\
\hline $\mathrm{B} 2$ & 1351753 & 480368 & EJCS13 & FLD & 18-Jul.94 & $10: 48$ & 2.3600 & 15.87 \\
\hline $\mathbf{B 3}$ & 1351758 & 480368 & EIC514 & FLD & 18-Jul-94 & $10: 48$ & 1.2700 & -14.75 \\
\hline A1 & 1351748 & 480363 & EICs15 & FLD & 18-JuJ-94 & 11,02 & 0,0000 & -50.42 \\
\hline A2 & 1351753 & 490363 & EIC516 & FLD & 18-Jal-94 & $11: 02$ & 1.7000 & -2.67 \\
\hline$A 3$ & 1351758 & 480363 & ElCs 17 & FLD & 18-Jul-94 & 11:02 & 0.1900 & -45.08 \\
\hline SI & $135154]$ & 480338 & EIC5 18 & STD & 18-Jul-94 & $12: 00$ & 1.6200 & -4.91 \\
\hline $\mathbf{s 2}$ & 1351508 & 480562 & E1C519 & STD & 18-Jv1-94 & $12: 00$ & 2.0800 & 8.01 \\
\hline CC6 & 1351534 & 480599 & ElCs20 & FLD & 18-JuL-94 & 12.00 & 1.3200 & -13.34 \\
\hline $\mathbf{X 8}$ & 1351650 & 480446 & EIC521 & FLD & 18-Jul-94 & $12: 00$ & 0.4400 & -98.06 \\
\hline U6 & 1351528 & 480354 & EIC522 & FLD & 18-Jग1-94 & 12.00 & 0.8800 & -25.70 \\
\hline 59 & 1351706 & 480294 & $\mathrm{EIC5} 23$ & FLD & 18-Jtzl|-94 & $12: 00$ & 0.8800 & -25.70 \\
\hline- & 1351727 & 480596 & EICS24 & FLD & 18-J11-94 & $12: 00$ & 0.0000 & -50.42 \\
\hline- & 1351725 & 480580 & EICs2S & FLD & 18-Jul-94 & $12: 43$ & 2.0800 & 8.01 \\
\hline- & 1351655 & 480577 & EIC526 & FLb & 18-hul-94 & $12: 43$ & 1.0400 & -21.21 \\
\hline
\end{tabular}


Table G-3: Composite Data Llating for Electret lonization Chamber Technology (continued)

[Negative total uramium values interpreted as below detection level. Leaders (-): not measured of not applicable]

\begin{tabular}{|c|c|c|c|c|c|c|c|c|}
\hline Gex Loc & $\begin{array}{l}x \text { coond } \\
\text { (feof) }\end{array}$ & $\begin{array}{l}Y \text { Caord } \\
\text { (fact) }\end{array}$ & $\mathbf{D}$ & Type & Date & $\begin{array}{l}\text { TIme } \\
\text { (EDT) }\end{array}$ & $\begin{array}{l}\text { Riow Dote } \\
\text { (volitshr) }\end{array}$ & $\begin{array}{l}\text { Toted U } \\
\text { (pCis) }\end{array}$ \\
\hline$\overline{-}$ & 1351635 & 4880597 & EIC527 & FLD & 18-Jul-94 & $12: 43$ & 0.2600 & -43.12 \\
\hline- & 1351632 & 480445 & EICS28 & $\mathbf{F L D}$ & 18-Ju1-94 & $12: 43$ & 2.6000 & 22.61 \\
\hline-- & 1351631 & 480419 & $\operatorname{EICS} 23$ & $F L D$ & 18-Ju1-94 & $12: 43$ & 0,0000 & $-50,42$ \\
\hline-- & 1351576 & 480507 & EICS30 & $\mathbf{F L D}$ & 18-Ju1-94 & $12: 58$ & 3.8900 & 58.85 \\
\hline- & 1351576 & 480536 & EIC531 & FLD & 18-Jut-94 & $12: 58$ & 3.0600 & 35.54 \\
\hline - & 1351474 & 480565 & EIC532 & FLD & 18-Jtt]-94 & 12:58 & 1.0400 & -21.21 \\
\hline- & 1351671 & 480474 & EICS33 & FLD & 18-JnI-94 & $12: 58$ & 0.7800 & -28.51 \\
\hline $\mathbf{C O}$ & -- & -- & EIC534 & CAL & 18-Jul-94 & $13: 41$ & 0.6300 & - \\
\hline$\infty$ & -- & -- & EICS33 & CAL & 18-Jul-94 & $13: 41$ & 0.5200 & - \\
\hline C35 & -- & -- & EIC536 & CAL & 18-Jut-94 & $13: 41$ & 13000 & - \\
\hline C35 & - & - & EICS37 & CAL & 18-Jot-94 & $13 \div 41$ & 3.7500 & - \\
\hline C100 & - & - & EIC538 & CAI & 18-Jn1-94 & $13 \div 41$ & 1.2000 & -- \\
\hline $\mathrm{C100}$ & - & -- & EIC539 & CAL & 18-Jal-94 & $13 \div 4]$ & 20900 & - \\
\hline $\mathrm{CP}$ & - & - & EICS40 & CAL & 18-Jul-94 & $13+55$ & 6.2500 & - \\
\hline $\mathrm{CP}$ & - & - & EIC541 & CAL & 18-Jul-94 & $13 \div 55$ & 2.2900 & 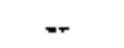 \\
\hline
\end{tabular}

t. The designation, "DUP" is in the original data base. The gooloction code and the coorfinates indicate that this is not a duplicate sample. 
Table G-4: Composite Data Listing for FDLER Scintillometer Technology

[Negative totsl urrenivm values interpretec as below detection level. Lesders (-m); not measured or not applicabie]

\begin{tabular}{|c|c|c|c|c|c|c|c|c|}
\hline Geo Loc & $\begin{array}{l}x \text { coond } \\
\text { (twit) }\end{array}$ & Y coond & ID & Type & Denc & Thime & $\begin{array}{c}\text { Raw Dato } \\
\text { (countes pir } \\
\text { minute) }\end{array}$ & $\begin{array}{l}\text { Totel U } \\
\text { (pet/a) }\end{array}$ \\
\hline $\bar{\phi}$ & $\overline{\bar{n}}$ & - & FitDo06 & $\overline{\mathrm{CAL}}$ & $\overline{0}-\sqrt{u n-94}$ & $08: 08$ & $\overline{469}$ & -- \\
\hline$\infty$ & - & - & FTD007 & CAl & $02-J_{2 n}-94$ & $08: 10$ & 440 & .. \\
\hline$\infty$ & - & - & FIDOOB & CAL & $02-J u m-94$ & $08: 12$ & 440 & - \\
\hline C35 & - & - & FiDoxy & CAL & O2-Ju-94 & $08: 14$ & 808 & - \\
\hline C35 & 4 & - & F[Dolo & CAL & 02-Jun-94 & $08: 16$ & 783 & - \\
\hline C35 & - & - & FIDOII & CAL & 02-Jn-94 & 08:18 & 782 & -- \\
\hline $\operatorname{cio} 0$ & - & -- & FDO012 & CAL & $02-J u n-94$ & $08: 20$ & 918 & -- \\
\hline C100 & -- & -- & FID013 & CAI & $02-J u n-94$ & $08: 22$ & 940 & .. \\
\hline $\mathrm{Cl00}$ & -- & - & FID014 & CAL & 02-Jun-94 & $08: 24$ & 969 & - \\
\hline$C 200$ & -- & - & FD015 & CAL & 02-Jun-94 & $08: 26$ & 1633 & .. \\
\hline C200 & -- & - & FIDO16 & CAL & 02-Jun-94 & $08: 28$ & 1622 & $*$ \\
\hline $\mathrm{C} 200$ & -- & $\ldots$ & FID017 & CAL & 02-Jun-94 & 08:30 & 1582 & .- \\
\hline \$1 & 1351541 & 480338 & FIDD18 & STD & 02-Jun-94 & 09:00 & 775 & 103.78 \\
\hline S1 & 1351541 & $4 \$ 0338$ & FID019 & STD & O2-Jun-94 & 09:02 & 752 & 97.27 \\
\hline s2 & 1351508 & 480562 & FIDO20 & STD & 02-Jua-94 & 09:05 & 674 & 75.18 \\
\hline S2 & 1351508 & 480562 & F[D021 & STD & O2-Jut-94 & $09: 07$ & 755 & 98.12 \\
\hline $\operatorname{ccs}$ & 1351474 & 480600 & FIDO22 & FLD & 12-Jun-94 & $09: 10$ & 717 & 87.35 \\
\hline CC6 & 1351534 & 480599 & FID024 & FLD & 02-Jun-94 & $09: 15$ & 727 & 90.19 \\
\hline $\mathrm{CC7}$ & 1351594 & 480597 & FIDO27 & FLD & 02-Jun-94 & $09: 23$ & 750 & 96.70 \\
\hline Cc8 & 1351654 & $480 \$ 96$ & FIDO29 & FLD & 02-Jun-94 & $09: 28$ & 726 & 89.90 \\
\hline $\cos$ & 1351714 & 480594 & FIDQ31 & FLD & 02-Jun-94 & $09: 34$ & 735 & 92.45 \\
\hline $\mathrm{CCl} 0$ & 1351774 & 480593 & FID033 & FLD & 02-Jun-94 & $09: 39$ & 713 & 86.22 \\
\hline$\infty{ }_{11}$ & 1351834 & 480591 & FID035 & FLD & $02-J u n-94$ & $09: 46$ & 672 & 74.61 \\
\hline AAS & 1351473 & 480540 & FID038 & FLD & 02-Jun-94 & 09:55 & 663 & 72.06 \\
\hline AA6 & 1351533 & 480539 & FID040 & FLD & 02 -Jun-94 & 09:59 & 697 & 81.69 \\
\hline F1 & 1351542 & 480829 & $\mathrm{FID} 042$ & FLD & 02-Jй-94 & $10: 04$ & 721 & $8 B .49$ \\
\hline F2 & 1351547 & 480528 & FIDO44 & FUD & 02-ปир-94 & 10:09 & 757 & 98.68 \\
\hline F3 & 1351552 & 480528 & FID046 & FLD & 02-Jun-94 & $10: 15$ & 712 & 85.94 \\
\hline E3 & 1351552 & 480523 & FIDO48 & FLD & ด2-Јน-94 & 10:19 & 706 & 84.24 \\
\hline E2 & 1351547 & 480523 & FID051 & FLD & 02-Jun-94 & $10: 26$ & 700 & 82.54 \\
\hline E1 & 1351542 & 480524 & FID053 & FLD & 02-Jun-94 & 10:30 & 716 & 87.07 \\
\hline D1 & 1351542 & 480519 & FID055 & FLD & 02-Jun-94 & $10: 35$ & 701 & 82.82 \\
\hline $\mathrm{D} 2$ & 1351547 & 480518 & FID059 & FLD & 02-Jun-94 & 10.42 & 725 & 89.62 \\
\hline D3 & 1351532 & 480518 & FID061 & FLD & 02-Jun-94 & 30.47 & 706 & 84.24 \\
\hline AA6.5 & 1351563 & 480538 & FID063 & FLD & 02-Jun-94 & $12: 33$ & 721 & 88.49 \\
\hline AA7 & 1351593 & 480537 & FID065 & FLD & 02-Jun-94 & $12: 38$ & 654 & 69.51 \\
\hline AA8 & 1351653 & 480536 & FID067 & FLD & 02-Jun-94 & $12: 42$ & 681 & 77.16 \\
\hline
\end{tabular}


Table G-4: Composite Data Usting for FIDLER Scintillometer Technology (continued)

[Negarive total aranum vahes inxerpreted as below detection kevel. Leaders (-): not measured or not applicsble]

\begin{tabular}{|c|c|c|c|c|c|c|c|c|}
\hline Geo Loc & $\begin{array}{l}x \text { coort } \\
\text { (fient) }\end{array}$ & Y coord & ID & Type & Date & $\begin{array}{l}\text { Time } \\
\text { (EDT) }\end{array}$ & $\begin{array}{l}\text { Ruw Detid } \\
\text { (counts per } \\
\text { minulo) }\end{array}$ & $\begin{array}{l}\text { Total u } \\
(\mathrm{p} C \mathrm{~g} / \mathrm{g})\end{array}$ \\
\hline$\overline{A A 9}$ & 1351713 & 460534 & FID070 & FLD & (02-Jun-94 & 121250 & $\overline{676}$ & 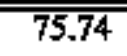 \\
\hline AA9.5 & 1351743 & 480533 & $\mathrm{FIDO} / 2$ & FLD & 02-Jun-94 & $12: 55$ & 713 & 86.22 \\
\hline AA10 & 1351760 & 480533 & FID074 & FLD & O2-Jun-94 & 12.59 & 692 & 80.27 \\
\hline AA11 & 1351833 & 480531 & FID076 & FLD & 02-Jun-94 & $13: 04$ & 664 & 72.34 \\
\hline $\mathrm{Z10}$ & 1351787 & 480502 & FID078 & FLD & 02-Jvo-94 & 13:10 & 663 & 72.06 \\
\hline Z95 & 1351742 & 480503 & FID081 & FLD & 02-Jua-94 & $13: 18$ & 711 & 85.66 \\
\hline Z9 & 1351712 & 480504 & FID082 & FLD & 02-Jun-94 & $13: 21$ & 699 & 82.26 \\
\hline $\mathbf{s}$ & 1351541 & 480338 & FID0\&3 & STD & 02-Jut-94 & $13: 24$ & 740 & 93.87 \\
\hline$\$ 2$ & 1351508 & 480562 & FID0:4 & STD & $02-J u n-94$ & $13: 27$ & 698 & 81.97 \\
\hline$\$ 1$ & t35154] & 480338 & FID095 & STD & 03-Juฺ-94 & $13: 21$ & 752 & 9727 \\
\hline S2 & 1351508 & 480562 & FID096 & STD & 03-Jun-94 & $13: 26$ & 729 & 90.75 \\
\hline 27 & 1351592 & 480507 & FID097 & FLD & 03-Jun-94 & $13: 30$ & $68 \mathrm{I}$ & 77.16 \\
\hline 26.5 & 1351562 & 480508 & FIID098 & ELD & 03-Jum-94 & 13:32 & 740 & 93.87 \\
\hline Z6 & 1351532 & 480509 & FID099 & FLD & 03-5பm-94 & $13: 35$ & 704 & 83.67 \\
\hline Y5 & 1351471 & 480480 & FID100 & FLD & 03-Jum-94 & $13: 37$ & 694 & 80.84 \\
\hline Y6 & 1351531 & 480479 & FD101 & FLD & 03-Jun-94 & $13: 40$ & 685 & 78.29 \\
\hline Y6.5 & 1351561 & 480478 & FID103 & FLD & 03-Jun-94 & $13: 45$ & 652 & 68.95 \\
\hline Y7 & 1351591 & 480477 & FID104 & FLD & 03-Jun-94 & $13: 47$ & 719 & 87.92 \\
\hline Y7.5 & 1351621 & 480476 & FIDIOS & FLD & 03-Јип-94 & $13: 50$ & 773 & 103.21 \\
\hline Y8 & 1351651 & 480476 & FID106 & FLD & 03-Jun-94 & $13: 54$ & 706 & 84.24 \\
\hline Y8.5 & 1351681 & 480475 & FDDI07 & FLD & $03-J u n-94$ & $13: 56$ & 699 & 82.26 \\
\hline Y9 & 1351711 & 480474 & FE108 & FLD & 03-Jun-94 & $13: 59$ & 722 & 88.7 \\
\hline$Y 9.5$ & 1351725 & 480474 & FID109 & FLD & 03-Jun-94 & $14: 01$ & 655 & 69.80 \\
\hline Y10 & 1351771 & 480473 & FID110 & FLD & 03-Jun-94 & $14: 04$ & 712 & 85.94 \\
\hline Y11 & 1351831 & 480471 & FID111 & FLD & 03-Jun-94 & $14: 06$ & 836 & 121.06 \\
\hline$x 7$ & 1351590 & 480447 & FID114 & FLD & 03-Jun-94 & $14: 16$ & 715 & 86.79 \\
\hline$X 7.5$ & 1351620 & 480447 & FID115 & FLD & 03-Jun-94 & $14: 19$ & 666 & 72.91 \\
\hline $\mathbf{X 8}$ & 1351650 & 480446 & FID116 & FLD & 03-Jun-94 & $14: 21$ & 698 & 81.97 \\
\hline X8.5 & 1351680 & 480445 & FID117 & FLD & 03-Jun-94 & $14: 25$ & 677 & 76.03 \\
\hline $\mathbf{X} 9$ & 1351711 & 480457 & FDD118 & FLD & 03-Jun-94 & $14: 27$ & 733 & 91.89 \\
\hline W11 & 1351829 & 480411 & FID119 & FLD & 03-Jun-94 & $14: 31$ & 742 & 94.43 \\
\hline W10 & 1351769 & 480413 & FIDI20 & FLD & 03-Jun-94 & $14: 35$ & 688 & 79.14 \\
\hline w9 & 1351709 & 480412 & FIDI21 & F1.D & 03-Jun-94 & $14: 41$ & 716 & 87.07 \\
\hline W8.5 & 1351679 & 480400 & FIDI22 & FLD & 03-Jun-94 & $14: 45$ & 735 & 92.45 \\
\hline w8 & 1351650 & 480429 & FID123 & FLD & O3-Jun-94 & $14: 48$ & 688 & 79.14 \\
\hline S1 & 1351541 & 480338 & FID 124 & STD & O3-Jun-94 & $14: 51$ & 751 & 96.98 \\
\hline$\$ 1$ & $135154]$ & 480338 & FID125 & STD & O3-Jun-94 & $14: 54$ & 740 & 93.87 \\
\hline $\mathbf{5 2}$ & 1351508 & 480562 & FIDI26 & STD & 03-Jun-94 & $14: 57$ & 676 & 75.74 \\
\hline
\end{tabular}


Table Q-4: Composite Data Llating for FDLef seintillometer Technology (continured)

[Negetive total nranitum valoes interperted as below detection kevel. Leaders (-): not measured of not epplicable]

\begin{tabular}{|c|c|c|c|c|c|c|c|c|}
\hline CHo Lod & $\begin{array}{c}x \text { Cootit } \\
\text { (6)it) }\end{array}$ & $\begin{array}{c}\text { Y Coond } \\
\text { (fost) }\end{array}$ & I9 & Type & Dat: & $\underset{\text { (TIm: }}{\text { Tim) }}$ & $\begin{array}{c}\text { Rew Data } \\
\text { (counte par } \\
\text { minute) }\end{array}$ & $\begin{array}{l}\text { Toted U } \\
\text { (pcig) }\end{array}$ \\
\hline \$1 & 1351541 & $\overline{480338}$ & FID137 & 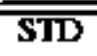 & $06-\sqrt{0} n-94$ & $10: 28$ & $\overline{763}$ & 10038 \\
\hline $\mathbf{s}$ & 1351508 & 480562 & FID138 & STD & 06-Jun-94 & 10:31 & 716 & 87,07 \\
\hline W7s & 1351620 & 480420 & FID139 & FLD & 06-Jun-94 & $10: 36$ & 773 & 103.21 \\
\hline W7 & $135 t 590$ & 480417 & FID140 & FLD & 06-Jun-94 & $10: 39$ & 751 & 96.98 \\
\hline W6.5 & 1351560 & 480418 & FID141 & FLD & 06-Jon-94 & $10: 42$ & 778 & 104.63 \\
\hline W6 & 1351530 & 480419 & FID142 & FLD & O6-Jun-94 & $10 \div 45$ & 771 & 102.65 \\
\hline ws & 1351470 & 480420 & FID143 & FLD & 06-Jun-94 & $10: 47$ & 717 & 87.35 \\
\hline V6 & 1351529 & 480394 & FID144 & FLD & O6-Jan-94 & $10: 52$ & 741 & 94.15 \\
\hline V6.5 & 1351559 & 480403 & FID145 & FLD & O6-Jun-94 & $10: 54$ & 787 & 107.18 \\
\hline U5 & 1351468 & 480365 & FDD147 & FLD & O6-Jun-94 & $12: 10$ & 650 & 68.38 \\
\hline U6 & 1351528 & 480354 & FIDi48 & FLD & (6-Jun-94 & $12: 14$ & 689 & 79.42 \\
\hline U6.5 & 1351558 & 480358 & FID149 & FLD & 06-Jun-94 & $12: 16$ & 711 & 85.66 \\
\hline U7 & 1351588 & 480361 & FID150 & FLD & 06-Jun-94 & $12: 20$ & 763 & 100.38 \\
\hline U8 & 1351648 & 480366 & FIDt51 & FLD & O6-Jun-94 & $12: 22$ & 784 & 106.33 \\
\hline U9 & 1351708 & 480354 & FIDI52 & FLD & O6-Jur-94 & $12: 25$ & 723 & 89.05 \\
\hline v9 & 1351709 & 480384 & FID 153 & FLD & 06-Jum-94 & $12: 27$ & 693 & 80.56 \\
\hline v9.5 & 1351739 & 480383 & FID 154 & FID & 06-Jun-94 & $12: 30$ & 646 & 67.25 \\
\hline V10 & 1351769 & 480383 & FIDI5S & FL.D & 06-Jun-94 & $12: 32$ & 648 & 67.81 \\
\hline CI & 1351748 & 480373 & FID156 & FUD & C6-Jun-94 & $12: 36$ & 680 & 76.83 \\
\hline$C 2$ & 1351753 & 480373 & FID157 & Ft. D & 06-Jun-94 & $12: 38$ & 670 & 74,04 \\
\hline $\mathrm{C} 3$ & 1351758 & 480373 & FID159 & FLD & 06-Jun-94 & $12: 43$ & 673 & 74.89 \\
\hline B3 & 1351758 & 480368 & F[D 160 & FLD & 06-Jun-94 & $12: 45$ & 657 & 70.36 \\
\hline B2 & 1351753 & 480368 & FIDI61 & FLD & 06-Jun-94 & $12: 47$ & 616 & 58.75 \\
\hline B1 & 1351748 & 480368 & FIDI62 & FLD & (6)-Јип-94 & $12: 50$ & 655 & 69.80 \\
\hline A1 & 1351748 & 480363 & FIDI63 & FLD & O6-Jun-94 & $12: 52$ & 648 & 67.81 \\
\hline A2 & 1351753 & 480363 & IID164 & FLD & 06-Jun-94 & $12: 55$ & 636 & 64.42 \\
\hline $\mathbf{A 3}$ & 1351758 & 480363 & FD165 & FLD & 06-Jum-94 & $12: 57$ & 675 & 75.46 \\
\hline U9.5 & 1351738 & 480353 & FD166 & FLD & 06-5un-94 & $13: 00$ & 658 & 70.65 \\
\hline U10 & 1351768 & 480353 & FIDI 67 & FLD & 06-Jun-94 & $13: 02$ & 680 & 76.88 \\
\hline U11 & 1351828 & $48035 !$ & FIDI68 & FLD & 06-Jun-94 & $13: 05$ & 697 & 81.69 \\
\hline S11 & 1351826 & 480291 & FiDl70 & FLD & 06-Jun-94 & $13: 14$ & 610 & 57.05 \\
\hline 510 & 1351766 & 480293 & FID171 & FLD & 06-Jon-94 & $13: 17$ & 684 & 78.01 \\
\hline 59 & 1351706 & 480294 & $\mathrm{FIDl72}$ & FLD & 06-Jun-94 & $13: 21$ & 738 & 93.30 \\
\hline ss & 1351466 & 480300 & FID173 & FLD & 06-Jun-94 & $13: 25$ & 681 & 77.16 \\
\hline \$1 & 1351541 & 480338 & FID 174 & STD & 06-Juk-94 & 13:28 & 705 & 83.96 \\
\hline s2 & 1351508 & 480562 & FID175 & STD & 66-Jon-94 & $13: 31$ & 732 & 91.60 \\
\hline$C 0$ & - & - & $\mathrm{FID} 176$ & CAL & O6-Jon-94 & $13: 43$ & 449 & -- \\
\hline $\mathrm{CO}$ & - & - & FID 177 & CAL & 66-Jon-94 & $13: 45$ & 442 & - \\
\hline
\end{tabular}


Table G-4; Composite Data Lieting for FDLER Scintillometer Technology (continued)

[Neqative total uramium values interpreted as below defection level. [eaders (-); not mensured or not applicable]

\begin{tabular}{|c|c|c|c|c|c|c|c|c|}
\hline Coo Loc & $x$ coond & $\begin{array}{l}\text { Y Coord } \\
\text { (fted) }\end{array}$ & ID & Typo & Dotis & $\underset{\text { (EDT) }}{\operatorname{Tm}}$ & $\begin{array}{l}\text { Row Dest } \\
\text { (oounte por } \\
\text { minute) }\end{array}$ & $\begin{array}{l}\text { Totel U } \\
\text { (pGig) }\end{array}$ \\
\hline$\overline{C 35}$ & $=$ & $\overline{-1-}$ & FID176 & CAL & 06-Jun-94 & $13: 55$ & 781 & $\overline{-}$ \\
\hline C35 & - & - & FID 179 & CAL & 06-Jun-94 & $13: 57$ & 735 & -- \\
\hline C100 & - & - & FID180 & CAL & 06-Jun-94 & $13: 59$ & 964 & -- \\
\hline Cion & -- & - & FID181 & CAL & 06-Jun-94 & $14: 01$ & 909 & - \\
\hline Cjoo & -- & - & FID182 & CAL & O6-Jun-94 & 14,03 & 913 & - \\
\hline $\mathrm{C} 200$ & -- & - & FID183 & CAL & 06-Jun-94 & 14,06 & 1519 & - \\
\hline $\mathrm{C} 200$ & -. & - & FID184 & CAL & O6-Jun-94 & $14: 08$ & $154]$ & - \\
\hline S! & 1351541 & 480338 & FID195 & STD & 09-Jug-94 & $10: 51$ & 683 & 77.73 \\
\hline S1 & 1351541 & 480338 & FID196 & STD & 09-Jun-94 & 10.53 & 711 & 85.66 \\
\hline s2 & 1351508 & 480562 & FIDIM & STD & 09-Jun-94 & 11:03 & 638 & 64.98 \\
\hline \$2 & 1351508 & 480562 & FID198 & STD & 09-Jum-94 & $11: 06$ & 613 & 57.90 \\
\hline S1 & 1351541 & 480338 & FID210 & STD & 10-Jut-94 & $09: 49$ & 777 & 104.35 \\
\hline st & 1351541 & 480338 & FID211 & STI & 10-Jun-94 & $09: 51$ & 769 & 102.08 \\
\hline \$2 & 1351508 & 480562 & FID212 & STD & 10-Jun-94 & 09.57 & 683 & 77.73 \\
\hline $\mathbf{S 2}$ & 1351508 & 480662 & FID213 & STD & 10-5un-94 & $09: 59$ & 668 & 73.48 \\
\hline$\infty$ & - & - & FID2 14 & CAL & 10-Jun-94 & $10: 13$ & 463 & - \\
\hline$\infty 0$ & - & - & FID215 & $\mathrm{CAL}$ & 10-Jun-94 & $10: 15$ & 481 & - \\
\hline$\infty$ & $\leftarrow$ & - & FID216 & CAL & 10-Jun-94 & $10: 17$ & 479 & - \\
\hline$\infty 0$ & - & - & FID217 & CAL & 10-Jun-94 & $10: 20$ & 463 & - \\
\hline$\infty$ & - & - & FID218 & CAL & 10-Jயn-94 & $10: 23$ & 475 & - \\
\hline $\mathrm{C35}$ & - & - & F1D219 & CAL & 10-5n-94-94 & $10: 26$ & 785 & - \\
\hline C35 & - & - & $\mathrm{FID} 220$ & CAL & 10-Jun-94 & 10:28 & 767 & -- \\
\hline C35 & - & - & FID 221 & CAL & $10-\ln -94$ & $10: 31$ & 748 & $\cdots$ \\
\hline C35 & - & - & FW222 & CAL & 10-Jயn-94 & $10: 34$ & 764 & - \\
\hline$C 35$ & - & - & FID 223 & CAL & 10-Jun-94 & $10: 36$ & 762 & - \\
\hline C35 & - & - & FID224 & CAL & 10-Jun-94 & $10: 38$ & 797 & -- \\
\hline $\mathrm{ClOO}$ & - & - & FID225 & CAL & 10-5uл-94 & $10: 40$ & 909 & $=$ \\
\hline C100 & - & - & FHD226 & CAL & 10-Jun-94 & $10 \div 42$ & 937 & -- \\
\hline $\cos$ & - & $\cdots$ & FID 227 & CAL & 10-Jun-94 & $10: 45$ & 897 & - \\
\hline Cion & $m$ & $*$ & FID 22B & CAL & 10-Jun-94 & $10: 47$ & 953 & $\leftrightarrow$ \\
\hline C100 & - & - & FID229 & CAL & 10-Jun-94 & $10: 49$ & 921 & - \\
\hline $\mathrm{C} 200$ & -- & - & FID230 & CAL & 10-Jun-94 & $10: 53$ & 1556 & - \\
\hline $\mathrm{C2OO}$ & - & -- & FID231 & CAL & $10-J u n-94$ & $10: 56$ & 1561 & - \\
\hline $\mathrm{C}_{200}$ & - & - & FID232 & CAL & J0-Jun-94 & $10: 58$ & 1638 & -- \\
\hline $\mathrm{C200}$ & -. & -- & FID 233 & CAL & 10-Jun-94 & $11: 01$ & 1543 & - \\
\hline $\mathrm{C200}$ & .* & - & FID234 & CAL & I0-Jun-94 & $11: 03$ & 1581 & -- \\
\hline St & 1351541 & 480338 & FID245 & $\$ T D$ & 13-Jun-94 & $09+36$ & 678 & 76.31 \\
\hline St & 1351541 & $4 \$ 0338$ & FID246 & STD & [3-Jun-94 & $09 \div 39$ & 650 & 68.38 \\
\hline
\end{tabular}


Table G-4: Composite Data Lieting for FDLER Scintillometer Tochnology (continued)

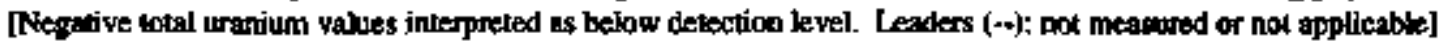

\begin{tabular}{|c|c|c|c|c|c|c|c|c|}
\hline Apo Lec & $\begin{array}{l}x \text { Coord } \\
\text { (tedt) }\end{array}$ & $\begin{array}{l}\text { Y Coord } \\
\text { (tist) }\end{array}$ & $\mathbf{D O}$ & Type & Dento & $\begin{array}{l}\text { Trme } \\
\text { (EDT) }\end{array}$ & $\begin{array}{l}\text { Rew Deto } \\
\text { (coumints per } \\
\text { minurto) }\end{array}$ & $\begin{array}{l}\text { Tobal U } \\
\left(\mathrm{PCH}_{\mathrm{j}}\right)\end{array}$ \\
\hline$\overline{52}$ & 1351508 & 480562 & FID247 & STD & 13-Jun-94 & $09: 49$ & $\overline{600}$ & 54.22 \\
\hline 52 & 1351508 & 480562 & FID248 & STD & 13-Jum-94 & 09:51 & 627 & 61.87 \\
\hline$\$ 1$ & 1351541 & 480338 & FID259 & STD & 14-Jum-94 & $13: 07$ & 660 & 71.21 \\
\hline S1 & 1351541 & 480338 & FID260 & SID & 14-Jun-94 & $13: 09$ & 686 & 78.58 \\
\hline \$2 & 1351508 & 480562 & FID261 & STD & 14-Jun-94 & $13: 20$ & 632 & 63.28 \\
\hline $\mathbf{s} 2$ & 1351508 & 480562 & FID262 & STD & 14-Jun-94 & $13: 22$ & 642 & 66.11 \\
\hline S1 & 1351541 & 480338 & FID273 & STD & 16-Jun-94 & $09: 20$ & 745 & 95.28 \\
\hline S1 & 1351541 & 480338 & FID274 & STD & 16-Jun-94 & $09: 22$ & 740 & 93.87 \\
\hline$\$ 2$ & 1351508 & 480562 & FID275 & STD & 16-Jum-94 & $09: 32$ & 668 & 73.48 \\
\hline$\$ 2$ & 1351508 & 480562 & FD276 & STD & 16-Jun-94 & $09: 34$ & 705 & 83.96 \\
\hline$\$ 1$ & 1351541 & 480338 & FD287 & STD & 17-Jun-94 & $10: 41$ & 729 & 90.75 \\
\hline S1 & 1351541 & 480338 & FID288 & STD & 17-Jun-94 & $10 \div 43$ & 728 & 90.47 \\
\hline$s 2$ & 1351508 & 480562 & FID289 & SHD & 17-Jun-94 & $10: 47$ & 686 & 78.58 \\
\hline s2 & 1351508 & 480562 & FID290 & STD & 17-Jun-94 & $10 \times 49$ & 722 & 88.77 \\
\hline$\$ 2$ & 1351508 & 480562 & FID296 & STD & 23-Jun-94 & $10: 37$ & 695 & 81.12 \\
\hline S1 & 1351541 & 480338 & FID297 & STD & 23-Jun-94 & 10.42 & 772 & 102.93 \\
\hline w9.5 & 1351739 & 480413 & FID298 & FLD & 23-Jun-94 & $10: 47$ & 687 & 78.86 \\
\hline- & $13518] 1$ & 490313 & FID 300 & FLD & 23-Jun-94 & $10: 50$ & 413 & 1.26 \\
\hline- & 1351810 & 480293 & FID301 & FLD & 23-Jun-94 & $10: 53$ & 372 & -10.35 \\
\hline-- & 1351825 & 480314 & FID & FLD & 23-Jon-94 & 10.56 & 609 & 56.77 \\
\hline$\infty 0$ & $=$ & ** & FID303 & CAL & 23-Jum-94 & $11: 47$ & 454 & - \\
\hline$\infty$ & -- & -- & FID304 & CAL & 23-Jun-94 & 1]:49 & 440 & -- \\
\hline$\infty$ & - & -- & FID305 & CAL & $23-J u n-94$ & $11: 51$ & 455 & - \\
\hline C35 & -- & -- & FID3O6 & CAL & 23- & $11: 56$ & 748 &.. \\
\hline C35 & -- & - & FID 307 & CAL & 23-Jun-94 & $11: 58$ & 794 & - \\
\hline C35 & -. & - & FID 308 & CAL & 23-Jun-94 & $12: 00$ & 773 & - \\
\hline CuOD & $=$ & - & FID309 & CAL & 23-Ju(n)-94 & 12702 & 898 & -- \\
\hline C100 & - & - & FID310 & CAI & 23-Jun-94 & $12 \div 04$ & 928 & $=$ \\
\hline $\mathbf{C P}$ & -. & - & FID311 & CAL & 23-Jun-94 & $12: 07$ & 551 & 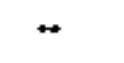 \\
\hline $\mathrm{CP}$ & -. & - & FID 312 & CAL & 23-Jun-94 & $12: 09$ & 513 & - \\
\hline $\mathbf{C P}$ & - & -- & FID 313 & CAL & 23-Јил-94 & $12: 11$ & 534 & -- \\
\hline
\end{tabular}


Table G-5: Composlte Data Lfoting for High-Mount Gamma Spectrometer Technology F* - Sail moisture cotrection factor (not applicahle to sample type CAL); Adj.: adjugted (see text). Leaders ( - ); not measured or not applicable]

\begin{tabular}{|c|c|c|c|c|c|c|c|c|c|c|c|}
\hline netoc & $\begin{array}{c}x \text { coond } \\
\text { (tow) }\end{array}$ & Coond & ID & met & Datio & (Iיס) & 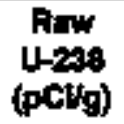 & 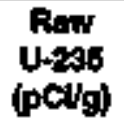 & $\begin{array}{l}\text { Total U } \\
\text { (pc//g) }\end{array}$ & $F$ & $\begin{array}{l}\text { Adj. } \\
\text { Total U } \\
\text { (pClol }\end{array}$ \\
\hline$\overline{c 0}$ & - & - & GMHO01 & . & $10-\mathrm{Jul}-94$ & $11: 25$ & 1.94 & 0.09 & - & - & - \\
\hline C35 & - & -- & GMHOO2 & CAL & |0-Jul-94 & $12: 00$ & 34.60 & 1.67 & - & - & - \\
\hline C100 & - & -- & GMHO03 & CAL & I0-Ju|-94 & $12: 31$ & 46.00 & 2.26 & - & - & - \\
\hline AA8 & 1351653 & 480536 & GMHOO4 & DUPY & 10-Jul-94 & $17: 10$ & 21,50 & 1.12 & & 1.000 & 63.61 \\
\hline S1 & 1351541 & 480338 & GMHOOS & STD & 11-5ul-94 & $09: 30$ & 27.70 & 1.44 & 2.73 & 1.000 & \\
\hline $\mathbf{X} 7$ & 1351590 & $4 \$ 0447$ & GMIH0O6 & FLD & 11-Jul-94 & 10:44 & 23.80 & 1.19 & 70.70 & 1.000 & 70.70 \\
\hline$Y 7$ & 1351591 & 480477 & GMHOOT & FLD & 11-Jul-94 & 11:17 & 23.40 & 1.20 & 69.47 & 1,000 & 69.47 \\
\hline $\mathrm{Z7}$ & 1351592 & 480507 & GMHOOB & FLD & [1-Jul-94 & $11+37$ & 90 & 1.04 & & 1.000 & 61.76 \\
\hline AAT & 93 & & GMHO09 & FLD & 1]-Jul-94 & $12: 00$ & 21.80 & 1.04 & 64.54 & 1.000 & 434 \\
\hline $\mathrm{CC7}$ & 1351594 & 480597 & GMH010 & FLD & 1 1-Jul-94 & $12: 22$ & & 0.96 & 56.83 & 1.000 & 6.83 \\
\hline CC6 & & & GMH011 & FLD & 11-J & & & & & 1.000 & \\
\hline AA6 & & & GMHO12 & FLD & & $13: 03$ & 20 & & 56.52 & 1.000 & \\
\hline Z6 & 1 & 48 & GMH013 & FLD & 11-J & $14: 18$ & & 4 & 67 & 1.000 & .67 \\
\hline Y6 & & & GMH0I4 & FLD & & & & & & 00 & \\
\hline W6 & & & GMHOI5 & FLD & & & & & & 00 & \\
\hline V6 & & & GMH016 & FLD & & & & & & & \\
\hline U6 & & & GMHOH7 & FLD & 1\|-J & & & & & $\infty$ & \\
\hline SI & & & GMHO18 & STD & & & & & & $\infty$ & .51 \\
\hline U6.5 & & & GMHOt9 & FLD & & & & & & $\infty$ & \\
\hline U7 & & & GMHO20 & FLD & 94 & $17: 28$ & & & & 1.000 & \\
\hline Ve & & & GMHO21 & FLD & 94 & & 30 & & & 00 & 79 \\
\hline $\cos$ & & & GMHO22 & $E D$ & & & & & & 0 & 35 \\
\hline$\$ 2$ & & & GMH023 & ID & & & & & & & \\
\hline$A \mathbf{A}$ & & & & D & 4 & & & & & & \\
\hline Y3 & & & GMHO2S & FLD & & & & & & 1.000 & 52.20 \\
\hline S2 & & & GMH026 & STD & 12 & & & & & 1.000 & 54.36 \\
\hline $\mathbf{s 1}$ & & & GMHO27 & TD & 24 & 0 & 70 & & & & \\
\hline S5 & & & GMHO28 & FLD & & & & & & 1.000 & 58.98 \\
\hline U5 & & 4 & GMHOZ9 & FLD & 12. & & 20 & & & 1.000 & \\
\hline Ws & & 4804 & GMHOMO & FLD & $12-$ & 5 & 40 & 3 & $y$ & & 50.97 \\
\hline E2 & & & GMHOS1 & FLD & & & & & & 1.000 & 56.21 \\
\hline 26.5 & & 48 & GMHO32 & FLD & 12-Ju1-94 & & & & & 1.000 & 59.29 \\
\hline AA6.5 & & & GMHO33 & FLD & & & & & & 1.000 & \\
\hline W6s & 1 & , & GMH034 & FLD & & & 30 & & & 1.000 & 76.87 \\
\hline & & & GMH035 & FLD & 12-Ju1-94 & 15:24 & 2030 & & & 1.000 & 60.53 \\
\hline & & & & & & & & & & & \\
\hline & & & GMHO37 & FLD & & & 24.00 & & 32 & 1.000 & 71.32 \\
\hline W7.5 & & & GMH038 & FLD & 12-Jol-94 & $16: 35$ & 24.30 & 1.26 & 25 & 1.000 & 72.25 \\
\hline $\mathbf{U}$ & & & GMH039 & FLD & & & & I. & & 1.000 & \\
\hline W8 & & & GMHO4O & FLD & 12-Ju1-94 & & & & 68.54 & 1.000 & 68.54 \\
\hline $\mathrm{x} 8$ & & 480446 & GMHOAI & FLD & 12-Jul-94 & $17: 45$ & 24.90 & 1.28 & 74.10 & 1.000 & 74.10 \\
\hline Y8 & 1351651 & 480476 & GMHO42 & FLD & 12-Jul-94 & $18: 12$ & 24.60 & 1,32 & 73.17 & 1.000 & 73.17 \\
\hline
\end{tabular}


Table G-6: Compoette Oata Llsting for Hlgh-Mount Gamma Spectrometer Technology (continued)

[F" - Soll moliture correction factor (not applicable to sample type CAL); Adj.: adjusted (see texi). Leaders ( $\rightarrow$ ); not messured or not applisable]

\begin{tabular}{|c|c|c|c|c|c|c|c|c|c|c|c|}
\hline $\mathbf{E} \infty$ & $\begin{array}{c}x \text { Coot } \\
\text { (thet }\end{array}$ & Coond & D & 100 & ate & $\underset{\text { (EDT) }}{\operatorname{Tin}}$ & $\begin{array}{c}\text { Row } \\
\text { Less } \\
(p \circ y)\end{array}$ & $\begin{array}{l}\text { Raw } \\
\text { U2ss } \\
\text { (pewo) }\end{array}$ & $\sec$ & $\boldsymbol{F}$ & $\begin{array}{c}\text { Acti. } \\
\text { Totiak U } \\
\text { (pevo) }\end{array}$ \\
\hline$\overline{\mathrm{AAB}}$ & 1351653 & 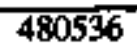 & MPO43 & $\overline{\mathrm{LD}}$ & {$[2+\sqrt{0}+94$} & $8: 41$ & 23.20 & 1.19 & 8.85 & 200 & $\overline{88.85}$ \\
\hline$\infty \mathrm{c} 8$ & 1351654 & 0596 & GMHO44 & FD. & 12-Jul-94 & $19: 08$ & 20.80 & 1.03 & 1.45 & 1.000 & 1.45 \\
\hline $\mathbf{s 2}$ & 1351508 & 0562 & GMH045 & STD & 12-Ju]-94 & 19.28 & 70 & 0.96 & 4.97 & 1.000 & 4.97 \\
\hline \$1 & 1351541 & 480338 & GMHO46 & STD & 12.Jul-94 & $19: 50$ & 28.80 & 1.52 & 36.12 & 1.000 & 6.12 \\
\hline $\mathbf{s 2}$ & 1351508 & 480562 & GMHO47 & STD & 13-Jul-94 & $08+55$ & 10 & 0.99 & 6.21 & 1.000 & 6.21 \\
\hline S1 & & 88 & МH048 & STD & 13-Jul-94 & $09: 43$ & & 1.52 & 666 & 1.000 & .66 \\
\hline W7 & 1351590 & $4 \$ 0417$ & MHO49 & FLD & 13-Ju1-94 & $10 \times 06$ & 10 & 1.34 & 0.88 & 1.000 & 0.88 \\
\hline Y8.5 & 1351681 & 480475 & GMHOS0 & FLD & 13-Jul-94 & $10: 25$ & 70 & 1.26 & 3.48 & 1.000 & 3.48 \\
\hline XB.5 & & .4 & GMHOS1 & FL.D & 13-Jud-94 & $10 \mathrm{st}$ & & 1.27 & 185 & 1.000 & .85 \\
\hline W8.5 & 679 & 480400 & GMHOS2 & FLD & 13-Ju1-94 & $11 \div 11$ & 60 & 1.39 & 9.34 & 1,000 & 9.34 \\
\hline $\mathbf{X 9}$ & 1711 & 480457 & GMHOS3 & FLD & 13-Jul-94 & $11: 33$ & 0 & 1.07 & 162 & 1.000 & 7.62 \\
\hline Y9 & & 4 & VHOS4 & FLD & 13-5al-94 & $11: 54$ & & 1.10 & .94 & 1.000 & 94 \\
\hline $\mathrm{Z9}$ & & 480504 & GMHOSS & FLD & 13-Jul-94 & $12: 2 \mathrm{I}$ & & 1.15 & & 1.000 & 8.85 \\
\hline AA9 & 13 & 480534 & GMHO56 & FLD & 13-Jul-94 & $12: 50$ & & 1.15 & 62.99 & 1.000 & 2.99 \\
\hline s9 & 13 & 480294 & MHOST & FLD & 13-ht1-94 & $16: 27$ & & 1.30 & 49 & 1.000 & .49 \\
\hline U9 & & 480 & GMHOS8 & FLD & 13-hul-94 & $17: 00$ & & 1.08 & .77 & 1.000 & 5.77 \\
\hline S1 & & 480338 & GMH059 & STD & 16-Ju\}-94 & $12: 07$ & 0 & 1.27 & 16 & 1.000 & 9.16 \\
\hline S2 & & 480562 & MHO6O & STD & 16-Ju1-94 & $11: 14$ & & 0.74 & .26 & 1.231 & 25 \\
\hline S1 & & 4 & GMHO61 & STD & 16-Jul-94 & $11: 35$ & & 1.17 & 3.54 & 1.231 & 1,38 \\
\hline S11 & & 480291 & GMHO62 & FLD & 16-Jul-94 & 11 & 10 & 0.50 & 26.29 & 1.231 & 2.37 \\
\hline S10 & & 3 & MHO63 & FLD & 16-Ju|-94 & $12: 08$ & 0 & 0.83 & 2.95 & $1.23 \mathrm{I}$ & .87 \\
\hline UIO & 68 & 4 & GMH064 & FLD & 16-Ju1-94 & $12: 20$ & 30 & 0.91 & 7.57 & 1.231 & 8.56 \\
\hline U9.5 & & 480 & GMH065 & FLD & 16 & $12: 34$ & & 0.96 & 42 & 1.231 & 0.84 \\
\hline A] & & 480363 & GMHO66 & FLD & 16-Ju1-94 & $12: 46$ & & 0.76 & .27 & 1.231 & 3.12 \\
\hline A2 & & 3 & GMH067 & FLD & 16-Jut]-94 & $12: 57$ & & 0.95 & .81 & I.231 & 0.08 \\
\hline A3 & & 480 & GMH068 & FLD & 16 & $13: 09$ & 0 & 0.91 & 65 & 1.231 & 742 \\
\hline B3 & & 480368 & MHO69 & FLD & 16-Jul-94 & $13 \div 23$ & & 0.87 & 34 & 1.231 & 704 \\
\hline B2 & & 480 & GMHO70 & FLD & 16-Ju1-94 & $13+38$ & & 0.88 & .49 & 1.231 & 4.77 \\
\hline $\mathrm{Bt}$ & & $4 \$ 0$ & GMHOT 1 & FLD & 16-J비-94 & $13 \div 53$ & & 0.84 & 46.96 & 1.231 & 57.80 \\
\hline $\mathrm{Cl}$ & 1748 & 480373 & GMHOT2 & FLD & 16-Jul-94 & $14 \div 07$ & 1 & 0.78 & 42.64 & 1.231 & 2.49 \\
\hline $\mathrm{C} 2$ & & 480373 & GMHO73 & FLD & 16-Jul-94 & $14: 19$ & 0 & 0.82 & 45.41 & 1.231 & 5.91 \\
\hline $\mathrm{C3}$ & & 480 & GMHO74 & DUP\$ & J-94 & 14 & & 1.20 & 70.70 & 1.231 & 7.04 \\
\hline V10 & 69 & 480383 & GMHOTS & FLD & 16-Jul-94 & $15 \div 04$ & 0 & 0.74 & 42.95 & 1.231 & $\$ 2.87$ \\
\hline U11 & & 480351 & GMHor6 & FRD & 16-Jul-94 & 15 & & 0.75 & 38.94 & 1.231 & 47.93 \\
\hline Wil & & 480 & GMHOT7 & FLD & $16-J u J-94$ & 15 & & 0.68 & 40.79 & 1.231 & 50.21 \\
\hline W10 & & 480413 & GMHOT: & FLD & 16-Ju1-94 & $15: 48$ & & 0.94 & 44.80 & 1.231 & 55.15 \\
\hline W9.5 & & 4 & GMHO79 & FLD & 16-Ju1-94 & & & 0.98 & 5.72 & 1.231 & 56.28 \\
\hline W9 & & & GMHOOO & FLD & 16-Jul-94 & $16: 14$ & 16.50 & 0.86 & 18.19 & 1.231 & 59.32 \\
\hline v9 & 1709 & 480384 & GMHOS1 & FLD & 16-Ju]-94 & $16: 30$ & 19.80 & 1.15 & 58.37 & 1.231 & 71.85 \\
\hline V9.5 & & 480383 & GMHOS2 & FLD & 16-Ju1-94 & $16 \times 42$ & & 0.83 & 42.33 & 1.231 & 52.11 \\
\hline Y10 & & 480473 & GMHOS3 & FLD & 16-Jul-94 & $16: 57$ & & 0.85 & 48,50 & 1.231 & 59.7 \\
\hline Yl1 & 1351831 & 480471 & GMHOS4 & FLD & 16-Jul-94 & $17: 11$ & 19.70 & 0.94 & 58.06 & 1.231 & 71.47 \\
\hline $\mathbf{Z 1 0}$ & 1351787 & 480502 & GMHOS5 & FLD & 16-Jul-94 & $17: 22$ & 16.30 & 0.78 & 47.57 & 1.231 & 58.56 \\
\hline
\end{tabular}


Toble C-5: Compostte Data Liating for High-Mount Gamma Spectrometer Technology (continued)

[F" - Soll moisture contection factor (not sppplicablo to sample type CAL); Adj.: adfusted (see text). Leaders ( $)$ ); not measured of not applicable]

\begin{tabular}{|c|c|c|c|c|c|c|c|c|c|c|c|}
\hline Gooloc & $\begin{array}{c}x \text { coond } \\
\text { (fincis) }\end{array}$ & $\begin{array}{c}Y \text { Coord } \\
\text { (fin) }\end{array}$ & ID & Type & Dofte & $\underset{(E D T)}{T / m 0}$ & $\begin{array}{c}\text { Raw } \\
\text { U-2838 } \\
(p C+g)\end{array}$ & $\begin{array}{c}\text { Raw } \\
\text { U-235 } \\
\text { (pClg) }\end{array}$ & $\begin{array}{l}\text { Tot: } \\
\text { fpc }\end{array}$ & $\boldsymbol{F}$ & $\begin{array}{l}\text { Adl. } \\
\text { Tote' U } \\
\text { (pClg) }\end{array}$ \\
\hline $\bar{A} \mathbf{A 1 1}$ & 1351833 & 480531 & GMHO\$6 & FLD & 16-JaI-94 & $17: 38$ & 15.60 & 0.65 & 45.41 & 1.231 & 5591 \\
\hline CC11 & 1351834 & 480591 & GMHOS7 & FLD & I6-Jut-94 & $17: 54$ & 7.40 & 0.37 & .13 & 1.231 & 24.77 \\
\hline CC10 & 1351774 & 480593 & GMHOIS & FLD & 16-Jat-94 & $18: 08$ & 15.80 & 0.89 & 46.03 & 1.231 & 56.66 \\
\hline $\operatorname{ccs}$ & 1351714 & 480594 & GMHOB9 & FLD & 16-Jul-94 & $18: 22$ & 16.00 & 0.87 & 46.65 & 1.231 & 57.42 \\
\hline AA9.5 & 1351743 & 480533 & GMHOSO & FLD & 16-Jul-94 & $18: 33$ & 19.30 & 0.92 & 56.83 & 1.231 & 69.95 \\
\hline AAJO & 1351760 & 480533 & GMIDO91 & FLD & 16-Jul-94 & $18: 43$ & 16.60 & 0.92 & 48.50 & 1231 & $\$ 9.70$ \\
\hline $\mathbf{Z 9 . 5}$ & 1351742 & 480503 & GMHOS2 & FLD & 16-Jul-94 & $18: 56$ & 1720 & 0.93 & 50.35 & 1.231 & 61.98 \\
\hline Y9.5 & 1351725 & 480474 & GMHO93 & FLD & 16-Jul-94 & $19: 08$ & 17.00 & 0.96 & 73 & 1.231 & 61.22 \\
\hline $\mathrm{S} 2$ & 508 & 480562 & GMH094 & STD & 16-Jul-94 & $19: 21$ & 14.60 & 0.68 & 42.33 & 1.231 & 52.11 \\
\hline s1 & 1351541 & 480338 & GMH095 & STD & 16-Jul-94 & $19: 33$ & 24.00 & 1.23 & 71.32 & 1.231 & 87.79 \\
\hline \$1 & 1351541 & 480338 & GMH096 & STD & 17-Jul-94 & 09007 & 14,60 & 0.65 & 42,33 & 1.254 & 53.08 \\
\hline $\mathrm{S} 2$ & 1351508 & 480562 & GMHO97 & STD & 17-Jul-94 & 09:19 & 1550 & 0.74 & 45.11 & 1.254 & 56.56 \\
\hline F1 & 1351542 & 480529 & GMF1098 & FLD & $17 \cdot 5 u \mid 94$ & 09:31 & 1650 & 0.75 & 48.19 & 1.254 & 60.43 \\
\hline F2 & 1351547 & $48052 x$ & GMH099 & FLD & 17-Jul-94 & $09: 48$ & 16.30 & 0.76 & 47.57 & 1.254 & 59.66 \\
\hline F3 & $1351 \$ 52$ & 480528 & GMH100 & FLD & 17-Jul-94 & $10+00$ & 1590 & 080 & 46.34 & 1,254 & 58.11 \\
\hline E3 & 1351552 & 480523 & GMH10! & FLD & 17.Jul-94 & $10: 17$ & 16.30 & 0.80 & 47.57 & 1.254 & 59.66 \\
\hline D3 & 1351552 & 480518 & GMH1O2 & FLD & 17-Jul-94 & 10.29 & 17.10 & 0.80 & 50.04 & 1.254 & 62.75 \\
\hline $\mathrm{D} 2$ & 1351547 & 480518 & GMH103 & FLD & 17-Jul-94 & 10.41 & 16.20 & 0.85 & 47.26 & 1.254 & 59.27 \\
\hline D] & 1351542 & $4 B O 519$ & GMH1O4 & FLD & 17-Jul-94 & $10 \div 55$ & 16.60 & 0.86 & 48.50 & 1.254 & 60.82 \\
\hline E1 & 1351542 & 480524 & GMH1OS & FLD & 17-5ut1-94 & $11: 19$ & 15.70 & 0.69 & 45.72 & 1.254 & 57.34 \\
\hline $\mathrm{C} 3$ & 1351758 & 480373 & GMH106 & FLD & 17-Jul-94 & $11: 42$ & 15,90 & 0.75 & 46.34 & 1.254 & 58.11 \\
\hline
\end{tabular}

'The designation, "DUP" is in the original data base. The geolocation code and the coordinates indicate that this is not a duplicate sample. 
Table G-6: Composite Data Listing for Low-Mount Gamma Spectrometer Technology [F* - Soll moisture comection factor (not applicable to sample types CAL or STD); Adj.: adjusted (see text). Lesders (-); not measured or aot applicable]

\begin{tabular}{|c|c|c|c|c|c|c|c|c|c|c|c|}
\hline 0 L L & $x$ Coond & $\mathrm{CoOr}$ & ID & Type & late & Ime & $\begin{array}{c}\text { Row } \\
\text { Uzzst } \\
\text { (powg) }\end{array}$ & $\begin{array}{l}\text { Row } \\
\text { unss } \\
\text { (pcify) }\end{array}$ & 0 & $\mathbf{F}$ & $\begin{array}{l}\text { Adj } \\
\text { Total } \\
\text { (pcly) }\end{array}$ \\
\hline C35 & - & - & GMLO01 & CAL & 10-Jut-94 & $11 \div 25$ & 36.70 & 1.82 & - & - & $\omega$ \\
\hline$\infty$ & - & -- & GMLOO2 & CAL & 10-Ju1-94 & $12: 00$ & 1.91 & 0,0 & - & .- & $\ldots$ \\
\hline C100 & - & - & GMIOOS & CAL & |0-Ju]-94 & $13: 00$ & 50.90 & 2.55 & - & -- & -- \\
\hline AA9 & 1351713 & 480534 & GMLOO4 & FLD & 10-Ju-94 & $17: 20$ & 21.00 & 1.02 & 58.45 & 1.000 & 58.45 \\
\hline U6.5 & 1351558 & 480358 & GMLOOS & FLD & $11-J u 1-94$ & $09: 32$ & 31.10 & 1.53 & 87.92 & 1.000 & 67,92 \\
\hline$\$ 1$ & 1351541 & 480338 & GMLDOG & SID & 11-Ju]-94 & $10: 08$ & 29.90 & 1.60 & 84.42 & 1.000 & 84.42 \\
\hline WT & 1351590 & 80417 & GMLOO & FLD & 11-Ju\}-94 & 10:37 & 27.90 & 1.47 & 78.59 & 1.000 & 78.59 \\
\hline$x 7$ & 1351590 & goddT & GMLO08 & FLD & 11-Jn士-94 & $11: 20$ & 40 & 1.37 & & 1.000 & $74,2]$ \\
\hline$Y 7$ & 1351591 & 4804 & GMLOOS & FLD & 11-JuI-94 & $11: 43$ & 23.50 & 1.22 & & 1.000 & 65.75 \\
\hline$z 7$ & 1351592 & 480507 & GMILIO & FLD & 11-Jui-94 & $12: 04$ & 20.50 & $1 . \infty$ & & 1.000 & 56.99 \\
\hline AA7 & 1351 & 4805 & GML011 & FLD & J-11 & $12: 25$ & & 1.08 & & 1.000 & 28 \\
\hline$\infty C 7$ & 13 & 1805 & GMILO12 & FLD & $11-1$ & $12: 47$ & 20.90 & 1.08 & & 1.000 & .16 \\
\hline CC6 & 134 & 480599 & GMLOI3 & FLD & 11-Jal-94 & 13:09 & 21.60 & 1.06 & & 1.000 & 60.20 \\
\hline AA6 & 135 & 4805 & GMLO14 & FLD & ل-11 & $14: 22$ & & 0.89 & & 1.000 & 49.11 \\
\hline 26 & & 4805 & GMLOLs & FLD & $11-3$ & $14: 45$ & 70 & 1.03 & & 1.000 & 66 \\
\hline Y6 & & 4804 & GMLO16 & FLD & 11 - & 15:04 & 20.40 & 1.11 & & 1.000 & 6.70 \\
\hline W6 & 135 & 4804 & GMLO17 & FLD & $11+J$ & $15: 28$ & & 1.29 & & 1,000 & 1.00 \\
\hline V6 & & 480 & GMLOI8 & FLD & 11-J & $16: 04$ & 60 & 1.31 & & 1,000 & .87 \\
\hline U6 & & 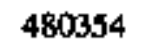 & GMLOI9 & FLD & $11=$ & $16: 37$ & & 1.23 & & 1.000 & .92 \\
\hline S1 & & $m$ & GMLOD20 & STD & & $17: 01$ & & 1.60 & & 1.000 & \\
\hline V6.5 & & 4804 & GML021 & FLD & & $17: 31$ & & 1.44 & & 0 & \\
\hline W6.5 & & 80 & GML022 & FLD & $11-$ & $17: 51$ & 20 & 1.48 & & 1.000 & 79.46 \\
\hline 52 & & 805 & GMLO23 & STD & & $18: 21$ & & 1.03 & & 1.000 & 62 \\
\hline $\cos$ & 13 & 480600 & GML024 & FLD & & 18:51 & & 0.87 & & 1.000 & .90 \\
\hline Y5 & & 1804 & GMLO2S & FLD & 11 - & $19: 12$ & 20,00 & 0.91 & & 1.000 & 5.53 \\
\hline AAS & & 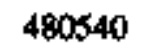 & GML.026 & FLD & & $19: 34$ & & 0.90 & & 1.000 & 0.86 \\
\hline S1 & 135 & 4803 & GMLO27 & STD & -94 & $10: 00$ & & 1.70 & & 1.000 & 88.51 \\
\hline S2 & 3 & dones & GMLO28 & STD & -94 & $10: 27$ & 00 & 0.99 & & 1.000 & 55.53 \\
\hline W5 & & 480420 & GML029 & FLD & 12-Jul-94 & $10: \$ 0$ & 20.40 & 1.08 & & 1.000 & 56.70 \\
\hline Us & 1468 & 480365 & GMLOSO & FLD & 12-Ju1-94 & $11 * 4 !$ & 19.20 & 1.00 & & 1,000 & 53.20 \\
\hline E2 & 1351547 & 480523 & GMLO31 & FLD & 12 & $12: 10$ & & 1.04 & & 1.000 & 55.24 \\
\hline A.A6.5 & 1351563 & 100030 & GMLO32 & FLD & $1-94$ & $13: 56$ & 19.30 & 1.06 & & 1.000 & 53.49 \\
\hline 26.5 & 1562 & 480508 & GML033 & FLD & $1-94$ & $14: 35$ & 23.00 & $1 . t 5$ & & 1.000 & 64.29 \\
\hline Y6.5 & & 480478 & GMLO34 & FLD & 12-Ju1-94 & 15:04 & & 1.12 & & 1,000 & 64.58 \\
\hline U6.5 & 1351558 & 480358 & GML035 & DUPt & 12-Jul-94 & $15: 29$ & 32.10 & 1.68 & 34 & 1.000 & 90.84 \\
\hline W7.5 & 13 & 480420 & GMLO36 & FLD & 12-Jul-94 & $15: 54$ & 28.40 & 1.50 & 80 & 1.000 & 80.05 \\
\hline Y7.5 & & 4804 & GML037 & FLD & -94 & $16: 16$ & 28.70 & 1.42 & & 1.000 & 80.92 \\
\hline$\times 75$ & 1351620 & 480447 & GML038 & FLD & 12-Ju|-94 & $16: 39$ & 22.70 & 1.13 & 63.41 & 1,000 & 63.41 \\
\hline w8 & 1351650 & 480429 & GML039 & FLD & 12-Jul-94 & $17: 00$ & 24.90 & 1.31 & 69.83 & 1.000 & 69.83 \\
\hline U8 & 1351648 & 480366 & GMLO40 & FLD & 12-Ju|-94 & $17: 28$ & 34,50 & 1.76 & 97 & 1.000 & 97,85 \\
\hline Y8 & & 480476 & GMLO41 & FLD & $12-\mathrm{Jul}-94$ & $17: 53$ & 25.60 & 1.38 & & 1.000 & 71.87 \\
\hline $\mathrm{X} 8$ & 1351650 & 480446 & GMLO42 & FLD & 12-Jul-94 & $18: 18$ & 26.10 & 1.34 & 73.33 & 1.000 & 73.33 \\
\hline
\end{tabular}


Table G-6: Composite Data Uating for Low-Hount Gamma Spectrometer Tochnology (continued)

[F" - Soil moisture cornection factor (not 4pplictble to sample types CAL or STD); Adj.: adjusted (see vext). Losders (-): not messured os not applicasble]

\begin{tabular}{|c|c|c|c|c|c|c|c|c|c|c|c|}
\hline $\mathbf{c}$ & $\begin{array}{l}x \text { Coond } \\
\text { (fient) }\end{array}$ & Y Coond & ID & קpo & at: & $\underset{(E D T)}{T l m e}$ & $\underset{(\mathbf{p C V})}{\operatorname{Rm}(y)}$ & $\begin{array}{c}\text { Raw } \\
\text { (pCVis }\end{array}$ & & $\boldsymbol{F}$ & $\begin{array}{c}\text { Ad]. } \\
\text { Total U } \\
\text { (PCVg) }\end{array}$ \\
\hline $\cos$ & 1351634 & 480596 & GMLO43 & FLD & $\overline{12-J u 1-94}$ & $\overline{18: 46}$ & 21.70 & 1.19 & 60.49 & 1.000 & $\overline{60.49}$ \\
\hline AAB & 1351653 & 480536 & GML044 & FLD & 12-Ju1-94 & $19 \div 11$ & 25.40 & 1.32 & 71.29 & 1.000 & 71.29 \\
\hline SI & 1351541 & 480338 & GML045 & STD & 12-Jul-94 & $19: 35$ & 31.70 & 1.69 & 89.68 & 1.000 & 89.68 \\
\hline$\$ 2$ & 1351508 & 480562 & GML046 & STD & 12-Jul.94 & $19: 56$ & 20.20 & 1.12 & 56.12 & 1.000 & 56.12 \\
\hline S1 & 1351541 & 480338 & GML047 & STD & 13-Jul-94 & $08+51$ & 32.50 & 1.67 & 92.01 & 1.000 & 92.01 \\
\hline $\mathbf{s 2}$ & 1351508 & 480562 & GMLO48 & \$TD & 13-Ju]-94 & $09: 38$ & 20.00 & 1.11 & $5 \$ 53$ & 1000 & 55.53 \\
\hline Y8.S & 1351681 & 480475 & GMLO49 & FLD & 13-Ju]-94 & $10 \times 00$ & 27.20 & 152 & 76.54 & 1.000 & 76.54 \\
\hline X8s & 1351680 & 480445 & GML050 & FLD & 13-Jul-94 & $10 \div 19$ & 25.00 & 1.35 & 70.12 & 1.000 & 70.12 \\
\hline W/8 & 1351679 & 480400 & GMLOS1 & FLD & 13-Ju-94 & $10 \div 45$ & 31.10 & 1.60 & 87.92 & 1.000 & 87.92 \\
\hline $\mathrm{X} 9$ & 1351711 & 480457 & GMLO52 & FLD & $13-J u+-94$ & $11: 07$ & 26.70 & 1.38 & & 1.000 & 75.08 \\
\hline Y9 & 1351711 & 480474 & GMLOS3 & FLD & 13-Jut-94 & $11: 27$ & 25.10 & 1.29 & 70.42 & 1.000 & 70.42 \\
\hline 29 & 1351712 & 480504 & GMLOSA & FD & 13-Jul-94 & $11: 50$ & 24.80 & 1.27 & 69.54 & 1.000 & 69.54 \\
\hline AA9 & 135 & 480 & GMLOSS & DUPY & 13-Jul-94 & $12: 15$ & 21.20 & 1.14 & 94 & 1.000 & 59.04 \\
\hline $\operatorname{CCg}$ & 135 & 480594 & GMILOS6 & FLD & $13-J u l-94$ & $12: 44$ & 24.50 & 1.27 & 68.67 & 1.000 & 68.67 \\
\hline U9 & 1351708 & 480354 & GMLO57 & FLD & 13-Jul-94 & $14: 26$ & 26.20 & 1.37 & 63 & 1.000 & 73.63 \\
\hline ve & 1351709 & 480384 & GMLOS8 & FWD & $13-\mathrm{J}$ & $16: 25$ & 24.30 & 1.32 & & 1.000 & 68.08 \\
\hline$\$ 5$ & 66 & 4 & GMLOS9 & FLD & 17-Jul-94 & $12: 02$ & 18.40 & 0.87 & & 1.217 & 61.90 \\
\hline \$1 & 135 & 38 & GMILO60 & STD & 17-Jul-94 & $12: 26$ & 25.60 & t. .37 & & 1.268 & 91.14 \\
\hline s2 & 1351508 & 480562 & GMLO6] & STD & $17-J u l-94$ & 3 & 0 & 0.84 & 3 & 1.268 & 52.29 \\
\hline FI & 1351542 & $480 \$ 29$ & GMLO62 & FLD & 17-Jul-94 & $12: 54$ & 70 & 0.83 & & 1268 & 54,51 \\
\hline F2 & 135 & 28 & GML063 & FLD & 17-Jul-94 & 13:06 & 16.30 & 0.67 & & 1.268 & 56.73 \\
\hline F3 & 1351552 & 480528 & GMLO64 & FLD & & 13 & & 0.82 & & 1.268 & 53.77 \\
\hline E3 & 1351552 & 480 & GMLO6s & FLD & $17-\mathrm{Jt}$ & 13:28 & 17.30 & 0.82 & & 1.268 & 60.43 \\
\hline E2 & 1351547 & 480523 & GMLO66 & DUP† & 17-Jul-94 & 13:39 & 16.00 & 0.84 & & 1.268 & 55.62 \\
\hline E1 & 1351542 & 480524 & GMLO67 & FLD & & 13 & & 78 & & 1.268 & 52.66 \\
\hline DI & 1351542 & 480819 & GMLO68 & FLD & 17-Jul-94 & $14: 00$ & 16.60 & 0.93 & & 1.268 & 57.84 \\
\hline $\mathrm{D} 2$ & 1351547 & 480518 & GMLO69 & FLD & 17-Jul-94 & 14:11 & 18.80 & 0.88 & 52.03 & 1.268 & 65.98 \\
\hline DO & 1351552 & 480518 & GMLO70 & FLD & 94 & $54: 22$ & 60 & 98 & 61 & 1.263 & 57.84 \\
\hline v7 & 1351588 & 480361 & GMLO7] & FLD & 17-Jul-94 & $14: 37$ & 26.90 & 1.48 & 67 & 1.268 & 95.95 \\
\hline S9 & 1351706 & 480294 & GMLOT2 & FLD & 17-Jul-94 & $14: 48$ & 25.80 & 1.42 & 72.46 & 1.268 & 91.88 \\
\hline$\$ 10$ & 1351766 & 480293 & GMLOT3 & FLD & 17-Jul-94 & $15: 07$ & 16.90 & 0.94 & 46.49 & 1.268 & 58.95 \\
\hline \$11 & 1351826 & 480291 & GMLO74 & FLD & 17-Jul-94 & $15: 20$ & 8.30 & 0.61 & 39 & 1.268 & 27.12 \\
\hline U11 & 1351828 & 480351 & GMLO7S & FLD & 17-Jul-94 & 15:32 & 1750 & 0.89 & 48.24 & 1.268 & 61.17 \\
\hline U10 & $135[768$ & 480353 & GML076 & FLD & 17-Jul-94 & 15:44 & 19.30 & 0.96 & 53,49 & 1268 & 67.83 \\
\hline U9.5 & & & GMLO77 & FLD & $17-J u 1-94$ & $15: 55$ & 19.30 & 0.90 & & 1.268 & 67.83 \\
\hline A1 & 135 & 480369 & GML078 & FLD & I7-Ju\}-94 & 16008 & 17.20 & 0.92 & 47.36 & 1.268 & 60.06 \\
\hline $\mathrm{A} 2$ & 1351753 & 480363 & GMLO79 & FLD & 17-JuJ-94 & $16: 18$ & 16.90 & 0.85 & 46.49 & 1.268 & 58.95 \\
\hline$A 3$ & 1351758 & 480363 & GMLOBO & FLD & 17-Ju\}-94 & 16.29 & 18.60 & 0.94 & 51.45 & 1.268 & 65.24 \\
\hline $\mathbf{B} 3$ & 1351758 & 480368 & OMLOS1 & FLD & 17-Jut-94 & $16: 40$ & 17.40 & 0.96 & 47.95 & 1.268 & 60.80 \\
\hline B2 & 1351753 & 480368 & GMLOS2 & FLD & 17-Jut-94 & $16+50$ & 37.90 & 0.90 & 49.41 & 1268 & 62.65 \\
\hline B1 & 1351748 & 480368 & GMLO083 & FLD & 17-Ju\}-94 & $17 \div 01$ & 16.50 & 0.95 & 45,32 & 1.268 & 57.47 \\
\hline C1 & 1351748 & 480373 & GMLOB4 & FLD & 17-Ju'-94 & $17: 14$ & 17.60 & 0.89 & 48.53 & t. 268 & 61.54 \\
\hline $\mathrm{C2}$ & 1351753 & 480373 & GMLOB5 & FLD & 17-Ju'-94 & $17: 24$ & 16.40 & 0.92 & 45.03 & 1.268 & 57.10 \\
\hline
\end{tabular}


Table G-6: Composite Data Liating for Low-Mount Gemma Spectrometer Technology (continued)

[F* - Soil moisture correction fsetor (not applicable to sample types CAL or STD); Adj.: adjusted (see text). Leaders (-): not measured or not applicable]

\begin{tabular}{|c|c|c|c|c|c|c|c|c|c|c|c|}
\hline Geo Loc & $\begin{array}{l}x \text { Coord } \\
\text { (1)eth }\end{array}$ & $\begin{array}{l}\text { Y Coord } \\
\text { (tent) }\end{array}$ & to & Yos & Datio & $\begin{array}{l}\text { Tint } \\
\text { (EDD) }\end{array}$ & $\begin{array}{c}\text { Pow } \\
\text { U2s: } \\
\text { (pCly) }\end{array}$ & 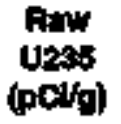 & $\begin{array}{l}\text { Tot. } \\
\text { fpc }\end{array}$ & $\boldsymbol{r}$ & $\begin{array}{c}\text { Ad]. } \\
\text { Total } \\
\text { (pollo) }\end{array}$ \\
\hline C3 & 1351758 & 480373 & GMI 086 & FLD & $17+\sqrt{n}-94$ & $17: 35$ & 15.70 & 0.93 & 42.99 & 1.268 & 5451 \\
\hline v10 & 1351769 & 480383 & GMLOS7 & FLD & 17-Jul-94 & $17: 45$ & 14.90 & 0.82 & 40.65 & 1.268 & 51.55 \\
\hline v9.5 & 1351739 & 480383 & GML0\&8 & FLD & $17-3$ al-94 & $17 \div 57$ & 14.70 & 0.84 & 40.07 & 1.268 & 50.81 \\
\hline W9 & 1351709 & 480412 & OML 089 & FLD & 17-Jnil-94 & 1809 & 17.60 & 0.90 & 48.53 & 1.268 & 6154 \\
\hline W9.5 & 1351739 & 480413 & GMLOSO & FLD & 17-Jvl-94 & $18: 21$ & 15.30 & 0.86 & 41.82 & 1.268 & 53.03 \\
\hline W10 & 1351769 & 480413 & GMLO9] & FLD & 17-Jut-94 & $18: 33$ & 20.10 & 1.10 & 55.83 & 1.268 & 70.79 \\
\hline W11 & 1351829 & 480411 & GML 092 & FLD & $17-J n t-94$ & $18: 45$ & 18.60 & 0.97 & 51.45 & 1.268 & 65.24 \\
\hline S1 & 1351541 & 480338 & GML093 & STD & $17+J u \mid-94$ & $19: 02$ & 25.80 & 1.40 & 72.46 & 1.268 & 91.88 \\
\hline S2 & 1351508 & 480562 & GMLO94 & STD & 18-Jul-94 & $11: 12$ & 13.40 & 0.65 & 36.27 & 1.305 & 47.34 \\
\hline s1 & 1351541 & 480938 & GML095 & STD & 18-Jul-94 & $11: 31$ & 26.80 & 1.34 & 75.38 & 1.305 & 98.37 \\
\hline Y9.5 & 1351725 & 480474 & GML096 & FLD & 18-Jul-94 & $11: 44$ & 16.90 & 0.91 & 46.49 & 1.305 & 60.67 \\
\hline 29.5 & 135 & 480 & GMLO97 & FLD & $18-5 \mathrm{at}-94$ & $11: 59$ & 21.60 & 1.10 & 60.20 & 1,305 & 78.56 \\
\hline AA95 & 1351743 & 480633 & GMLOSB & FLD & 18-Jul-94 & $12: 2 t$ & 20.00 & 1,06 & 55,53 & 1,305 & 72.47 \\
\hline AAIO & 1351760 & 48 & GML099 & FLD & 18-Jul-94 & $12: 34$ & 19.30 & 1.13 & 53.49 & 1.305 & 69.81 \\
\hline $\operatorname{ccc} 10$ & & & GML100 & FLD & 18-Jul-94 & $12: 48$ & 17.30 & 1.89 & 47.65 & 1.305 & 62.19 \\
\hline CC11 & 135 & 48 & GML10! & FLD & 18-Jul-94 & $13: 04$ & 11.00 & 0.55 & 29.27 & 1.305 & 38.20 \\
\hline AA11 & 1351833 & 480531 & GML102 & FLD & 18-Jul+94 & $13: 29$ & 20.10 & 0.77 & & 1.305 & 72.85 \\
\hline Z10 & 135 & & GML103 & FLD & & & 20 & 1.00 & & 1.305 & 62 \\
\hline Y11 & 135 & 48 & GMLL104 & FLD & 18-Jol-94 & 14.02 & 26.00 & 1.21 & 73.04 & 1.305 & 95.32 \\
\hline Y 10 & 1351771 & 480473 & GML105 & FLD & 18-Jul-94 & $14: 14$ & 18.90 & 1.07 & 52.32 & 1.305 & 68.28 \\
\hline S1 & 1351541 & 480338 & GML106 & STD & $18-J$ & $14: 31$ & 25.60 & 1.37 & & 1.305 & 93.80 \\
\hline$\$ 2$ & 1351508 & 480562 & GML10? & STD & 18-Jul-94 & $14: 43$ & 14.70 & 0.78 & 40.07 & 1.305 & 52.29 \\
\hline$\infty$ & $*$ & - & GML10 & CAL & 18-Jul-94 & $15: 05$ & 0.70 & 0.00 & -0.79 & - & -0.79 \\
\hline C35 & - & - & GML109 & CAL & $1-94$ & 15:17 & 80 & 1.77 & 95.80 & - & 95.80 \\
\hline C100 & - & - & GMLIIO & CAL & 18-Ju1-94 & $15: 28$ & 49.50 & 2.42 & 141,62 & - & 141.62 \\
\hline $\mathrm{CO}$ & - & - & GML111 & CAL & 19-Jul-94 & 13:39 & 4.10 & 0.08 & 9.14 & - & - \\
\hline C35 & - & - & GML112 & CAL & 19.Jut-94 & $13: 50$ & 36.90 & 1.80 & 104.85 & - & 9.14 \\
\hline C100 & - & - & GML113 & CAL & 19-Jul-94 & $14: 01$ & 47.60 & $25 i$ & 136.07 & - & 104.85 \\
\hline $\mathbf{S} 2$ & 1351508 & 480562 & GMLI14 & STD & 19-Jul-94 & $15: 00$ & 17.30 & 0.89 & 47.65 & 1.145 & 136.07 \\
\hline-- & 1351629 & 480339 & GML116 & FLD & 19-Iul-94 & $15: 54$ & 32.60 & 1.69 & 92.30 & 1.145 & - \\
\hline ه & I3S1568 & & GML117 & FLD & 19-Jnl-94 & $16: 17$ & 28.00 & 1.40 & 78.88 & 1.145 & 54.56 \\
\hline-- & 1351685 & 480353 & GML118 & FLD & 19-Jul-94 & $16: 43$ & 28.00 & 1.49 & 78.88 & 1.145 & 105.69 \\
\hline 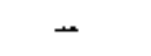 & 1351666 & 480383 & GML119 & FLD & 19-Jal-94 & $16: 31$ & 27.90 & 1.51 & 78.59 & 1.145 & 90.32 \\
\hline مـ & 1351683 & 480294 & GML120 & FLD & 19-Jn1-94 & $16 \div 56$ & 30.60 & 1.62 & 86,47 & 1.145 & 90.32 \\
\hline- & 1351811 & 480469 & GML121 & FLD & 19-Jul-94 & $17: 11$ & 4,40 & 0.24 & 10.01 & 1.145 & 89.98 \\
\hline- & 1351829 & 480485 & GMLl22 & FLD & 19.Jul-94 & $17: 22$ & 27.70 & 1.33 & 78,00 & 1.145 & 99.00 \\
\hline
\end{tabular}

'The designation, "DUP" is in the original data base. The geolocation code and the coondinates indicate that this is not a duplicate sample. 
Table G-7: Compoeite Data Listing for Laser Abtatlon-Inductively Coupled Plasma-Atomic Emlssion Spectrometer Technology

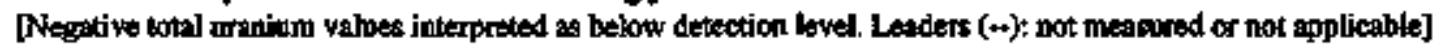

\begin{tabular}{|c|c|c|c|c|c|c|c|c|}
\hline C: & $\begin{array}{c}x \text { Coord } \\
\text { (twel) }\end{array}$ & $\begin{array}{c}\text { Y Coord } \\
\text { (tit) }\end{array}$ & ID & Typo & $D_{i}+\infty$ & $\underset{f(\mathbb{E})}{\operatorname{Tim}}$ & $\begin{array}{l}\text { fow Dato } \\
\text { foounts U } \\
\text { por count \$) }\end{array}$ & $\begin{array}{l}\text { Total U } \\
\text { (pclo) }\end{array}$ \\
\hline $\mathbf{C 0}$ & - & -- & ICF001 & CAL & 15-Jun-94 & $11: 20$ & $0,005]$ & $\pi$ \\
\hline C35 & - & -- & ICPOO2 & CAL & 15-Jun-94 & $11: 40$ & 0.0367 & $=$ \\
\hline C100 & -- & -- & КСPO03 & CAL & 15-Jun-94 & $12: 02$ & 0.0508 & -- \\
\hline $\mathrm{CO}$ & - & $\ldots$ & ICPO04 & CAL & 15-Jun-94 & $12 \div 20$ & $0.004]$ & -- \\
\hline C35 & -- & -- & KCPOOS & CAL & 15-Jun-94 & $12: 34$ & 0.0397 & $*$ \\
\hline C190 & -- & -- & ICPO06 & CAL & 15-Jun-94 & $12+50$ & 0.0504 & $=$ \\
\hline$C 0$ & $=$ & $=$ & LCPC07 & CAL & 15-Jun-94 & 13:06 & 0.0046 & - \\
\hline $\mathrm{C} 35$ & - & - & ICP008 & CAL & 15-Jun-94 & $13: 21$ & 0.0394 & - \\
\hline C100 & $\ldots$ & - & ICPOOS & CAL & 15-Jun-94 & $13: 35$ & 0.0502 & -- \\
\hline C35 & - & - & ICPOIO & STD & 15-Jun-94 & $14 \div 01$ & 0.0357 & 115.52 \\
\hline$C 0$ & - & - & ICPO]l & STD & 15-Jun-94 & $14: 19$ & 0.0047 & 9.32 \\
\hline CP & -- & .. & ICP012 & STD & 15-Ju世-94 & $14: 42$ & 0.0344 & 111.06 \\
\hline $\mathrm{CP}$ & - & - & ICP013 & STD & 15-Jun-94 & $14: 55$ & 0.0436 & 142.58 \\
\hline $\mathrm{CP}$ & - & - & ICP014 & STD & 15-Jun-94 & $15: 09$ & 0.0451 & 147.72 \\
\hline C35 & - & -- & tCP015 & STD & 15-Jun-94 & 16.54 & 0.0373 & 121.00 \\
\hline$\infty$ & - & -- & ICPO18 & STD & 15-Jun-94 & $17: 56$ & 0.0048 & 9.66 \\
\hline C35 & -. & -. & ICPO19 & STD & 15-Jon-94 & $17: 56$ & 0.0418 & 136.41 \\
\hline C35 & - & $=$ & ICPOQO & CAL & I6-Jnt-94 & $8: 45$ & 0.0367 & 118.94 \\
\hline$\infty 0$ & -- & -- & ICP021 & STD & 16-Jan-94 & $9: 05$ & 0.0053 & 11.37 \\
\hline c3s & $=$ & -- & $1 \mathrm{CPO} 22$ & STD & 16-Jun-94 & $9: 21$ & 0.0362 & 117.23 \\
\hline $\mathrm{C} 35$ & -- & -- & ICP029 & STD & 16-Jun-94 & $16: 44$ & 0.2627 & 893.15 \\
\hline$C$ & $\rightarrow$ & - & $\operatorname{LCP} 032$ & STD & 16-Jun-94 & $18: 36$ & 0.0148 & 43.92 \\
\hline C35 & -- & -- & КСР033 & STD & 16-Jun-94 & t8:49 & 0.0637 & 211.44 \\
\hline C35 & .. & - & ICPOB4 & CAL & 17-Jon-94 & $10: 50$ & 0.0341 & 110.03 \\
\hline C35 & -- & $=$ & KCP035 & STD & 17-Jun-94 & $11: 21$ & 0.0346 & 111.75 \\
\hline $\mathrm{CO}$ & - & - & KCP036 & STD & 17-Jun-94 & $11 \div 36$ & 0.0046 & 8.98 \\
\hline C35 & $*$ & $\omega$ & ICPO41 & STD & 17-Jun-94 & $13: 15$ & 0.0400 & 130.25 \\
\hline $\mathrm{CO}$ & - & $*$ & ICPO42 & CAL & 18-Jun-94 & 10.51 & 0.0040 & 6.92 \\
\hline C35 & -- & -- & $\mathrm{ICPO43}$ & CAL & 18-Jur-94 & 11:00 & 0.0247 & 77.83 \\
\hline $\mathrm{C} 100$ & 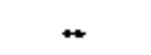 & - & ICP044 & CAL & 18-Jum-94 & $11: 08$ & 0.0304 & 97.36 \\
\hline$C 0$ & - & -- & ICP045 & STD & 18-Jun-94 & $11: 13$ & 0.0037 & 5.89 \\
\hline C35 & - & - & ICPO46 & STD & 18-Jun-94 & $11: 21$ & 0.0242 & 76.12 \\
\hline $\cos$ & 1351474 & 480600 & 1CPO47 & FLD & 18-Jun-94 & $11: 30$ & 0.0103 & 28.50 \\
\hline कc6 & 1351534 & 480599 & ICP048 & FLD & $18-54 n-94$ & $11: 40$ & 0.0136 & 39.81 \\
\hline $\mathrm{CC} 7$ & 1351594 & 480597 & ICP049 & FLD & $18-5$ เมा-94 & $11: 5 t$ & 0.0114 & 32.27 \\
\hline $\operatorname{cc} 8$ & 1351654 & 480596 & ICPOSO & FLD & 18-Jum-94 & $12 \times 00$ & $0.0 \$ 40$ & 41.18 \\
\hline $\operatorname{ccg}$ & 1351714 & 480594 & ICP(16] & FLD & 18-Jun-94 & $12: 11$ & 0.0139 & 40.84 \\
\hline $\mathrm{CC} 10$ & 1351774 & 480593 & ICP0S2 & FLD & 18-Jon-94 & $12: 22$ & 0.0147 & 43.58 \\
\hline col1 & 1351834 & 480591 & ICP053 & FLD & 18-ปที-94 & $12: 31$ & 0.0068 & 16.51 \\
\hline $\mathrm{C35}$ & 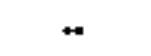 & - & ICP054 & SID & 18-Jun-94 & $12: 42$ & 0.0212 & 65.84 \\
\hline C35 & - & - & ICPOSS & CAL & 18-Jun-94 & $14: 38$ & 0.0211 & - \\
\hline AAS & 1351473 & 480540 & ICP056 & FLD & 18-Jum-94 & $14: 49$ & 0.0114 & 32.27 \\
\hline
\end{tabular}


Tabla Q-7: Composite Data Liating for Laser Ablationtinductively Coupled Plasma-Atomic Emission Spectrometer Technology (continued)

INegative total urantum values inerpreted as below detection level. Leaders (- ) : not measured or not applicable]

\begin{tabular}{|c|c|c|c|c|c|c|c|c|}
\hline 000 loc & $\begin{array}{c}x \text { coord } \\
\text { (foit) }\end{array}$ & $\begin{array}{l}Y \text { Coord } \\
\text { fileofil }\end{array}$ & ID & Typo & Dete & TIm) & $\begin{array}{c}\text { Faw Dif } \\
\text { (counte U } \\
\text { par count si) }\end{array}$ & $\begin{array}{l}\text { Total U } \\
\text { (peto) }\end{array}$ \\
\hline$\overline{\mathrm{AA6}}$ & $13 \$ 1533$ & $480 \$ 39$ & 1cp057 & FLD & 18-Jum-94 & $14: 59$ & 0.0127 & 36.72 \\
\hline AA6.5 & 1351563 & 480538 & ICPO58 & FLD & 18-Jun-94 & $15: 10$ & 0.0173 & 52,48 \\
\hline AA7 & 1351593 & 480537 & ICP059 & FLD & 18-Jun-94 & $15: 20$ & 0.0127 & 36.72 \\
\hline AAS & 1351653 & 480536 & ICPO60 & FLD & 18-Jum-94 & $15: 32$ & 0.0172 & $\$ 2.14$ \\
\hline AA 9 & 1351713 & 480534 & ICP061 & FLD & 18-Jum-94 & $15: 45$ & 0.0140 & 41.18 \\
\hline AA95 & 1351743 & 480533 & ICPO62 & FLD & 18-Jun-94 & $15: 57$ & 0.0165 & 49.74 \\
\hline AA10 & 1351760 & 480533 & ICP063 & FLD & 18-Jun-94 & $16: 10$ & 0.0172 & 52.14 \\
\hline AA11 & 1351833 & 480531 & ICP064 & FLD & 18.Jun-94 & $16: 22$ & 0.0179 & 54.54 \\
\hline C35 & - & - & 1CPO65 & STD & 18-Iun-94 & $16: 33$ & 0,0236 & 74.06 \\
\hline C35 & -- & - & ICFO66 & STD & 19-Jun-94 & $7: 19$ & 0.0224 & 69.95 \\
\hline $\mathrm{CO}$ & + & - & ICP067 & STD & 19-Jun-94 & $7: 33$ & 0.0060 & 13.77 \\
\hline YS & 1351471 & 480480 & ICP068 & FLD & 19-J4⿴囗十-94 & $7: 43$ & 0.0153 & 45.63 \\
\hline Y6 & $1351 \$ 31$ & 480479 & ICP069 & FLD & 19-Jun-94 & $7: 57$ & 0.0180 & 54.88 \\
\hline Y6.5 & 1351561 & 480478 & ICPOT0 & FLD & 19.Jun-94 & 8.06 & 0.0236 & 74.06 \\
\hline$Y 7$ & 1351591 & 480477 & ICFO 71 & FLD & 19-Jum-94 & $8: 19$ & 0.0227 & 70.98 \\
\hline Y7.5 & 1351621 & 480476 & ICPO72 & FLD & 19-Jun-94 & $8: 34$ & 0,0306 & 98.04 \\
\hline C35 & - & - & ICPO75 & CAL & 19. Itun-94 & $9: 12$ & 0.0298 & - \\
\hline C35 & - & - & ICP076 & STD & 19-Jum-94 & $9: 22$ & 0.0297 & 94.96 \\
\hline Y8 & 1351651 & 480476 & ICFV77 & FLD & 19-Jun-94 & $9 * 32$ & 0.0349 & $112 . \pi$ \\
\hline Y8.5 & 1351681 & 480475 & ICPOT9 & FLD & 19-Jen-94 & $9: 34$ & 0.0303 & 97.02 \\
\hline Y9 & 1351711 & 480474 & ICFOBO & FLD & 19-Jım-94 & 10:05 & 0,0315 & $10 \mathrm{~L} .13$ \\
\hline Y95 & 1351725 & 480474 & ICPOB1 & FLD & 19-3ym-94 & $10: 15$ & 0,0273 & 86.74 \\
\hline Y10 & 1351771 & 480473 & ICP082 & FLD & $19-J(x)-94$ & $10: 26$ & 0.0329 & 10592 \\
\hline C35 & - & - & ICPOS3 & \$TD & 19-Jun-94 & $10: 40$ & 0.0900 & 95.99 \\
\hline YU1 & 1351831 & 480471 & ICP084 & FLD & 19-Jun-94 & 10.53 & 0.0237 & 74.41 \\
\hline $\mathbf{Z 6}$ & 1351532 & 480509 & ICPOAS & FLD & 19-Jumt-94 & 11:04 & 0.0222 & 69.27 \\
\hline Z6.5 & 1351562 & 480508 & ICP036 & FLD & 19-Im-94 & 11:13 & 0.0304 & 97.36 \\
\hline 27 & $135[592$ & 480507 & ICFOA87 & FLD & 19-Jun-94 & $11: 24$ & 0.0254 & 8023 \\
\hline $\mathbf{z g}$ & 1351712 & 480504 & ICF0\$8 & FLD & 19-Jun-94 & [1:34 & 0.0946 & 111.75 \\
\hline 29.5 & 1351742 & 480503 & ICPO89 & FLD & 19-Jur 94 & $11: 46$ & 0,0379 & 123.05 \\
\hline Zlo & 1351787 & 480502 & ICP090 & FLD & 19-Jun-94 & $12: 07$ & 0.0231 & 72.35 \\
\hline C35 & - & - & ICPOSI & STD & $19-5(\tan ) 94$ & $12: 18$ & $0,029 ?$ & 94.96 \\
\hline D1 & 1351542 & 480519 & $\mathrm{ICPO} 92$ & FLD & 19-Jun-94 & $12 \div 31$ & 0.0196 & 60.36 \\
\hline $\mathbf{D} 2$ & 1351547 & 480518 & ICP093 & FLD & 19-Jun-94 & $12: 42$ & 0.0254 & 80.23 \\
\hline C35 & - & -- & ICP0\% & CAL & 19-Jnn-94 & $13 \div 43$ & 0.0221 & - \\
\hline D3 & 1351552 & 480518 & ICPOY & FLD & 19-Jan-94 & $13+55$ & 0.0196 & 60.36 \\
\hline Ft & 1351542 & 480529 & ICP098 & FLD & 19-Jus-94 & $14: 09$ & 0.0150 & 44,60 \\
\hline $\mathbf{F} 2$ & 1351547 & 480528 & $1 C P 099$ & FLD & 19-Jup-94 & $14: 20$ & 0,0153 & 45.63 \\
\hline 53 & 1351552 & 480528 & ICPIO0 & FLD & 19-Jun-94 & $14 \div 38$ & 0.0171 & 51.80 \\
\hline E1 & 1351542 & 480524 & ICPIO] & FLD & J9-Jun-94 & $14: 50$ & 0.0186 & 56.94 \\
\hline E2 & $135 \pm 547$ & $480 \$ 23$ & 1CP102 & FLD & 19-Jар-94 & $15 \div 03$ & 0.0161 & 48.37 \\
\hline E3 & 1351552 & $480 \$ 23$ & tCP103 & FLD & 19-J光n-94 & $15 \div 15$ & 0.0182 & 55.57 \\
\hline $\mathbf{x t}$ & $135] 590$ & 480447 & 1CPI04 & FLD & 19-Juณ-94 & $15: 29$ & 0.0234 & 73.38 \\
\hline
\end{tabular}


Table G-7: Composite Data Llating for Laser Ablation-Inductively Cospled Plasma-Atomlc Emisision Spectrometer Technology (continued)

[Negative botal uraminn values interpreted as below detection level. Leadeas (-)): tror measured or not appiticable]

\begin{tabular}{|c|c|c|c|c|c|c|c|c|}
\hline Ceo Loc & $\begin{array}{c}x \text { coond } \\
\text { (fiot) }\end{array}$ & $\begin{array}{l}\text { Y coord } \\
\text { (fiet) }\end{array}$ & ID & Type & Date & $\begin{array}{l}\text { Time } \\
\text { (EDT) }\end{array}$ & $\begin{array}{l}\text { Row Dotia } \\
\text { (counts U } \\
\text { per count si) }\end{array}$ & $\begin{array}{l}\text { Total y } \\
\text { (pci/g) }\end{array}$ \\
\hline$\overline{X 75}$ & 1351620 & 480447 & ICPPIOS & FLD & 19-Jur-94 & t5:41 & 0.0232 & 72.69 \\
\hline C35 & - & - & ICPI07 & STD & 19-5nu-94 & $16: 06$ & 0.0228 & 71.32 \\
\hline$x 8.5$ & 1351680 & 480445 & ICPI0: & FLD & 19-Jan-94 & $16: 17$ & 0.0183 & 35.91 \\
\hline $\mathbf{X 8}$ & 1351650 & 480446 & ICP109 & FLD & 19-Jur-94 & $16: 29$ & 0.0172 & 52.14 \\
\hline $\mathbf{X g}$ & 1351711 & 480457 & 1CP110 & FLD & 19-Jun-94 & $16: 40$ & 0.0185 & 56.59 \\
\hline C35 & - & - & ICPI]1 & STD & 19-Jun-94 & $17: 00$ & 0.0225 & 70.30 \\
\hline C35 & - & - & ICPII2 & CAL & 20-Jun-94 & $7: 27$ & 0.0206 & - \\
\hline C35 & -. & -- & 1CP113 & STD & 20-Jum-94 & $7: 44$ & 0.0188 & 57.62 \\
\hline$c 35$ & - & - & ICP114 & STD & 20-Jun-94 & $7: 55$ & 0,0211 & 65.50 \\
\hline $\mathrm{CO}$ & $*$ & - & KCP115 & SID & 20-Jun-94 & $8: 07$ & 0.0052 & 11.03 \\
\hline ws & 1351470 & 480420 & ICPII6 & FLD & $20-\mathrm{Jum}-94$ & $8+20$ & 0.0096 & 26.10 \\
\hline W6 & 1351530 & 480419 & FCPII7 & FLD & 20-Jur-94 & $8: 32$ & 0.0133 & 38.78 \\
\hline w65 & 1351560 & 480418 & KCP118 & FLD & 20-Jun-94 & $8: 43$ & 0.0127 & 36.72 \\
\hline$w_{7}$ & $1351 \$ 90$ & 480417 & KP119 & FLD & 20-Jun-94 & $8: 52$ & 0.0143 & 42.21 \\
\hline Wh.s & 1351620 & 480420 & ICP120 & FLD & 20-Jun-94 & $9: 03$ & 0.0186 & 56.94 \\
\hline w9 & 1351709 & 480412 & ICP121 & FLD & 20-Juo-94 & $9:$ ts & 0.0154 & 45.97 \\
\hline W9.5 & 1351739 & 480413 & ICP122 & FLD & 20-Jun-94 & $9: 27$ & 0.0211 & 65.50 \\
\hline W10 & 1351769 & 480413 & ICP123 & FLD & 20-Ju世-94 & $9: 41$ & 0.0146 & 43.23 \\
\hline W1I & 1351829 & 480411 & ICP124 & FLD & 20-Juڤ-94 & $9: 51$ & 0.0184 & 56.25 \\
\hline $\mathrm{C} 35$ & -- & -- & ICP125 & CAL & 20-Jun-94 & $10: 06$ & 0.0265 & - \\
\hline V6 & 1351529 & 480394 & ICP126 & FLD & 20-Jun-94 & $10: 17$ & 0.0183 & 55.91 \\
\hline v9 & 1351709 & 480384 & ICP127 & FLD & 20-Jun-94 & $10: 29$ & 0.0295 & 94.28 \\
\hline C35 & - & - & ICP130 & CAL & 20-Jun-94 & $11: 16$ & 0.0248 & - \\
\hline $\mathrm{C} 35$ & - & - & ICP131 & STD & 20-Jun-94 & $11: 49$ & 0.0224 & 69.95 \\
\hline$v 9.5$ & 1351739 & 480383 & ICP134 & FLD & 20-Jயง-94 & $12: 15$ & 0.0206 & 63.79 \\
\hline V 10 & 1351769 & 480383 & ICP135 & FLD & 20-Jun-94 & $12: 29$ & 0.0214 & 66.53 \\
\hline U8 & 1351648 & 480366 & ICP136 & FLD & 20-Jun-94 & $12: 41$ & $0.02 \pi$ & 88.11 \\
\hline V6.5 & 1351559 & 480403 & ICP139 & FLD & 20-Jun-94 & $13: t 9$ & 0.0179 & 54.54 \\
\hline W8.5 & 1351679 & 480400 & ICP 140 & FLD & 20-Jun-94 & $13: 30$ & 0.0241 & 73.78 \\
\hline C35 & - & -- & ICP141 & CAL & 20-Jor-94 & $13: 48$ & 0.0248 & - \\
\hline A1 & 1351748 & 480363 & ICPJ42 & FLD & 20-Jun-94 & $14: 00$ & 0.0252 & 79.55 \\
\hline$A 2$ & 1351753 & 480363 & ICPI43 & FLD & 20-Jug-94 & $14: 11$ & 0.0188 & 57.62 \\
\hline$A 3$ & 1351758 & 480363 & ICP144 & FLD & 20-Jon-94 & $14: 24$ & 0.0297 & 94.96 \\
\hline B1 & 1351748 & 480368 & ICP145 & FLD & 20-Jan-94 & $14: 36$ & 0.0271 & 86.05 \\
\hline $\mathrm{C} 35$ & - & .- & ケCP146 & STD & 20-Jun-94 & $14: 43$ & 0.0275 & 87.42 \\
\hline$C 0$ & -- & 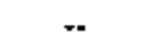 & 1CP147 & STD & 20-Jun-94 & $14: 55$ & 0.0087 & 23.02 \\
\hline C35 & -- & -- & KCP148 & STD & 21-Jun-94 & $7 \pm 58$ & 0.0221 & 68.93 \\
\hline$\infty$ & - & $\leftarrow$ & ICP149 & SID & 21-Jun-94 & $8: 12$ & 0.0053 & 11.37 \\
\hline $\mathrm{B} 2$ & 1351753 & 480368 & ICP150 & FLD & 21-Jun-94 & $8: 22$ & 0.0140 & 41.18 \\
\hline B3 & 1351758 & 480368 & KCP15: & FLD & 21-Jun-94 & $8: 36$ & 0.0138 & 40.49 \\
\hline C1 & 1351748 & 480373 & XCP152 & FLD & 21-Jus-94 & $8: 49$ & 0.0193 & 59.33 \\
\hline $\mathrm{C} 2$ & 1351753 & 480373 & ICP153 & FLD & 21-Jun-94 & $9: 01$ & 0.0172 & 52.14 \\
\hline $\mathrm{C} 3$ & 1351758 & 480373 & KCP154 & FLD & 21-Jun-94 & $9: 15$ & 0.0210 & 65.16 \\
\hline
\end{tabular}


Table G.7: Composite Data Lating tor Laser Ablatlon-Inductively Coupled Plasma-Atomic Emiasion Spectrometer Technology (comtinued)

[Nequtive tofal uraminum values interpieted as below detection level. Lesders (*): not measured or not applicabte]

\begin{tabular}{|c|c|c|c|c|c|c|c|c|}
\hline Cos Loo & $\begin{array}{c}x \text { Coord } \\
\text { (fitet) }\end{array}$ & $\begin{array}{l}\text { Y coord } \\
\text { (teet) }\end{array}$ & 10 & Туре & Date & $\begin{array}{l}\text { Time } \\
\text { (EDT) }\end{array}$ & $\begin{array}{l}\text { Fow Dut } \\
\text { (counts U } \\
\text { por coilnt s) }\end{array}$ & $\begin{array}{l}\text { Totof U } \\
\text { (pCU/g) }\end{array}$ \\
\hline$\overline{C 35}$ & $-\bar{r}$ & $\overline{-}$ & $\overline{\text { ICP1S5 }}$ & STD & 21-Jun-94 & $9: 31$ & 0.0232 & 72.69 \\
\hline US & t351468 & 480365 & ICP156 & FLD & 21-Jun-94 & $9: 42$ & 0.0204 & 63.10 \\
\hline C35 & - & - & ICP158 & CAL & 21-Jun-94 & $10: 11$ & 0.0241 & $\rightarrow$ \\
\hline $\mathbf{C o}$ & - & - & 1CP159 & CAL & 21-Jun-94 & $10: 23$ & 0.0068 & - \\
\hline U6 & 1351528 & 480354 & ICP161 & FLD & $2 l-\sqrt{u n-94}$ & $10: 55$ & 0.0314 & 100.78 \\
\hline U6.5 & 1351558 & 480358 & ICP162 & FLD & 21-Jun-94 & $11 \div 07$ & 0.0327 & 105.24 \\
\hline U7 & 1351588 & 480361 & 1CP163 & FLD & 21-Jun-94 & $11: 21$ & 0.0295 & 94.28 \\
\hline U9 & 1351708 & 480354 & ICP 164 & FLD & 21-Jun-94 & $11: 36$ & 0.0222 & 69.27 \\
\hline U9.5 & 1351738 & 480553 & $1 C P 165$ & FLD & 21-Jun-94 & $11: 49$ & 0.0158 & 47.34 \\
\hline U10 & 1351768 & 480353 & 1CP166 & FLD & 2]-Jun-94 & $12: 03$ & 0,0216 & 67.21 \\
\hline U11 & 1351828 & 480351 & ICP167 & FLD & 21-Jun-94 & $12: 19$ & 0.0275 & 87,42 \\
\hline C35 & -- & -- & ICP168 & STD & 21-Ju็-94 & $12: 30$ & 0.0234 & 73.38 \\
\hline Ss & 1351466 & 480300 & ICP169 & FLD & 21-Jux|-94 & $12: 46$ & 0.0134 & 39.12 \\
\hline$\$ 9$ & 1351706 & 480294 & ICP170 & FLD & 21-Jun-94 & $12: 57$ & 0.0276 & 87.77 \\
\hline S10 & 1351766 & 480293 & ICP171 & FLD & $21 \cdot J u n-94$ & $13: 09$ & 0.0159 & 47.69 \\
\hline s11 & 1351826 & 480291 & $1 \mathrm{CP} 172$ & FLD & 21-Jเมn-94 & $13: 19$ & 0.0249 & 78.52 \\
\hline C35 & - & $\rightarrow$ & ICP173 & \$TD & 21-J目-94 & $13: 30$ & 0.0272 & 86.40 \\
\hline$\infty 0$ & -- & -- & ICP174 & STD & 2I-Jun-94 & $13: 42$ & 0.0126 & 36.38 \\
\hline$C 35$ & - & -- & ICP175 & STD & 21-Jun-94 & 13.54 & 0.0329 & 105.92 \\
\hline$\infty 0$ & - & .- & ICP176 & CAL & $12-0 \mathrm{ct}-94$ & t3:24 & 0.0018 & -- \\
\hline C35 & -- & -- & ICP177 & CAL & $12-0 c t \cdot 94$ & $13: 35$ & 0.0212 & $\leftrightarrow$ \\
\hline C35 & - & - & ICP178 & STD & $12-0 \mathrm{ct}-94$ & $13: 40$ & 0.0214 & 66.53 \\
\hline $\mathrm{Co}$ & - & - & ICP179 & STD & $12-0 \mathrm{ct}-94$ & $13: 53$ & 0,0019 & -0.27 \\
\hline- & 1351473 & 480509 & ICP180 & FED & $12-0 \mathrm{ct}-94$ & $14: 08$ & 0.0095 & 25.76 \\
\hline .- & 1351471 & 480451 & ICP181 & FLD & $12-\operatorname{Oet}-94$ & $14: 21$ & 0.0085 & 22.34 \\
\hline- & 1351494 & 480454 & ICP182 & FLD & $12-0<t-94$ & $14: 34$ & 0.0095 & 25.76 \\
\hline C35 & - & - & ICP183 & STD & $12-0 \mathrm{ct}-94$ & $14: 46$ & 0.0267 & 84.68 \\
\hline- & 1351500 & 480421 & ICP184 & FLD & $12-0 \mathrm{ct}-94$ & $15: 00$ & 0.0104 & 28.85 \\
\hline -- & 1351469 & 480393 & ICP185 & FLD & $12-0 \mathrm{ct}-94$ & $15: 13$ & 0.0100 & 27.48 \\
\hline- & 1351469 & 480328 & ICP186 & FLD & $12-0<t-94$ & $15: 26$ & 0.0087 & 23,02 \\
\hline- & 1351742 & 480295 & 1CP187 & FLD & $12-0$ t-94 & $15: 37$ & 0.0128 & 37.07 \\
\hline- & $135171 \mathrm{i}$ & 480324 & ICP188 & FLD & $12-0 \mathrm{c}-94$ & $15: 48$ & 0.0135 & 39.46 \\
\hline C35 & - & - & ICP189 & STD & $12-0 \mathrm{ct}-94$ & $15: 59$ & 0.0266 & 84.34 \\
\hline $\mathrm{CO}$ & + & - & ICP190 & \$TD & $12-0,04$ & $16: 16$ & 0.0026 & 2.12 \\
\hline 0 & - & - & ICP191 & STD & 12-Oct-94 & $17: 15$ & 0.0012 & -2.67 \\
\hline Co & -- & -- & ICP192 & CAL & $12-0 \mathrm{ct}-94$ & $8: 40$ & 0.0029 & - \\
\hline C35 & -- & -- & ICP193 & CAL & 12-Oct-94 & $8: 51$ & 0.0264 & - \\
\hline $\mathrm{CO}$ & - & - & ICP194 & STD & 12-Oet-94 & $8: 57$ & 0.0035 & 5.21 \\
\hline C35 & - & - & ICP195 & STD & $12-0 \mathrm{at}-94$ & 9:08 & 0.0233 & 73.04 \\
\hline$*$ & $135180 \mathrm{~J}$ & 480432 & ICP196 & FLD & $12-0 c t-94$ & $9: 20$ & 0.0123 & 35.35 \\
\hline-- & 1351802 & 480474 & ICP197 & FL.D & $12-0 \mathrm{kt}-94$ & $9: 34$ & 0.0105 & 27.82 \\
\hline-- & 1351744 & 480591 & ICP198 & FLD & $12-0 x t-94$ & $9: 52$ & 0.0163 & 49.06 \\
\hline C 35 & - & - & ICP1999 & STD & $12-0$ ct-94 & 1006 & 0.0216 & 67.21 \\
\hline
\end{tabular}


Table Q-7: Composite Data Listing for Laser Ablation-Inductivaly Coupled Plasma-Atomle Emlseion Spectrometer Technology (continued)

[Nkerative toilal uraniam valuss intepreked as below detection level. Leaders (-): not mensured or not applicable]

\begin{tabular}{|c|c|c|c|c|c|c|c|c|}
\hline Eoo Loo & $\begin{array}{l}x \text { coond } \\
\text { (foot) }\end{array}$ & $\begin{array}{c}Y \text { Coond } \\
\text { (teet) }\end{array}$ & 10 & Type & Date & (EDT) & $\begin{array}{l}\text { Fow Deta } \\
\text { (oounis U } \\
\text { per count Sl) }\end{array}$ & $\begin{array}{l}\text { Total U } \\
\text { (pcus) }\end{array}$ \\
\hline- & 1351831 & 480662 & ICP2O0 & $\overline{\text { FLD }}$ & 12-0et-94 & $10: 22$ & 0.0069 & 16.86 \\
\hline W8 & 1351650 & 480429 & ICP20I & FLD & 12-0tt-94 & $10: 34$ & 0.0141 & 41.52 \\
\hline - & 1351473 & 480509 & ICP2O2 & DUP† & $12-0 \mathrm{ct}-94$ & $10: 45$ & 0,0000 & 24,05 \\
\hline- & 1351494 & 480454 & ICP203 & DUP† & $12-0 c t-94$ & $10: 58$ & 0.0093 & 25.08 \\
\hline 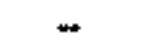 & 1351469 & 480328 & ICP204 & DUP† & 12-Oct-94 & $11 \pm 12$ & 0,0081 & 20.97 \\
\hline co & - & $*$ & JCP205 & STD & $12-0 \mathrm{ct}-94$ & $11: 29$ & 0,0026 & 2.12 \\
\hline C35 & - & -- & ICP206 & STD & 12-Oct-94 & $1: 14$ & 0.0213 & 66.19 \\
\hline
\end{tabular}

'The designation, "DUP" is in the original data base. The geolocation code and the coondinales jadicate that this is not a duplicate sanple. 
Table 0-8: Compoalte Data Liating for Soll Sampling and Laboratory Geochemlcal Analysis Tochnoilogy

(Additional semple types unique to this nechology: COR: core ample, 1-8 inches depth; CORt: care sample, 0-2 inches; COR2: core sampte, 2-4 jnetres; COR3: core sample, 4.6 inches; COR4; core semple, 6-8 inches]

\begin{tabular}{|c|c|c|c|c|c|}
\hline Coo Loc & $\begin{array}{l}X \text { Coord } \\
\text { (icent) }\end{array}$ & $\begin{array}{c}\text { Y Coord } \\
\text { (fient) }\end{array}$ & D & Typ: & $\begin{array}{l}\text { Toted U } \\
\text { (pcilfig) }\end{array}$ \\
\hline A! & 1351748 & 480363 & LAB082 & FLD & 63.36 \\
\hline A2 & 1351753 & 480363 & LABOS3 & FLD & 56.58 \\
\hline A3 & 1351758 & 480363 & LAB084 & FLD & 65.60 \\
\hline AA10 & 1351760 & 480533 & LAB018 & FLD & 53.89 \\
\hline AA10 & 1351760 & 480533 & LAB 121 & COR & 22.25 \\
\hline AA11 & 1351833 & 480531 & LAB019 & FLD & 51.54 \\
\hline AA5 & 1351473 & 480540 & LABO11 & FLD & 39.41 \\
\hline AA 6 & 1351533 & 480539 & $\mathrm{LABO12}$ & FLD & 59.80 \\
\hline AA6 & 1351533 & 480539 & LAB119 & COR & 21.68 \\
\hline AA6.5 & 1351563 & $4 \$ 0638$ & LABOt3 & FLD & 52.99 \\
\hline AA7 7 & 1351593 & 480537 & LABO14 & FLD & 48.42 \\
\hline AA7 & 1351593 & 480537 & LAB 136 & COR1 & 40.94 \\
\hline AA7 & 1351593 & 480537 & LAB137 & COR2 & 16.85 \\
\hline AA? & 1351593 & 480537 & LAB138 & COR3 & 6.27 \\
\hline AA7 & 1351593 & 480537 & LAB 139 & COR4 & 6.39 \\
\hline AA 8 & 1351653 & 480536 & LAEOIS & FLD & 61.79 \\
\hline$A A 8$ & 1351653 & 480536 & LAB 120 & COR & 29.87 \\
\hline $\mathrm{AAg}$ & 1351713 & 480534 & LABO16 & $F L D$ & 54.20 \\
\hline AA 9 & 1351713 & 480534 & LAB140 & COR1 & 50.46 \\
\hline AA9 & 1351713 & 480534 & LAB 141 & $\operatorname{COR} 2$ & 32.60 \\
\hline AAG & 1351713 & 480534 & LAB 142 & COR3 & 16.03 \\
\hline AA 9 & 1351713 & 480534 & LAB 143 & COR4 & 4.88 \\
\hline AA9.5 & 1351743 & 480533 & LABOI7 & FLD & 68.27 \\
\hline B1 & 1351748 & 480368 & LAB079 & FLD & 46.80 \\
\hline $\mathbf{B 2}$ & 1351753 & 480368 & LABOBO & ELD & 71.08 \\
\hline B3 & 1351758 & 480368 & LABOB1 & FLD & 64.39 \\
\hline C1 & 1351748 & 480373 & LABO75 & FLD & 72.21 \\
\hline$C 2$ & 1351753 & 480373 & $\mathrm{LABO} 66$ & FLD & 61.84 \\
\hline $\mathrm{C3}$ & 1351758 & 480373 & 148077 & FLD & 61.10 \\
\hline $\mathrm{Cl}_{3}$ & 1351758 & 480373 & LAB078 & DUP & 59.02 \\
\hline $\operatorname{cc10}$ & 1351774 & 480593 & LABOOS & FLD & 60.74 \\
\hline $\cos 10$ & 1351774 & 480593 & LAB1t8 & $\mathrm{COR}$ & 12.23 \\
\hline CCl1 & 1351834 & 480591 & $\angle A B 009$ & FLD & 31.41 \\
\hline CC11 & 1351834 & 480591 & LABO10 & DUP & 27.73 \\
\hline $\cos$ & 1351474 & 480600 & LABO01 & FLD & 50.12 \\
\hline CC6 & 1351534 & 480599 & LABO02 & FLD & 59.33 \\
\hline CC6 & 1351534 & 480599 & $\mathrm{LAB} 003$ & DUP & 58.62 \\
\hline CC6 & 1351534 & 480599 & LABt 14 & COR & 25.81 \\
\hline CC7 & 1351594 & 480597 & LABOO4 & FLD & 52.48 \\
\hline $\mathrm{CC} 7$ & 1351594 & 480597 & LAB115 & COR & 25.09 \\
\hline $\operatorname{ccs}$ & 1351654 & 480596 & LABOXS & FLD & 51.36 \\
\hline CC8 & 1351654 & 480596 & LAB006 & DUP & 55.49 \\
\hline
\end{tabular}


Table G-8: Composite Data Listing for Soit Sampling and Laboratory Geochemical Analysis Technoloyy (continued)

[Additional sample types unique to this tectnolozy: COR: core sample, 1.8 inches depth; COR1: core sample, 0-2 inches; COR2: cone sampte, 2-4 inches; COR3: core ssmple, 46 inches; COR4: core sample, 6-8 inches]

\begin{tabular}{|c|c|c|c|c|c|}
\hline Ceo loc & $\begin{array}{c}x \text { Coord } \\
\text { (feel) }\end{array}$ & $\begin{array}{l}\text { coond } \\
\text { (fost) }\end{array}$ & ID & Typo & $\begin{array}{l}\text { Tosad U } \\
\text { (pcilg) }\end{array}$ \\
\hline $\mathrm{CO}$ & 1351654 & 480596 & $\overline{\mathrm{L}} \mathbf{A B 1 1 6}$ & COR & 21.35 \\
\hline$\infty \mathrm{C}$ & 1351714 & 480594 & LABDO7 & FLD & 61.59 \\
\hline $\operatorname{CCg}$ & 1351714 & 480594 & LAB117 & COR & 18.19 \\
\hline D1 & 1351542 & 480519 & LABO33 & FLD & 64.89 \\
\hline D2 & 1351547 & 480518 & LAB034 & FLD & 53.81 \\
\hline D3 & 1351552 & 480518 & LAB035 & FLD & 55.36 \\
\hline El & 1351542 & 480524 & LAB030 & FLD & 56.83 \\
\hline E2 & 1351547 & 480523 & LAB031 & FLD & 52.44 \\
\hline E3 & 1351552 & 480523 & LAB032 & FLD & 56.38 \\
\hline $\mathbf{F t}$ & 1351542 & 480529 & LAB027 & FLD & 50.93 \\
\hline $\mathbf{F} 2$ & 1351547 & 480528 & LAB028 & FLD & 49.90 \\
\hline F3 & 1351552 & 480528 & LABO29 & FLD & $\$ 2,56$ \\
\hline $\mathbf{s 1}$ & $135154:$ & 480338 & LAB 104 & STD & 74.82 \\
\hline S1 & $\$ 351541$ & 480338 & LAB 105 & STD & 57.30 \\
\hline s1 & 1351541 & 480338 & LAB 106 & STD & 68.18 \\
\hline s1 & 1351541 & 480338 & LAB107 & STD & 76.19 \\
\hline S1 & 1351541 & 480338 & LAB 108 & STD & 70.70 \\
\hline S1 & 1351541 & 480338 & LAB I34 & COR & 32.60 \\
\hline $\mathbf{s 1 0}$ & 1351766 & 480293 & LAB 10I & FLD & 71.75 \\
\hline s10 & 1351766 & 480293 & LAB 102 & DUP & 73.52 \\
\hline \$11 & 1351826 & 480291 & $\mathrm{LAB} 103$ & FLD & 39.21 \\
\hline $\mathbf{S 2}$ & 1351508 & 480562 & LAB 109 & STD & 49.84 \\
\hline \$2 & 1351508 & 480562 & LAB110 & STD & 47.99 \\
\hline$\$ 2$ & 1351508 & 480562 & LAB 111 & STD & 52.23 \\
\hline$\$ 2$ & 1351508 & 480562 & LABt12 & STD & 46.98 \\
\hline s2 & $1351 \$ 08$ & 480562 & LABH 13 & STD & 46.99 \\
\hline \$2 & 1351508 & 480562 & LAB135 & COR & 23.34 \\
\hline S5 & 1351466 & 480300 & LA円097 & FLD & 50.98 \\
\hline S5 & 1351466 & 480300 & LAB098 & DUP & 50.58 \\
\hline$\$ 9$ & 1351706 & 480294 & LABO99 & FLD & 90.68 \\
\hline$\$ 9$ & 1351706 & 480294 & LAB 100 & DUP & 93.07 \\
\hline U10 & 1351768 & 480353 & LAB094 & FLD & 59.77 \\
\hline U10 & 1351768 & 480353 & LAB095 & DUP & 54.18 \\
\hline U10 & 1351768 & 480353 & LAB133 & COR & 23.33 \\
\hline U11 & 1351828 & 480351 & LAB096 & FLD & 58.04 \\
\hline Us & 1351468 & 480365 & LABOB5 & FLD & 47.53 \\
\hline U6 & 1351528 & 480354 & LABOB6 & FLD & 65.60 \\
\hline U6 & 1351528 & 480354 & LAB 129 & COR & 45.80 \\
\hline U6.5 & 1351558 & 480358 & LAB087 & FLD & 82.55 \\
\hline $\mathrm{UT}$ & 1351588 & 480361 & LADOB8 & FLD & 89.03 \\
\hline U7 & 1351588 & 480361 & LAB089 & DUP & 83.88 \\
\hline U7 & 1351588 & 480361 & $L_{-A B} 130$ & COR & 46.26 \\
\hline U8 & 1351648 & 480366 & LABO90 & FLD & 105.50 \\
\hline
\end{tabular}


Table G-8: Composite Data Listing for Soil Sampling and Laboratory Geochemlcal Analyals Tochnology (continued)

(Additional sample types unique to this technology, COR: core sample, 1-8 inches depth; COR1: core sample, 0-2 inches; COR2: core sample, 2-4 inches; COR3: core sample, 4-6 inches; COR4; core sample 6-8 inches]

\begin{tabular}{|c|c|c|c|c|c|}
\hline Ceo Loc & $\begin{array}{c}x \text { coord } \\
\text { ffoct })\end{array}$ & $\begin{array}{c}\text { coord } \\
\text { (fect) }\end{array}$ & ID & Type & $\begin{array}{l}\text { Totel U } \\
\text { (pcits) }\end{array}$ \\
\hline U88 & 1351648 & 480366 & LAB 13] & $\overline{\text { COR }}$ & $57 . \overline{75}$ \\
\hline U9 & 1351708 & 480354 & LABD9] & FLD & 76.02 \\
\hline U9 & 1351708 & 480354 & $\mathrm{LABO} 22$ & DUP & 75.82 \\
\hline U9 & 1351708 & 480354 & LAB I32 & COR & 33.30 \\
\hline U9.5 & 1351738 & 480353 & LAB093 & FLD & 52.16 \\
\hline V10 & 1351769 & 480383 & LAB074 & FLD & $\$ 3.72$ \\
\hline v6 & 1351529 & 480394 & LAB070 & FLD & 58.81 \\
\hline V6.5 & 1351559 & 480403 & LABO7] & FL, & 86.46 \\
\hline v9 & 1351709 & 480384 & LABO72 & FLD & 81.67 \\
\hline v9.5 & 1351739 & 480383 & LABO73 & FLD & 54.12 \\
\hline W10 & 1351769 & 480413 & LAB068 & FLD & 75.26 \\
\hline W10 & 1351769 & 480413 & LAB 128 & $\operatorname{COR}$ & 30.50 \\
\hline W11 & 1351829 & 480411 & LABC69 & FLD & 82.98 \\
\hline ws & 1351470 & 480420 & LAB057 & FLD & 61.86 \\
\hline w6 & 1351530 & 480419 & LAB05\& & FLD & 70.52 \\
\hline W6 & 1351530 & 480419 & LAB I26 & COR & 31.46 \\
\hline W6.5 & $135] 560$ & 480418 & LAB059 & FLD & 74.04 \\
\hline w7 & 1351590 & 480417 & LABO60 & FLD & 79.11 \\
\hline w7 & 1351590 & 480417 & LABO6I & DUP & 76.11 \\
\hline W7 & 1351590 & 480417 & LAB148 & COR1 & 77.09 \\
\hline W7 & 1351590 & 480417 & LAB 149 & COR2 & 22.83 \\
\hline w? & 1351590 & 480417 & LAB150 & COR3 & 12.08 \\
\hline w7 & 1351590 & 480417 & LAB 151 & COR4 & 13.64 \\
\hline W7.5 & 1351620 & 480420 & LAB062 & FLD & 77,83 \\
\hline w8 & 1351650 & 480429 & LABO63 & FLD & 62.32 \\
\hline W8 & 1351650 & 480429 & LAB127 & COR & 22.08 \\
\hline W8.5 & 1351679 & 480400 & LAB064 & FLD & 81.23 \\
\hline W8.5 & 1351679 & 480400 & LABN65 & DUP & 82.55 \\
\hline wg & 1351709 & 480412 & LAB066 & FLD & 52.94 \\
\hline W9 & 1351709 & 480412 & LAB152 & COR1 & 46.60 \\
\hline w9 & 1351709 & 480412 & LAB153 & $\cos 2$ & 24.76 \\
\hline W9 & 1351709 & 480412 & LAB 154 & COR3 & 11.85 \\
\hline w9 & 1351709 & 480412 & LAB1s5 & COR4 & 14.46 \\
\hline W9.5 & 1351739 & 480413 & LABO67 & FLD & 51.20 \\
\hline$x 7$ & 1351590 & 480447 & LAB049 & FLD & 68.76 \\
\hline$x 7$ & 1351590 & 480447 & LABOSO & DUP & 80.17 \\
\hline$\times 7.5$ & 1351620 & 480447 & LABOSI & FLD & 62.73 \\
\hline $\mathbf{X 8}$ & 1351650 & 480446 & LABOS2 & FLD & 62.24 \\
\hline $\mathbf{X 8 . 5}$ & 1351680 & 480445 & LABCS3 & FLD & 61.53 \\
\hline$X 8.5$ & 1351680 & 480445 & LAB054 & DUP & 62.55 \\
\hline$\times 9$ & 1351711 & 480457 & LABOS5 & FLD & 78.12 \\
\hline$x 9$ & 1351711 & 480457 & LAB056 & DUP & 60.46 \\
\hline Y10 & 1351771 & 480473 & LAB046 & FLD & 57.80 \\
\hline
\end{tabular}


Table G-8: Compoette Data Lieting for Soll Sampling and Leboratory Geochemical Analysis Technology (continued)

[Additional sample types unique to this tectoolozy: COR: sore sample, 1-8 inchess depth; COR1: cose sample, 0-2 inctes; COR2: core sample, 2-4 inches; COR3: core staple, 46 inches; COR4; Core sample, 6-8 inches]

\begin{tabular}{|c|c|c|c|c|c|}
\hline Coo Los & $\begin{array}{c}x \text { ceond } \\
\text { (fent) }\end{array}$ & $\begin{array}{c}Y \text { coord } \\
\text { (bed) }\end{array}$ & ID & Type & $\begin{array}{l}\text { Toted U } \\
\text { (pCly) }\end{array}$ \\
\hline Y10 & 1351771 & 480473 & LABI2S & COR & 15.10 \\
\hline $\mathbf{Y 1 1}$ & 1351831 & 480471 & LABO47 & FLD & $86 . \%$ \\
\hline Yl] & 1351831 & 480471 & LABO48 & DUP & 86.51 \\
\hline YS & 1351471 & 480480 & LAB036 & FLD & 49.60 \\
\hline Y6 & 1351531 & 480479 & LAB037 & FLD & 55.32 \\
\hline Y6 & 1351531 & 480479 & LAB122 & COR & 18.46 \\
\hline Y6.5 & 1351561 & 480478 & LAB038 & FLD & 60.17 \\
\hline$Y 7$ & 1351591 & 480477 & LAB039 & FLD & 57.39 \\
\hline Y7 & 1351591 & 480477 & LAB 123 & COR & 20.29 \\
\hline Y7s & 1351621 & 480476 & LAB040 & FLD & 76.00 \\
\hline $\mathbf{Y} \$$ & 1351651 & 480476 & LAB041 & FLD & 59.93 \\
\hline Y8 & 1351651 & 480476 & LAB 144 & CORI & 52.26 \\
\hline Y8 & 1351651 & 480476 & LAB145 & CoR2 & 30.31 \\
\hline Y & 1351651 & 480476 & LAB 146 & COR3 & 16.99 \\
\hline Y8 & 1351651 & 480476 & LAB 147 & COR4 & 4.97 \\
\hline Y8.5 & 1351681 & 480475 & LABO42 & FLD & 68.69 \\
\hline Y8.5 & 1351681 & 480475 & LAB043 & DUP & 68.95 \\
\hline Y9 & 1351711 & 480474 & LABD 444 & FLD & 62,19 \\
\hline Y9 & 1351731 & 480474 & LAB 124 & COR & 22.42 \\
\hline Y9.5 & 1351725 & 480474 & LAB045 & FLD & 60.78 \\
\hline 210 & 1351787 & 480502 & LAB026 & FLD & 58.82 \\
\hline $\mathbf{Z 6}$ & 1351532 & 480509 & LABO2O & FLD & 45.36 \\
\hline 263 & 1351562 & 480508 & LABO21 & FLD & 56.85 \\
\hline $\mathbf{Z 7}$ & 1351592 & 480507 & $\mathrm{LABO22}$ & FLD & 49.57 \\
\hline 27 & 1351592 & 480507 & LAB023 & DUP & 51.11 \\
\hline $\mathbf{Z 9}$ & 1351712 & 480504 & LAB024 & FLD & 57.49 \\
\hline 29.5 & 1351742 & 480503 & LAB025 & FLD & 67.36 \\
\hline
\end{tabular}


Table G-9: Composite Data Lleting for Long-Ringe Alpha Detoctor Technology

INegative tofal uranium valpes interpreted as below detection level. Leaders (-): not messured or not upliegble]

\begin{tabular}{|c|c|c|c|c|c|c|c|c|}
\hline Co Lac & $\begin{array}{c}x \text { Coond } \\
\text { (in:tit) }\end{array}$ & $\begin{array}{c}\text { Y coord } \\
(i \rightarrow 0)\end{array}$ & ID & Type & Dote & $\begin{array}{l}\text { Thine } \\
\text { (EDT) }\end{array}$ & Raw Dompo: & $\begin{array}{l}\text { Totw U } \\
\text { (bocifg) }\end{array}$ \\
\hline CO & - & - & LRAOOT & $\overline{C A L}$ & $07-J u n-94$ & 10.49 & 5700 & $=$ \\
\hline C35 & - & . & LRAOOL & CAL & 07-Jun-94 & $11: 30$ & 7600 & -- \\
\hline C100 & - & -- & LRAOO3 & CAL & 07-Jun-94 & $11: 44$ & 9800 & - \\
\hline 0200 & -- & - & L.RAO04 & CAL & 07.Jun-94 & $12: 02$ & 19000 & -- \\
\hline S1 & 1351541 & 480338 & LRACOS & STD & 08-Jun-94 & $8: 55$ & 6400 & 46.02 \\
\hline$\$ 2$ & 1351508 & 486862 & LRADOS & STD & 08-Jup-94 & $9: 10$ & 6800 & 55.39 \\
\hline $\mathrm{CC5}$ & 1351474 & 480600 & LRAOO? & FLD & 08-Jun-94 & $9: 29$ & 6300 & 43.67 \\
\hline CC6 & 1351534 & 480599 & LRAOOB & FLD & 0:-Jun-94 & $9: 42$ & 6700 & 53.06 \\
\hline $\mathrm{CC} 7$ & 1351594 & 480597 & LRA009 & FLD & $08-J u n-94$ & 954 & 7800 & 78.83 \\
\hline $\operatorname{ccs}$ & 1351654 & 480696 & LRA0JO & FLD & 08-Jun-94 & $10: 07$ & 8900 & 104.62 \\
\hline AA8 & 1351653 & 480536 & LRA011 & FLD & $08-J u n-94$ & $10: 21$ & 5900 & 34.30 \\
\hline AA7 & 1351593 & 480537 & LRAOI2 & FLD & 08-5um-94 & $10: 33$ & 8700 & 99.93 \\
\hline AA6s & 1351563 & 480538 & LRA013 & FLD & 08-Jum-94 & $11: 17$ & 7700 & 76.49 \\
\hline AAS & 1351473 & 480540 & LRA014 & FLD & 08-Jum-94 & $11: 29$ & 7000 & 60.08 \\
\hline Y5 & 1351471 & 480480 & LRA015 & FLD & 08-Juo-94 & $11: 50$ & 7700 & 76.49 \\
\hline Y6 & 1351531 & 480479 & LRA016 & FLD & 08-Jun-94 & $12: 22$ & 6000 & 36.64 \\
\hline AA6 & 1351533 & 480539 & LRA017 & FLD & 08-Jй-94 & $12: 33$ & 6000 & 36.64 \\
\hline Y65 & 1351561 & 480478 & LRA018 & FLD & 08-Jun-94 & $12: 48$ & 6300 & 43.67 \\
\hline $\mathbf{Y}$ & 1351591 & 480477 & LRA 019 & FLD & $08-5$ inn-94 & $13: 00$ & 6400 & 46.02 \\
\hline Y7.5 & 1351621 & 480476 & LRAOEO & FLD & 08-Jun-94 & $13: 12$ & 6300 & 43.67 \\
\hline Y8 & 1351651 & 480476 & LRA02I & FLD & 08-Jun-94 & $13: 24$ & 5900 & 34.30 \\
\hline X8 & [351650 & 480446 & LRA022 & FLD & 08-Jun-94 & $13: 35$ & 6400 & 46.02 \\
\hline$\times 75$ & 1351620 & 480447 & LRA023 & FLD & 08-Jun-94 & $13: 46$ & 7000 & 60.08 \\
\hline$\times 7$ & 1351590 & 480447 & LRA024 & FLD & 08-Jun-94 & $13: 57$ & 7600 & 74.14 \\
\hline w6 & 1351530 & 480419 & LRA025 & FLD & 08-Jua-94 & 14.08 & 9000 & 106.96 \\
\hline W6.5 & 1351560 & 480418 & LRA 026 & FLD & 08-Juo-94 & $14: 27$ & 9200 & 111.65 \\
\hline w? & $\$ 351590$ & 480417 & LRA027 & FLD & 08-Jus-94 & $14: 37$ & 8200 & 88.21 \\
\hline W7.s & 1351620 & 480420 & LRAO28 & FLD & (o8-Jun-94 & $14: 48$ & 7700 & 76.49 \\
\hline$W 8$ & 1351650 & 480429 & LRAO29 & FW & Os-Jut-94 & $14: 58$ & 6800 & 55.39 \\
\hline U5 & 1351468 & 480365 & LRAOBX & FLD & OB-Jan-94 & $15: 10$ & 10400 & 139.78 \\
\hline V6 & 1351529 & 480394 & LRA031 & FLD & O8-Jun-94 & $15: 21$ & 10700 & 146.81 \\
\hline V6.5 & $1351 \$ 59$ & 480403 & LRA032 & FLD & 08-Jus-94 & $15: 50$ & 10900 & 151.50 \\
\hline X8.5 & 1351680 & 480445 & LRA033 & FLD & $08+J u=-94$ & $16 \div 01$ & 7800 & 78.83 \\
\hline Y8.5 & 1351681 & 480475 & L.RA034 & FLD & 08-Jun-94 & $16: 12$ & 7400 & 69.46 \\
\hline $\mathbf{X 9}$ & I35171! & 480457 & LRA035 & FLD & 08-Jum-94 & $16: 24$ & 7400 & 69.46 \\
\hline Y9 & 1351711 & 480474 & LRA036 & FLD & 08-Jun-94 & $16: 35$ & 7300 & 67.11 \\
\hline $\mathrm{zg}$ & 1351712 & 480504 & LRA037 & ELD & Q8-Jun-94 & $16: 45$ & 6600 & 50.70 \\
\hline AAS & 1351713 & 480534 & LRA038 & FLD & 08-Jun-94 & $16: 55$ & 7300 & 67.11 \\
\hline $\operatorname{ccs}$ & 1351714 & 480594 & LRA039 & FLD & 03-Jun-94 & $17: 06$ & 9100 & 109.30 \\
\hline$\infty 10$ & 1351774 & 480593 & LRA040 & FLD & 08-Jun-94 & $17: 17$ & 5800 & 31.95 \\
\hline AA10 & 1351760 & 480533 & LRA041 & FLD & 08-Jum-94 & $17: 27$ & 7700 & 76.49 \\
\hline AA9.5 & 1351743 & 480533 & LRA042 & FLD & 08-Jum-94 & $17: 38$ & 7300 & 67.11 \\
\hline 29.5 & 1351742 & 480503 & LRA043 & FLD & 08-Jun-94 & 17:49 & 7800 & 78.83 \\
\hline
\end{tabular}


Table G-9: Composite Dota Listing for Long-Range Alpha Detector Technology (continued)

\begin{tabular}{|c|c|c|c|c|c|c|c|c|}
\hline Ceo Las & $\begin{array}{l}x \text { coord } \\
\text { (ived) }\end{array}$ & $\begin{array}{l}Y \text { coond } \\
\text { (fect) }\end{array}$ & ID & Type & Date & $\begin{array}{l}\text { Tine } \\
\text { (IED) }\end{array}$ & $\begin{array}{l}\text { Raw Dalia } \\
\text { (ferdapto. } \\
\text { anperes) }\end{array}$ & $\begin{array}{l}\text { Totad U } \\
\text { ((pc)/g) }\end{array}$ \\
\hline Y9.5 & 1351725 & $4 \overline{80474}$ & LRA044 & FLD & 98-Jun-94 & $\overline{18}: 00$ & 7300 & 67.11 \\
\hline$S 1$ & $\mathbf{5 3 5 1 5 4 1}$ & 480338 & LRA045 & STD & 08-Jun-94 & $18: 11$ & 7700 & 76.49 \\
\hline s2 & 1351508 & 480562 & LRA046 & STD & 08-Jun-94 & $18: 23$ & 8700 & 99.93 \\
\hline 26 & 1351532 & 480509 & LRA047 & FLD & 08-Jun-94 & $18: 35$ & 7800 & 78.83 \\
\hline Z6.5 & 1351562 & 480508 & LRA048 & FLD & 08-Jut1-94 & $18: 45$ & 7600 & 74.14 \\
\hline $\mathrm{Z7}$ & 1351592 & 480507 & LRA049 & FLD & 08-Jun-94 & $18: 56$ & 7300 & 67.11 \\
\hline s2 & 1351508 & 480562 & LRAOSO & STD & 09.Jun-94 & $9: 16$ & 8400 & 92.90 \\
\hline s1 & 1351541 & 480338 & ERAOS1 & STD & O2-Jun-94 & $9: 32$ & 7300 & 67.11 \\
\hline ss & 1351466 & 480300 & LRAOS2 & FLD & 09-Jun-94 & $9: 46$ & 7200 & 64.77 \\
\hline U6 & 1351528 & 480354 & LRA053 & FLD & 09-Jun-94 & $10 \div 00$ & 6800 & 55.39 \\
\hline U6.5 & 1351558 & 480358 & LRA054 & FLD & 09-Jun-94 & $10: 10$ & 7500 & 71.80 \\
\hline U8 & 1351648 & $4 \$ 0366$ & LRA055 & FLD & 09-Jun-94 & 1033 & 10100 & 132.74 \\
\hline w85 & 1351679 & 480400 & LRAOS6 & FLD & 09-Jขn-94 & $10: 48$ & 9100 & 109.30 \\
\hline w9 & 1351709 & 480412 & LRAOST & FLD & 09-Jun-94 & $10: 58$ & 7800 & 78.83 \\
\hline vg & 1351709 & 480384 & LRAOS8 & FLD & 09-Jun-94 & 11:09 & 8100 & 85.86 \\
\hline U9 & 1351708 & 480354 & LRA059 & FLD & 09-Jun-94 & $11: 20$ & 6400 & 46.02 \\
\hline 59 & 1351687 & 480295 & LRAO60 & FLD & 09-Jun-94 & $11: 31$ & 6800 & 55.39 \\
\hline 510 & 1351766 & 480293 & LRAO61 & FLD & 09-Jun-94 & $11: 42$ & 5300 & 20.23 \\
\hline s11 & 1351826 & 480291 & LRAO62 & FLD & o-Jun-94 & $11: 53$ & 7000 & 60.08 \\
\hline U11 & 1351828 & 480351 & LRAO63 & FLD & 09-Jun-94 & $12: 11$ & 8200 & 88.21 \\
\hline w11 & 1351829 & $4804 \ 1$ & LRA064 & FLD & 09-Jun-94 & $12: 21$ & 9300 & 113.99 \\
\hline$Y 11$ & 1351831 & 480471 & LRA065 & FLD & 09-Jun-94 & $12: 30$ & 10700 & 146.81 \\
\hline AA11 & 1351833 & 480531 & LRA066 & FLD & 09-Jun-94 & $12: 44$ & 8200 & 88.21 \\
\hline $\mathrm{Z10}$ & 1351787 & 480502 & LRA067 & FLD & 0)-Jun-94 & $12: 57$ & 7800 & 78.83 \\
\hline Y 10 & $135177 \mathrm{t}$ & 480473 & LRA068 & FLD & 09.Jun-94 & $13: 08$ & 8000 & 83.52 \\
\hline W10 & 1351769 & 480413 & IRA069 & FLD & 09-Jun-94 & $13: 21$ & 9200 & 111.65 \\
\hline$V_{10}$ & 1351769 & 480383 & LRAOTO & FLD & C2-Ju1-94 & $13: 34$ & 8000 & 83,52 \\
\hline U10 & 1351768 & 480353 & LRAO71 & FLD & 09-Jun-94 & $13: 45$ & 5600 & 27.26 \\
\hline U9.5 & 1351738 & 480353 & LRAOT2 & FLD & 09-Jun-94 & $13: 59$ & 8500 & 95.24 \\
\hline V9.s & 1351739 & 480383 & LRA073 & FLD & 09-Jum-94 & $14: 10$ & 8800 & 102.27 \\
\hline w9.5 & 1351739 & 480413 & LRAOTS & FLD & 09-Jin-94 & $14: 21$ & 8700 & 99.93 \\
\hline CC11 & 1351834 & 480591 & LRAOTS & FLD & 09-hm-94 & $14: 35$ & 6000 & 36.64 \\
\hline $\mathbf{A} \mathbf{3}$ & 1351758 & 480363 & LRAOT6 & FLD & 09-Jun-94 & $14: 48$ & 8500 & 95.24 \\
\hline A2 & 1351753 & 480363 & LRAOT7 & FLD & 09-Jun-94 & $14: 59$ & 8500 & 95.24 \\
\hline Al & 1351748 & 480363 & LRA078 & FLD & $09-10 n+94$ & $15: 09$ & 8000 & 83.52 \\
\hline B3 & 1351758 & 480368 & LRAOT9 & FLD & 09-Jun-94 & $15: 20$ & 8100 & 85.86 \\
\hline $\mathrm{B} 2$ & 1351753 & 480368 & LRA080 & FLD & 09-Jun-94 & $15: 31$ & 6500 & 48.36 \\
\hline B1 & 1351748 & 480368 & LRA081 & FLD & 09-Jun-94 & $15: 41$ & 9000 & 106.96 \\
\hline $\mathrm{C} 3$ & 1351758 & 480373 & LRA082 & FLD & 09-Jun-94 & $15 \div 53$ & 7100 & 62.42 \\
\hline $\mathrm{C} 2$ & 1351753 & 480373 & LRA0 083 & FLD & 09-Jun-94 & $16: 03$ & 7000 & 60.08 \\
\hline Ct & 1351748 & 480373 & LRA0BA & FLD & 09-Jun-94 & $16: 13$ & 8500 & 95.24 \\
\hline U7 & 1351588 & 480361 & LRA085 & FLD & 09-Jun-94 & $16: 26$ & $7 \mathrm{BOOO}$ & 78.83 \\
\hline W5 & 1351470 & 490420 & LRAÖ6 & FLD & 09-Jun-94 & $16: 39$ & 9500 & 118.68 \\
\hline DI & I35I542 & 480519 & LRA087 & FLD & 09-Jute-94 & $16: 51$ & 8400 & 92.90 \\
\hline
\end{tabular}


Table G-9: Composite Data Llating for Long-Range Alpha Detector Twahnology (continued)

\begin{tabular}{|c|c|c|c|c|c|c|c|c|}
\hline Coo loc & $\begin{array}{l}x \text { Coond } \\
\text { (1)it) }\end{array}$ & $\begin{array}{c}\text { Y Coond } \\
\text { (fiest) }\end{array}$ & $\mathbf{I D}$ & туре & Dets & TIme & $\begin{array}{l}\text { Row Dita } \\
\text { (fentplo. } \\
\text { empentes) }\end{array}$ & $\begin{array}{l}\text { Totol U } \\
\text { ((pov } / \mathrm{p})\end{array}$ \\
\hline$\overline{\mathbf{D} 2}$ & 1351547 & 480518 & LRA088 & $\overline{F L D}$ & $09-5 n+1-94$ & $17: 02$ & 7200 & 64.77 \\
\hline D3 & 1351552 & 480518 & LRA089 & FLD & 09-Jun-94 & $17: 13$ & 7700 & 76.49 \\
\hline E1 & 1351542 & 480324 & LRA090 & FLD & $09-5$ un-94 & $17: 23$ & 7700 & 76.49 \\
\hline B2 & 1351547 & 480523 & LRA091 & FLD & 09-Jum-94 & $17 ; 35$ & 6900 & 57.74 \\
\hline E3 & 1351552 & 480523 & LRAO92 & FLD & 09-J1ก-94 & $17: 46$ & 8600 & 97.58 \\
\hline F1 & 1351542 & 480529 & LRA093 & FLD & 09-Jun-94 & $17: 58$ & 7800 & 78.83 \\
\hline F2 & 1351547 & $4 \$ 0528$ & LRA094 & FLD & $09-34 n-94$ & $18: 11$ & 8500 & 95.24 \\
\hline $\mathrm{F3}$ & 1351552 & 480528 & LRA09S & FLD & 09-Jun-94 & $18: 22$ & 8400 & 92,90 \\
\hline $\mathbf{s} 2$ & 1351506 & 480562 & LRA096 & STD & 09-Jun-94 & $18: 33$ & 8700 & 99.93 \\
\hline SI & 1351541 & 480338 & LRA097 & STD & 09-Jum-94 & I8:44 & 7800 & 78.89 \\
\hline SI & 1351541 & 480338 & LRA098 & STD & 10-Jun-94 & $9: 19$ & 7700 & 76.49 \\
\hline s2 & 1351508 & 480562 & IRA099 & $\$ T D$ & 10-Jun-94 & $9 \times 41$ & 8500 & 95.24 \\
\hline $\mathrm{ClOO}$ & -- & - & LRA 101 & CAL & 10-Jun-94 & to:t1 & 9600 & 121.02 \\
\hline$C 0$ & -- & - & LRA102 & CAL & 10-Jun-94 & $10: 27$ & 6400 & 46.02 \\
\hline C35 & .. & + & LRA 103 & CAL & $10-J u m \cdot 94$ & $10: 41$ & 7800 & 78.83 \\
\hline S1 & 1351541 & 480338 & LRA10S & STD & 13-Jun-94 & $13: 13$ & 3900 & $-12,58$ \\
\hline$s 2$ & 1351508 & 480562 & LRA106 & STD & 13-Jun-94 & $13: 30$ & 5000 & 1320 \\
\hline S1 & $135154 !$ & 480338 & LRA II & STD & 13-Jun-94 & $14: 35$ & 4300 & -3.21 \\
\hline $\mathbf{s 2}$ & 1351508 & 480562 & LRA118 & STD & 13-Jun-94 & 16:08 & 6000 & 36.64 \\
\hline s1 & 1351541 & $48033 \mathrm{~B}$ & LRA119 & STD & 13-Jun-94 & $16: 21$ & 5700 & 29.61 \\
\hline$\$ 2$ & 1351508 & 480562 & LRA 120 & STD & 14-Jun-94 & $9: 46$ & 7200 & 64.77 \\
\hline S1 & 1351541 & 480338 & LRA12I & STD & 14-Jun-94 & $10: 11$ & 6500 & 48.36 \\
\hline- & 1351800 & 480664 & LRA122 & FLD & 14-Jun-94 & $10: 26$ & 4000 & -10.24 \\
\hline- & 1351682 & 480505 & LRA123 & FLD & 14-Jun-94 & 10.42 & 5400 & 22.58 \\
\hline- & 1351651 & 480504 & LRA124 & FLD & 14-Jun-94 & $10: 52$ & 5300 & 20.23 \\
\hline- & 1351621 & 480504 & LRA125 & FLD & 14-Jun-94 & 11:04 & 5500 & 24.92 \\
\hline- & 1351561 & 480445 & LRA130 & FLD & 14-Jun-94 & $12: 09$ & 5400 & 22.58 \\
\hline-- & $135150 \mathrm{I}$ & 480524 & LRA [3] & FLD & 14-Jun-94 & $12: 22$ & 6300 & 43.67 \\
\hline- & 1351503 & 480574 & LRA132 & FLD & 14-Jun-94 & $12: 34$ & 6700 & $\$ 3.05$ \\
\hline$*$ & 1351563 & 480573 & LRA:33 & FLDD & 14-Jup-g4 & $12: 44$ & 3600 & -19.62 \\
\hline S2 & 1351508 & 480562 & LRA134 & STD & 14-Jun-94 & $12: 56$ & 7100 & 62.42 \\
\hline s1 & 1351541 & 480338 & LRA135 & STD & 14-Juo-94 & $13: 08$ & 6500 & 48.36 \\
\hline$*$ & 1351740 & 480315 & LRA136 & FLD & 14-Jup-94 & $13: 20$ & 5200 & 17.89 \\
\hline$=$ & J35180t & 480315 & LRA137 & FLD & 14-JuJo-94 & $13 \times 47$ & 3200 & -28.99 \\
\hline
\end{tabular}


Table G-10; Composite Dete Lleting for Sodlum-lodide Scintlilometer Technology [Leaders (--): pot measuced or pot applicable]

\begin{tabular}{|c|c|c|c|c|c|c|c|c|}
\hline Coo Lot & $\begin{array}{c}x \text { coord } \\
\text { (tolit) }\end{array}$ & $Y$ Coord & ID & Type & Date & $\operatorname{Time}_{\text {(EDT) }}$ & $\begin{array}{l}\text { Rowr Dot: } \\
\text { (counts per } \\
\text { minute) }\end{array}$ & $\begin{array}{l}\text { Totw U } \\
\text { (pCHg) }\end{array}$ \\
\hline$\infty$ & $\Rightarrow$ & - & NAD006 & CAL & 31-May-94 & 10.50 & 3717 & - \\
\hline$\infty$ & - & - & NADQOT & CAL & 31-May-94 & $10 \div 32$ & 3724 & - \\
\hline $\mathrm{C} 35$ & - & $\leftrightarrow$ & NADO0S & CAL & 31-May-94 & $10+\$ 5$ & 5361 & - \\
\hline C35 & - & -- & NADOO9 & CAL & $31-M a y-94$ & $10: 57$ & 5420 & - \\
\hline $\mathrm{C} 35$ & $\cdots$ & -. & NADO10 & CAL & 31-May-94 & 10.59 & 5420 & . \\
\hline $\mathrm{cjod}$ & -- & -- & NADO11 & CAL & 3!-May-94 & 11:02 & 6340 & $=$ \\
\hline $\mathrm{ClOO}$ & $\rightarrow$ & - & NADO12 & CAL & 31-May-94 & $11: 04$ & 6250 & -- \\
\hline C200 & - & - & NADO13 & CAI & 31-May-94 & 11:0? & 9970 & -- \\
\hline$c 200$ & .. & $\ldots$ & NADO14 & CAL & 31-May-94 & 11:09 & 9870 & - \\
\hline Co.11 & 1351834 & 480591 & NADO15 & FLD & 31-May-94 & $11: 25$ & 5400 & 95.30 \\
\hline OC10 & 1351774 & 480593 & NADO16 & FLD & 31-May-94 & $11: 27$ & 5750 & 113.57 \\
\hline $\operatorname{ccs}$ & 1351714 & 480594 & NAD017 & FLD & 31-May-94 & $11: 29$ & $\$ 750$ & 113.57 \\
\hline $\mathrm{CCg}$ & I351634 & 480596 & NADO18 & FLD & 31-May-94 & $11: 31$ & 5750 & 113.57 \\
\hline CC7 & 1351394 & 480597 & NADO19 & FLD & 31-May-94 & 11:33 & 5950 & 124.01 \\
\hline CC6 & I351534 & 480599 & NADOOOO & FLD & 31-May-94 & 11:35 & 5900 & 121.40 \\
\hline $\operatorname{ccs}$ & 1351474 & 430600 & NAD021 & FLD & 31-May -94 & $11: 37$ & 5700 & 110.96 \\
\hline AAS & 1351473 & 480540 & NAD022 & FLD & 3i-May-94 & $11: 40$ & 5950 & 124.01 \\
\hline AA6 & 1351533 & 480539 & NADO23 & FLD & 31-May-94 & $11: 42$ & 6100 & 131.84 \\
\hline AA7 & 1351593 & 480537 & NAD024 & FLD & $31+\mathrm{May}-94$ & $11: 44$ & 5800 & t16.18 \\
\hline AAB & 1351653 & 480536 & NADO2S & FLD & 31-May-94 & $11: 46$ & 5800 & 116.18 \\
\hline AA9 & 1351713 & 480534 & NADO26 & FLD & 31-May-94 & $11: 48$ & 5600 & 105.74 \\
\hline AA95 & 1351743 & 480533 & NADO2T & FLD & 31-May-94 & $11: 50$ & 5700 & 110.96 \\
\hline AAI0 & 1351760 & 480533 & NADO28 & FLD & 31-May-94 & $11: 52$ & 5450 & 97.91 \\
\hline AA]l & 1351833 & 480531 & NADO29 & FLD & 3l-May-94 & 11:54 & 5260 & 87.99 \\
\hline AAGSS & 1351563 & 480538 & NAD030 & FLD & 31-May-94 & $11: 57$ & 5600 & 105.74 \\
\hline Y11 & 1351831 & 480471 & NAD031 & FLD & $31-M a y+94$ & $13: 57$ & 6200 & 137.06 \\
\hline YLO & 1351771 & 480473 & NADOB2 & FLD & 3L-May-94 & 14:05 & 5560 & 103.65 \\
\hline 210 & 1351787 & 480502 & NAD 033 & FLD & 31-May-94 & 14:07 & 5550 & 103.13 \\
\hline Z9.5 & 1351742 & 480503 & NADO34 & FLD & 31-May-94 & $14: 10$ & 5600 & 108.74 \\
\hline $\mathbf{Z 9}$ & 1351712 & 480504 & NAD035 & FLD & 31-May-94 & $14: 12$ & 5310 & 90.60 \\
\hline Y9.S & 1351725 & 480474 & NAD036 & FLD & 31-May-94 & $14: 14$ & s750 & 163.57 \\
\hline Y9 & 1351711 & 480474 & NAD037 & FLD & 31-May-94 & $14: 16$ & 5550 & 103.13 \\
\hline Y8.5 & 1351681 & 480475 & NAD038 & FLD & 31-May-94 & $14: 20$ & 5700 & 110.96 \\
\hline Y8 & 1351651 & 480476 & NADOB9 & FLD & 31-May-94 & $14: 22$ & 5600 & 105.74 \\
\hline Y7.5 & 1331621 & 480476 & NADO40 & FLD & 31-May-94 & $14: 24$ & 5850 & 118.79 \\
\hline$Y 7$ & 1351591 & 480477 & NADO41 & FLD & 31-May-94 & $14: 26$ & $\$ 650$ & 108.35 \\
\hline 27 & 1351592 & 480507 & NAD042 & FLD & 31-May-94 & $14: 28$ & 5800 & 16.18 \\
\hline Z6.5 & 1351562 & $48050 \mathrm{~B}$ & NADO43 & FUD & 31-May-94 & $14: 31$ & 5650 & 108.35 \\
\hline 26 & 1351532 & 480509 & NADO44 & FLD & 31-May-94 & $14: 33$ & 5650 & 108.35 \\
\hline Y6 & 1351531 & 480479 & NAD045 & FLD & $31-$ May-94 & $14: 35$ & 5500 & 100.52 \\
\hline Y6.5 & 1351561 & 480478 & NAD046 & FLD & 3I-May-94 & $14: 38$ & 5500 & 100.52 \\
\hline Ys & 1351471 & 480480 & NADO47 & FLD & 3l-May-94 & $14: 40$ & 5550 & 103.13 \\
\hline F) & 1351542 & 480529 & NAD048 & FLD & 31-May-94 & $14: 44$ & $\$ 600$ & 105.74 \\
\hline
\end{tabular}


Table G-10: Composite Data Usting for Sodlum-fodide Scintillometer Technology (continued)

[Ladeco (-); not measured of not oppticable)

\begin{tabular}{|c|c|c|c|c|c|c|c|c|}
\hline teo Loc & $\begin{array}{c}x \text { Coond } \\
\text { (tisint })\end{array}$ & $\begin{array}{c}\text { Y coord } \\
\text { (fieat) }\end{array}$ & ID & Type & Dots & $\underset{\text { (EDT) }}{T \rightarrow}$ & 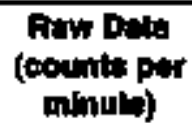 & $\begin{array}{l}\text { Toted U } \\
\text { (petto) }\end{array}$ \\
\hline$\overline{\mathrm{F2}}$ & 1351547 & 480528 & MADO49 & FLD & 31-May-94 & $14: 46$ & 5600 & 105.74 \\
\hline F3 & 1351552 & 480528 & NADOSO & FLD & 31-May-94 & $14: 48$ & 5600 & 105.74 \\
\hline E3 & 1351552 & 480523 & NADOS1 & FLD & 31-May-94 & $14: 50$ & 5610 & 106.26 \\
\hline $\mathrm{E} 2$ & 1351547 & 480523 & NADOS2 & FLD & 31-May-94 & $14: 52$ & 5500 & 100.52 \\
\hline E1 & 1351542 & 480524 & NAD053 & FLD & 31-May-94 & $14: 54$ & 5600 & 105.74 \\
\hline Dl & 1351542 & 480519 & NADOS4 & FLD & 31-May-94 & $14 \div 56$ & 5700 & 110.96 \\
\hline D2 & 1351547 & 480518 & NAD0SS & FLD & 31-May-g4 & $14: 58$ & 5650 & 108.35 \\
\hline D3 & 1351552 & 480518 & NADOS6 & FLD & $31-M a y-94$ & $15: 00$ & 5400 & 95.30 \\
\hline$x$ & 1351711 & 480457 & NAD067 & FLD & 01-Jun-94 & $8: 34$ & 6000 & 126.62 \\
\hline $\mathrm{X8.5}$ & 1351680 & 480445 & NADOG8 & FLD & $01-J$ (unn-94 & $8: 37$ & 6150 & 13445 \\
\hline $\mathbf{X 8}$ & 1351650 & 480446 & NADO69 & FLD & 01-Jun-94 & $8: 40$ & 6000 & 126.62 \\
\hline X7.5 & 1351620 & 480447 & NADO70 & FLD & OI-Jun-94 & $8: 42$ & 5950 & 124,01 \\
\hline$\times 7$ & 1351590 & 480447 & NADM1 & FLD & 01-Jun-94 & $8+47$ & 6150 & 134.45 \\
\hline S1 & 1351541 & 480338 & NADOT3 & STD & 01-Jun-94 & $8: 51$ & 6250 & 139.67 \\
\hline$S 2$ & 1351508 & 480562 & NADO74 & STD & 01-Jun-94 & $8: 59$ & 6050 & 129.23 \\
\hline ws & 1351470 & 480420 & NAD075 & FLD & 01-Jun-94 & $9 ; 03$ & 6100 & 131.84 \\
\hline W6 & 1351530 & 480419 & NADO76 & FLD & 0]-Ju|n-94 & $9 ; 06$ & 6200 & 137.06 \\
\hline W6.5 & 1351560 & 480418 & NAD077 & FLD & 01-Jun+94 & 9.09 & 6200 & 137.06 \\
\hline$w 7$ & 1351590 & 480417 & NADOT8 & FLD & 01-Jun-94 & $9: 11$ & 6350 & 144.89 \\
\hline w75 & 1351620 & 480420 & NADN79 & FLD & 0]-łun-94 & $9: 14$ & 6250 & 139.67 \\
\hline W8 & 1351650 & 480429 & NAD080 & FLD & 01-Jun-94 & $9 \div 17$ & 5850 & 118.79 \\
\hline w9 & 1351709 & 480412 & NADOB1 & FLD & 01-Jum-94 & $9: 20$ & 5750 & 11357 \\
\hline W9.5 & 1351739 & 480413 & NADO82 & FLD & 01-Jun-94 & $9: 23$ & 5650 & 108.35 \\
\hline W10 & 1351769 & 480413 & NADOB4 & FLD & 01-Jun-94 & $9: 29$ & 5850 & 118.79 \\
\hline W11 & 1351829 & 480411 & NAD0B5 & FLD & 01-Jun-94 & 9.32 & 5800 & 116.18 \\
\hline U11 & 1351828 & 480351 & NAD086 & FLD & 01-รัก-94 & $9: 49$ & 5550 & 103.13 \\
\hline U10 & 1351768 & 480353 & NADNB? & FLD & 01-5un-94 & $9-53$ & 5560 & 103.65 \\
\hline V10 & 1351769 & 480383 & NAD088 & FLD & 03-Jun-94 & 9.55 & 5450 & 97.91 \\
\hline $\mathrm{C3}$ & 1351758 & 480373 & NAD089 & FLD & 01-Jum-94 & $9: 58$ & 5460 & 98.43 \\
\hline $\mathrm{C2}$ & 1351753 & 480373 & NADOSO & FLD & 01-Jum-94 & 10.01 & 5450 & 97.91 \\
\hline $\mathrm{Cl}$ & 1351748 & 480373 & NADO91 & FLD & 0]-Jun-94 & 10:04 & 5650 & 108.35 \\
\hline B1 & 1351748 & 480368 & NADO92 & FLD & 0]-Jun-94 & $10: 06$ & 3450 & 97.91 \\
\hline B2 & 1351753 & 480368 & NADO93 & FL.D & 01-Jun-94 & $10: 08$ & 5600 & 105.74 \\
\hline B3 & 1351758 & 480368 & NADO9S & FLD & 01-Jun-94 & $10: 14$ & 5500 & 100.52 \\
\hline A3 & 1351758 & 480363 & NAD0 96 & FLD & 01-Jun-94 & 10.16 & 5700 & 110.96 \\
\hline$A 2$ & 1351753 & 480363 & NADO97 & FLD & 01-Jum-94 & $10: 18$ & 5400 & 95.30 \\
\hline Al & 1351748 & 480363 & NADO98 & FLD & $01-J v a-94$ & $10: 21$ & 5400 & 9530 \\
\hline v9.5 & 1351739 & 480383 & NAD099 & FLD & 01-Jur-94 & $10: 23$ & 5500 & 100.52 \\
\hline U9.5 & 1351738 & 480353 & NAD100 & FLD & 01-Jum-94 & $10: 26$ & 5500 & 100.52 \\
\hline U9 & 1351708 & 480354 & NAD101 & FLD & 01-Jun-94 & $10: 29$ & 5800 & 116.18 \\
\hline v9 & 1351709 & 480384 & NAD102 & FLD & 01-Jun+94 & 10:33 & 6050 & 129.23 \\
\hline W8.5 & 1351679 & 480400 & NAD109 & FLD & 01-Jon-94 & 10.35 & 5950 & 124.01 \\
\hline U8 & 1351648 & 480966 & NAD104 & FLD & 01-Jum-94 & $50: 38$ & 6400 & 147.50 \\
\hline
\end{tabular}


Table C-10: Composite Data Liating for Sodilumbodide Scintlilometer Technology (continused)

[Leaders (-): nod measured of nol applicable]

\begin{tabular}{|c|c|c|c|c|c|c|c|c|}
\hline Ceo Loc & $x$ Coord & $\begin{array}{c}Y \text { coord } \\
\text { (feot) }\end{array}$ & 10 & Type & Date & $\underset{\text { (EDT) }}{\operatorname{Tim}}$ & $\begin{array}{c}\text { Row Date } \\
\text { (oounts pew } \\
\text { minutio) }\end{array}$ & $\begin{array}{l}\text { Total y } \\
\text { (pc) }\end{array}$ \\
\hline U7 & 1351588 & 480361 & NADI0́S & $\bar{F} \overline{L D}$ & 01-Jun-94 & $10: 45$ & 6450 & 150.11 \\
\hline V6.5 & 1351559 & 480403 & NADIO & FLD & 01-Jun-94 & $12: 29$ & 6450 & t50.11 \\
\hline v6 & 1351529 & 480394 & NAD108 & FLD & 01-Jun-94 & $12: 33$ & 6050 & 129.23 \\
\hline US & 1351468 & 480365 & NAD109 & FLD & 01-Jun-94 & $12: 36$ & 5750 & 113.57 \\
\hline 55 & 1351466 & 480300 & NAD110 & FLD & 01.Jun-94 & $12: 39$ & 5850 & 118.79 \\
\hline U6 & 1351528 & 480354 & NAD111 & FLD & 01-Jun-94 & $12: 42$ & 6250 & 139.67 \\
\hline U6.5 & 1351558 & 480358 & NADI:2 & FLD & 01-Jum-94 & $12 ; 44$ & 6200 & 137.06 \\
\hline 59 & 1351706 & 480294 & NADI13 & FLD & 01-Jun-94 & $12: 49$ & 6000 & 126.62 \\
\hline$\$ 10$ & 1351766 & 480293 & NADH14 & FLD & 01-Ju-94 & $12 \div 53$ & 5400 & 95.30 \\
\hline S1t & 1351826 & 480291 & NADIS & FLD & 01-Jun-94 & $12: 56$ & 5080 & 78.60 \\
\hline $\mathbf{s 1}$ & 1351541 & 480338 & NADI16 & STD & 01-Jun-94 & $13: 00$ & 6060 & 129.23 \\
\hline s1 & 1351541 & 480338 & NADIH' & STD & 01-Jun-94 & $13 \div 02$ & 6200 & 137.06 \\
\hline 52 & 1351508 & 480562 & NAD118 & STD & 01-Jnn-94 & 13:07 & 5850 & 118.79 \\
\hline$\infty$ & - & - & NAD119 & CAL & 01-Jun-94 & $13: 17$ & 3704 & - \\
\hline$\infty$ & $=r$ & - & NAD120 & CAL & 01-Jun-94 & $13 \div 26$ & 3703 & - \\
\hline C35 & -- & - & NADl21 & CAL & 0t-Jun-94 & $13: 28$ & 5360 & - \\
\hline C35 & - & - & NAD 122 & CAL & 01-Jun-94 & $13,3 t$ & 5210 & - \\
\hline C100 & - & - & NADH23 & CAL & 0I-Jun-94 & 13:34 & 6050 & -- \\
\hline C100 & - & - & NAD124 & CAL & 01-Jun-94 & 13:36 & 6200 & - \\
\hline $\mathrm{C200}$ & - & - & NAD125 & CAL & 01-Jthin-94 & $13: 39$ & 9820 & - \\
\hline $\mathrm{COO}$ & -. & - & NAD126 & CAL & 01-Jan-94 & $13: 41$ & 10020 & -- \\
\hline $\mathrm{C} 200$ & - & - & NAD127 & CAL & 01-Jงอ-94 & $13: 43$ & 9870 & -. \\
\hline$C_{0}$ & -- & - & NAD138 & CAL & 03-Jun-94 & 9:45 & 3571 & - \\
\hline$\infty$ & - & - & NAD139 & $\mathrm{CAL}$ & 03-Jun-94 & $9: 50$ & 3777 & - \\
\hline$\infty$ & - & - & NADI40 & CAL & 03-Jun-94 & $9: 55$ & 3720 & -. \\
\hline$\infty$ & - & - & NAD141 & CAL & 03-Ja12-94 & $9: 58$ & 3735 & - \\
\hline$\infty 0$ & - & - & NADI42 & $\mathrm{CAL}$ & 03-Jun-94 & $10: 00$ & 3856 & -- \\
\hline C35 & - & - & NAD143 & CAL & 03-Jun-94 & $10: 04$ & 5400 & - \\
\hline C35 & - & - & NAD144 & CAL & 03-Jעם-94 & $10: 06$ & 5400 & $*$ \\
\hline C35 & - & $=$ & NAD145 & CAL & OB-Jun-94 & $10: 09$ & 5450 & -- \\
\hline C35 & - & 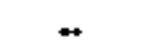 & NAD146 & CAL. & 03-Jug-94 & $10: 14$ & 5400 & - \\
\hline C35 & + & - & NAD 47 & CAL & 03-Jud-94 & 10.16 & 5650 & - \\
\hline C100 & - & - & NAD148 & CAL & 03-Jun-94 & $10: 19$ & 6100 & - \\
\hline $\mathrm{ClOO}$ & - & $=$ & NADl49 & CAL & OB-Jun-94 & 10.21 & 6300 & -- \\
\hline C100 & -- & -- & NADISO & CAL & 03-Jun-94 & $10: 25$ & 6400 & -. \\
\hline $\operatorname{cio} 0$ & - & ** & NADIS1 & CAL & 03-Juo-94 & 10.27 & 6430 & - \\
\hline C100 & - & -- & NADIS2 & $\mathrm{CAL}$ & 03-Jun-94 & 10.30 & 6450 & - \\
\hline $\mathrm{C} 200$ & - & -- & NADI53 & CAL & 03-Jun-94 & $10: 34$ & 100020 & - \\
\hline $\cos 00$ & - & -- & NADIS4 & CAL & 03-Jug-94 & $10: 36$ & 9970 & - \\
\hline$C_{2} 00$ & - & - & NADI5S & CAL & 03-Juמ-94 & $10: 40$ & 10050 & - \\
\hline $\mathrm{C} 200$ & - & - & NAD156 & CAL & 03-Jun-94 & $10: 43$ & 10030 & -- \\
\hline $\mathrm{C} 200$ & -. & -- & NADIS7 & CAL & 03-Jun-94 & $10: 46$ & 10170 & -. \\
\hline S1 & 1351541 & 480338 & NADI68 & STD & 07-J:14-94 & $9: 46$ & 6050 & 129.23 \\
\hline
\end{tabular}


Table Q-10: Componite Data Lieting for Sodium-todide Scintillomefer Technology (continued)

[Laders (-): not measured or not applicente]

\begin{tabular}{|c|c|c|c|c|c|c|c|c|}
\hline C.00 Loo & $\begin{array}{c}x \text { Coond } \\
\text { (foet) }\end{array}$ & $\begin{array}{c}Y \text { Coord } \\
\text { (ienc) }\end{array}$ & ID & Type & Duse & $\underset{\text { (EDT) }}{\text { Thin) }}$ & $\begin{array}{l}\text { Aaw Dati } \\
\text { (countep per } \\
\text { minuto) }\end{array}$ & $\begin{array}{l}\text { Totol U } \\
(p c t p)\end{array}$ \\
\hline$\overline{\$ 2}$ & 1351308 & 480562 & NAD169 & SID & 07-Jan-94 & $9: 30$ & 5750 & 113.57 \\
\hline 52 & 1351508 & 480562 & NAD180 & STD & 08-Jun-94 & $14: 32$ & $\$ 800$ & 116.18 \\
\hline $\mathbf{s} \mathbf{2}$ & 1351508 & 480562 & NAD181 & STD & 08-Jun-94 & $14: 34$ & 5850 & 118.79 \\
\hline$\$ 1$ & 1351541 & 480338 & NAD182 & STD & 08-Jun-94 & $14: 38$ & 6050 & 129.23 \\
\hline$\$ 1$ & 1351541 & 480338 & NAD183 & STD & 0:-Jun-94 & $14: 40$ & 6050 & 129.23 \\
\hline s1 & 1351541 & 480338 & NAD189 & STD & 09-Juo-94 & $14: 00$ & 5900 & 121.40 \\
\hline st & 1351541 & 480338 & NAD190 & \$TD & 09-Juמ-94 & $14: 02$ & 5850 & 118.79 \\
\hline$\$ 2$ & 1351508 & $\$ 80562$ & NAD191 & STD & 09-Jun-94 & $14: 12$ & 5750 & 113.57 \\
\hline s2 & 1351508 & 480562 & NAD192 & STD & C9-Jun-94 & $14: 14$ & 5800 & 116.18 \\
\hline$\$ 1$ & 1351541 & 480338 & NAD203 & SID & 10-Jum-94 & $9: 48$ & 6300 & 142.28 \\
\hline si & 1351541 & 480338 & NAD204 & STD & 10-Jun-94 & $9: 50$ & 6550 & 155.33 \\
\hline s2 & 1351508 & 480562 & NAD205 & STD & 10-Jun-94 & $9: 56$ & 6000 & 126.62 \\
\hline$\$ 2$ & $₫ 351508$ & $480 \$ 62$ & NAD206 & \$TD & 10-Jun-94 & $9: 58$ & 6100 & 131.84 \\
\hline s1 & 1351541 & 480338 & $\mathrm{NAD}_{217}$ & STD & 13-Jun-94 & $9: 30$ & 5800 & :16.18 \\
\hline sI & 1351541 & 480338 & NAD218 & STD & 13-Jup-94 & 9:32 & 5900 & 121.40 \\
\hline 52 & 1351508 & 480562 & NAD219 & STD & 13-Jus-94 & $9: 44$ & 5750 & 113.57 \\
\hline s2 & 1351508 & 480562 & $N A D 220$ & STD & 13-Juo-94 & $9: 46$ & 5800 & 116.18 \\
\hline s1 & 1351541 & 480338 & NAD231 & \$TD & 14-Jun-94 & $13: 00$ & 5900 & 121.40 \\
\hline si & 1351541 & 480338 & NAD232 & STD & 14-Jva-94 & 13.02 & 6050 & 129.23 \\
\hline S2 & 1351508 & 480562 & NAD233 & STD & 14-Jon-94 & $13: 14$ & 5700 & 11096 \\
\hline s2 & 1351508 & 480562 & NAD234 & STD & 14-Jan-94 & $13: 16$ & 5650 & 108.35 \\
\hline si & 1351541 & 480338 & NAD245 & STD & 16.Jun-94 & $15: 15$ & 6060 & 129.23 \\
\hline S1 & $135154 ?$ & 480338 & NAD246 & STD & I6-Jun-94 & $15: 17$ & 5900 & $12 t, 40$ \\
\hline $\mathbf{s} 2$ & 1351508 & 480562 & NAD 247 & STD & 16-Jun-94 & 15:23 & 5700 & 110.96 \\
\hline s2 & 1351508 & 480562 & $\mathrm{NAD} 248$ & STD & 16-3us-94 & $15: 25$ & 5760 & 114.09 \\
\hline s1 & 1351541 & 480338 & NAD259 & STD & 17-Jup-94 & $10: 41$ & 6200 & 137.06 \\
\hline si & 1351541 & 480338 & NAD260 & STD & 17-Jun-94 & $10: 43$ & 6400 & 147.50 \\
\hline$s 2$ & 1351508 & 480562 & NAD261 & STD & 17-Juo-94 & L0:47 & 6050 & 129.23 \\
\hline S2 & 1351508 & 480562 & NAD262 & STD & 17-Jun-94 & $10: 49$ & 5900 & 121,40 \\
\hline
\end{tabular}


Table G-11: Compoilte Data Listing for X-Fay Fluorescence Detector Technology [Leaders (-): not measured or not appliceble]

\begin{tabular}{|c|c|c|c|c|c|c|c|c|}
\hline Coo Loo & $x$ Coord & $\begin{array}{c}y \text { Coond } \\
\text { (iset) }\end{array}$ & $\mathbf{D}$ & Type & Date & $\begin{array}{l}\operatorname{Tim}_{\text {teOT }} \\
\end{array}$ & $\begin{array}{c}\text { Raw Dots } \\
\text { (ppm) }\end{array}$ & $\begin{array}{l}\text { Total U } \\
\text { (pcl/g) }\end{array}$ \\
\hline$C 0$ & - & $*$ & XRFDOF & CAE & 03-Jan-94 & $9: 57$ & 151 & $\rightarrow$ \\
\hline $\mathrm{Co}$ & -- & - & $\mathrm{XRFOO2}$ & CAL & 03-Jun-94 & $10+08$ & 7.14 & -- \\
\hline$C O$ & - & - & XRFO03 & CAL & 03-Jun-94 & $10: 18$ & 2.47 & -- \\
\hline$\infty$ & - & - & XRF(104 & CAL & (03-Jun-94 & 10.28 & 5.01 & -- \\
\hline$c 0$ & -- & -- & XRFOOS & CAL & 03-Fon-94 & 10:38 & -3.13 & -- \\
\hline $\mathrm{C35}$ & - & -- & XRFOOS & CAL & 03-Jun-94 & $10: 48$ & 87.62 & -- \\
\hline C35 & -- & -- & XRF007 & CAL & 03-Jun-94 & $10-59$ & 87.09 & - \\
\hline C35 & - & - & XRFOOB & CAL & 03-Jun-94 & 11:09 & 83.77 & -- \\
\hline C35 & - & -- & XRFong & CAE & 03-Jun-94 & $11: 21$ & 83.23 & - \\
\hline C35 & $\ldots$ & -- & XRF010 & CAL & 03-Jun-94 & 11:31 & 80.58 & - \\
\hline$C 100$ & -- & -- & XRFOII & CAL & 03-Jun-94 & $11: 41$ & 131.24 & -- \\
\hline cloo & - & - & XRF012 & CAL & 03-Juก-94 & $11: 51$ & 130.38 & - \\
\hline $\mathrm{Cl00}$ & - & -- & XRF(13 & CAL & 03-Jun-94 & 12:01 & 126.27 & - \\
\hline CI0O & -. & .. & XRF014 & CAL & 03-Jun-94 & $12: 10$ & 13451 & -- \\
\hline$C 100$ & -- & - & XRFO15 & CAL & 03-Jun-94 & $12: 20$ & 137.21 & - \\
\hline $\mathrm{C} 200$ & 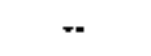 & - & XRF016 & CAL & 03-Jun-94 & $12: 30$ & 297.77 & - \\
\hline $\mathrm{C} 200$ & - & - & $\mathrm{XRF} 017$ & CAL & 03-Jun-94 & $12: 41$ & 469.40 & - \\
\hline$C 200$ & -- & -- & XRF018 & CAL & 03-Jun-94 & 13:01 & 330.44 & -- \\
\hline $\mathrm{C} 200$ & $\cdots$ & -- & XRFO19 & CAL & 06-Jun-94 & 9.58 & 293.20 & - \\
\hline $\mathrm{C} 200$ & - & - & XRFU20 & CAL & 06-Ju世-94 & 10.09 & 320.07 & -. \\
\hline CC11 & 1351834 & 480591 & XRF021 & FLD & 06-Ju-94 & $10: 37$ & 35.04 & 42.44 \\
\hline AA11 & 1351833 & 480531 & XRFO22 & FLD & 06-Jun-94 & $10: 51$ & 68.02 & 74,23 \\
\hline Y11 & 1351831 & 480471 & XRF023 & FLD & 06-Jun-94 & $11: 04$ & 106.71 & 111.53 \\
\hline$\$ 1$ & 1351541 & 480339 & XRF024 & STD & 06-Juo-94 & $11: 2 t$ & 84.71 & 90.32 \\
\hline $\mathbf{5 2}$ & 1351508 & 480562 & XRF(25 & \$TD & 06-Jun-94 & $11 \div 37$ & 31.00 & 38.54 \\
\hline w11 & 1351829 & 480411 & XRFO26 & FLD & O6-Jun-94 & $11: 53$ & 60.77 & 67.24 \\
\hline U11 & 1351828 & 480351 & XRFO27 & FLD & 06-Jun-94 & $13: 14$ & 60.12 & 66.61 \\
\hline$\$ 11$ & 1351826 & 480291 & XRFO28 & FLD & O6-Jun-94 & $13: 30$ & 16.97 & 25,02 \\
\hline S1 & 1351541 & 480338 & XRF029 & STD & 06-Jun-94 & $13: 43$ & 69.93 & 76.07 \\
\hline 52 & 1351508 & 480962 & XRF030 & STD & 06-Jun-94 & $13: 53$ & 70.52 & 76.64 \\
\hline S1 & 1351541 & 480338 & XRFO3i & $5 T D$ & 08-Jun-94 & $9+13$ & 68.70 & 74.89 \\
\hline $\mathbf{S 2}$ & 1351508 & 480562 & XRF032 & STD & 08-Jun-94 & $9: 29$ & $\$ 1.90$ & 58.69 \\
\hline$\$ 10$ & 1351766 & 480293 & XRF033 & FLD & Q8-Jun-94 & $9: 45$ & 6491 & 71.23 \\
\hline U10 & 1351768 & 480353 & XRFO34 & FLD & 08-Jun-94 & $9 \div 7$ & 55.38 & 62.04 \\
\hline V10 & 1351769 & 480383 & XRF035 & FLD & Q8-Jun-94 & $10 ; 07$ & 60.08 & 66.58 \\
\hline W10 & 1351769 & 480413 & XRFO36 & $F L D$ & 08-Jun-94 & $10: 19$ & 63.84 & 70.20 \\
\hline Y10 & 1351771 & 480473 & XRF037 & FLD & 08-Jun-94 & $10: 50$ & 78.66 & 84.49 \\
\hline $\mathrm{Z10}$ & 1351787 & 480502 & XRFO38 & FLD & 08-Jun-94 & 11.05 & 53.38 & 60.12 \\
\hline AA10 & 1351760 & 480533 & XRF039 & FLD & 08-Jun-94 & $12: 18$ & 85.63 & 91.21 \\
\hline $\operatorname{ccs} 0$ & 1351774 & 480593 & XRF040 & FLD & D8-Jun-94 & $12: 29$ & 47.96 & 54,89 \\
\hline AAG,5 & 1351743 & $480 \$ 33$ & XRF041 & FLD & 08-Jun-94 & $12: 42$ & 98.97 & 104,06 \\
\hline 29.5 & 1351742 & 480503 & XRF042 & FLD & 08-Јuณ-94 & $12: 55$ & 67.65 & 73.88 \\
\hline Y95 & 1351725 & 480474 & XRFM43 & FLD & 08-Juा -94 & $13 \div 05$ & 53.34 & 60.08 \\
\hline
\end{tabular}


Table Q-11: Composite Data Lieting for X-Ray Fluoreccence Detector Technology (continued)

[Leaders (-); not measured of not applicabte]

\begin{tabular}{|c|c|c|c|c|c|c|c|c|}
\hline Cen loc & $\begin{array}{c}x \text { Coord } \\
\text { (fent) }\end{array}$ & $\begin{array}{c}\text { Ycoond } \\
\text { (tit) }\end{array}$ & ID & Typo & Dusto & 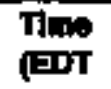 & $\begin{array}{c}\text { Amp } \\
\text { (ppm) }\end{array}$ & $\begin{array}{l}\text { Tothl U } \\
\text { (pCH/g) }\end{array}$ \\
\hline$\overline{W 9.5}$ & 1351739 & 480413 & XRF044 & FLD & 08-Ju世-94 & $13: 17$ & 53.01 & 59.76 \\
\hline v9s & 1351739 & 480383 & XRFO45 & F.D & 08-Jan-94 & $13: 29$ & 60.17 & 66.66 \\
\hline 49.5 & 1351738 & 480353 & XRFO46 & FLD & 08-Jug-94 & $13: 39$ & 7209 & 78.16 \\
\hline$\$ 1$ & 1351541 & 480338 & XRF047 & STD & 08-Jun-94 & $13: 49$ & 83.80 & 89.45 \\
\hline $\mathbf{s 2}$ & 1351508 & 480562 & XRF048 & STD & 06-Jun-94 & $14: 01$ & 60.93 & 67.39 \\
\hline S1 & 1351541 & 480338 & XRFO49 & STD & 09-Jnn-94 & $9: 50$ & 70.54 & 76.66 \\
\hline $\mathbf{\$ 2}$ & 1351508 & 480562 & XRFO50 & STD & C9-Jan-94 & $10: 01$ & 65.15 & 71.46 \\
\hline Al & 1351748 & 480363 & XRF051 & FLD & 09-Jun-94 & $10: 17$ & 66.01 & 72.29 \\
\hline A2 & 1351753 & 480363 & XRFOS2 & FLD & 09-Jun-94 & $10: 32$ & 53.51 & 60.25 \\
\hline A3 & 1351758 & 480363 & XRF053 & FLD & 09-Ju-94 & $10: 47$ & 55.19 & 61.87 \\
\hline B1 & 1351748 & 480368 & XRFOS4 & FLD & 09-Jun-94 & $10: 56$ & 43.62 & 50.71 \\
\hline B2 & 1351753 & 430368 & XRF05S & FLD & 09-Jun-94 & $11: 06$ & 47.20 & 54.16 \\
\hline B3 & 1351758 & 480368 & XRF0S6 & FLD & 09-Jan-94 & $11: 17$ & 56.81 & 63.43 \\
\hline $\mathrm{Cl}$ & 1351748 & 480373 & XRFOST & FLD & 09-Jur-94 & $11: 32$ & 77.22 & 83.10 \\
\hline $\mathrm{C2}$ & 1351753 & 480373 & XRF058 & FLD & 09-Jun-94 & $11: 43$ & 5530 & 61.97 \\
\hline $\mathrm{C}$ & 1351758 & 480373 & XRF0S9 & FLD & 09-Jun-94 & $11: 53$ & 58.10 & 64.67 \\
\hline s9 & 1351706 & 480294 & XRFOGO & FLD & 09-Jun-94 & $12: 13$ & 95.17 & 100,41 \\
\hline U9 & $1351 \% 08$ & 480354 & XRF061 & FLD & 09-Jun-94 & $12: 24$ & 59.30 & 65.83 \\
\hline v9 & 1351709 & 480384 & XRF 062 & FLD & 09-Jun-94 & $12: 33$ & 67.70 & 73.92 \\
\hline W9 & 1351709 & 480412 & XRFO63 & FLD & 09-Jun-94 & $12: 52$ & 54.77 & 61.45 \\
\hline$x 9$ & 1351711 & 480457 & XRF064 & FLD & $09-J u n-94$ & 13:09 & 7296 & 78.99 \\
\hline Y9 & $135 t 711$ & 480474 & XRF065 & FLD & 09-Jun-94 & $13: 13$ & 7997 & 85.75 \\
\hline Z9 & 1351712 & 480604 & XRFO66 & FLD & 09-Jun-94 & $13: 39$ & 64,06 & 70.41 \\
\hline AA9 & 1351713 & 480534 & XRFD67 & FLD & 09-Ju-94 & $13: 52$ & 77.89 & 83.75 \\
\hline$\$ 1$ & 1351541 & 480938 & XRFOS8 & STD & 09-Jpn-94 & $14: 08$ & 68.48 & 74.68 \\
\hline S2 & 1351508 & 480562 & XRF069 & STD & 09-Jun-94 & $14: 22$ & 64.49 & 70.83 \\
\hline $\cos$ & 1351714 & 480594 & XRFVT0 & FLD & 09-Jun-94 & $14: 33$ & 76.58 & 82.48 \\
\hline S1 & 1351541 & 480338 & XRFOI & STD & 10-Jum-94 & $9: 36$ & 72.19 & 78.25 \\
\hline S2 & 1351508 & 480562 & XRFOT2 & STD & $10-J \omega n-94$ & $10 ; 06$ & 63.94 & 70.30 \\
\hline $\operatorname{ccs}$ & 1351654 & 480596 & XRF073 & FLD & 10-Jus-94 & $10: 20$ & 55.93 & 62.58 \\
\hline AA8 & 1351653 & 480536 & XRFM74 & FLD & 10-Jun-94 & $10: 31$ & 25.65 & 33.38 \\
\hline Y8 & 1351651 & 480476 & XRFO75 & FLD & 10-Jun-94 & $10: 44$ & 55.73 & 62.38 \\
\hline $\mathbf{X} 8$ & 1351650 & 480446 & XRFO76 & FLD & 10-Jun-94 & $10: 57$ & 75.32 & 81.27 \\
\hline ws & 1351650 & 480429 & XRF0T & FLD & 10-Jon-94 & 11.09 & 75.23 & 81.18 \\
\hline LS & 1351648 & 480366 & XRF078 & FLD & 10-Jvo-94 & $11: 35$ & 83.28 & 88.94 \\
\hline W7.5 & 1351620 & 480420 & XRFO79 & FLD & $10-\mathrm{Jum}-94$ & $11: 50$ & 78.09 & 83.94 \\
\hline X7.5 & 1351620 & 480447 & XRF080 & FLD & 10-Jun-94 & $12: 10$ & $\$ 7.61$ & 64.19 \\
\hline Y7.5 & 1351621 & 480476 & XRF081 & FLD & 10-Jun-94 & $12: 21$ & 58.62 & 65.17 \\
\hline U7 & 1351588 & 480361 & XRF082 & FLD & 10-Jum-94 & 13:05 & 89.68 & 95.11 \\
\hline$w 7$ & 1351590 & 480417 & XRFOS3 & FLD & 10-Jun-94 & $13 \div 16$ & 81.50 & 87.23 \\
\hline $\mathbf{X 7}$ & 1351590 & 480447 & XRFQ84 & FLD & 10-Jum-94 & $13+36$ & 78.10 & 83.95 \\
\hline$Y 7$ & 1351591 & 480477 & XRF085 & FLD & 10-Jun-94 & $13: 43$ & 66.27 & 72.54 \\
\hline si & 1351541 & 480338 & XRF086 & STD & 10-Jun-94 & $14: 06$ & 85.19 & 90.79 \\
\hline s2 & 1351508 & 480562 & XRF087 & STD & 10-Jun-94 & $14: 17$ & 55.50 & 62.56 \\
\hline
\end{tabular}


Table G-11: Composite Data Llsting for X-Ray Fluorescence Detector Technology (continued)

[Leadens (-): not measured or not applicatite]

\begin{tabular}{|c|c|c|c|c|c|c|c|c|}
\hline Ceo Loc & $\begin{array}{l}x \text { Coondd } \\
\text { (fonit) }\end{array}$ & $\begin{array}{c}Y \text { Coond } \\
\text { (ineit) }\end{array}$ & 10 & Type & Date & $\begin{array}{l}\text { Time } \\
\text { (EDT }\end{array}$ & $\begin{array}{c}\text { Raw Deta } \\
\text { (ppm) }\end{array}$ & $\begin{array}{l}\text { Totot U } \\
\text { (pct/s) }\end{array}$ \\
\hline S1 & 1351541 & 480338 & XRFO88 & $\overline{\text { STD }}$ & 14-Jun-94 & $9: 37$ & 80.61 & 86.36 \\
\hline $\mathbf{S 2}$ & 1351508 & 480562 & XRF0899 & STD & 14-Jun-94 & $10: 12$ & 58.36 & 64.92 \\
\hline $\mathbf{Z 7}$ & 1351592 & 480507 & XRFOSO & FLD & 14-Jum-94 & $10: 26$ & 49.89 & 56.75 \\
\hline AA7 & 1351593 & 480537 & XRFO91 & FLD & 14-J|บ1-94 & 10:38 & 30,60 & 38.16 \\
\hline$\infty$ & 1351594 & 480597 & XRF092 & FLD & 14-Јuூ•94 & $10: 49$ & 59.32 & 65.85 \\
\hline Y8.5 & 1351681 & 480475 & XRFQ93 & FLD & 14-Juส-94 & $11: 02$ & 79.40 & 85.20 \\
\hline $\mathrm{x} 8.5$ & 1351680 & 480445 & XRFO94 & FLD & 14-Jun-94 & $1 \mathrm{j}: 13$ & 60.15 & 66.65 \\
\hline W8.S & 1351679 & 480400 & XRFO95 & FLD & 14-Jun-94 & $11: 26$ & 83.25 & 88.91 \\
\hline U6.5 & 1351558 & 480358 & XRF096 & FLD & 14-Jan-94 & $11 \div 43$ & 78.40 & 84.24 \\
\hline V6.5 & 1351559 & 480403 & XRFOS7 & FLD & 14-Jun-94 & $11: 54$ & 87.40 & 92.91 \\
\hline W6.5 & 1351560 & 480418 & XRF098 & FLD & I4-Jun-94 & $12: 04$ & 70.21 & 76.34 \\
\hline Y6.5 & 1351561 & 480478 & XRF099 & FLD & 14-Jun-94 & $12: 54$ & 6190 & 68.34 \\
\hline Z6.5 & 1351562 & 480508 & XRF100 & FLD & 14-Jun-94 & $13: 07$ & 59.13 & 65.66 \\
\hline AA6.5 & 1351563 & 480538 & XRF101 & FLD & 14-Jun-94 & $13: 17$ & 40.70 & 47.90 \\
\hline CC6 & 1351534 & 480599 & XRF102 & FLD & 14-Jub-94 & $13: 27$ & 71.74 & 77.82 \\
\hline $\mathbf{S 2}$ & 1351508 & $480 \$ 62$ & XRF103 & STD & 14-3an-94 & $13: 38$ & 56.98 & 63.59 \\
\hline \$! & 1351541 & 480338 & XRF104 & STD & 14-Jun-94 & $13: 55$ & 77.62 & 83.48 \\
\hline S1 & 1351541 & 480338 & XRFIOS & STD & 15-Jun-94 & $9: 48$ & 83.66 & 89.30 \\
\hline $\mathbf{S 2}$ & 1351508 & 480562 & XRFIO6 & STD & 15-Jum-94 & 10405 & 64.33 & 70.67 \\
\hline AA 6 & 1351533 & 480539 & XRF107 & FLD & 15-Iun-94 & $10: 12$ & 66.11 & 72.39 \\
\hline D1 & 1351542 & 480519 & XRFI08 & FLD & 15-5un-94 & $10: 25$ & 65.39 & 71.69 \\
\hline $\mathrm{D} 2$ & 1351547 & 480518 & XRFJ09 & FLD & 15-Jun-94 & $10: 34$ & 61.83 & 68.26 \\
\hline D3 & 1351552 & 480518 & XRF110 & FLD & $15-J u m-94$ & $10: 44$ & 60.88 & 67.35 \\
\hline El & 1351542 & 480524 & XRF111 & FLD & 15-Jun-94 & 10.59 & 47.18 & 54.14 \\
\hline E2 & 1351547 & 480523 & XRF112 & FLD & 15-Jun-94 & $11: 10$ & 62.36 & 68.78 \\
\hline $\mathrm{E} 3$ & 1351552 & 480523 & XRF113 & FLD & 15-Jun-94 & $11: 21$ & 64.71 & 71.04 \\
\hline F1 & 1351542 & 480529 & XRF114 & FED & 15-Jun-94 & $11: 31$ & 70.55 & 76.67 \\
\hline $\mathbf{F} 2$ & 1351547 & 480528 & XRF115 & FLD & $15-J u m-94$ & $12: 47$ & 54.13 & 60.84 \\
\hline F3 & 1351552 & 480528 & XRP116 & $F L D$ & $15-J u n-94$ & $12: 59$ & 57.10 & 63.71 \\
\hline Z6 & 1351532 & 480509 & XRP117 & FLD & $15-\operatorname{tin}-94$ & $13 \div 08$ & 55.40 & 62.07 \\
\hline 52 & J351508 & 480562 & XRF118 & STD & $15-J ı m-94$ & $13: 17$ & 58.82 & 65.36 \\
\hline s1 & 1351541 & 480338 & XRF119 & STD & 15-Jun-94 & $13: 30$ & 80,09 & 85.87 \\
\hline s1 & 1351541 & 480338 & XRFi20 & STD & 16-Jun-94 & $9: 24$ & 73.25 & 79.28 \\
\hline S2 & 1351508 & 480562 & XRF121 & STD & $16-J$ เn-94 & $9: 38$ & 56.83 & 63,44 \\
\hline Y6 & 1351531 & 480479 & XRF122 & FLD & 16-Jum-94 & $9: 50$ & 58.37 & 64.92 \\
\hline W6 & 1351530 & 480419 & XRF123 & FLD & 16-Jun-94 & $10: 00$ & 68.63 & 74.82 \\
\hline V6 & 1351529 & 480394 & XRF124 & FL.D & 16-5uo-94 & $10 \div 12$ & 62.32 & 68.74 \\
\hline U6 & 1351528 & 480354 & XRF125 & FLD & 16-Jon-94 & $10: 22$ & 68.18 & 74.38 \\
\hline 55 & 1351466 & 480300 & XRF126 & FLD & 16-Juo-94 & $10: 33$ & 76.44 & 82.35 \\
\hline US & 1351468 & 480365 & XRF127 & FLD & 16-Jun-94 & $10: 44$ & $\$ 8.43$ & 64.98 \\
\hline ws & 1351470 & 480420 & XRFI28 & FLD & 16-Jun-94 & $10 \div 55$ & 63.53 & 69.90 \\
\hline YS & 1351471 & 480480 & XRF129 & FLD & 16-Jun-94 & 11:05 & 47.76 & 54.70 \\
\hline AA5 & 1351473 & 480540 & $\mathrm{XRF} 130$ & FLD & 16-Jun-94 & $11 \div 15$ & 54,40 & 61.10 \\
\hline $\operatorname{ccs}$ & 1351474 & 480600 & XRF131 & FLD & 16-Jup-94 & $11: 24$ & 61.33 & 67.78 \\
\hline
\end{tabular}


Tabte G-11: Composite Data Listing for X-fay Fluoreecence Detector Technology (continued)

[Leaders ( -$\rangle$ not meacured or not aplicable]

\begin{tabular}{|c|c|c|c|c|c|c|c|c|}
\hline too Loc & $\begin{array}{c}x \text { Coond } \\
\text { (tent) }\end{array}$ & $\begin{array}{c}\text { Y Coord } \\
\text { (tiant) }\end{array}$ & 10 & Туре & Dots & (EDT & $\begin{array}{c}\mathrm{R}=\mathrm{w}_{\mathrm{w}} \mathrm{Dath} \\
\text { (ppm) }\end{array}$ & $\begin{array}{l}\text { Tolpd U } \\
\text { (pcilg) }\end{array}$ \\
\hline S2 & 1351508 & 480562 & XRF132 & STD & 16-Jun-94 & 11:33 & 60.35 & $6 \overline{6.84}$ \\
\hline S1 & 1351541 & $4803 \$ 8$ & XRF133 & STD & 16-Jun-94 & 11:44 & 98.53 & 103.64 \\
\hline$\infty$ & -- & - & XRF134 & $\mathrm{CAL}$ & 28-Jun-94 & $9: 52$ & -0.33 & - \\
\hline$\infty$ & -. & $\rightarrow$ & XRF135 & CAL & 28-Jun-94 & $10: 04$ & 8.08 & - \\
\hline$\infty$ & -- & -- & XRF136 & CAL & 28-Jun-94 & $10: 17$ & 11.06 & $=$ \\
\hline$\infty$ & -- & - & XRFI37 & CAL & 28-Jun-94 & $10: 26$ & 0.15 & -- \\
\hline$\infty$ & - & - & XRF138 & CAL & 28-Jun-94 & $10: 35$ & 6.35 & -- \\
\hline $\mathrm{C} 35$ & -- & - & XRF139 & CAL & 28-Jun-94 & 10:45 & 81.61 & - \\
\hline C35 & $\cdots$ & - & XRF140 & CAL & 28-Jun-94 & 11:04 & 60.78 & - \\
\hline C35 & -- & -- & XRF141 & CAL & 28-Jun-94 & 1):13 & 82.83 & -- \\
\hline $\mathrm{C} 35$ & - & - & XRF142 & CAL & 28-Jun-94 & $11: 22$ & 72.29 & - \\
\hline C35 & - & -- & XRF143 & CAL & 28-Jun-94 & $11: 44$ & 97.77 & 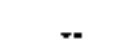 \\
\hline $\mathbf{C 1 0 0}$ & -- & -- & XRFl44 & CAL & 29-Jun-94 & $9: 13$ & 150.49 & - \\
\hline $\mathrm{Cl0O}$ & - & $\rightarrow$ & XRF145 & CAL & 29-Jun-94 & $9: 22$ & 110.00 & - \\
\hline Croo & 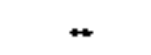 & - & XRF146 & CAL & 29-Jun-94 & $9: 32$ & 107.17 & - \\
\hline $\mathrm{CrOO}$ & - & -- & XRF147 & CAL & 29-Jun-94 & $9: 41$ & 119.16 & -- \\
\hline $\mathrm{Cl0}$ & - & -- & XRF148 & CAL & 29-Jun-94 & $9: 53$ & 133.94 & - \\
\hline$C P$ & - & -. & XRF149 & CAL & 29-Jun-94 & $10: 02$ & 45.72 & - \\
\hline$C P$ & - & - & XRF150 & CAE & 29-Jun-94 & $10 \div 11$ & 62.46 & -- \\
\hline $\mathrm{CP}$ & -- & - & XRF151 & CAL & 29-Jun-94 & $10: 23$ & 74.30 & - \\
\hline $\mathrm{CP}$ & - & - & XRF1S2 & CAL & 29-Jun-94 & $10: 32$ & 56.23 & - \\
\hline $\mathbf{C P}$ & - & -- & XXFls3 & CAL & 29-Jun-94 & $10: 40$ & 59.67 & - \\
\hline S1 & 1351541 & 480338 & XRF154 & STD & 30-Jun-94 & 9.02 & 80.82 & 86.57 \\
\hline S2 & 1351508 & 480562 & XRF15s & STD & 30-Jun-94 & $9: 13$ & 54.08 & 60.80 \\
\hline- & 1351683 & 480555 & XRF156 & FLD & 30-Jun-94 & $9+34$ & 58.36 & 64,92 \\
\hline- & 1351651 & 480555 & XRF157 & FLD & 30-Jun-94 & $9: 48$ & 73.97 & 79.96 \\
\hline- & 1351621 & 480553 & XRF158 & FLD & $30-54 n-94$ & $9+59$ & 83.85 & 89.50 \\
\hline- & 1351591 & 480555 & XRF159 & FLD & 30-Jun-94 & $10: 08$ & 53.77 & 60.50 \\
\hline- & 1351620 & 480535 & XRF]60 & FLD & 30-Jun-94 & 10.18 & 59.82 & 66.33 \\
\hline- & 1351685 & 480533 & XRF161 & FLD & 30-Jun-94 & 10:28 & 49.09 & 55.98 \\
\hline- & 1351650 & 480506 & XRF162 & FLD & 30-Jun-94 & $10 \cdot 38$ & 68.56 & 74.75 \\
\hline- & 1351620 & 480507 & XRF163 & FLD & $30-5$ แn-94 & $10 \times 49$ & 49.65 & 56.52 \\
\hline- & 1351504 & 480506 & XRFI64 & FLD & 30-Jun-94 & 11:02 & 45.38 & 52.41 \\
\hline- & 1351472 & 480506 & XRF165 & FLD & 30-Jun-94 & $11: 16$ & 47.75 & 54.69 \\
\hline- & 1351825 & 480315 & XRF166 & FLD & 30-Jun-94 & $11: 40$ & 31.67 & 39.19 \\
\hline- & 1351801 & 480315 & XRF167 & FLD & 30-Jum-94 & $11: \$ 2$ & 37.15 & 44.47 \\
\hline- & 1351800 & 480291 & XRFt68 & FLD & $30-J u n-94$ & $12 \div 02$ & 56.05 & 62.69 \\
\hline Si & 1351541 & 480338 & XRF169 & STD & 30-Jun-94 & $12: 30$ & 89.53 & 9497 \\
\hline$\$ 1$ & 1351541 & 480338 & XRFt70 & STD & 01-Jut-94 & $8: 44$ & 87.64 & 93.14 \\
\hline S2 & 1351508 & 480562 & XRF17I & STD & 01-Ju1-94 & $8 \div 54$ & 60.13 & 66.63 \\
\hline- & 1351786 & 480592 & XRFIT2 & FL.D & 01-Jnl-94 & $9 \div 09$ & 63,00 & 69.39 \\
\hline $\mathrm{CO}$ & -- & - & XRFI73 & $\mathrm{CAL}$ & 01-Jul-94 & 9:32 & 5.14 & .. \\
\hline $\mathrm{CO}$ & - & - & XRF174 & CAL & $01-J u l-94$ & $9: 43$ & 9.59 & -- \\
\hline$\infty$ & -- & - & XRF175 & CAL & 01-Jul-94 & 9:53 & 1.99 & -- \\
\hline
\end{tabular}


Table G-11: Composite Data Ljating for X-Ray Fuorescence Detector Technology (comtinued)

[Leaders ( - ): not measured or not upplicsble]

\begin{tabular}{|c|c|c|c|c|c|c|c|c|}
\hline Coo Lod & $\begin{array}{c}x \text { Coond } \\
\text { (lool) }\end{array}$ & $\begin{array}{c}\text { Y coord } \\
\text { (feot) }\end{array}$ & ID & Type & Date & Time & $\begin{array}{c}\text { Rew Dnts } \\
\text { (ppm) }\end{array}$ & $\begin{array}{l}\text { Toted U } \\
\text { (pclotg) }\end{array}$ \\
\hline $\bar{\infty}$ & $=$ & 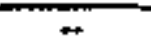 & XRF176 & $\overline{\mathrm{AL}}$ & $01 \cdot 3 u \mid-94$ & $10: 03$ & $8 . \overline{85}$ & - \\
\hline$\infty$ & - & - & XRFI 77 & CAL & 0]-Jul+94 & $10: 12$ & 3.74 & - \\
\hline C35 & - & -- & XRF178 & CAL & 01-Jul-94 & $10: 23$ & 78.95 & -- \\
\hline C35 & - & - & XRP179 & CAL & 01-Jul-94 & $10: 33$ & 69.61 & -- \\
\hline $\mathrm{C} 35$ & -- & -- & XRF180 & CAL & 01-Jul-94 & $10: 44$ & 66.56 & -- \\
\hline C35 & $\leftarrow$ & - & XRF181 & CAL & 0]-Jul-94 & $10: 56$ & 69.51 & .. \\
\hline C35 & - & -- & XRF182 & CAL & 01-Jul-94 & $11: 05$ & 78.03 & -- \\
\hline C100 & - & $*$ & XRF183 & CAL & $01-5 u+94$ & 13.02 & 120.03 & - \\
\hline C100 & - & - & XRF1\$4 & CAL & 01-Jul-g4 & $13: 13$ & 113.09 & - \\
\hline $\mathrm{C} 100$ & - & - & XRP185 & CAL & 01-Jul-94 & $13: 21$ & 119.54 & - \\
\hline $\mathrm{C} 100$ & $=$ & 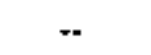 & XRF186 & CAL & $01-J 101-94$ & $13: 30$ & 118.09 & - \\
\hline $\mathrm{C} 100$ & - & -- & XRF187 & $\mathrm{CAL}$ & (0)-Jul-94 & $13: 40$ & 139.24 & - \\
\hline $\mathrm{CP}$ & - & 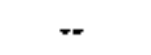 & XRF188 & CAE & 01-Jul-94 & $13: 49$ & 43.62 & - \\
\hline CP & - & - & XRF189 & CAL & 0I-Jul-94 & $13+59$ & 68.62 & $*$ \\
\hline $\mathrm{CP}$ & - & - & XRF190 & CAL & 01-JuJ-94 & 14.07 & 71.21 & - \\
\hline $\mathrm{CP}$ & - & -- & XRF191 & CAL & 01-Jul-94 & $14: 18$ & 39.05 & - \\
\hline $\mathrm{CP}$ & - & - & XRF192 & CAL & $01-3 u 1-94$ & $14: 27$ & 52.12 & - \\
\hline$\$ \mathbf{I}$ & 1351541 & 480338 & XRF193 & STD & $01-3 u 1-94$ & $14: 51$ & 88.98 & 94.44 \\
\hline$\$ 2$ & 1351508 & 480562 & XRFI94 & STD & 01-J마-94 & $15: 07$ & 36.35 & 43.70 \\
\hline
\end{tabular}


(This page intentionally left blank.) 